ENVIRONMENTAL RESTORATION PROGRAM

\section{Quality Assurance/Quality Control Summary Report for Phase 1 of the Clinch River Remedial Investigation}

$\begin{array}{ll}\text { S. K. Holladay } & \text { L. A. Hook } \\ \text { M. S. Bevelhimer } & \text { D. A. Levine } \\ \text { C. C. Brandt } & \text { R. C. Longman } \\ \text { R. B. Cook } & \text { S. E. Madix } \\ \text { W. D. Crumby } & \text { R. L. Moody } \\ \text { C. J. Ford } & \text { C. D. Rash } \\ \text { M. J. Gentry } & \text { L. F. Williams }\end{array}$




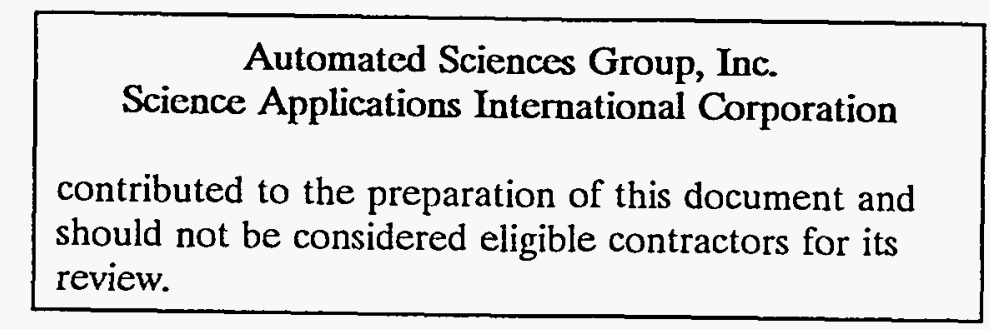

This report has been reproduced directly from the best available copy.

Available to DOE and DOE contractors from the Office of Scientific and Technical Information, P.O. Box 62, Oak Ridge, TN 37831; prices available from 615-576-8401.

Available to the public from the National Technical Information Service, U.S. Department of Commerce, 5285 Port Royal Rd., Springfield, VA 22161.

\section{DISCLAIMER}

This report was prepared as an account of work sponsored by an agency of the United States Government. Neither the United States Government nor any agency thereof, nor any of their Government. Neither the United States Government nor any agency thes liability or responsibility for the accuracy, completeness, or usefulness of any information, apparatus, product, or process disclosed, or represents that its use would not infringe privately owned rights. Reference herein to any specific commercial product, process, or service by trade name, trademark, manufacturer, or otherwise does not necessarily constitute or imply its endorsement, recommendation, or favoring by the United States Government or any agency thereof. The views and opinions of authors expressed herein do not necessarily state or reflect those of the United States Government or any agency thereof. 


\section{DISCLAIMER}

Portions of this document may be illegible in electronic image products. Images are produced from the best available original document. 
ORNL/ER-152

Energy Systems Environmental Restoration Program

Clinch River Environmental Restoration Program

\title{
Quality Assurance/Quality Control Summary Report for Phase 1 of the Clinch River Remedial Investigation
}
S. K. Holladay
L. A. Hook
M. S. Bevelhimer
D. A. Levine
C. C. Brandt
R. C. Longman
R. B. Cook
S. E. Madix
W. D. Crumby
R. L. Moody
C. J. Ford
C. D. Rash
M. J. Gentry
L. F. Williams

Date Issued-July 1994

\author{
Prepared by \\ Environmental Sciences Division \\ Oak Ridge National Laboratory \\ ESD Publication 4021 \\ Prepared for \\ U.S. Department of Energy
}

Office of Environmental Restoration and Waste Management

under budget and reporting code EW 20

Environmental Restoration and Waste Management Programs

Oak Ridge National Laboratory

Oak Ridge, Tennessee 37831-6285

managed by

MARTIN MARIETTA ENERGY SYSTEMS, INC.

for the

U.S. DEPARTMENT OF ENERGY

under contract DE-AC05-84OR21400 


\section{Author Affiliations}

R. B. Cook (Program Manager), C. J. Ford, S. K. Holladay, S. E. Madix, C. D. Rash, and L A. Hook are members of the Environmental Sciences Division; C. C. Brandt is a member of the Engineering Physics and Mathematics Division. Both of the aforementioned divisions are part of Oak Ridge National Laboratory, Martin Marietta Energy Systems, Inc. M. S. Bevelhimer, W. D. Crumby, and D. A. Levine are with Automated Sciences Group, Inc. M. J. Gentry, R. C. Longman, and L. F. Williams are with The University of Tennessee, Knoxville. R. L. Moody is with Science Applications International Corporation. 


\section{CONTENTS}

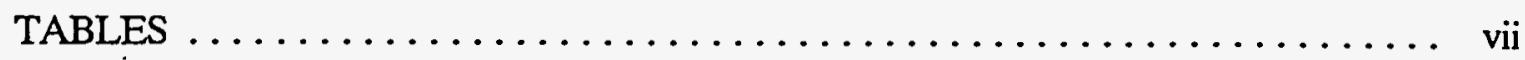

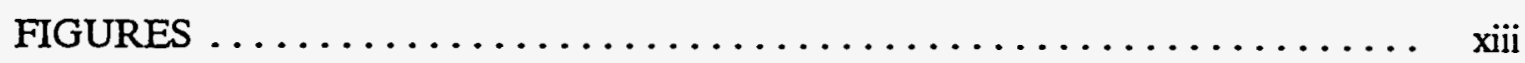

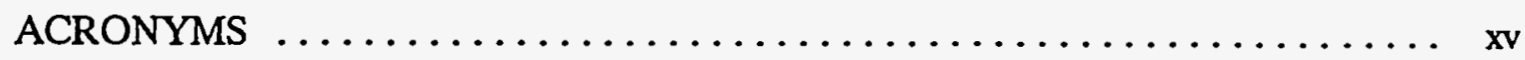

EXECUTIVE SUMMARY $\ldots \ldots \ldots \ldots \ldots \ldots \ldots \ldots \ldots \ldots \ldots \ldots \ldots \ldots \ldots \ldots \ldots \ldots$

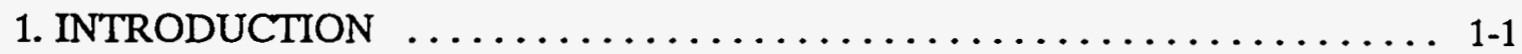

1.1 PURPOSE OF REPORT $\ldots \ldots \ldots \ldots \ldots \ldots \ldots \ldots \ldots \ldots \ldots \ldots \ldots \ldots \ldots \ldots \ldots \ldots$

1.2 BACKGROUND AND REGULATORY DRIVERS $\ldots \ldots \ldots \ldots \ldots \ldots \ldots .1-1$

1.3 OBJECTIVES AND APPROACH OF THE CLINCH RIVER

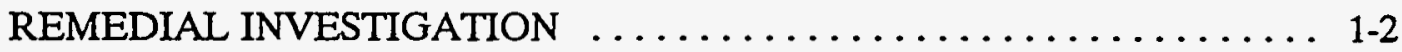

1.4 OBJECTIVES OF THE QA/QC DATA SUMMARY

FOR THE PHASE 1 INVESTIGATION $\ldots \ldots \ldots \ldots \ldots \ldots \ldots \ldots \ldots \ldots \ldots \ldots$

2. QUALITY ASSURANCE/QUALITY CONTROL PROGRAM $\ldots \ldots \ldots \ldots .2-1$

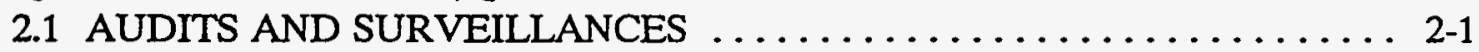

2.2 STANDARD OPERATING PROCEDURES

AND TRAINING PROGRAM $\ldots \ldots \ldots \ldots \ldots \ldots \ldots \ldots \ldots \ldots \ldots \ldots \ldots \ldots \ldots, 2-2$

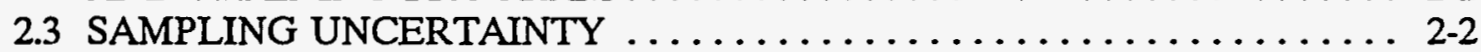

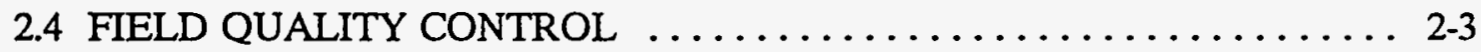

2.5 LABORATORY QUALITY CONTROL PROGRAM $\ldots \ldots \ldots \ldots \ldots \ldots 2-3$

2.6 DATA QUALITY INDICATORS $\ldots \ldots \ldots \ldots \ldots \ldots \ldots \ldots \ldots \ldots \ldots \ldots \ldots \ldots \ldots \ldots$

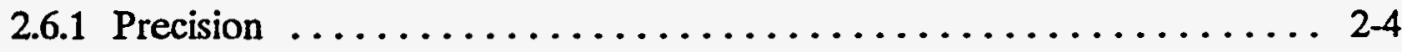

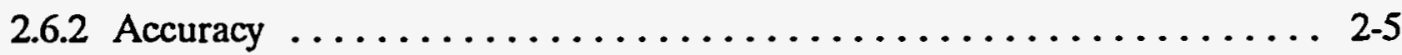

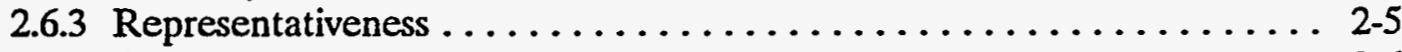

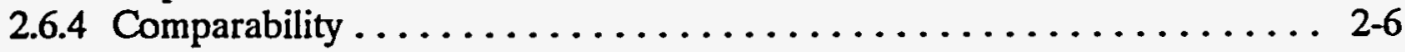

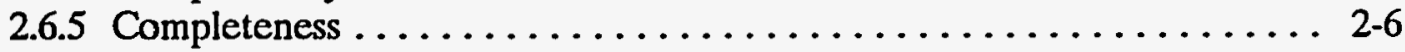

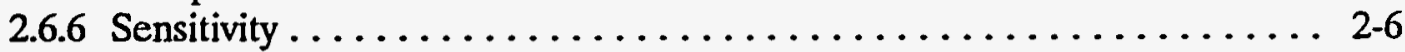

2.7 DATA AND RECORDS MANAGEMENT $\ldots \ldots \ldots \ldots \ldots \ldots \ldots \ldots .2-6$

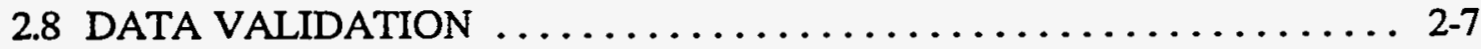

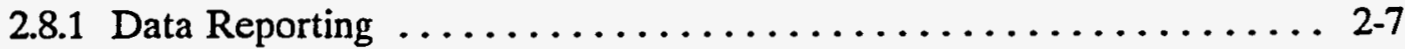

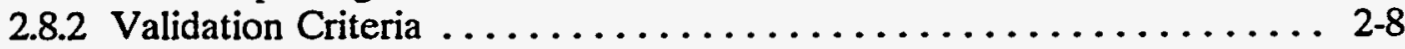

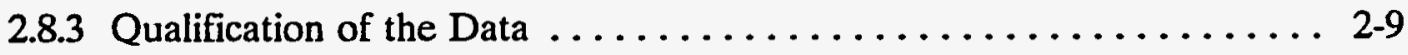

3. FIELD QUALITY CONTROL $\ldots \ldots \ldots \ldots \ldots \ldots \ldots \ldots \ldots \ldots \ldots \ldots \ldots \ldots \ldots, 1$

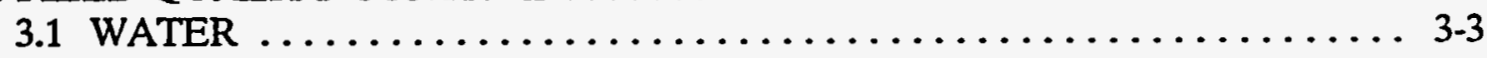

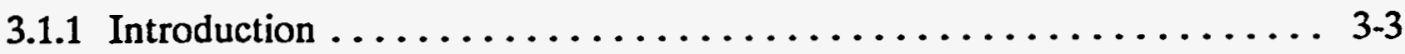

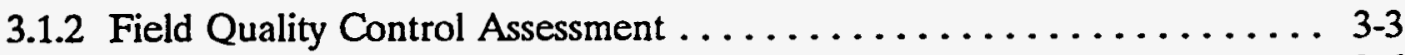

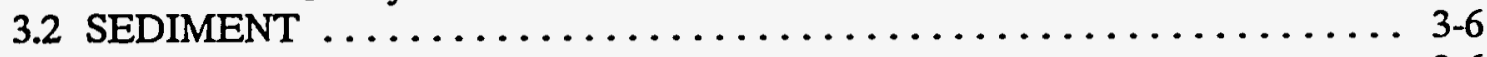

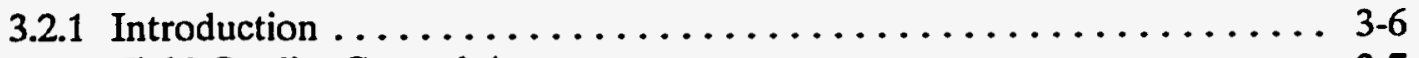

3.2.2 Field Quality Control Assessment .................. 3-7 


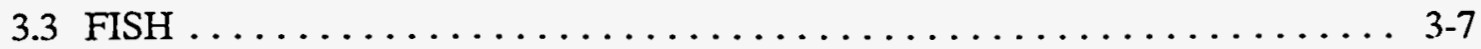

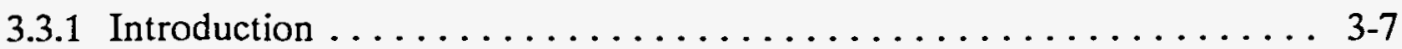

3.3.2 Field Quality Control Assessment ................. 3-8

4. ANALYTICAL SAMPLE DATA EVALUATION $\ldots \ldots \ldots \ldots \ldots \ldots \ldots, 4-1$

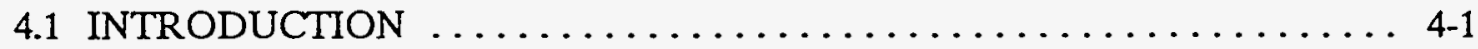

4.1.1 Method Quality Control ......................... 4-1

4.1.2 Sample Quality Control $\ldots \ldots \ldots \ldots \ldots \ldots \ldots \ldots \ldots \ldots \ldots \ldots \ldots \ldots \ldots, 2$

4.1.3 Supporting Quality Assurance $\ldots \ldots \ldots \ldots \ldots \ldots \ldots \ldots \ldots \ldots, 4-2$

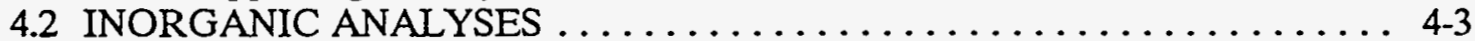

4.2.1 Atomic Absorption (AA) Water Analyses . . . . . . . . . . . . . . .

4.2.2 AA Soil/Sediment Analyses $\ldots \ldots \ldots \ldots \ldots \ldots \ldots \ldots \ldots . \ldots \ldots .4 .3$

4.2.3 AA Analysis of Fish Tissue $\ldots \ldots \ldots \ldots \ldots \ldots \ldots \ldots \ldots \ldots \ldots \ldots \ldots \ldots .4 .4$

4.2.4 ICP Water Analyses .......................... 4-4

4.2.5 ICP Sediment Analyses ...................... 4.5

4.2.6 ICP and ICP/MS Analysis of Fish Tissue $\ldots \ldots \ldots \ldots \ldots \ldots \ldots \ldots .4$

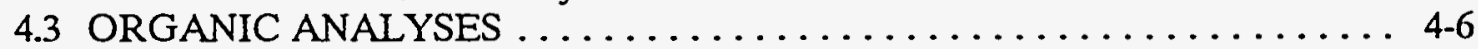

4.3.1 Semivolatile Water and Sediment Analyses ............. 4-6

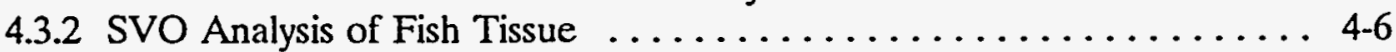

4.3.3 Pesticide/PCB Water and Sediment Analyses .............. 4-7

4.3.4 Pesticide/PCB Analysis of Fish Tissue . . . . . . . . . . . . . . .

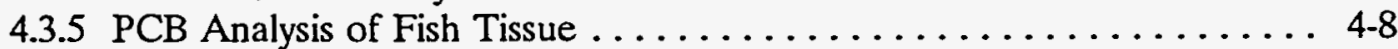

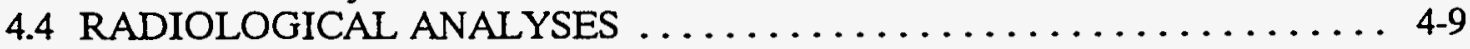

4.4.1 Gamma Analysis of Sediment, Water, and Fish Tissue ......... 4-9

4.4.2 Alpha and Beta Analysis of Sediment, Water, and Fish Tissue . . . . . 4-10

4.5 PERFORMANCE EVALUATION AND INTERLABORATORY

COMPARISON SAMPLE RESULTS $\ldots \ldots \ldots \ldots \ldots \ldots \ldots \ldots \ldots .4 .11$

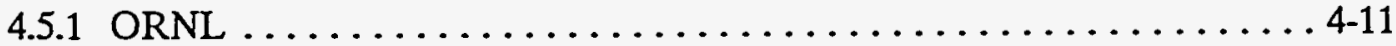

4.5.1.1 EPA Environmental Monitoring Systems Laboratory, Las Vegas ... 4-11

4.5.1.2 PETC Program at ORNL . . .................. 4-12

4.5.1.3 EPA Performance Evaluation Discharge Monitoring Report ...... 4-12

4.5.1.4 Water Supply Performance Evaluation Study ............ 4-12

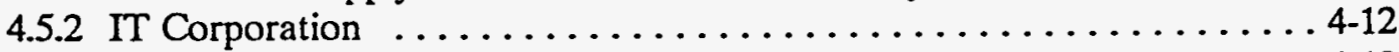

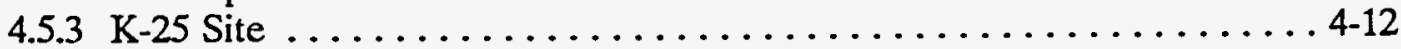

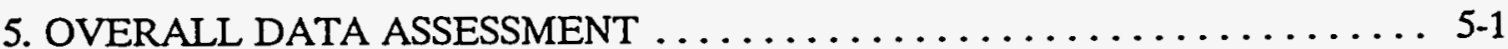

5.1 DATA ASSESSMENT OF WATER RESULTS $\ldots \ldots \ldots \ldots \ldots \ldots \ldots .5-1$

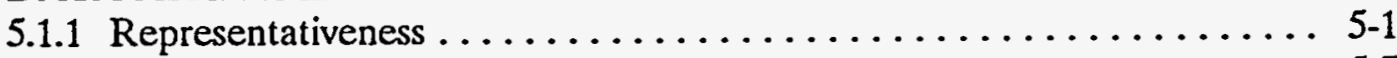

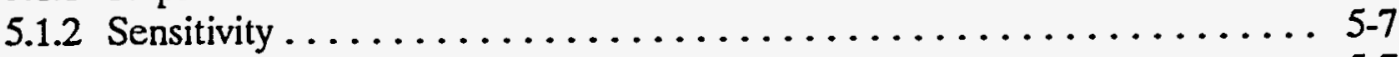

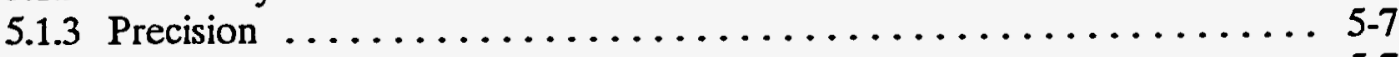

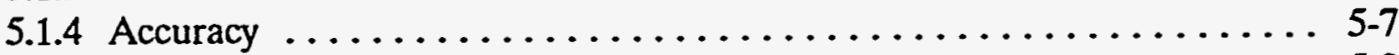

5.1 .5 Completeness ............................ 5-8

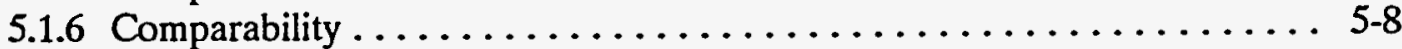

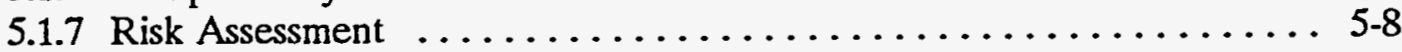


5.2 DATA ASSESSMENT OF SEDIMENT RESULTS $\ldots \ldots \ldots \ldots \ldots \ldots .5-8$

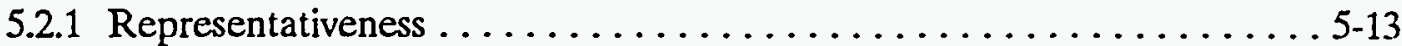

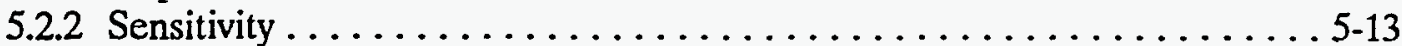

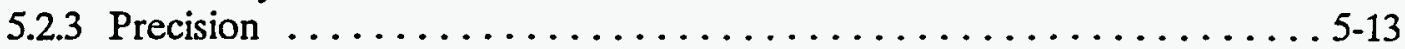

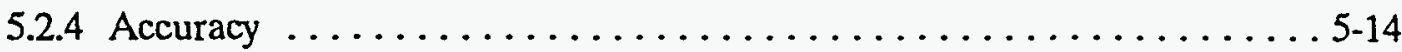

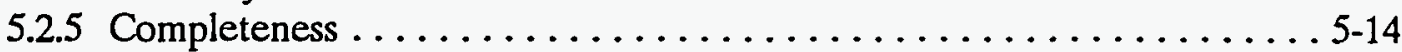

5.2 .6 Comparability ..........................

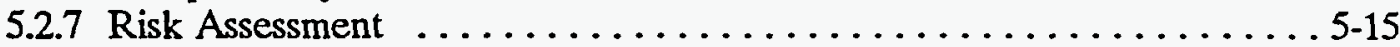

5.3 DATA ASSESSMENT OF FISH TISSUE RESULTS $\ldots \ldots \ldots \ldots \ldots \ldots 5-15$

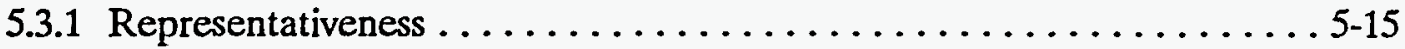

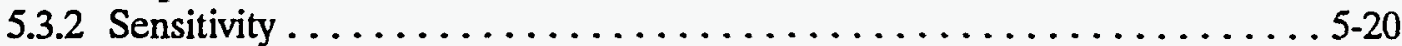

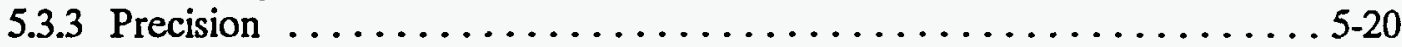

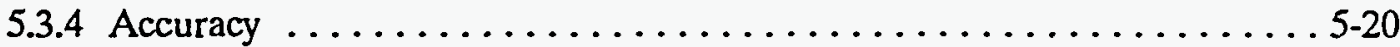

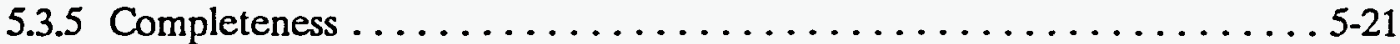

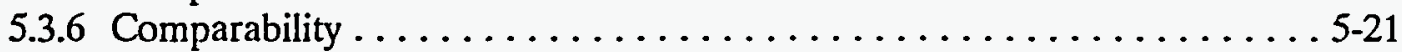

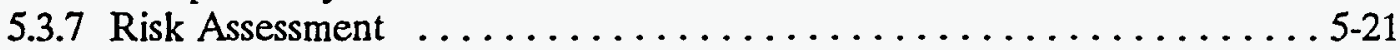

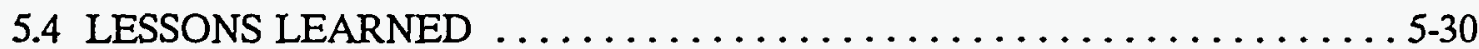

5.4.1 Water Sampling, Processing, and Preservation ............. 5-30

5.4.2 Sediment Sampling, Processing, and Preservation ............ 5-30

5.4.3 Fish Sampling, Processing, and Preservation .............. 5-31

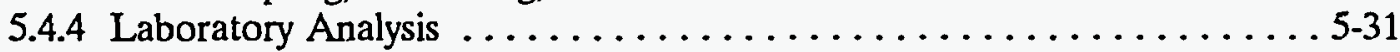

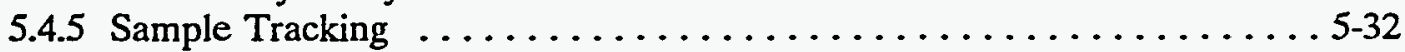

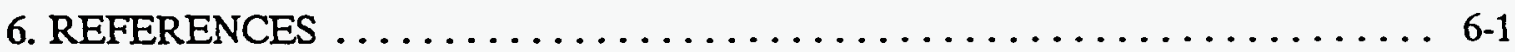

Appendix A. ANALYTICAL DATA EVALUATION $\ldots \ldots \ldots \ldots \ldots \ldots \ldots$ A-1

Appendix B. ADDITIONAL FIGURES $\ldots \ldots \ldots \ldots \ldots \ldots \ldots \ldots \ldots \ldots$ B-1

Appendix C. FIELD QUALITY CONTROL $\ldots \ldots \ldots \ldots \ldots \ldots \ldots \ldots \ldots$ C-1 


\section{TABLES}

1.1 Stream and river reaches used in the CRRI site characterization and screening risk assessment $\ldots \ldots \ldots \ldots \ldots \ldots \ldots \ldots \ldots \ldots \ldots \ldots$

2.1 Distribution of nonconformances by laboratory and method $\ldots \ldots \ldots \ldots$ 2-11

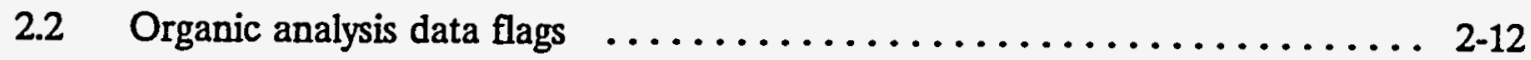

2.3 Inorganic analysis data flags $\ldots \ldots \ldots \ldots \ldots \ldots \ldots \ldots \ldots \ldots \ldots \ldots \ldots$

2.4 Validation data flags $\ldots \ldots \ldots \ldots \ldots \ldots \ldots \ldots \ldots \ldots \ldots \ldots \ldots \ldots \ldots$

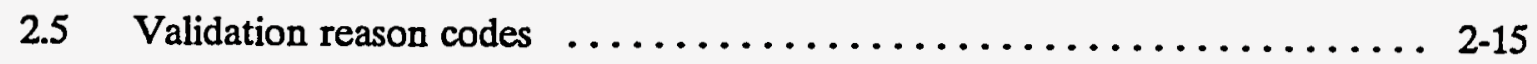

2.6 Frequency of reason codes for qualified and rejected data $\ldots \ldots \ldots \ldots$ 2-18

3.1 List of all CRRI Phase 1 water samples submitted for analysis . . . . . . 3-4

3.2 Sample sites for Phase 1 fish collection in the Clinch River/

Watts Bar system ........................... $3-9$

5.1 Overall assessment of water data collected during Phase $1 \ldots \ldots \ldots \ldots$

5.2 Overall assessment of sediment core data collected during

Phase 1 .................................. 5-9

5.3 Overall assessment of sediment grab data collected during Phase $2 \ldots \ldots$ 5-12

5.4 Data assessment summary for fish tissue analyses for each of the data quality indicators and in total $\ldots \ldots \ldots \ldots \ldots \ldots \ldots \ldots \ldots . \ldots .16$

5.5 Summary of water, sediment, and fish samples submitted to laboratory and rejected during validation $\ldots \ldots \ldots \ldots \ldots \ldots \ldots \ldots \ldots \ldots \ldots . \ldots \ldots$ 5-22

5.6 Summary of the number of regular samples (i.e., excludes QC samples) rejected as a result of data validation ................... 5-29

A.1 Atomic absorption analyses of water samples conducted at $\mathrm{K}-25 \ldots \ldots \ldots$ A-20

A.2 Atomic absorption analyses of water samples conducted at $\mathrm{K}-25 \ldots \ldots \ldots$ A-20

A.3 Inorganic accuracy in water samples summary of matrix spike recoveries conducted at the $\mathrm{K}-25$ laboratory

vii 
A.4 Inorganic precision in water samples summary of laboratory duplicates conducted at the K-25 laboratory

A.5 Inorganic accuracy in water samples summary of laboratory control samples conducted by the K-25 laboratory

A6 Atomic absorption analyses conducted at International Technology laboratories

A.7 Atomic absorption analyses conducted at International Technology laboratories

A.8 Inorganic accuracy in soil samples summary of spike recoveries conducted at International Technology laboratories . . . . . . . . . A-26

A.9 Inorganic accuracy in soil samples summary of postdigestion spike

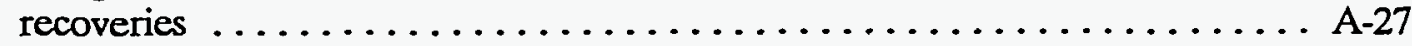

A.10 Inorganic precision in soil samples summary of laboratory duplicates conducted at International Technology laboratories

A.11 Inorganic accuracy in soil samples summary of laboratory control samples

A.12 Atomic absorption analyses of fish tissue conducted by Environmental Analysis Laboratory at Oak Ridge National Laboratory

A.13 Atomic absorption analyses of fish tissue examined for mercury by Environmental Analysis Laboratory at Oak Ridge National Laboratory . . . . A-30

A.14 Inductively coupled plasma analyses of water samples conducted by the K-25 Analytical Chemistry Division

A.15 Inductively coupled plasma analyses of water samples conducted by the K-25 Analytical Chemistry Department for ten metals

A.16 Inductively coupled plasma analyses of sediment conducted by International Technology laboratories

A.17 Inductively coupled plasma analyses of sediment samples conducted by International Technology laboratories

A.18 Inductively coupled plasma and inductively coupled plasma and mass spectrometry analyses of fish tissue conducted at Oak Ridge National Laboratory/Chemical and Physical Analysis Group 
A.19 Inductively coupled plasma and inductively coupled plasma and mass spectrometry analyses of fish tissue examined for metals at Oak Ridge National Laboratory/Chemical and Physical Analysis Group . . . . . . A-34

A.20 Inductively coupled plasma and inductively coupled plasma and mass spectrometry analyses of fish tissue examined for metals at Oak Ridge National Laboratory/Chemical and Physical Analysis Group ... . . . A A-35

A.21 Semivolatile analyses of water and sediment samples conducted at K-25 . . A-35

A.22 Semivolatile analyses of water and sediment samples conducted at K-25 . . A-36

A.23 Organic accuracy in water summary of surrogate recoveries conducted at the $\mathrm{K}-25$ laboratory $\ldots \ldots \ldots \ldots \ldots \ldots \ldots \ldots \ldots \ldots \ldots . \ldots \ldots$

A.24 Organic accuracy in soil summary of surrogate recoveries conducted at the K-25 laboratory

A.25 Organic accuracy in soil summary of matrix spike/matrix spike duplicate conducted at the $\mathrm{K}-25$ laboratory $\ldots \ldots \ldots \ldots \ldots \ldots \ldots \ldots \ldots \ldots$

A.26 Organic precision in soil summary of matrix spike/relative percent differences conducted at the $\mathrm{K}-25$ laboratory $\ldots \ldots \ldots \ldots \ldots \ldots \ldots$ A-40

A.27 Semivolatile analyses of fish tissue (by SDG) conducted by the Organic Analysis Laboratory at Oak Ridge National Laboratory ........... A-41

A.28 Semivolatile analyses of fish tissue conducted by the Organic Analysis Laboratory at Oak Ridge National Laboratory ................ A-42

A.29 Pesticide/PCB analyses of water and sediment samples conducted at the K-25 laboratory

A.30 Pesticide/PCB analyses of water and sediment samples conducted at K-25

A.31 Organic accuracy in water samples summary of surrogate recoveries conducted at $\mathrm{K}-25$

A.32 K-25 laboratory organic accuracy and precision in sediment samples of surrogate and matrix spike recoveries 
A.34 Pesticide/PCB analyses of fish tissue conducted by the Organic Analysis Laboratory at Oak Ridge National Laboratory $\ldots \ldots \ldots \ldots \ldots \ldots \ldots$ A -48

A.35 Samples analyzed for 11 pesticides and 2 PCBs by the Organic Analysis Laboratory at Oak Ridge National Laboratory

A.36 Pesticide/PCB analyses of fish tissue conducted by the Chemical and Physical Analysis Group at Oak Ridge National Laboratory $\ldots \ldots \ldots \ldots \ldots \ldots \ldots \ldots \ldots \ldots \ldots \ldots \ldots \ldots \ldots \ldots . \ldots \ldots$

A.37 Pesticide/PCB analyses of fish tissue conducted by the Chemical and Physical Analysis Group at Oak Ridge National Laboratory

A.38 Gamma analysis of sediment, water, and fish tissue conducted by Environmental Sciences Division at Oak Ridge National Laboratory ...... A-50

A.39 Gamma analysis of sediment, water, and fish tissue conducted by Environmental Sciences Division at Oak Ridge National Laboratory

A.40 Number of accepted and rejected analyses and associated explanation codes for Environmental Sciences Division/ Radiological Analysis Laboratory

A.41 Frequency by instrument and detector of background analyses conducted by Environmental Sciences Division/Radiological Analysis Laboratory ...... A-54

A.42 Environmental Sciences Division/Radiological Analysis Laboratory control sample results

A.43 Environmental Sciences Division/Radiological Analysis Laboratory duplicate analysis results by instrument and matrix

A.44 Results of Environmental Protection Agency interlaboratory comparison samples analyzed by Environmental Sciences Division/Radiological Analysis Laboratory

A.45 Alpha and beta analysis of sediment, water, and fish tissue conducted at Oak Ridge Associated Universities $\ldots \ldots \ldots \ldots \ldots \ldots \ldots \ldots \ldots$ A -58

A.46 Alpha and beta analysis of sediment, water, and fish tissue conducted at Oak Ridge Associated Universities

A.47 List of samples analyzed by Oak Ridge Associated Universities/ Environmental Survey Site Assessment Program 
A.48 Chemical recovery results for alpha analyses conducted by Oak Ridge Associated Universities/Environmental Survey Site Assessment Program . . . . . . . . . . . . . . . . . . . . . . A A-59

A.49 Chemical recovery results for strontium-90 analyses conducted by Oak Ridge Associated Universities/Environmental Survey Site Assessment Program

A50 Laboratory control sample results conducted by Oak Ridge Associated Universities/Environmental Survey Site Assessment Program . . . . . . . . . . . . . . . . . . . . A-61

A.51 Duplicate analysis results conducted by Oak Ridge Associated Universities/Environmental Survey Site Assessment Program

C.1 Quality control sample results for equipment rinse blank samples submitted for dissolved and total inorganic analyses (detected analytes only) $\ldots \ldots \ldots \ldots \ldots \ldots \ldots \ldots$ C-12

C.2 Trip and field blank water samples submitted for dissolved and total inorganic analyses

C.3 Precision assessment for field duplicate water samples.

Relative percent difference values greater than $20 \%$ reflect unacceptable levels of precision

C.4 Test for precision of duplicate pairs with average values $<5$ times the mean detection limit for particular water analytes

C.5 Test comparing dissolved and total inorganic results for regular and field duplicate samples

C.6 Test comparing dissolved and total inorganic results for quality control blank and equipment rinse samples (insoluble, inorganic analytes only) $\ldots \ldots \ldots \ldots \ldots \ldots \ldots \ldots \ldots \ldots \ldots$

C.7 Number of sediment cores and field splits collected during Phase 1 C-16

C.8 Evaluation of organic analysis of field splits from sediment cores 
C.9 Evaluation of inorganic analysis of field splits from sediment cores

C.10 Relative percent differences of radionuclide concentrations for field splits of sediment grabs

C.11 Relative percent differences for laboratory test samples submitted for inorganic analysis

C.12 Relative percent differences for laboratory test samples submitted for alpha-emitting radionuclide analysis

C.13 Number of regular samples submitted for each analytical group

by location

C.14 Summary of relative standard deviations of concentrations of mercury, zinc, ${ }^{137} \mathrm{Cs}$, Aroclor 1254 , and Aroclor 1260 in fish tissue for Phase 1 sampling locations

C.15 Summary of duplicate analyses performed on inorganic analyses of fish samples

C.16 Summary of duplicate analyses performed on pesticide analyses of fish samples

C.17 Summary of duplicate analyses performed on polychlorinated biphenyls (PCB) analyses of fish samples 


\section{FIGURES}

2.1 Total nonconformances from analytical validation $\ldots \ldots \ldots \ldots \ldots \ldots \ldots$

B.1 Nonconformances from analytical validation by the IT laboratory using AA/ICP methods $\ldots \ldots \ldots \ldots \ldots \ldots \ldots \ldots \ldots \ldots$ B-3

B.2 Nonconformances from analytical validation by the K-25 laboratory using $\mathrm{AA} / \mathrm{ICP}$ methods

B.3 Nonconformances from analytical validation by the ORNL Chemical and Physical Analysis Group laboratory using the ICP method . . . . . . . . B-5

B.4 Nonconformances from analytical validation by the ORNL/EAL laboratory using the AA method $\ldots \ldots \ldots \ldots \ldots \ldots \ldots \ldots \ldots \ldots \ldots \ldots$

B.5 Nonconformances from analytical validation by the K-25 laboratory using the semivolatiles method

B.6 Nonconformances from analytical validation by the ORNL/OAL laboratory using the semivolatiles method $\ldots \ldots \ldots \ldots \ldots \ldots \ldots \ldots \ldots \ldots$ B-8

B.7 Nonconformances from analytical validation by the K-25 laboratory using pesticide/PCB methods

B.8 Nonconformances from analytical validation by the ORNL/OAL laboratory using pesticide/PCB methods $\ldots \ldots \ldots \ldots \ldots \ldots \ldots \ldots \ldots \ldots \ldots$ B-10

B.9 Nonconformances from analytical validation by the ORNL/CPA laboratory using pesticide/PCB methods $\ldots \ldots \ldots \ldots \ldots \ldots \ldots \ldots \ldots \ldots$ B-11

B.10 Nonconformances from analytical validation by the ORNL/ESD RAL using the gamma spectroscopy method

B.11 Nonconformances from analytical validation by the ORAU laboratory using the alpha spectroscopy method

B.12 Nonconformances from analytical validation from ORAU laboratory using the Sr-90 method

B.13 Nonconformances from analytical validation by the ORAU laboratory using the tritium method 
. 


\section{ACRONYMS}

\begin{tabular}{|c|c|}
\hline$\% \mathrm{D}$ & percent difference \\
\hline$\% \mathrm{R}$ & percent recovery \\
\hline $\mathrm{AA}$ & atomic absorption \\
\hline $\mathrm{ACD}$ & Analytical Chemistry Division (ORNL) Department (K-25) \\
\hline AES & atomic emission spectroscopy \\
\hline ANSI & American National Standards Institute \\
\hline ASME & American Society of Mechanical Engineers \\
\hline BMAP & Biological Monitoring and Abatement Program \\
\hline CERCLA & Comprehensive Environmental Response, Compensation, and Liability Act \\
\hline CLP & Contract Laboratory Program \\
\hline CPA & Chemical and Physical Analysis Group \\
\hline CRDL & contract-required detection limit \\
\hline CRM & Clinch River mile \\
\hline CRRI & Clinch River Remedial Investigation \\
\hline CR/WBR & Clinch River/Watts Bar Reservoir \\
\hline CVAA & cold vapor atomic absorption \\
\hline $\mathrm{DBC}$ & dibutylchlorendate \\
\hline DDD & dichlorodiphenyldichloroethane \\
\hline DDE & dichlorodiphenyldichloroethene \\
\hline DDT & dichlorodiphenyltrichloroethane \\
\hline DER & duplicate error ratios \\
\hline DL & detection limit \\
\hline DMC & Document Management Center \\
\hline DMR & Discharge Monitoring Report \\
\hline DOE & U.S. Department of Energy \\
\hline DOE-ORO & Department of Energy Oak Ridge Operations \\
\hline DQO & data quality objective \\
\hline EAL & Environmental Analysis Laboratory \\
\hline EFPC & East Fork Poplar Creek \\
\hline EML & Environmental Monitoring Laboratory \\
\hline EMSL & Environmental Monitoring Systems Laboratory \\
\hline EPA & U.S. Environmental Protection Agency \\
\hline ER & Environmental Restoration \\
\hline ERM & Emory River Mile \\
\hline ESD & Environmental Sciences Division \\
\hline ESSAP & Environmental Survey and Site Assessment Program \\
\hline FDA & U.S. Food and Drug Administration \\
\hline FFA & Federal Facility Agreement \\
\hline GC & gas chromatography \\
\hline HSWA & Hazardous and Solid Wastes Amendments \\
\hline ICP/MS & inductively coupled plasma/mass spectrometry \\
\hline ICS & interference check sample \\
\hline
\end{tabular}




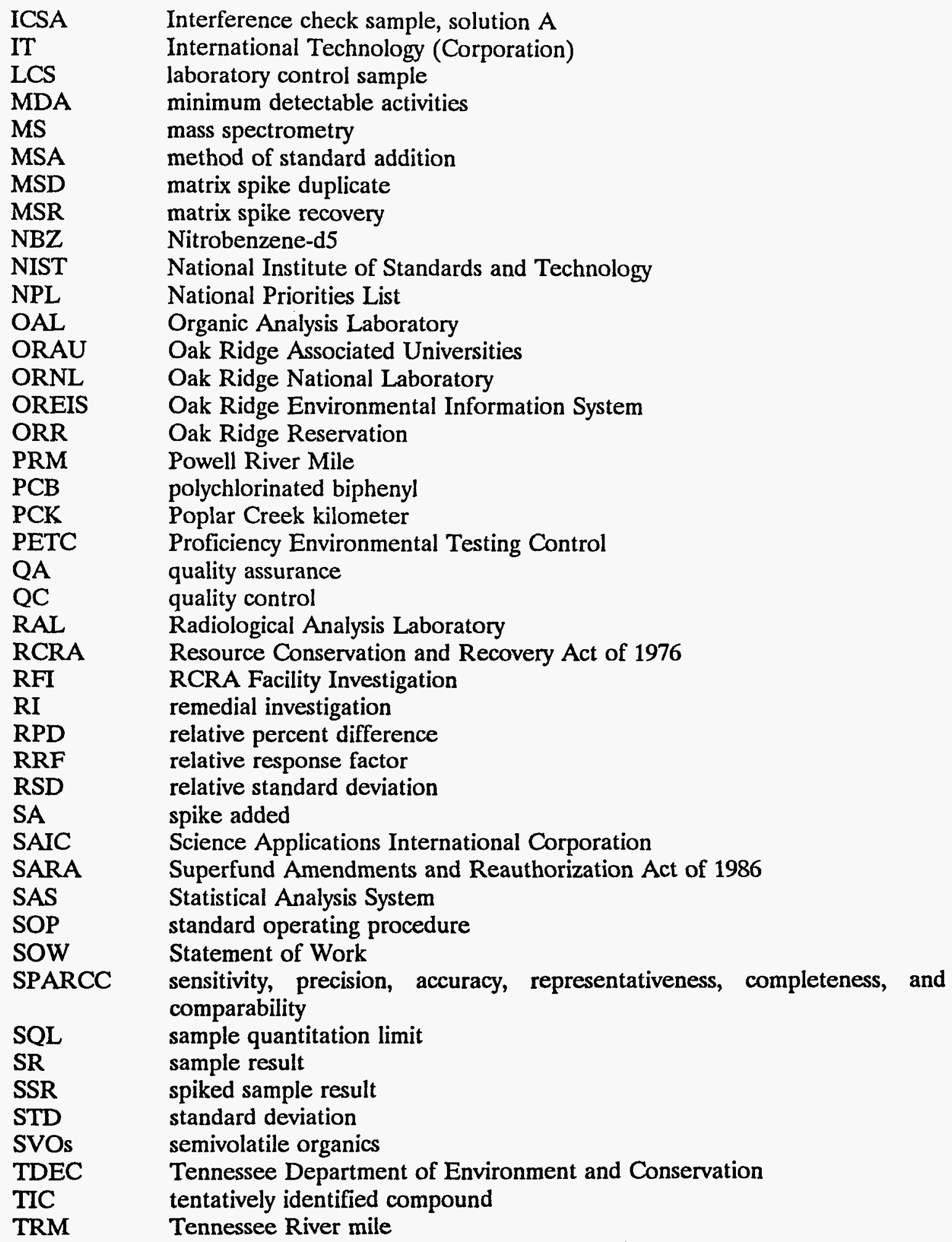


TVA Tennessee Valley Authority

WOC White Oak Creek

WOCE White Oak Creek Embayment

xvii 


\section{EXECUTIVE SUMMARY}

The Clinch River Remedial Investigation (CRRI) is designed to address the transport, fate, and distribution of waterborne contaminants released from the U.S. Department of Energy Oak Ridge Reservation and to assess potential risks to human health and the environment associated with these contaminants. Primary areas of investigation are Melton Hill Reservoir, the Clinch River from Melton Hill Dam to its confluence with the Tennessee River, Poplar Creek, and Watts Bar Reservoir.

Phase 1 of the CRRI was a preliminary study in selected areas of the Clinch River/Watts Bar Reservoir. Fish, sediment, and water samples were collected and analyzed for inorganic, organic, and radiological parameters. Phase 1 was designed to (1) obtain high-quality data to confirm existing historical data for contaminant levels; (2) determine the range of contaminant concentrations present in the river-reservoir system; (3) identify specific contaminants of concern; and (4) establish the reference (background) concentrations for those contaminants.

Quality assurance (QA) objectives for Phase 1 were that (1) scientific data generated would withstand scientific scrutiny; (2) data would be gathered using appropriate procedures for field sampling, chain-of-custody, laboratory analyses, and data reporting; and (3) data would be of known precision and accuracy. These objectives were met through the development and implementation of (1) a QA oversight program of audits and surveillances; (2) standard operating procedures accompanied by a training program; (3) field sampling and analytical laboratory quality control requirements; (4) data and records management systems; and (5) validation of the data by an independent reviewer.

Approximately 1700 inorganic samples, 1500 organic samples, and 2200 radiological samples were analyzed and validated. The QA completeness objective for the project was to obtain valid analytical results for at least $95 \%$ of the samples collected. Overall completeness for all Phase 1 media and analyses was $88 \%$.

Valid data were obtained for $98 \%$ of the water samples. Most of the rejected analyses occurred because of improper sample preservation, holding times exceedance, and/or poor surrogate recoveries.

Both sediment core and grab samples were evaluated. Valid data were obtained for $96 \%$ of the core samples and $91 \%$ of the grab samples. Rejected data occurred because of low spike recoveries, holding times exceedance, and calibration difficulties.

For fish tissue analyses, only $68 \%$ of the data was considered valid; $50 \%$ of the semivolatile data was rejected because of inadequate surrogate recoveries. The CRRI completeness objective of $95 \%$ was attained for all analysis types except the semivolatiles.

A review of the QA systems and quality control (QC) data associated with the Phase 1 investigation is presented to evaluate whether the data were of sufficient quality to satisfy 
Phase 1 objectives. The data quality indicators of precision, accuracy, representativeness, comparability, completeness, and sensitivity were evaluated to determine any limitations associated with the data. To provide an overall qualitative assessment of the data, each analyte (or analyte group) was assigned a grade of $\mathrm{A},>90 \%$ acceptable data (very adequate); $\mathrm{B}, 70 \%$ to $90 \%$ acceptable data (mostly adequate with some deficiencies); or C, $<70 \%$ acceptable data (inadequate).

For water data the overall assessment grade for inorganic results was very adequate, with representativeness and comparability grades as mostly adequate. Pesticide/PCB organic analytes were graded only mostly adequate because of the absence of results from Poplar Creek. Semivolatile organic compounds and radionuclides, except tritium, were all graded very adequate; tritium data was graded inadequate.

For sediment results the overall assessment for gamma-emitting radionuclide analyses for grab and core samples was graded very adequate. Organic and inorganic analyses of sediment grabs were judged to be inadequate, and further sampling and analysis is warranted. Inorganic analyses of sediment core samples were judged to be mostly adequate except for arsenic, chromium, copper, lead, nickel, mercury, selenium, and zinc, which were determined to be inadequate because of excessive detection limits. Organic data from sediment cores were judged to be mostly adequate and acceptable for risk screening analysis; however, because of high detection limits and the number of rejected samples, additional sampling is warranted. Alpha-emitting radionuclide data were judged to be mostly adequate; the only limitation is that there is no measure of field precision. Only one reference site sample was collected, which prevents statistically valid comparison to be made with affected sites. This limits the value of the entire sediment data base.

For fish tissue data the overall assessment graded inorganic analyses very adequate except for lead analyses, which were graded mostly adequate. The PCB and radionuclides data were also graded very adequate. The pesticides data met validation requirements for risk assessment and were judged mostly adequate, but some $\mathrm{QC}$ results were less than desirable, indicating consideration of further sampling and analysis for pesticides in Phase 2. Although 50\% of the semivolatile fish data were usable, the overall objective was compromised so the semivolatiles data were graded inadequate.

In summary, reproducible, precise, and accurate measurements consistent with CRRI objectives and the limitations of the sampling and analytical procedures used were obtained for most of the data collected in support of Phase 1. Because a phased approach is being employed in the CRRI, iterative sampling efforts for Phase 2 will incorporate the lessons learned from Phase 1 and correct for those problems that resulted in any pieces of insufficient data. 


\section{INTRODUCTION}

\subsection{PURPOSE OF REPORT}

The purpose of this report is to present and provide an assessment of the results of field sampling and analytical laboratory quality assurance (QA) and quality control (QC) activities performed during Phase 1 of the Department of Energy (DOE) remedial investigation (RI) of the Clinch River/Watts Bar Reservoir (CR/WBR) system. These QA/QC results are presented herein to document that the data collected during Phase 1 are of sufficient quality to use for the intended purpose. The results of Phase 1 are presented in the data summary report (Cook et al. 1992), and this report serves as a companion to the data summary report.

\subsection{BACKGROUND AND REGULATORY DRIVERS}

The Clinch River remedial investigation (CRRI) focuses on the portions of the Clinch and Tennessee rivers that may have been adversely affected by contaminants released from the DOE Oak Ridge Reservation (ORR) from the mid-1940s to the present. The contaminants released from the ORR to the Clinch and Tennessee rivers originated from research, industrial, and waste disposal activities conducted on the ORR at the Oak Ridge National Laboratory (ORNL), the Oak Ridge Gaseous Diffusion Plant (now known as the Oak Ridge K-25 Site), and the Oak Ridge Y-12 Plant. The contaminants released from these facilities into the Clinch River include a variety of radionuclides, metals, and organic compounds. The primary areas of investigation are the Melton Hill and Watts Bar reservoirs [with particular emphasis on the Clinch River arm of Watts Bar Reservoir (Melton Hill to the Clinch River-Tennessee River confluence)] and Poplar Creek. The areal extent of the CRRI is discussed in Cook et al. (1992).

The DOE ORR was added to the National Priorities List (NPL) in December 1989. A Federal Facility Agreement (FFA) [under Sect. 120 of the Comprehensive Environmental Response, Compensation, and Liability Act (CERCLA), as amended by the Superfund Amendment and Reauthorization Act (SARA) and Sect. 6001 of the Resource Conservation and Recovery Act (RCRA) of 1976] between DOE, the U.S. Environmental Protection Agency (EPA) Region IV, and the Tennessee Department of Environment and Conservation (TDEC) became effective on January 1, 1992. These parties coordinate DOE's CERCLA RCRA response obligation with corrective measures required and conducted by DOE under its current permit under the Hazardous and Solid Waste Amendments (HSWA) to RCRA of 1984. Section 3004(v) of the HSWA of RCRA specifically addresses requirements for corrective actions for releases of hazardous wastes or constituents beyond the boundaries of RCRA-permitted sites. In addition TDEC, DOE, and EPA expect that the response actions under the FFA, together with corrective measures, will achieve comprehensive remediation of releases and potential releases of contaminants from the ORR. The CRRI is being conducted in compliance with the FFA and with Sect. 3004(v) of RCRA. 


\subsection{OBJECTIVES AND APPROACH OF THE CLINCH RIVER REMEDIAL INVESTIGATION}

An assessment of the quality of the data collected during Phase 1 of the CRRI must begin with the objectives of Phase 1 of the RI and the data quality objectives (DQOs) of the investigation. This section describes the overall objectives and the phased approach of the CRRI.

The primary objectives of the CRRI (Energy Systems 1990) are the following:

- To define the nature and extent of contamination of the off-site surface water and sediment environment downstream from the ORR, which resulted from operations and waste disposal activities at DOE's facilities on the ORR

- To quantify any risk posed to human health and to the environment resulting from the existing off-site contamination

- To preliminarily identify and evaluate potential corrective measures and remedial action alternatives

A phased approach is being employed in the CRRI because a large number of samples may be required to characterize such a large and complex river and reservoir system. The phased approach relies heavily on iterative screening-level risk analysis for estimating human and ecological health and is based on obtaining the data needed for risk analyses and for evaluating remediation alternatives. Primary components of the phased RI approach include scoping studies and Phase 1 and 2 studies.

The scoping studies were performed before the work plan for the CRRI was developed and approved. In the scoping studies, extant data were synthesized and used in a screeninglevel risk analysis, which served to (1) preliminarily identify contaminants of concern in the CR/WBR system and (2) identify areas of the river and reservoir in which additional data collection was necessary for site characterization, risk assessment, and evaluation of remediation alternatives. The scoping studies were summarized in Olsen et al. (1992), Suter (1991), and Hoffman et al. (1991).

The Phase 1 study followed the scoping study and consisted of collecting and analyzing samples from areas selected to represent areas that have a range of contamination (including reference sites located upstream from the ORR). The objectives of the Phase 1 study (Energy Systems 1990) were the following:

- To obtain high-quality data to confirm preliminary results from the scoping studies

- To determine the range of contaminant concentrations present in the off-site environment

- To identify the contaminants of concern

- To establish the reference concentrations for those contaminants

Data collected during the Phase 1 investigation must be of sufficient quality to meet each of the general objectives. The specific QA objectives for all data collected during Phase 1 were to obtain reproducible, precise, and accurate measurements consistent with the intended 
use of the data and the limitations of the sampling and analytical procedures used. The Phase 1 study has been completed and is summarized in Cook et al. (1992).

During Phase 1, water, sediment, and fish tissue samples were collected from reaches of the river/reservoir system and analyzed for organic, inorganic, and radiochemical contaminants. The CR/WBR system was divided into ten reaches (Table 1.1) following those of Hoffman et al. (1991). For information purposes, Table 1.1 lists all ten reaches, but not all the reaches were sampled for all three matrixes during Phase 1. For example, sediment cores were not collected for reaches $6,13,15$ or 18 , and water samples were not collected for reaches 15 or 18. Fish samples were not collected for reaches 16 or 18 . The lack of Phase 1 data from these reaches does not affect the data completeness because no samples were planned for these reaches.

Table 1.1. Stream and river reaches used in the CRRI site characterization and screening risk assessment

\begin{tabular}{|c|c|c|}
\hline $\begin{array}{l}\text { Reach } \\
\text { number }\end{array}$ & Reach name (description) & $\begin{array}{c}\text { River } \\
\text { mile/km } \underline{a}\end{array}$ \\
\hline 1 & $\begin{array}{l}\text { Melton Hill Reservoir (from the Oak Ridge Marina to } \\
\text { Melton Hill Dam) }\end{array}$ & CRM 52.0-23.1 \\
\hline 2 & Clinch (Clinch River from Melton Hill Dam to Poplar Creek) & CRM 23.0-12.1 \\
\hline 3 & $\begin{array}{l}\text { Poplar Creek (Poplar Creek below the confluence of the East } \\
\text { Fork) }\end{array}$ & PCK 8.9-0.0 \\
\hline 4 & $\begin{array}{l}\text { Poplar Creek Clinch (the Clinch River from the mouth of } \\
\text { Poplar Creek to the confluence with the Tennessee River) }\end{array}$ & CRM $120-0.0$ \\
\hline 5 & $\begin{array}{l}\text { Watts Bar Reservoir (the Tennessee River from the } \\
\text { confluence of the Clinch River to Watts Bar Dam) }\end{array}$ & TRM 567.5-530.0 \\
\hline 6 & Emory River & ERM 14.0-0.0 \\
\hline 10 & Norris Reservoir (the Clinch River above Norris Dam) & CRM 103 \\
\hline 13 & $\begin{array}{l}\text { Poplar Creek (Poplar Creek above the confluence of the East } \\
\text { Fork) }\end{array}$ & PCK 11.0-9.0 \\
\hline 15 & Chickamauga Reservoir (below Watts Bar Dam) & TRM 529.9-515.0 \\
\hline 18 & $\begin{array}{l}\text { Tennessee River arm of WBR (from Fort Loudon and Tellico } \\
\text { dams to the confluence of the Clinch River) }\end{array}$ & TRM 602.0-567.6 \\
\hline
\end{tabular}

${ }_{\text {a }}$ CRM $=$ Clinch River mile, PCK = Poplar Creek kilometer, TRM = Tennessee River mile, and $\mathrm{ERM}=$ Emory River mile.

The information collected during Phase 1 will be used to further focus the Phase 2 study on specific contaminants and areas or locations that might require further study. Specifically, the objectives of the Phase 2 study are to (1) perform iterative screening risk analyses as additional data become available, (2) quantitatively estimate potential risks posed to human health and the environment, and (3) perform additional focused sampling during Phase 2. 
These risk analyses will guide more extensive sampling and analysis and risk assessment, ultimately leading to a baseline risk assessment presented in a final RI report. In addition, the Phase 2 study will include a preliminary evaluation of potential remediation alternatives and identification of effective and acceptable corrective measures.

After the Phase 1 sampling and analysis began, a task was initiated to characterize the near-shore sediment in the CR/WBR. The primary objective of the near-shore sediment task is to provide information on the risks posed to human health from surface sediments (between 0 and $10 \mathrm{~cm}$ depth in the sediments) in shallow waters of the near-shore areas. These sediments are exposed to the air during the winter season, when the water levels in these reservoirs are lowered as part of the water management activities of the Tennessee Valley Authority (TVA), or they are from areas that are permanently submerged but that may have the potential for human contact resulting from dredging operations for private boat docks and other similar activities. This task supports the efforts of TVA and the U.S. Army Corps of Engineers to evaluate permit applications for sediment-disturbing activities (e.g., dredging for private boat access channels, installation of boat docks, stabilizing of shorelines). An interagency working group composed of TVA, the Corps of Engineers, DOE, TDEC, EPA, and staff from the CRRI preliminarily evaluates the levels of contamination prior to TVA and the Corps of Engineers performing their evaluation. Almost 600 surface sediment samples in near-shore areas of Watts Bar Reservoir and the Clinch River were collected as part of this task. The results of this sampling are summarized in Cook et al. (1992), and the $\mathrm{QA} / \mathrm{QC}$ program for this near-shore sediment sampling task is discussed in this report.

\subsection{OBJECTIVES OF THE QAVQC DATA SUMMMARY FOR THE PHASE 1 REMEDIAL INVESTIGATION}

The objectives of this QA/QC report are to present and assess the results of the QA/QC activities for Phase 1 of the CRRI. Chapter 2 describes the QA/QC program and the methods used for field and laboratory QA/QC activities. Chapter 3 presents a more detailed evaluation of the results of the field QA/QC program, and Chap. 4 evaluates the results of the laboratory QA/QC activities and the results of the analysis of water, sediment, and fish tissue samples. Chapter 5 provides an assessment of the overall quality of the data. Chapter 5 also contains a summary of QA/QC lessons identified during Phase 1 and specific recommendations for additional sampling and analysis. 


\section{QUALITY ASSURANCE/QUALITY CONTROL PROGRAM}

The QA/QC Program for Phase 1 of the CRRI was designed to comply with both EPA QAMS-005/80 (EPA 1980a) and American National Standards Institute/American Society of Mechanical Engineers (ANSI/ASME) NQA-1 (ASME 1989) guidelines. (Note that Phase 1 predated DOE Order $5700.6 \mathrm{C}$.) Project-specific QA requirements and the general QA objectives for Phase 1 data were defined in the RCRA Facility Investigation (RFI) Plan (Energy Systems 1990).

The QA objectives for Phase 1 data were the following:

- Scientific data generated would withstand scientific scrutiny.

- Data would be gathered using appropriate procedures for field sampling, chain-ofcustody, laboratory analyses, and data reporting.

- Data would be of known precision and accuracy.

The QA objective for all data collected during Phase 1 was, therefore, to obtain reproducible, precise, and accurate measurements consistent with the intended use of the data and the limitations of the sampling and analytical procedures used.

These objectives were met through the development and implementation of (1) a QA oversight program of audits and surveillances, (2) standard operating procedures (SOPs) accompanied by a training program, (3) field sampling and analytical laboratory QC requirements, and (4) data and records management systems.

\section{AUDITS AND SURVEILANCES}

Audits and surveillances were performed by DOE Oak Ridge Operations (DOE-ORO); Martin Marietta Energy Systems, Inc., Central QA; and the Energy Systems Environmental Restoration (ER) QA specialist who reviewed and evaluated the adequacy of field and laboratory performance and ascertained whether the QA/QC Plan was completely and uniformly implemented. Results of these audits and surveillances were documented and reported to management. Follow-up corrective actions were taken as needed. Implementation was monitored by the Clinch River QA specialist and verified by the auditing organization.

The chronology of audits and surveillances was as follows:

March 1990 DOE-ORO multifunctional appraisal of ORNL

June 1990 DOE-ORO environmental protection audit

November 1991 Beginning of Energy Systems ER QA specialist monthly surveillance

December 1991 Energy Systems Corporate audit 


\subsection{STANDARD OPERATING PROCEDURES AND TRAINING PROGRAM}

Whenever applicable, existing procedures were used for CRRI activities. Field sampling procedures from Kimbrough et al. (1990) were used, and many EPA Contract Laboratory Program (CLP) analytical procedures (field and laboratory) were specified. Procedures were developed to support technical and administrative activities of the CRRI when none existed. These activities included the following:

- Sampling processes

- Sample handling/custody

- Calibration of equipment used in obtaining samples and/or data

- Analytical processes

- Data reduction, validation, and reporting

- Internal QC checks

- Audits

- Surveillance and corrective action processes

- Specific routine functions required to assess data precision and completeness

The CRRI training program consists of a training plan, which defines requirements for training frequency and trainer designation; a training needs assessment, which identifies personnel to be trained; and the actual training on CRRI procedures. Training is completed as required in the appropriate SOP, and training records are maintained by the training coordinator for the CRRI. Generally, the extent of training is commensurate with the scope, complexity, and nature of the activity and the education, experience, and proficiency of the person.

\section{SAMPLING UNCERTAINTY}

Sample data always contain a degree of uncertainty that needs to be evaluated in order to determine if the sample data meet the project objectives as set forth in the project data quality objectives. There are five major sources of uncertainty for sample data, and each source of uncertainty contains contributions from both systematic uncertainty and random uncertainty. Summing the systematic uncertainty from each source produces the total measurement bias. Summing the random uncertainty from each source produces the total measurement variability or precision. The five major sources of uncertainty for sample data are (1) natural sample variability, (2) sampling error, (3) laboratory subsampling error, (4) laboratory analytical error, and (5) reporting error. The objective of a QA/QC program is to evaluate the contribution to both bias and precision from each source.

Natural sample variability has components of both spatial and temporal heterogeneity. The CRRI Phase 1 Sampling and Analysis Plan was designed to collect samples in areas of the CR/WBR that had unique sets of possible contributing pollution sources. This was done in order to qualitatively characterize the contribution from each pollution source in the system and to produce an estimate of the spatial heterogeneity of pollution in the system. No 
attempt was made in Phase 1 to characterize the CR/WBR system for temporal heterogeneity. A more complete nature and extent characterization of the CR/WBR system is planned for Phase 2.

The variability contributed by natural sample variability is difficult to measure and may be reasonably evaluated only by the subjective judgment of an expert in the field. Natural sample variability contribution to sampling uncertainty can not be separated as an individual component by evaluation of QC samples.

Bias and variability from some components of sampling error may be evaluated by the collection and analysis of various types of field QC blanks. Equipment rinse blanks, field blanks, and trip blanks may be analyzed to evaluate contributions of bias due to sample collection equipment, sample containers, and storage for volatile organic compound analysis, respectively. Field duplicate and field split collection and analysis provide a measurement of the sampling uncertainty.

Laboratory QC samples can be used to evaluate the contribution of laboratory subsampling error and laboratory analytical error to total measurement error. Method blanks and matrix spike samples may be analyzed to evaluate contributions of bias due to laboratory subsampling and laboratory analysis. Laboratory duplicates may be analyzed to evaluate the contribution of laboratory subsampling error and laboratory analysis error to sampling uncertainty.

\section{FIELD QUALITY CONTROL}

QC measures for field operations, including selection of sampling locations, field data recording, and sample collection, were implemented to meet the Phase 1 project objectives. Sampling sites for each matrix (fish, sediment, or water) and QC sample collection frequencies were specified by the CRRI Plan (Energy Systems 1990), with final determination of each site and QC sample collection the responsibility of the sample team leader. Methods for field activities, including record keeping, establishment and maintenance of sample custody, instrument calibration, and sample identification, were specified in SOPs; sample collection procedures followed those of Kimbrough et al. (1990).

All field activities followed standard record keeping and chain-of-custody procedures. These included recording site-specific information in waterproof notebooks, with routine reviews of the notebooks. Sample custody was established by the sampling team upon collection, through the use of standard chain-of-custody forms, and was maintained throughout sample processing and delivery to analytical services. The goal for frequency of submittal of field QC samples was once for every 20 samples, as appropriate. Field QC samples included field duplicates, field splits, equipment-cleaning rinse samples, and field rinse water blanks. Matrix-specific field QC activities are discussed in Chap. 3.

\section{LABORATORY QUALITY CONTROL PROGRAM}

The CRRI Program required the independent review and validation of the analytical laboratory data for all Phase 1 analyses. The review and validation were conducted by a third- 
party subcontractor following EPA and/or project-specified guidelines to ensure a uniform and comprehensive review.

The laboratory QC Program ensured that all data generated and reported were scientifically valid, consistent with accepted methods, and of known accuracy. Results from QC samples were used to document data quality, verify that the analytical system was functioning for a given matrix/analyte, identify when additional corrections need to be made to the analytical system, and determine the effect of these corrections. The QC data provided an important indication of how well the data quality objectives were met. The types of laboratory QC samples used included laboratory control samples (LCSs), matrix spikes, surrogate spikes, replicates, and performance evaluation samples. The assessment of laboratory QC samples used during Phase 1 is summarized in Chap. 4.

The QA objectives for precision and accuracy in the laboratory were defined by control limits established for the EPA CLP. Acceptance criteria for the radiological analyses were generated by each laboratory.

All laboratories performing chemical analyses participated in performance evaluation sample programs during their period of performance for Phase 1 samples. The performance of each laboratory for a specific method is discussed in Chap. 4. An assessment of these results as they may impact the use of Phase 1 data is presented in Chap. 5.

The Environmental Sciences Division (ESD) gamma analysis laboratory's participation in the EPA/Environmental Monitoring Systems Laboratory (EMSL) Interlaboratory Comparison Program and the Oak Ridge Associated Universities (ORAU) Radiological Laboratory's use of laboratory control standards are discussed in Sect. 4.5.

\subsection{DATA QUALITY INDICATORS}

Both qualitative and quantitative criteria are used as indicators of the quality of the data. In determining whether the data are usable, especially in the decision process, the integrity and authenticity of the data must be evaluated, and the analytical uncertainty must be known. Indicators generally used to assess the data quality are precision, accuracy, representativeness, comparability, completeness, and sensitivity.

\subsection{Precision}

Precision is the degree of mutual agreement between independent measurements made under identical, specified conditions. Standard deviation (STD), relative standard deviation (RSD), and relative percent difference (RPD) are used to express precision. Analysis of laboratory replicates provides an assessment of the precision associated with the laboratory method. Analysis of field duplicates provides a total assessment of the overall precision of the sample data because it includes both the field and laboratory variability. Evaluation of sampling precision may be determined from the difference between the overall precision and the analytical precision. The usefulness of the precision data is limited to samples that contain contaminants at concentrations above the method detection limit (DL). Also, the analytical process must be in statistical control, or the estimates of precision will not be meaningful. 


$$
\begin{aligned}
\mathrm{RSD} & =100(\mathrm{STD} / \text { mean }) \\
\mathrm{RPD} & =\frac{\left|D_{1}-D_{2}\right|}{\left(D_{1}+D_{2}\right) / 2} \times 100,
\end{aligned}
$$

where $D_{1}$ is the value of the first measurement, and $D_{2}$ is the value of the second measurement.

\subsubsection{Accuracy}

Accuracy is the closeness of agreement between an observed value and an accepted reference value. When applied to a set of observations, accuracy will be a combination of a random component and a common systematic error component (bias). Bias is calculated as:

$$
\text { Bias }=\left(x_{s}-x_{u}\right)-K,
$$

where

$x_{s}=$ measure value for spiked sample,

$x_{u}=$ measure value for unspiked sample,

$K=$ known value of the spike in the sample.

Accuracy was primarily measured in Phase 1 through the use of LCSs, matrix spikes, surrogate spikes, and performance evaluation samples. When used correctly, blanks, both in the field and the analytical laboratory, provided a means for checking for bias resulting from contamination. Blanks must be treated the same as the samples. When contamination is found, the causes must be eliminated. Use of blank results to correct sample results can add more variability to the result because blanks results are also subject to analytical error. No blank corrections were performed on the Phase 1 data. Calibration standards at the required concentrations and frequency were used to estimate the data variability. Analytical error may occur from variability in calibration constants, infrequent recalibration or over-calibration of the analytical system, and unstable calibration standards.

\subsection{Representativeness}

Representativeness expresses the degree to which the data accurately reflect the analyte or parameter of interest at an environmental site. Several factors may contribute to whether a sample result is representative of the sampling site. SOPs and approved analytical methods must be used both in the field and in the analytical laboratory. Any measures taken to ensure that bias has not been introduced into the sampling and analysis will contribute to sample representativeness. These measures include proper preservation; use of standard analytical methods; adherence to appropriate holding times; and use of field and laboratory blanks, equipment rinsates, and proper containers. 


\subsubsection{Comparability}

Comparability is the confidence with which one data set can be compared with another data set generated by a different sampling event or by a different laboratory. The use of accepted methods and SOPs and participation in intralaboratory performance evaluation testing demonstrate comparability. Sample collection, preservation, storage, preparation, analysis, and reporting must be consistent for comparability to be achievable.

\subsection{Completeness}

Completeness is a measure of the amount of valid data obtained from the sampling and analysis process. Analytical completeness is typically expressed as the total number of samples taken for which acceptable analytical data are generated divided by the total number of samples collected. Sampling completeness is defined as the number of samples actually collected divided by the total number of samples planned to be collected.

\subsection{Sensitivity}

Sensitivity is the capability of methodology or instrumentation to discriminate between samples having differing concentrations of analytes (Taylor 1987). Sensitivity is defined by the limit of detection, the limit of quantitation, the instrument DL, and the method limit of detection. The ability to accurately report a contaminant of concern at or above the DL is a primary concern in evaluating false positives and false negatives. Holding times and sample preservation must also be evaluated for effects on sensitivity.

\section{DATA AND RECORDS MANAGEMENT}

Data management activities ensured the organization, consistency, traceability, integrity, and security of the data sets generated during Phase 1 to enable the program to meet its objectives. Data and programs from field sampling, analytical analyses, and risk assessment activities are maintained in the program data base.

Standardized identification codes were used to ensure internal consistency and compatibility with external data bases such as the Oak Ridge Environmental Information System (OREIS). Sufficient information was recorded to ensure that data were traceable to the sampling task and location; the sample identification, sample depth, and sampling date; the analytical laboratory; the batch; the result; and the data qualifier. Data were reviewed by technical staff for completeness. Data were maintained so as to minimize the introduction of error resulting from faulty entry, transcription, storage, or management. Most data reside on the ORNL IBM 3090 mainframe computer, are manipulated with Statistical Analysis System (SAS) software, and are stored as SAS data sets. Data sets are protected from unauthorized access, deletion, and modification by the ACF2 security system on the IBM 3090. Daily and weekly backups are performed by computer operations staff. SAS and other compatible software (Lotus 1-2-3 and dBASE) are used with individual personal computers.

The Phase 1 data will be maintained by the program for continued analysis by technical staff in preparation for Phase 2 sampling activities. Phase 1 data have been transferred to OREIS for general accessibility. 
Records generated by the program that are required to (1) provide a complete and accurate history of sample collection, analysis, and data reporting; (2) document conduct of program business; and (3) support any future legal or administrative actions that may be taken are retained in the project files. Similarly, records that furnish documentation or evidence of quality (e.g., program work plans and results of QA oversight activities) were designated QA records and added to the project files.

Records identified for Phase 1 sampling and analysis activities included project plans and approvals, field and laboratory notebooks, chain-of-custody and request-for-analysis forms, instrument listings for gamma spectroscopy, analytical laboratory data packages, and data validation summary reports.

A hard-copy repository is maintained in the Clinch River ER Program Document Management Center (DMC), which is located at ORNL, Building 1505. This repository and associated index data base provide for the organization, protection, retrievability, and accountability of project records. The indexing system provides sufficient information to permit identification of the record and the items or activities to which it applies.

A CERCLA administrative record file has been created for the CRRI and will be the recipient of officially designated documents.

\section{DATA VALIDATION}

The primary goal of the Clinch River ER QA Program is to ensure that the analysis of all environmental samples produces data of known quality. According to EPA, "the quality of data is known when all components associated with its derivation are thoroughly documented, with such documentation being verifiable and defensible" (EPA 1990). To meet this goal, the Phase 1 data were validated using available EPA guidelines. According to EPA guidance found in QAMS 005/80 (EPA 1980a), data validation is "a systematic process for reviewing a body of data against a set of criteria to provide assurance that the data are adequate for their intended use. Data validation consists of data editing, screening, checking, auditing, verification, certification, and review." Extensive validation of the Phase 1 data was not preplanned; therefore, the extent of the validation had to be tailored to the laboratory QC documentation that was available several months after the sample analyses were complete. Approximately 198 sample data packages were prepared by the analytical laboratories and validated by a third-party subcontractor. Subcontractor personnel performing the validation were required by the Clinch River ER Program statement of work (SOW) to be trained, experienced, and proven able to perform the review procedures. The Clinch River ER Program required, reviewed, and approved resumes and work training records.

\subsection{Data Reporting}

The data were compiled by each laboratory into sample data packages that contained sample raw data and all QC associated with each sample. Sample results were also received electronically by the project data base manager and merged into a large working data base. Following compilation of the sample data packages, a subcontractor independent of the analytical laboratory that generated the data was employed by the Clinch River ER Program to validate the analytical results. 
The subcontractor's data review deliverables consisted of the following:

- A data validation narrative summarizing by fraction the problems found that affected the data quality and the potential impact on the sample results (each narrative includes the name and signature of the data reviewer)

- A completed checklist that detailed the review elements and QC problems

- Report forms for each sample with validation flags attached to each analyte result

- A list of data review qualifiers and their meanings for use in the data evaluation

After validation was completed, the subcontractor reentered the inorganic and organic sample results along with the validation flags. Each flag was also accompanied by one or more reason codes that summarized the flag assignment. Because the radiological data packages were produced from electronic data already in the program data base, only the validation flags and reason codes were entered into the data base by the subcontractor.

\subsection{Validation Criteria}

Organic data packages were assessed by Laboratory Data Validation Functional Guidelines for Evaluating Organics Analyses (EPA 1988d), and inorganic data packages were assessed by Laboratory Data Validation Functional Guidelines for Evaluating Inorganics Analyses (EPA 1988c), as applicable. Because there were no available EPA guidelines for the inductively coupled plasma/mass spectrometry (ICP/MS) analyses, program-specific guidelines were written that addressed holding times, calibration, blanks, matrix spikes, field duplicates, DL results, sample quantitation, and internal standards. Radiological parameters were assessed by Laboratory Data Validation Guidelines for Evaluating Radionuclide Analysis, Revision 3 (SAIC 1991), since no EPA or DOE CLP requirements were available for radionuclides. The validation process included an assessment of a variety of QA/QC practices, including holding times, matrix spike recovery (MSR) rates, surrogate recovery rates, calibration standards, and method blanks. The guidelines used for review and validation of radiological analyses were not in existence at the time the analyses were performed. As a result, some evaluation criteria elements were missing from the data packages. These exceptions were noted in the data review narrative and addressed as nonconformances. Also, if the frequencies of blanks, controls, matrix spikes, duplicates, or calibration of the gamma-spectrometry analyses differed from the Science Applications International Corporation (SAIC) document, these were noted in the data package narrative. SAIC had developed radiological review and validation guidelines using CLP requirements for other types of analyses as a framework. Using the SAIC-generated guidelines, the validator conducted the most comprehensive review of the radiological data possible. The validator, the Clinch River ER Program technical staff, and the analytical laboratories were able to evaluate each nonconformance and its effect on the technical validity and legal defensibility of the data. Validation flags (or qualifiers) were assigned by the reviewer to each result depending on the quality of the data as determined by the reviewer. The QA objectives for precision and accuracy in the laboratory were defined by control limits established by each method or the laboratory if method-specific limits were not available. 


\subsection{Qualification of the Data}

Summaries of the inorganic and organic sample batches validated (summaries by laboratory and method) are presented in Appendix A. A summary of the radiological analyses is presented in Sect. 4.5. A total of 198 packages containing 1700 inorganic samples, 1500 organic samples, and 2200 radiological samples were validated. The validators reported QC deficiencies to the Clinch River ER Program using a nonconformance reporting and tracking process. There were 219 nonconformance reports containing -1230 nonconforming items were received by the Clinch River ER Program. A FoxPro data base was used to track each nonconforming item and to provide responses back to the validator's QA personnel. Each deficiency was tracked to closure by the subcontracting validation team and Clinch River ER Program personnel. A key word that summarized a type of quality problem was assigned to each nonconforming item to track trends. Figure 2.1 illustrates the distribution of the types of problems that were found.

Figures B.1-B.13 in Appendix B further summarize the nonconforming items by analytical laboratory and method. Several types of problems were considered repairable during the validation process. These included missing information, transcription errors, illegible information, missing chain-of-custody forms, errors in calculation, and missing or incorrect units.

Two major areas for nonconformances were method use and missing data information. The term "method use" was used to apply to those situations wherein the method was not strictly adhered to and/or interpretation was questioned. Table 2.1 summarizes the distribution . of nonconformances between analysis types, laboratories, and methods.

During review and validation of the analytical data, two sets of flags were assigned to the data. The first set of flags was assigned by the analytical laboratory, as required by each individual method. These flags are summarized in Tables 2.2 and 2.3. The second set of flags was assigned by the data validators. These flags are summarized in Table 2.4. The validation flags were also accompanied by one or more reason codes (Table 2.5). Analytical results included the concentration of the analyte in the sample if it was present and measurable. When an analyte was not detected in a sample, the sample quantitation limit for that particular sample was reported as the result accompanied by a "U" prefix. When spectral data indicated the presence of a compound that met the identification criteria but the result was less than the sample quantitation limit, a "J" flag was assigned, indicating that the result was an estimated value. In data analyses, these " J" values were treated as normal results.

Additional data checking was performed as the data were summarized and evaluated for the health and ecological screening assessment. Table 2.6 presents an overall summary of the QC problems found during data validation using the numerical reason codes assigned with each validation flag. This summary shows that six areas account for more than $75 \%$ of the validation flags. These are holding times being exceeded, unconventional procedure being used, surrogate recovery criteria not being met, multiple problems being encountered, MSRs not being met, and method validation being undocumented. The number of rejected samples is summarized in Appendix A and discussed in detail in Chap. 3. 
MISSING INFORMATIOH

METHOO USE PROBLEMS

TRANSCRIPTION ERROR

CALIBRATION PROBLENS (ORGANIC/IKORGANIC)

MS/MSD PROBLEKS

MISSING QC IMFORMTION

LOCBOOKS/WORKSHEETS PROBLEMS

ILLEGIBLE IMFORMATION

BATCH PROBLEMS

COC MISSING

nO BLANKS, CONTAMIHATION PRESENT

UNITS IMCORRECT OR HISSING

SURROGATE PROELEMS

SAMPLE ID IMCORRECT

CALCULATIOWAL PROBLEMS (ORGANIC/IMORGANIC)

SPIKE PROBLEMS

MINIMUA DETECTION ALLONABLE

CALIBRATION PROBLENS (RADS)

HOLDING TIMES

INSTRUMENT DETECTION LIMIT MISSING

DUPLICATE PROBLEMS

TENTATIVELY IDENTIFIED COAPOUHDS

LAB CONTROL SAMPLES MISSING

RAD ADJUSTKENT FACTORS

REQUEST FOR AKALYSIS INCONSISTENCIES

CALCULATIOHAL PROBLEMS (RADS)

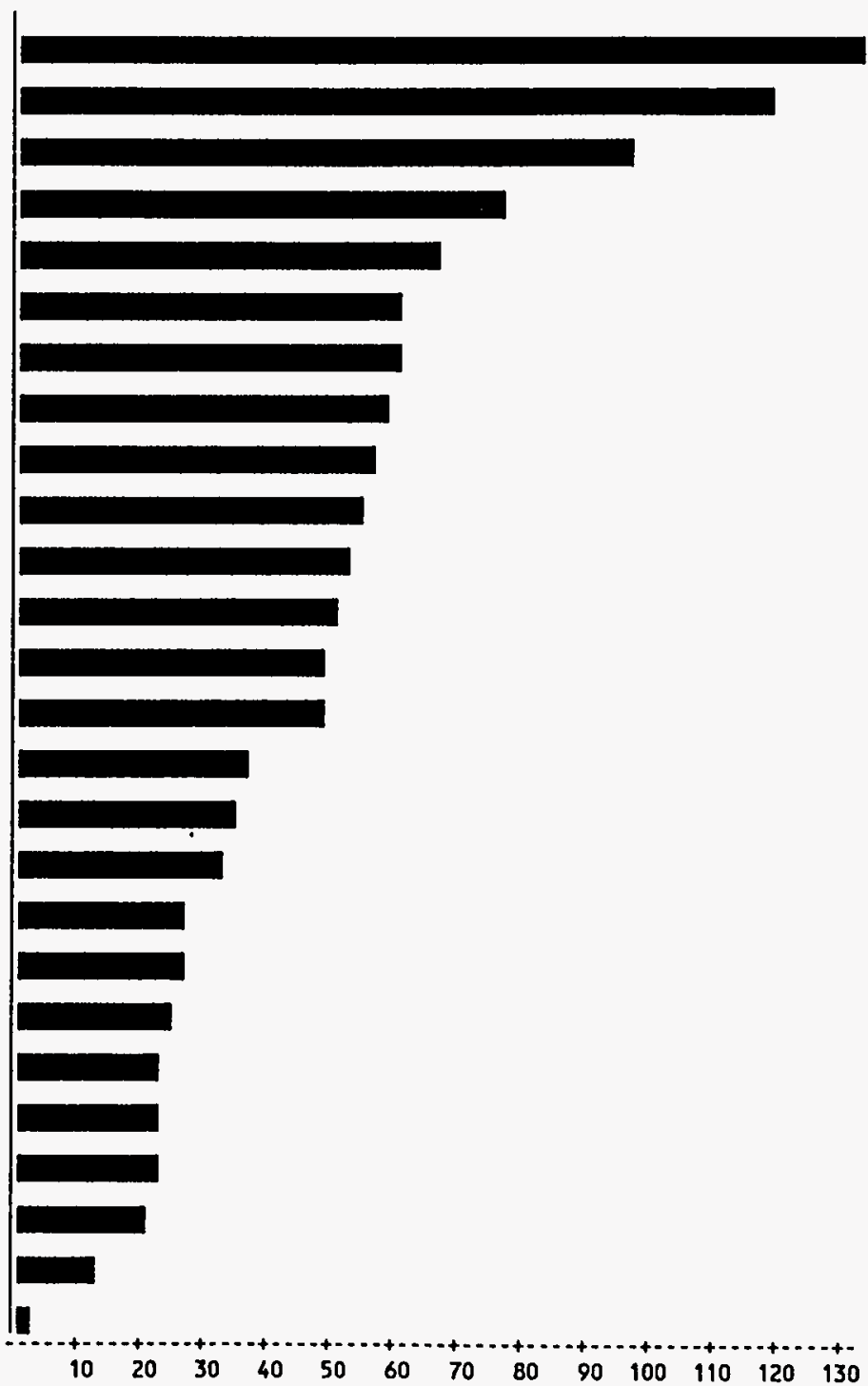

Fig. 21. Total nonconformances from anałytical validation 
Table 21. Distribution of nonconformances by laboratory and method

\begin{tabular}{|c|c|c|c|}
\hline Laboratory & Method & Matrix & $\begin{array}{c}\text { Number of } \\
\text { nonconformances }\end{array}$ \\
\hline \multicolumn{4}{|c|}{ Radiological } \\
\hline ORNL/ESD & Gamma analyses & All $\underline{a}$ & 225 \\
\hline ORAU & Alpha/beta analyses & All & 38 \\
\hline Total & & & 263 \\
\hline \multicolumn{4}{|c|}{ Organic } \\
\hline ORNL/OAL & sVo & Fish & 128 \\
\hline ORNL/OAL & Pesticides/PCBs & Fish & 78 \\
\hline ORNL/CPA & PCBs & Fish & 31 \\
\hline $\mathrm{K}-25$ & SVO & Water, sediment & 70 \\
\hline $\mathrm{K}-25$ & Pesticides/PCBs & Water, sediment & 80 \\
\hline Total & & & 387 \\
\hline \multicolumn{4}{|c|}{ Inorganic } \\
\hline ORNL/EAL & Mercury & Fish & 50 \\
\hline ORNL/CPA & AA/ICP & Fish & 138 \\
\hline $\mathrm{K}-25$ & AA/ICP & Water & 43 \\
\hline $\mathbf{I T}$ & AA/ICP & Sediment & 350 \\
\hline Total & & & 581 \\
\hline
\end{tabular}

a All = sediment, water, and fish

ORNL = Oak Ridge National Laboratory, ESD = Environmental Sciences Division, ORAU = Oak Ridge Associated Universities, OAI = Organic Analysis Laboratory, SVO = semivolatile organic, $\mathrm{PCB}=$ polychlorinated biphenyl, $\mathrm{CPA}=$ Chemical and Physical Analysis Group, EAL = Environmental Anabysis Laboratory, IT = International Technology Corporation, AA/ICP = atomic absorption/inductively coupled plasma 
Table 22. Organic analysis data flags

\begin{tabular}{|c|c|}
\hline Flag & Description \\
\hline $\mathrm{U}$ & $\begin{array}{l}\text { This flag indicates the analyte was analyzed for, but was not detected above, } \\
\text { the reported sample quantitation limit. The sample quantitation limit is } \\
\text { corrected for dilution and percent moisture }\end{array}$ \\
\hline $\mathrm{J}$ & $\begin{array}{l}\text { This flag indicates an estimated value. It is used when there are tentatively } \\
\text { identified compounds with a } 1: 1 \text { response assumed or when the mass spectral } \\
\text { data indicate the presence of a compound that meets the identification } \\
\text { criteria but the result is less than the sample quantitation limit but greater } \\
\text { than zero }\end{array}$ \\
\hline $\mathbf{N}$ & $\begin{array}{l}\text { This flag is used when the analysis indicates the presence of an analyte for } \\
\text { which there is presumptive evidence to make a "tentative identification." } \\
\text { This flag is only used for tentatively identified compounds, where the } \\
\text { identification is based on a mass spectral library search }\end{array}$ \\
\hline $\mathbf{P}$ & $\begin{array}{l}\text { This flag is used for a pesticide/Aroclor target analyte when there is greater } \\
\text { than a } 25 \% \text { difference for detected concentrations between the two GC } \\
\text { columns. The lower of the two values is reported on Form I and flagged with } \\
\text { a "P" }\end{array}$ \\
\hline C & $\begin{array}{l}\text { This flag applies to pesticide results where the identification has been } \\
\text { confirmed by GC/MS. If GC/MS confirmation was attempted but was } \\
\text { unsuccessful, this flag should not be used }\end{array}$ \\
\hline B & $\begin{array}{l}\text { This flag is used when the analyte is found in the associated blank as well as } \\
\text { in the sample. It indicates possible/probable blank contamination and warns } \\
\text { the data user to take appropriate action. This flag must be used for a } \\
\text { tentatively identified compound (TIC) as well as for a positively identified } \\
\text { target compound }\end{array}$ \\
\hline $\mathrm{E}$ & $\begin{array}{l}\text { This flag identifies compounds whose concentrations exceed the calibration } \\
\text { range of the GC/MS instrument for that specific analysis. All such } \\
\text { compounds with a response greater than full scale should have the } \\
\text { concentration flagged with an "E" on Form I for the original analysis }\end{array}$ \\
\hline $\mathrm{D}$ & $\begin{array}{l}\text { This flag identifies all compounds identified in an analysis at a secondary } \\
\text { dilution factor. A "DL" suffix is appended to the sample number on Form I } \\
\text { for the diluted sample and all concentration values reported on that Form I } \\
\text { are flagged with the "D" flag. This flag alerts data users that any } \\
\text { discrepancies between the concentrations reported may be due to dilution of } \\
\text { the sample or extract }\end{array}$ \\
\hline $\mathbf{A}$ & This flag indicates that a TIC is a suspected aldol-condensation product \\
\hline $\mathbf{X}$ & $\begin{array}{l}\text { This is a laboratory-specified flag. It must be fully described in the case } \\
\text { narrative }\end{array}$ \\
\hline
\end{tabular}


Table 23. Inorganic anałysis data flags

\begin{tabular}{|c|c|}
\hline Flag & Description \\
\hline & Concentration qualifiers \\
\hline B & $\begin{array}{l}\text { This flag is used when the reported value was obtained from a reading that } \\
\text { was less than the contract-required detection limit but greater than or equal } \\
\text { to the instrument detection limit }\end{array}$ \\
\hline \multirow[t]{2}{*}{$\mathbf{U}$} & This flag indicates the analyte was analyzed for but not detected \\
\hline & Quality qualifiers \\
\hline $\mathrm{E}$ & $\begin{array}{l}\text { This flag is used when the reported value was estimated because of the } \\
\text { presence of interference }\end{array}$ \\
\hline $\mathbf{M}$ & This flag indicates duplicate injection precision was not met \\
\hline $\mathrm{N}$ & This flag indicates spiked sample recovery was not within control limits \\
\hline $\mathbf{S}$ & $\begin{array}{l}\text { This flag indicates the reported value was determined using the method of } \\
\text { standard additions (MSA) }\end{array}$ \\
\hline $\mathbf{W}$ & $\begin{array}{l}\text { This flag indicates postdigestion spike for Furnace AA analysis was out of } \\
\text { control limits while sample absorbance was less than } 50 \% \text { of spike } \\
\text { absorbance }\end{array}$ \\
\hline$\bullet$ & This flag indicates the duplicate analysis was not within control limits \\
\hline \multirow[t]{2}{*}{+} & This flag indicates the correlation coefficient for the MSA is less than 0.995 \\
\hline & Method qualifiers \\
\hline $\mathbf{P}$ & This flag denotes ICP \\
\hline $\mathbf{A}$ & This flag denotes Flame AA \\
\hline $\mathbf{F}$ & This flag denotes Furnace AA \\
\hline CV & This flag denotes Manual Cold Vapor AA \\
\hline AV & This flag denotes Automated Cold Vapor AA \\
\hline AS & This flag denotes Semi-Automated Spectrophotometric \\
\hline $\mathbf{C}$ & This flag denotes Manual Spectrophotometric \\
\hline $\mathbf{T}$ & This flag denotes Titrimetric \\
\hline NR & This flag is used if the analyte is not required to be analyzed \\
\hline
\end{tabular}


Table 24. Validation data flags

\begin{tabular}{|c|c|}
\hline Flag & Description \\
\hline $\mathrm{U}$ & $\begin{array}{l}\text { This flag indicates the analyte was analyzed for, but was not detected above, the } \\
\text { reported sample quantitation limit }\end{array}$ \\
\hline $\mathrm{J}$ & $\begin{array}{l}\text { This flag indicates the analyte was positively identified; the associated } \\
\text { numerical value is the approximate concentration of the analyte in the sample }\end{array}$ \\
\hline $\mathbf{N}$ & $\begin{array}{l}\text { This flag indicates the analysis showed the presence of an analyte for which } \\
\text { there is presumptive evidence to make a "tentative identification" }\end{array}$ \\
\hline NJ & $\begin{array}{l}\text { This flag indicates the analysis showed the presence of an analyte that has been } \\
\text { "tentatively identified," and the associated numerical value represents its } \\
\text { approximate concentration }\end{array}$ \\
\hline UJ & $\begin{array}{l}\text { This flag indicates the analyte was not detected above the reported sample } \\
\text { quantitation limit. However, the reported quantitation limit is approximate and } \\
\text { may or may not represent the actual limit of quantitation necessary to } \\
\text { accurately and precisely measure the analyte in the sample }\end{array}$ \\
\hline $\mathbf{R}$ & $\begin{array}{l}\text { This flag indicates the sample results have been rejected due to serious } \\
\text { deficiencies in the ability to analyze the sample and meet quality control } \\
\text { criteria. The presence or absence of the analyte cannot be verified }\end{array}$ \\
\hline $\mathbf{X}$ & $\begin{array}{l}\text { This flag indicates fish tissue that was held frozen while awaiting extraction } \\
\text { exceeded the allowable holding time for water samples. However, these criteria } \\
\text { are not applicable to biological samples, and the results are considered valid }\end{array}$ \\
\hline UX & $\begin{array}{l}\text { This flag indicates that the compound was analyzed for but was not detected } \\
\text { and that water holding times were exceeded (See the description for "X") }\end{array}$ \\
\hline $\mathrm{V} / \mathrm{V}$ & This flag indicates that the result has been verified and is a valid result \\
\hline
\end{tabular}

Note: Data qualifiers were applied to the sample analysis result by the analytical laboratories and/or independent data validator. In cases where there was no data qualifier required, "V/V" has been inserted in the data qualifier field for this report. 
Table 25. Validation reason codes

\begin{tabular}{|c|c|}
\hline Code & Description \\
\hline 1 & Holding times exceeded \\
\hline 2 & Mass calibration did not meet ion abundance criteria \\
\hline 3 & Initial calibration relative response factor $(\mathrm{RRF})<0.05$ \\
\hline 4 & Initial calibration $\% \mathrm{RSD}>30 \%$ \\
\hline 5 & Continuing calibration $\mathrm{RRF}<0.05$ \\
\hline 6 & Continuing calibration $\% \mathrm{D}>25 \%$ \\
\hline 7 & Evaluation check for linearity $\% \mathrm{RSD}>10 \%$ \\
\hline 8 & Calibration factors of compounds did not meet criteria \\
\hline 9 & Retention time of compounds outside established windows \\
\hline 10 & Breakdown of DDT or Endrin $>20 \%$ \\
\hline 11 & Retention time of $\mathrm{DBC}, \% \mathrm{D}$ criteria not met \\
\hline 12 & Blank contamination \\
\hline 13 & Surrogate recovery criteria not met \\
\hline 14 & Matrix spike and/or matrix spike duplicate recovery outside limit \\
\hline 15 & Matrix spike/matrix spike duplicate, RPD outside limits \\
\hline 16 & Internal standard area outside limits \\
\hline 17 & Internal standard area retention time $>\mathbf{3 0} \mathrm{sec}$ \\
\hline 18 & Daily calibration not performed properly \\
\hline 19 & Calibration standards recovery outside limits \\
\hline 20 & Standard curve correlation coefficient $<0.995$ \\
\hline 21 & Mid-range CN standard not distilled \\
\hline 22 & Interference check sample recovery outside limits \\
\hline 23 & Duplicate analyses RPD outside limits \\
\hline 24 & Laboratory control sample recovery outside limits \\
\hline 25 & Duplicate injections, $\%$ RSD $>20 \%$ \\
\hline 26 & Postdigestion spike recovery outside limits \\
\hline 27 & Method of standard additions criteria not met \\
\hline 28 & Serial dilution criteria not met \\
\hline 29 & Sample not preserved properly \\
\hline 30 & $\begin{array}{l}\text { Calibration verification indicates an unacceptable change in system } \\
\text { efficiency }\end{array}$ \\
\hline
\end{tabular}


Table 25 (continued)

\begin{tabular}{|c|c|}
\hline Code & Description \\
\hline 31 & $\begin{array}{l}\text { Calibration verification indicates an unacceptable change in system } \\
\text { energy calibration }\end{array}$ \\
\hline 32 & $\begin{array}{l}\text { Calibration verification indicates an unacceptable change in system } \\
\text { background }\end{array}$ \\
\hline 33 & $\begin{array}{l}\text { Calibration verification indicates an unacceptable change in system } \\
\text { resolution }\end{array}$ \\
\hline 34 & $\begin{array}{l}\text { Calibration verification indicates an unacceptable change in system } \\
\text { plateau curve }\end{array}$ \\
\hline 35 & $\begin{array}{l}\text { Calibration verification indicates an unacceptable change in system } \\
\text { alpha/beta crosstalk factors }\end{array}$ \\
\hline 36 & Initial/continuing calibration not performed at required intervals \\
\hline 37 & Sample-specific chemical recovery outside limits \\
\hline 38 & Activity incorrectly calculated \\
\hline 39 & $\begin{array}{l}\text { Uncertainty overestimated due to not propagating the uncertainty } \\
\text { for the average of the peak results. This applies to the uncertainty } \\
\text { only and does not reflect on the quality of the result }\end{array}$ \\
\hline 40 & Sample aliquot size less than acceptable value \\
\hline 41 & Net negative results with uncertainty smaller than absolute value \\
\hline 42 & Minimum detectable activities (MDA) reported as less than value \\
\hline 43 & Interference peak present in region of interest \\
\hline 44 & $\begin{array}{l}\text { Radionuclide peak energy greater than } 40 \mathrm{keV} \text { difference from } \\
\text { observed peak (alpha) }\end{array}$ \\
\hline 45 & $\begin{array}{l}\text { Radionuclide peak energy greater than } 2 \mathrm{keV} \text { difference from } \\
\text { observed peak (gamma) }\end{array}$ \\
\hline 46 & $\begin{array}{l}\text { Less than } 50 \% \text { of total gamma abundance present in sample } \\
\text { spectrum }\end{array}$ \\
\hline 47 & Duplicate analyses duplicate error ratios outside limits \\
\hline 48 & Mount mass/area exceeded for alpha/beta \\
\hline 49 & Degraded system performance \\
\hline 50 & Blank not analyzed at required frequency \\
\hline 51 & Second column confirmation not performed \\
\hline 52 & $\begin{array}{l}\text { Conventional procedure not followed; inadequate } Q C \text { available for } \\
\text { validation }\end{array}$ \\
\hline 53 & Validity of analytical method undocumented \\
\hline 54 & Interference found in the ICSA \\
\hline 55 & Uncertainty incorrectly calculated \\
\hline
\end{tabular}


Table 25 (continued)

\begin{tabular}{cl}
\hline Code & \multicolumn{1}{c}{ Description } \\
\hline 56 & Analytical uncertainties not reported \\
57 & Inadequate chromatographic resolution for positive identification \\
58 & Multiple problems affecting analytical performance \\
59 & Analysis terminated prematurely \\
60 & Calibration curve not established \\
61 & Instrument baseline shift \\
62 & Sample identity/origin uncertain \\
63 & Analysis occurred outside 12-h GC/MS tune window \\
64 & No results provided \\
\hline
\end{tabular}


Table 26. Frequency of reason codes for qualified and rejected data

\begin{tabular}{|c|c|c|c|c|}
\hline \multirow[b]{2}{*}{ Reason code } & \multirow[b]{2}{*}{ Validation reason } & \multicolumn{3}{|c|}{$\begin{array}{c}\text { Occurrence of reason codes } \\
\%\end{array}$} \\
\hline & & Qualified & Rejected & Total \\
\hline 1 & Holding times exceeded & 67.22 & 5.19 & 52.17 \\
\hline 52 & $\begin{array}{l}\text { Conventional procedure not followed; } \\
\text { inadequate quality control available for } \\
\text { validation }\end{array}$ & 7.84 & 26.94 & 12.47 \\
\hline 13 & Surrogate recovery criteria not met & 3.14 & 27.64 & 9.08 \\
\hline 58 & $\begin{array}{l}\text { Multiple problems affecting analytical } \\
\text { performance }\end{array}$ & 0.47 & 26.59 & 6.81 \\
\hline 14 & $\begin{array}{l}\text { Matrix spike and/or matrix spike duplicate } \\
\text { recovery outside limit }\end{array}$ & 3.21 & 7.78 & 4.32 \\
\hline 53 & Validity of analytical method undocumented & 4.86 & 0.24 & 3.74 \\
\hline 6 & $\begin{array}{l}\text { Continuing calibration percent difference (\%D) } \\
>25 \%\end{array}$ & 2.40 & 0.82 & 2.01 \\
\hline 42 & $\begin{array}{l}\text { Minimum detectable activity reported as less } \\
\text { than value }\end{array}$ & 1.87 & 0.00 & 1.42 \\
\hline 18 & Daily calibration not performed properly & 1.34 & 0.90 & 1.23 \\
\hline 12 & Blank contamination & 1.29 & 0.00 & 0.98 \\
\hline 26 & Postdigestion spike recovery outside limits & 1.03 & 0.01 & 0.78 \\
\hline 63 & $\begin{array}{l}\text { Analysis occurred outside } 12 \text {-h gas } \\
\text { chromatograph/mass spectrometer window }\end{array}$ & 1.03 & 0.01 & 0.78 \\
\hline 51 & Second column confirmation not performed & 0.87 & 0.11 & 0.68 \\
\hline 60 & Calibration curve not established & 0.62 & 0.14 & 0.51 \\
\hline 19 & Calibration standards recovery outside limits & 0.32 & 0.63 & 0.40 \\
\hline 39 & $\begin{array}{l}\text { Uncertainty overestimated due to not } \\
\text { propagating the uncertainty for the average of } \\
\text { the peak results. This applies to the uncertainty } \\
\text { only and does not reflect on the quality of the } \\
\text { result }\end{array}$ & 0.48 & 0.00 & 0.36 \\
\hline 24 & $\begin{array}{l}\text { Laboratory control sample recovery outside } \\
\text { limits }\end{array}$ & 0.36 & 0.00 & 0.28 \\
\hline 5 & Continuing calibration RRF $<0.05$ & 0.09 & 0.80 & 0.26 \\
\hline 37 & Sample-specific chemical recovery outside limits & 0.26 & 0.14 & 0.23 \\
\hline 11 & Retention time of $\mathrm{DBC}, \% \mathrm{D}$ criteria not met & 0.00 & 0.88 & 0.21 \\
\hline 28 & Serial dilution criteria not met & 0.26 & 0.00 & 0.19 \\
\hline
\end{tabular}


Table 26 (continued)

\begin{tabular}{|c|c|c|c|c|}
\hline \multirow[b]{2}{*}{ Reason code } & \multirow[b]{2}{*}{ Validation reason } & \multicolumn{3}{|c|}{$\begin{array}{c}\text { Occurrence of reason codes } \\
\qquad \%\end{array}$} \\
\hline & & Qualified & Rejected & Total \\
\hline 54 & $\begin{array}{l}\text { Interference found in the interference-check- } \\
\text { solution } \mathrm{A}\end{array}$ & 0.13 & 0.19 & 0.15 \\
\hline 4 & Initial calibration $\%$ RSD $>\mathbf{3 0 \%}$ & 0.19 & 0.00 & 0.14 \\
\hline 22 & $\begin{array}{l}\text { Interference check sample recovery outside } \\
\text { limits }\end{array}$ & 0.17 & 0.00 & 0.13 \\
\hline 62 & Sample identity/origin uncertain & 0.00 & 0.47 & 0.11 \\
\hline 16 & Internal standard area outside limits & 0.14 & 0.00 & 0.10 \\
\hline 29 & Sample not preserved properly & 0.08 & 0.11 & 0.09 \\
\hline 47 & $\begin{array}{l}\text { Duplicate analyses duplicate error ratios outside } \\
\text { limits }\end{array}$ & 0.06 & 0.00 & 0.05 \\
\hline 27 & Method of standard additions criteria not met & 0.06 & 0.00 & 0.04 \\
\hline 32 & $\begin{array}{l}\text { Calibration verification indicates an } \\
\text { unacceptable change in system background }\end{array}$ & 0.05 & 0.01 & 0.04 \\
\hline 9 & $\begin{array}{l}\text { Retention time of compounds outside } \\
\text { established windows }\end{array}$ & 0.00 & 0.16 & 0.04 \\
\hline 23 & $\begin{array}{l}\text { Duplicate analyses relative percent difference } \\
\text { outside limits }\end{array}$ & 0.05 & 0.00 & 0.03 \\
\hline 61 & Instrument baseline shift & 0.03 & 0.05 & 0.03 \\
\hline 50 & Blank not analyzed at required frequency & 0.04 & 0.00 & 0.03 \\
\hline 15 & $\begin{array}{l}\text { Matrix spike/matrix spike duplicate, RPD } \\
\text { outside limits }\end{array}$ & 0.03 & 0.00 & 0.02 \\
\hline 59 & Analysis terminated prematurely & 0.00 & 0.06 & 0.02 \\
\hline 20 & Standard curve correlation coefficient $<0.995$ & 0.00 & 0.06 & 0.01 \\
\hline 25 & Duplicate injections, RSD $>20 \%$ & 0.02 & 0.00 & 0.01 \\
\hline 38 & Activity incorrectly calculated & 0.00 & 0.01 & 0.01 \\
\hline 8 & $\begin{array}{l}\text { Calibration factors of compounds did not meet } \\
\text { criteria }\end{array}$ & 0.01 & 0.00 & 0.01 \\
\hline 3 & $\begin{array}{l}\text { Initial calibration relative response factor } \\
(\mathrm{RRF})<0.05\end{array}$ & 0.00 & 0.02 & 0.01 \\
\hline 41 & $\begin{array}{l}\text { Net negative results with uncertainty smaller } \\
\text { than absolute value }\end{array}$ & 0.00 & 0.01 & 0.00 \\
\hline 57 & $\begin{array}{l}\text { Inadequate chromatographic resolution for } \\
\text { positive identification }\end{array}$ & 0.00 & 0.00 & 0.00 \\
\hline 10 & Breakdown of DDT or Endrin $>20 \%$ & 0.00 & 0.01 & 0.00 \\
\hline
\end{tabular}


Table 26 (continued)

\begin{tabular}{clccc}
\hline \multirow{2}{*}{ Reason code } & \multicolumn{1}{c}{ Validation reason } & \multicolumn{2}{c}{$\begin{array}{c}\text { Occurrence of reason codes } \\
\%\end{array}$} & \\
\cline { 3 - 5 } & & Qualified & Rejected & Total \\
\hline 35 & $\begin{array}{l}\text { Calibration verification indicates an } \\
\text { unacceptable change in system alpha/beta } \\
\text { crosstalk factors }\end{array}$ & 0.00 & 0.01 & 0.00 \\
\hline
\end{tabular}




\section{FIELD QUALITY CONTROL}

Samples and data collected to evaluate QC for Phase 1 field activities were outlined in the CRRI Plan (Energy Systems 1990). The frequency and type of QC samples collected depended on the matrix being sampled and the analyses requested. Because of this specificity, this chapter is organized by sample matrix. Each section contains an overview of the QC samples and procedures planned, the control results observed, and an assessment of the QC data collected. The specific QA objectives for all data were to obtain reproducible, precise, and accurate measurements consistent with the intended use of the data and the limitations of the sampling and analytical procedures used. For this report, field QC includes, but is not limited to sample collection, custody, processing, preservation, container selection, and transport, as well as field record keeping. Each of these actions will be discussed as appropriate by matrix.

Each site was either representative of average conditions in a particular reach of the CR/WBR system or representative of conditions directly downstream from known or suspected contaminant sources. Two reference sites for water (Norris Reservoir and Poplar Creek upstream from the ORR), one reference site in Norris reservoir for sediment, and two reference sites for fish (Norris Reservoir and Poplar Creek upstream from the ORR) were included to represent sites unaffected by surface water contamination originating on the ORR.

Quality control samples were collected to address the following indicators for field quality: precision, representativeness, comparability, and completeness. (See Sect. 2.5.) The other two QA parameters discussed in Sect. 2.5-accuracy and sensitivity-are applicable to analytical processes rather than field processes. Completeness and precision are quantitative measurements that are evaluated numerically; comparability and representativeness are qualitative and must be assessed by other means. These field $\mathrm{QC}$ activities are discussed in the following sections for each of the three matrices.

The QA completeness objective for this project was to obtain valid analytical results for at least $95 \%$ of the planned samples. The first step in calculating total completeness was to assess sampling completeness. Completeness of sample collection was measured by comparing the number planned versus the number collected and submitted for analysis. Completeness for field QC purposes included a comparison of those submitted for a particular analysis with those rejected because of errors in collection, processing, preservation, or other procedures related to field activities.

Sample precision was controlled through the collection of field duplicates and splits, depending on sample collection and processing techniques for each matrix. The criteria for evaluating the acceptability of this measure of precision were as follows. If the mean concentration for a particular analyte of a duplicate or split sample pair exceeded five times the average detection limit for that analyte and the RPD was $<20 \%$ (35\% for sediments), then the level of precision could be judged acceptable. If the RPD was $>20 \%$, then the level of precision was assessed in terms of the total sampling and analysis variability. RPD was calculated as follows. 


$$
\operatorname{RPD}=\frac{\left|D_{1}-D_{2}\right|}{\left(D_{1}+D_{2}\right) / 2} \times 100,
$$

where $D_{1}$ was the value of the first measurement and $D_{2}$ was the value of the second measurement.

If the mean concentration observed in duplicate pairs for a particular analyte was less than five times the average detection limit and the absolute value of the difference between the duplicate samples was less than the detection limit, then the level of precision was judged to be acceptable. If the difference was greater than the detection limit, precision was unacceptable. If both values were nondetects, no evaluation of precision could be made.

Comparability for field activities is the confidence with which data collected at different times from the same site may be compared. Objectives for comparability between samples are met by (1) applying narrowly defined sampling methodologies, (2) performing site surveillance and using standard sampling devices and monitoring devices, (3) training personnel, (4) documenting sampling locations, (5) defining stringent control limits for QC checks, and (6) reporting results in units that are consistent with national standards.

Sample representativeness is an assessment of (1) how well environmental conditions are represented by the sites sampled, (2) whether observed sample contamination occurred due to field sampling activity, and (3) how well the sample collection technique performed at detecting the true analyte concentration for the anticipated condition. Representativeness is evaluated relative to field activities through a review of site selection rationale, frequency of sampling individual sites, number of samples collected, sampling technique, and selection of analytical parameters to be characterized, as well as through a review of rinse blank data.

Field QC samples were treated identically to routine samples in terms of sample identification, custody, request for analytical services, and data processing. Results for QC samples were not used to adjust the results obtained for original samples. QC samples included blank, replicate, and split samples as described here.

Trip blank: A sealed container of organic-free water used to identify contamination contributed to field samples during transport. Trip blanks were transported to and from the field in the same manner as routine samples. Information from trip blanks is relevant to analyses of volatile organic compounds, which were not requested for any matrix sampled during Phase 1 of the CRRI.

Equipment rinsate: Final rinse water from the cleaning of sample collection and processing equipment either in the laboratory or in the field between sites. Analysis of the rinsate determines if the cleaning procedures are adequate to avoid carryover of contamination from one sample to another. Rinsate samples were collected for both field and laboratory cleaning operations for water sample collection. No rinsates were collected for sediment or fish samples.

Field blank: Distilled water samples transported to the field, opened during water sample collection, and closed following collection to simulate any atmospheric or other source of contamination related to the actual water sample collection process. Field blanks were not collected for sediment or fish samples. 
Field duplicate: Duplicate samples from one sampling location collected to indicate whether the field sampling technique was reproducible. Duplicate sample collection involved repeating the sample collection process for each sample taken from a discrete site. Specific field duplicate samples involved the collection of two individual samples from the same spot using the same sampling device and procedures to fill separate sample containers.

Field split: A sample collected by a single sample event that is homogenized and then split into at least two portions. Samples are to assess field homogenization techniques and laboratory precision.

\subsection{WATER}

\subsubsection{Introduction}

Water samples were collected during Phase 1 to confirm suspected low dissolved concentrations of contaminants identified in scoping studies (Suter 1991, Hoffman et al. 1991, Olsen et al. 1992). Characterization of the nature and extent of surface water contamination in the CR/WBR system during Phase 1 of the CRRI was limited to collection of one to three water samples at each site (Fig. 2.2) (Energy Systems 1990, Cook et al. 1992). One routine water sample was collected from twelve sites, and two routine samples from three sites for a total of eighteen samples from fifteen sites that corresponded to sediment and biota sampling sites (Cook et al., 1992). Water samples were analyzed for total and filtered inorganic analytes, total organic analytes, ${ }^{3} \mathrm{H},{ }^{90} \mathrm{Sr}$, total and evaporated ${ }^{137} \mathrm{Cs}$, and total and evaporated ${ }^{60} \mathrm{Co}$. Quality control samples were included at a regular frequency, at least one every twenty regular samples, as outlined in Table 3.1. Site descriptions were documented at the time of collection in a field logbook. Samples were not collected to assess temporal variability in water quality throughout the reservoir.

Quality control samples collected for inorganic and organic analytes in water included (1) duplicates for precision, (2) rinse water samples from the final cleaning step for sample collection and processing equipment to assess comparability, and (3) distilled water blanks to check for contaminants introduced into the sample from sources other than the field sampling activity at a given site to assess representativeness. Additionally, a comparison of dissolved and total inorganic analyses was made to assess the adequacy of filtration and analytical procedures. No QC samples were collected for radiological analysis.

\subsection{Field Quality Control Assessment}

The representativeness and comparability of these data, assessed through the dissolvedto-total results, were not acceptable for lead at three sites; cadmium and zinc at two sites; and mercury and silver at one site. Representativeness and comparability criteria assessed through blank results were not acceptable for lead at two sites and for beryllium, cadmium, calcium, chromium, copper, iron, magnesium, nickel, potassium, and zinc at one site. Precision, assessed through a comparison of field duplicates, was not acceptable for lead at two sites and for cadmium and zinc one site. Duplicate samples for assessment of precision were collected for 5 of 18 sites. Completeness for field sampling activities was $100 \%$. These results indicate that, for the sites and analytes listed, sources other than field sampling activities may account for the inorganic values reported in the Phase 1 data summary report (Cook et al. 1992). However, the overall QC assessment is that the data were adequate for the criteria of 
$3-4$

Table 3.1. List of all CRRI Phase 1 water samples submitted for analysis $a, b$

\begin{tabular}{|c|c|c|c|c|c|c|}
\hline Date & Site & Regular & Duplicate & Trip blank & Rinse check & Field blank \\
\hline \multirow[t]{3}{*}{ 12Dec89 } & CRM 1.0 & 1010 & 1070 & & & \\
\hline & & $102 \mathrm{M}$ & $108 \mathrm{M}$ & & & \\
\hline & & $102 \mathrm{~T}$ & $108 \mathrm{~T}$ & & & \\
\hline \multirow[t]{3}{*}{$08 \operatorname{Jan} 90$} & CRM 103 & 1110 & & & & \\
\hline & & $112 \mathrm{M}$ & & & & \\
\hline & & $112 \mathrm{~T}$ & & & & \\
\hline \multirow[t]{6}{*}{$11 \operatorname{Jan} 90$} & TRM 531 & 1310 & 13110 & & & \\
\hline & & $131 \mathrm{M}$ & $1311 \mathrm{M}$ & & & \\
\hline & & $131 \mathrm{~T}$ & $1311 \mathrm{~T}$ & & & \\
\hline & TRM 547 & 1320 & 13210 & & & \\
\hline & & $132 \mathrm{M}$ & $1321 \mathrm{M}$ & & & \\
\hline & & $132 \mathrm{~T}$ & $1321 \mathrm{~T}$ & & & \\
\hline \multirow[t]{9}{*}{$17 \operatorname{Jan} 90$} & CRM 9.6 & 1330 & & 1400 & & \\
\hline & & $133 \mathrm{M}$ & & $140 \mathrm{M}$ & & \\
\hline & & $133 \mathrm{~T}$ & & $140 \mathrm{~T}$ & & \\
\hline & CRM 14.5 & 1340 & & 1400 & & \\
\hline & & $134 \mathrm{M}$ & & $140 \mathrm{M}$ & & \\
\hline & & $134 \mathrm{~T}$ & & $140 \mathrm{~T}$ & & \\
\hline & CRM 19.6 & 1350 & & 1400 & & \\
\hline & & $135 \mathrm{M}$ & & $140 \mathrm{M}$ & & \\
\hline & & $135 \mathrm{~T}$ & & $140 \mathrm{~T}$ & & \\
\hline \multirow[t]{6}{*}{$18 \operatorname{Jan} 90$} & TRM 567 & 1360 & & & & \\
\hline & & $136 \mathrm{M}$ & & & & \\
\hline & & $136 \mathrm{~T}$ & & & & \\
\hline & CRM 0.5 & 1370 & 13710 & & & \\
\hline & & $137 \mathrm{M}$ & $1371 \mathrm{M}$ & & & \\
\hline & & $137 T$ & $1371 \mathrm{~T}$ & & & \\
\hline \multirow[t]{4}{*}{$22 \operatorname{Jan} 90$} & CRM 24 & 1380 & & & & \\
\hline & & $138 \mathrm{M}$ & & & & \\
\hline & & $138 \mathrm{~T}$ & & & & \\
\hline & CRM 43 & 1390 & 13910 & & & \\
\hline
\end{tabular}


Table 3.1 (Continusd)

\begin{tabular}{|c|c|c|c|c|c|c|}
\hline Date & Site & Regular & Duplicate & Trip blank & Rinse check & Field blank \\
\hline & & $139 \mathrm{M}$ & $1391 \mathrm{M}$ & & & \\
\hline . & & $139 \mathrm{~T}$ & $1391 \mathrm{~T}$ & & & \\
\hline \multirow[t]{6}{*}{$24 \operatorname{Jan} 90$} & PCK 0.25 & 1410 & & 1500 & & \\
\hline & & $141 \mathrm{M}$ & & $150 \mathrm{M}$ & & \\
\hline & & $141 \mathrm{~T}$ & & $150 \mathrm{~T}$ & & \\
\hline & PCK 2.2 & 1420 & & 1500 & 14120 & \\
\hline & & $142 \mathrm{M}$ & & $150 \mathrm{M}$ & $1412 \mathrm{M}$ & \\
\hline & & $142 \mathrm{~T}$ & & $150 \mathrm{~T}$ & $1412 \mathrm{~T}$ & \\
\hline \multirow[t]{9}{*}{ 01Feb90 } & PCK 7.4 & 1430 & & & 14420 & \\
\hline & & $143 M$ & & & $1442 \mathrm{M}$ & \\
\hline & & $143 \mathrm{~T}$ & & & $1442 \mathrm{~T}$ & \\
\hline & PCK 8.8 & 1440 & & & 14520 & \\
\hline & & $144 \mathrm{M}$ & & & $1452 \mathrm{M}$ & \\
\hline & & $144 \mathrm{~T}$ & & & $1452 \mathrm{~T}$ & \\
\hline & PCK 9.6 & 1450 & & & 14220 & \\
\hline & & $145 \mathrm{M}$ & & & $1422 \mathrm{M}$ & \\
\hline & & $145 \mathrm{~T}$ & & & $1422 \mathrm{~T}$ & \\
\hline \multirow[t]{6}{*}{ 07Feb90 } & TRM 557 & 1460 & & & $1432 \mathrm{~T}$ & \\
\hline & & $146 \mathrm{M}$ & & & $1432 \mathrm{M}$ & \\
\hline & & $146 \mathrm{~T}$ & & & $1432 \mathrm{~T}$ & \\
\hline & CRM 50.5 & 1470 & & & 14620 & 14700 \\
\hline & & $147 \mathrm{M}$ & & & $1462 \mathrm{M}$ & $1470 \mathrm{M}$ \\
\hline & & $14 \pi T$ & & & $1462 \mathrm{~T}$ & $1470 \mathrm{~T}$ \\
\hline
\end{tabular}

aThis table is presented here to permit a comparison of the sample collection rate with the completeness and bracketing objectives of the QC program.

$\underline{b}_{O}=$ Total organic analysis, $M=$ Inorganic analysis (dissolved), and $T=$ total inorganic analysis. 
representativeness and comparability.

A complete assessment of precision, completeness, comparability, and representativeness would need to consider factors such as environmental variability, which is beyond the scope of the Phase 1 investigation, and laboratory-introduced error, which is discussed in Chap. 4. This QC information focuses discussion of the quality of Phase 1 water data in terms of (1) the adequacy and control of field collection and processing procedures combined with (2) the adequacy and control of analytical laboratory processing and analysis procedures to assess whether observed results reflect actual conditions at these sites. The adequacy of precision results as a whole; the consistency of cation results (Cook et al. 1992); and the lack of contamination throughout a set of blank, rinse, or dissolved-to-total pair samples collected and processed at the same time indicate that field procedures were adequate for accomplishing the objectives of the Phase 1 plan (Energy Systems 1990). The observed, more random occurrence of unacceptable QC results suggests that analytical processes may be a source of sample contamination. The QC sample results showing inorganic contamination, as just highlighted, may not reflect actual conditions at these sites.

All values for ${ }^{3} \mathrm{H}$ were rejected during data validation because of the use of sample preservation that was inappropriate for the analytical procedure specified. This resulted in the ${ }^{3} \mathrm{H}$ data being considered unacceptable for their intended purposes. Samples for ${ }^{3} \mathrm{H}$ analysis will be collected and analyzed during Phase 2 of the CRRI. There were no other parameters rejected from the water data base as a result of improper preservation. All field QC samples are summarized in Table 3.1. Custody for all Phase 1 samples, established in the field, was adequately maintained throughout the processing and delivery of samples to the analytical laboratories. Sample preservation practices as specified in the Phase 1 plan (Energy Systems 1990) were followed.

For a more detailed discussion of the field QC for water samples, see Appendix C.

\subsection{SEDIMENT}

\subsection{Introduction}

The original Clinch River RCRA Investigation Plan (Energy Systems 1990) called for sediment cores to be collected at 14 locations representing both background and contaminated areas. Three sediment cores were to be collected and analyzed for organic, inorganic, and alpha- and gamma-emitting radionuclide contaminants. Sediment surface grab samples were also to be collected at each of the 14 locations. The plan also allowed for additional samples to be collected if appropriate based on data and information collected during Phase 1.

The plan for Phase 1 of the CRRI (Energy Systems 1990) identified the types and frequencies of QC samples to be collected for sediment during Phase 1 . The plan stated that field sampling would include trip blanks, field rinsates, field blanks, and field duplicates for each sediment core collected. During implementation of Phase 1 sampling, it was determined that taking QC samples for each core was unnecessarily excessive. Instead field splits were collected from at least $25 \%$ of the total number of cores collected and analyzed for gammaemitting radionuclides, inorganics, and organics. These were collected by homogenizing two contiguous sections of the core and splitting the homogenate into equal portions, which were 
then submitted blindly to the analytical laboratories. Trip blanks, field rinse blanks, and field rinsates were not collected for sediment sampling during Phase 1.

Field splits were collected for the sediment grab samples collected for the near-shore sediment characterization project, which was added during Phase 1 and not described in the Phase 1 plan. These field splits were collected using a Ponar grab sampling device. At least two samples from the same location were collected, homogenized in a bucket, and split into two separate samples. All sediment grab samples were analyzed for gamma-emitting radionuclides.

\section{Field Quality Control Assessment}

Sediment sampling locations used during Phase 1 provided the necessary amount of information to (1) determine the range of concentrations of contaminants of concern, (2) identify areas for focused further sampling, and (3) focus the analysis to a smaller number of contaminants of concern. Fourteen sites were sampled as planned, resulting in $100 \%$ sampling completeness. However, because only one reference location was sampled, statistical comparison between reference concentrations and concentrations in the study area was not possible. This oversight will be rectified as part of Phase 2 work.

Assessment of data quality as a result of field procedures is limited because true field duplicates were not collected. Rather, field QC samples were splits, which provided a measure of homogenization and field procedures and not precision. Assessment of the organic contaminant data relative to field $\mathrm{QC}$ was difficult because nearly all organic contaminant concentrations were below detection limits. However, the RPDs of the detection limits were within acceptable bounds, indicating that the field methods were sound and that the concentrations are below the detection limit. The RPDs for inorganic contaminants are within acceptable bounds except for selenium. Additional data are required before removing selenium as a contaminant of concern. Gamma-emitting radionuclide RPDs from both core and grab samples are well within bounds and suggest that precision was high. No conclusion regarding the precision of the alpha-emitting radionuclides could be made because no field splits were analyzed.

It is difficult to determine if there was contamination of samples from containers or during field collection activities because no rinse blanks were collected. However, the number of non-detects in the organic data and the fact that no anomalous values in the inorganic and radionuclide data indicate that contamination was not a problem. Also, each core was collected in separate tube liners that were never reused. Therefore, the data should be representative of field conditions.

For a more detailed discussion of the field QC for sediment samples, see Appendix C.

\subsection{FISH}

\subsubsection{Introduction}

The original plan for Phase 1 of the CRRI (Energy Systems 1990) called for the collection of eight specimens each of two species of fish [bluegill sunfish (Lepomis macrochirus) and channel catfish (Ictalurus punctatus)] and as many as available (up to eight) 
of a third species [largemouth bass (Micropterus salmoides)] from 13 different sites (plus one optional site in Poplar Creek). The samples collected from White Oak Creek Embayment (WOCE) will not be discussed here, however, because they have already been discussed in a separate report on the WOCE (Blaylock et al. 1993). Two additional sites were added later [Grassy Creek (catfish only) at CRM 14.7 and upper Chickamauga Reservoir at TRM 518], which brings the total number of sites to be discussed in this report to 15 (Table 3.2).

Different combinations of one or more of these species were submitted for organic (PCB, pesticide, and semivolatile); inorganic (metal); and radionuclide analysis. Bluegill were submitted for metals and gamma emitters; bass for metals, PCBs, and gamma emitters; and catfish for PCBs, pesticides, SVOs, gamma emitters, and ${ }^{90} \mathrm{Sr}$. The numbers of samples submitted for radiological analysis may be less than the number submitted for other analyses because of the lack of sufficient tissue quantity, which necessitated combining some samples for analysis.

QC samples (matrix spike blank, matrix spike, and split samples) were to be included with each batch of regular samples ( -15 to 20 samples). Matrix spike results are discussed in Chap. 4 on laboratory QC.

\subsubsection{Field Quality Control Assessment}

The field QC problem that had the greatest impact on the usable data was the improper preparation of largemouth bass fillets, which resulted in the rejection of the PCB analyses of these samples. Sample collection was generally complete and achieved the proposed goals of collecting enough fish from a variety of sample sites to corroborate historical data and to provide adequate information to conduct preliminary human health and ecological risk screening. The availability of largemouth bass samples was limited as expected, and at many sites the number of bass samples was insufficient for analyses of among-species differences. There were few obvious differences among species, so bass results were combined with other species for data analysis. Although there was little apparent difference among species, future sampling should be designed to collect greater numbers of bass because they are such a popular game fish.

Sampling from the primary reference site (Norris Reservoir) provided adequate information to perform statistical comparisons of the study sites to the reference site (Cook et al. 1992). However, the second reference site (Poplar Creek/Hartland Bridge) was inadequate for this purpose because of its proximity to contaminated areas, and future sampling should include other reference areas.

Split-sample analyses of precision were generally good ( $>75 \%$ acceptable) for most metals, pesticides, and Aroclor 1260. Poor results were obtained for beryllium and Aroclor 1254, and insufficient information was obtained for several other metals and SVOs. Poor precision as indicated by either the duplicate samples or the split samples does not render the data unusable but does produce higher uncertainty in the results of any analyses that make use of these data.

For a more detailed discussion of the field QC for fish samples, see Appendix C. 
Table 3.2. Sample sites for Phase 1 fish collection in the Clinch River/Watts Bar system

\begin{tabular}{ccll}
\hline $\begin{array}{c}\text { Site } \\
\text { number }\end{array}$ & Reach & $\begin{array}{l}\text { River mile } \\
\text { or kilometer }\end{array}$ & \multicolumn{1}{c}{ Name } \\
\hline 1 & 10 & CRM 105.0 & Norris Reservoir (reference site) \\
2 & 1 & CRM 51.0 & Upper Melton Hill Reservoir \\
3 & 1 & CRM 24.0 & Lower Melton Hill Reservoir \\
4 b & 4 & WOCM 0.8 & White Oak Cr. embayment (near CRM 20.9) \\
5 & 2 & CRM 20.6 & Jones Island \\
6 & 2 & CRM 14.7 & Grassy Creek mouth \\
7 & 13 & PCK 9.6 & Poplar Cr. at Hartland Bridge \\
8 & 3 & PCK 8.6 & Poplar Cr. at East Fork Poplar Cr. mouth \\
9 & 3 & PCK 7.4 & Poplar Cr. at Mitchell Branch mouth \\
10 & 3 & PCK 2.2 & Poplar Cr. at K-1007B pond outfall \\
11 & 3 & PCK 0.8 & Poplar Cr. embayment \\
12 & 4 & CRM 9.5 & Brashear's Island \\
13 & 4 & CRM 0.5 & Kingston park \\
14 & 5 & TRM 557.0 & Mid Watts Bar Reservoir \\
15 & 5 & TRM 530.5 & Lower Watts Bar Reservoir \\
16 & 15 & TRM 518.0 & Upper Chickamauga Reservoir \\
\hline & 5 & &
\end{tabular}

a Largemouth bass and bluegill were collected from CRM 105.5 but channel catfish were collected in the Powell River arm of Norris Reservoir at PRM 30.

bhite Oak Creek (WOC) results were reported in Blaylock et al (1992) as this area is no longer considered part of the CRRI.

GFish at sites 10 and 11 were sometimes combined because of small sample sizes. 


\section{ANALYTICAL SAMPLE DATA EVALUATION}

\subsection{INTRODUCTION}

Approximately 1700 inorganic samples, 1500 organic samples, and 2200 radiological samples, were submitted for laboratory analysis. These samples were analyzed for potential contaminants of concern using EPA-approved procedures wherever possible. Each laboratory implemented a QC program to ensure that all data generated and reported were scientifically valid, consistent with accepted methods, and of known accuracy. This chapter summarizes the results of the laboratory QC data. The chapter begins by defining the type of QC samples data generated by the laboratories. Next, a summary of the data validation process is presented. The remainder of the chapter summarizes the results of the laboratory $Q C$ program. Additional information on the laboratory QC program is presented in Appendix A.

\subsubsection{Method Quality Control}

Method quality control consists of those practices common to a group or batch of samples that have been analyzed simultaneously by the same analytical method.

Instrument tuning is evaluated to determine if the instrument was properly configured to maximize analyte sensitivity. This evaluation is part of the gas chromatograph/mass spectrometer (GC/MS) methods, where criteria specify tuning compounds, concentrations, and frequencies.

Calibration is assessed to document the accuracy and sensitivity of the instrument for the target analytes. Method criteria usually specify the number of standards, the concentration levels, the frequency of analysis, and the required response factors and precision criteria.

Blanks assess contamination levels in the sampling process, in transport of the samples from the site to the laboratory, and in the analytical process itself that may bias the analytical results.

Control samples contain known concentrations of analytes and are used to assess method bias, precision, and comparability.

Matrix spikes assess the bias of the method for the matrix, as well as the precision of the method when performed in duplicate. MSR is calculated as follows:

where

$$
\text { MSR }=((\text { SSR-SR }) / S A) \times 100
$$

MSR = matrix spike recovery (percent),

SSR = spiked sample result,

$\mathrm{SR}=$ sample result,

$\mathrm{SA}=$ spike added.

Duplicates assess the precision of the sampling process and/or the analytical method. The RPD and DER are used to evaluate duplicate control requirements. (See Chap. 2.) 


\subsubsection{Sample Quality Control}

Sample quality control consists of those elements that are applicable to individual samples.

Holding time deviations from method and/or project requirements are noted. Exceeding holding times may result in contaminant loss. For purposes of this document, sample extraction holding time is the time elapsed between when the sample was extracted and when the sample was collected. Sample analysis holding time for semivolatiles and pesticides/PCBs is the time elapsed between when the sample was analyzed and when the sample was extracted. Sample analysis holding time for metals is the time elapsed between when the sample was analyzed and when the sample was collected.

Internal standards are used to evaluate the stability of the instrumentation between calibration runs.

Analyte identification consists of evaluating the sample spectra against standards and or standard libraries of spectra to ensure that acceptable identifications are made. Retention times or relative retention times are also evaluated against standard criteria.

Surrogates are organic compounds not found in environmental samples that are added to a sample to evaluate the accuracy and bias of the method. The recovery of each surrogate is calculated as follows:

Analyte quantitation must be reviewed in terms of detection limits as well as specificity for the contaminants of concern. Any detection limits that exceed regulatory or action levels must be identified. The laboratory's ability to detect the analyte of concern in the sample matrix at the prescribed threshold must be documented. Increasing variability in the estimate of the concentration will increase the uncertainty of the end product (e.g., risk assessment). The detection limits must reflect dilutions, interferences, or correction for moisture.

\subsubsection{Supporting Quality Assurance}

Other QA/QC elements consist of additional documentation necessary to assess the analytical laboratory conduct of operations and sample tracking and general laboratory QC.

Chain-of-custody records document sample possession from the time of collection to disposal. All discrepancies between the sample identification and the information contained on the chain-of-custody documents must be addressed. Sample security must be demonstrated as required by the project objectives.

Logbooks used to record all information pertinent to the analysis of the samples are reviewed to ensure technical adequacy and legal defensibility.

Internal QC measures include performance evaluation samples and laboratory control samples that determine analytical accuracy and method performance. Control charts may be evaluated to determine the statistical performance of the laboratory.

Certifications of the laboratory from performance evaluation programs such as the Water Pollution Studies, Water Supply Studies, State Drinking Water Programs, EMSL, CLP, 
Environmental Monitoring Laboratory (EML), Analytical Products Group Proficiency Evaluation Testing Control (PETC) Program, and others will support the performance of the laboratories for those analytes reported.

Standard operating procedures within the laboratory ensure that the samples are analyzed and data reported using approved and documented techniques.

\subsection{INORGANIC ANALYSES}

The K-25 Analytical Chemistry Department (ACD) analyzed water samples for metals but subcontracted the sediment metals analyses to International Technology Corporation (IT) laboratories. Fish tissue samples were analyzed for metals by the ORNL Analytical Chemistry Division (ACD).

\subsection{Atomic Absorption (AA) Water Analyses}

AA analyses of water samples were conducted at the K-25 ACD by graphite furnace for antimony, arsenic, cadmium, lead, selenium, silver, and thallium. Mercury was determined by cold vapor AA (CVAA). The USEPA Contract Laboratory Program Statement of Work for Inorganic Analysis, Multi-media, Multi-Concentration, 7/87 (EPA 1987) was used as the analytical protocol.

Sixty-eight samples were analyzed in four batches for the eight metals listed above. The major QC problems were blank contamination and spike recoveries that did not meet the required limits. Of the total 544 analyses, only one thallium result was rejected because of the postdigestion spike recovery that did not meet criteria (sample 144M).

Evaluation of the holding times, calibrations, blanks, laboratory control samples, and spiked samples indicate that these QC samples meet the method requirements and that accuracy is acceptable for all detectable contaminants, with the exception of thallium in sample 144M. The corresponding unfiltered sample, 144T, did not contain any thallium. Antimony, selenium, and lead results reported at or near the detection limit must be considered estimated because of blank and spike results that did not meet the criteria. Based on the duplicate control results, precision is acceptable.

\subsection{AA Soil/Sediment Analyses}

AA analyses of soil/sediment samples were conducted at IT laboratories by graphite furnace for antimony, arsenic, lead, selenium, silver, and thallium. Mercury was determined by CVAA. The USEPA Contract Laboratory Program Statement of Work for Inorganic Analysis, Multi-media, Multi-Concentration, 7/87 (EPA 1987) was used as the analytical protocol for most of the samples.

Three hundred seventy-two samples were analyzed in 14 batches for the seven metals listed above. The major QC problems were spike recoveries, calibrations that did not meet criteria, laboratory control sample recoveries outside limits, and duplicate RPDs outside criteria. One hundred twenty-two mercury results were rejected primarily because the calibration did not meet requirements, although 6 of the 122 also missed the holding time. Fifteen antimony results were rejected because the calibration curve standard coefficient was 
$<0.995$, with an additional 156 antimony results rejected because of MSRs not being met. Sixty-six selenium results were rejected because MSRs were not met. One hundred sixty-seven silver results were rejected because of inadequate spike recoveries and analysis interferences. Of the total number of analyses, the following approximate percentages of data were rejected: antimony, $46 \%$; mercury, 33\%; selenium, $17 \%$; and silver, $45 \%$.

Evaluations of the holding times, calibrations, and blanks indicate that most of these QC samples meet the method requirements and that accuracy is acceptable for arsenic, lead, and thallium. Antimony, mercury, selenium, and silver results were either rejected or considered as estimates because of blank and spike results that did not meet the criteria. Those results labeled "J" may exhibit a negative bias because of low spike recoveries. Based on the duplicate control results, precision is acceptable. At least ten analyses were available for every reach by analyte combination except antimony for Reach 2 and silver for Reach 4.

\section{AA Analysis of Fish Tissue}

AA analysis of fish tissue was conducted by the EAL at the ORNL ACD. Fish tissue was prepared by the ORNL $\mathrm{HNO}_{3} / \mathrm{HClO}_{4}$ method (AC-MM10915) and analyzed by a CVAA method (AC-MM1214922) for mercury. The cold vapor method measures mercury using a standard addition technique. A National Institute of Standards and Technology (NIST) standard was used for the standard addition.

One hundred seventy-eight samples ( 169 regular samples and 9 field splits) were analyzed for mercury in 12 batches. The major QC problems were conventional holding times exceeded, conventional procedures not followed, and calibration curves not established. None of these problems resulted in the rejection of any samples.

Although the method used for the analysis of mercury in fish tissue was considered unconventional by the data validators, the results from laboratory QC suggest that the method is accurate and reliable. The recovery rates of calibration standards and laboratory control samples were accurate. Based on the laboratory $\mathrm{QC}$, these data meet the data quality objectives (DQOs) and are totally usable for the screening risk assessment.

\subsection{ICP Water Analyses}

ICP analysis of water samples was conducted by the K-25 ACD for beryllium, calcium, chromium, copper, iron, magnesium, nickel, potassium, sodium, and zinc. The USEPA Contract Laboratory Program Statement of Work for Inorganic Analysis, Multi-media, MultiConcentration (EPA 1988a) was used as the analytical protocol.

Sixty-four samples were analyzed in four batches for the ten metals just listed. The major QC problems were blank contamination and shift in the instrument baseline. Of the 638 analyses, only 7 iron results were rejected as a result of both of these problems $(\sim 1 \%)$.

Evaluations of holding times, calibrations, laboratory control samples, and spike recoveries indicate that these QC samples met the method requirements and accuracy is acceptable. Duplicate criteria were met, so precision was within $20 \%$ and therefore acceptable. Iron results in samples $1422 \mathrm{M}, 1432 \mathrm{M}, 1442 \mathrm{M}, 145 \mathrm{M}, 1452 \mathrm{M}, 146 \mathrm{M}$, and 147M were rejected because of contamination. Four of these samples were field QC samples. At 
least four iron results are available for Reaches $1,2,3,4,5$, and 10, but only one result is available for Reach 13.

\subsection{ICP Sediment Analyses}

ICP analysis of sediment samples was conducted by IT laboratories for beryllium, calcium, chromium, copper, iron, magnesium, nickel, potassium, sodium, and zinc. The USEPA Contract Laboratory Program Statement of Work for Inorganic Analysis, Multi-media, MultiConcentration (EPA 1988a) was used as the analytical protocol for most of the samples.

Fourteen sample batches containing 372 samples were processed for six metals. Spike recoveries not within limits, duplicate RPDs out of criteria, and serial dilution criteria not met were the top three quality control problems found. However, none of these QC problems was severe enough to warrant rejection of any of these data.

Evaluation of holding times, calibrations, laboratory control samples, blanks, duplicates, and spike recoveries indicate that these QC samples met the method requirements for beryllium, cadmium, and nickel. Accuracy and precision for these elements are acceptable. It should be noted that $26 \%, 33 \%$, and $65 \%$ of the chromium, copper, and zinc data, respectively, were flagged as estimated, indicating possible bias.

\subsubsection{ICP and ICP/MS Analysis of Fish Tissue}

ICP and ICP/MS analyses of fish tissue were conducted by the CPA at the ORNL ACD. For the analysis of metals, ICP/MS was used to measure arsenic, beryllium, and thallium, and ICP/atomic emission spectroscopy (AES) was used to measure antimony, cadmium, chromium, copper, lead, nickel, selenium, silver, and zinc. An internal method was used for sample preparation. A VG Plasma Quad PQ2 was used for the ICP/MS analyses, and a JY-48 instrument was used for the ICP/AES analyses. The ICP/MS measurements were made using the standard addition technique.

One hundred seventy-seven samples (169 regular samples and 8 field splits) were analyzed for 12 metals in 10 batches. Because of analytical problems, one zinc analysis was not performed. The major QC problems were (1) calibration standards recovery outside limits, (2) conventional procedures not followed, and (3) validity of method undocumented. Most of the QC problems resulted in the data being flagged as an estimated value but not rejected outright. However, 96 of the 2291 analyses (including 85 regular analyses) were rejected because of deficiencies in calibration standards recovery ( 52 lead, 7 beryllium, 20 nickel, and 9 thallium analyses) and standard curve correlation coefficients ( 8 beryllium analyses).

QC problems during calibration resulted in the rejection of 4.6\% (94 of 2027) of the analyses performed on regular samples. However, measures of accuracy as determined with MSRs were consistently within control criteria for all the analytes except for lead, which had three percent recoveries slightly below the acceptable lower limit of $75 \%$.

Most (74) of the rejected analyses were nondetects that were from samples collected from sites (Norris Reservoir, Melton Hill Reservoir, Poplar Creek/Hartland Bridge, and lower Watts Bar Reservoir) that are not immediately downstream of ORR surface waters. Because the rejections are mostly nondetects, the means calculated from the remaining data will be higher than if the rejected data were included. Even without the rejected data, at least ten 
analyses were available for every reach by analyte combination except for beryllium in Reach 13 (Poplar Creek/Hartland Bridge), lead in Reaches 5 (lower Watts Bar Reservoir) and 10 (Norris Reservoir), and nickel in Reach 5 (lower Watts Bar Reservoir). The rejected analytes were rarely detected in the acceptable data; lead, nickel, and thallium were never detected, and beryllium was detected in only $12 \%$ of the samples. Therefore, the rejection of a small portion of these analyses should have little effect on the ultimate data analysis and risk screening.

\subsection{ORGANIC ANALYSES}

The K-25 ACD analyzed water samples for semivolatiles and pesticides/PCBs. Organic soils analyses were performed both by the K-25 ACD and by IT laboratories. Fish samples were analyzed for semivolatiles and pesticides/PCBs by the ORNL ACD.

\subsubsection{Semivolatile Water and Sediment Analyses}

Semivolatile analyses of water and sediment samples were conducted at the K-25 ACD by GC/MS. The USEPA Contract Laboratory Program Statement of Work for Organic Analysis, Multi-media, Multi-Concentration (EPA 1988b) was used as the analytical protocol. Sample 35800 was analyzed by IT, but the data were rejected because of exceeded holding times.

Three hundred forty-two samples were analyzed for 65 organic compounds in 23 batches. The major QC problems were calibration standards percent RSD outside limits, surrogate recovery criteria not met, and blank contamination. However, of the 22,230 analyses, only $3 \%$ (617) were rejected because of deficiencies in meeting holding time, calibration, and surrogate recovery requirements.

Samples 1442O, 1909O, 1912O, 19150, 3107O, 33030, 31110, 3112O, 7304O, 7305O, 73060 , and 73070 were rejected for a large number of analytes because holding times were exceeded. All but four of these samples were rinsate blanks or reference samples. Calibration difficulties affected quantitation of 2,4-dinitrophenol, 4-nitrophenol, benzyl alcohol, 2-methylphenol, 4-methylphenol, 2,4,6-trichlorophenol, and 2,4,5-trichlorophenol for a few of the samples. However, only $72(0.3 \%)$ of the routine sample analyses were rejected, so for the majority of the semivolatile analyses, precision and accuracy CLP requirements were satisfied.

\section{SVO Analysis of Fish Tissue}

Semivolatile analyses of fish tissue were performed by the OAL of ORNL ACD. Semivolatiles were analyzed using a modified GC/MS procedure with no acid surrogates. Laboratory QC elements included matrix spikes, method blanks, internal standardization, initial calibration, continuing calibration, and GC/MS tuning.

One hundred twenty-three samples (116 regular samples and 7 field splits) were analyzed for 65 SVOs in 17 batches. The major QC problems were (1) holding times were exceeded, (2) continuing calibration percent difference was $>25 \%$, (3) surrogate recovery criteria were not met, (4) conventional procedures were not followed, and (5) multiple problems affecting analytical performance and analysis occurred outside the 12-h GC/MS tune window. The most 
serious QC problems (continuing calibration RRF $<0.05$, conventional procedures not being followed, and multiple problems affecting analytical performance resulted in the rejection of $48 \%$ (3609 of 7539) of the semivolatile analyses.

Several serious laboratory QC problems resulted in the rejection of nearly half of the SVO analyses. This left eight or fewer acceptable analyses for each analyte in every reach except Reach 3 (Poplar Creek), which had $>30$ acceptable values for each analyte. This is noteworthy because the Poplar Creek reach is adjacent to the K-25 facility and is probably more likely to be contaminated with SVOs than any other reach. However, given the poor matrix spike and surrogate spike recoveries, the acceptable data are also highly suspect. The acceptable data are probably insufficient for a reliable risk screening analysis, although it is unlikely that this class of contaminants would exist in very high concentrations in fish tissue anyway.

\subsubsection{Pesticide/PCB Water and Sediment Analyses}

Pesticide/PCB analyses of water and sediment samples were conducted at the K-25 ACD by $\mathrm{GC} /$ electron capture detector for the target compound list of pesticides/PCBs. The sediment samples were extracted at IT Corporation in Knoxville in accordance with the preparation protocol outlined in the USEPA Contract Laboratory Program Statement of Work for Organic Analysis, Multi-Media, Multi-Concentration (EPA 1988b). The water samples were extracted by K-25 ACD personnel, using an extraction procedure that differed slightly from that outlined in the EPA CLP SOW. Semivolatile and pesticide/PCB extracts were prepared from separate sample aliquots. A separatory funnel extraction procedure was used. A modified version of the EPA CLP SOW, which required analysis on only a single column, was used as the analytical protocol. The analyses were performed on two Hewlett Packard Model HP5890 gas chromatographs equipped with electron capture detectors.

Twenty-one sample batches were processed containing 364 samples. Holding time, surrogate recovery, and matrix spike/MSD recovery violations were the major $\mathrm{QC}$ problems. The data are potentially biased low because of missed holding times. The low bias contributes an increased probability of false negatives. Surrogate recovery is intended to quantitate bias of the sample results because of laboratory sample preparation and analysis. The pesticide/PCB content for sediment samples appears to be biased high. However, most of the data package case narratives indicate the presence of an interfering peak that probably contributed to the high recovery values for the surrogate compound. This makes it impossible to determine the amount or direction of bias for this data set.

There was a slightly elevated failure rate (35\%) for sediment MS/MSD recovery. However, much of the sediment MS/MSD recovery failure rate was because of nondetect results for early-eluting spike compounds. There were large interference peaks in many of the sample chromatograms, which required dilution analysis. For the MS/MSD samples, this frequently caused the early-eluting compounds to either fail to be detected (a potential false negative problem) or to be imprecisely quantitated. Much of the sample data were rejected during the validation process to prevent the possibility of false negative results. The necessity of dilution analysis, required to reduce the data signal to less than full-scale response of the detector for the entire chromatogram, also resulted in elevated detection limits for most of these data. The average sediment MS/MSD RPD was $15 \%$. This level of precision is relatively good, especially considering the matrix interference problem for these samples. 


\subsubsection{Pesticide/PCB Analysis of Fish Tissue}

Pesticide/PCB analyses of fish tissue were performed by the OAL of ORNL ACD. Fish tissue was extracted by sonification in methylene chloride with sodium sulfate. Extracts were concentrated and solvent-exchanged with hexane using Kuderna-Danish concentrators and nitrogen blowdown. Pesticide extracts were acid washed using concentrated sulfuric acid. The extracts were analyzed on a DB-5 capillary column and a DB-1701 megabore column using electron capture collection.

One hundred twenty-three samples (116 regular samples and 7 field splits) were analyzed for 11 pesticides (aldrin, DDE, DDD, DDT, alpha chlordane, alpha chlordene, gamma chlordane, gamma chlordene, oxychlordane, chlordene, and technical chlordane) and two PCBs (Aroclor 1254 and Aroclor 1260) in 11 batches. The major QC problems were (1) holding times were exceeded, (2) a calibration curve was not established, and (3) daily calibration was not performed properly. These problems did not result in the rejection of any analyses, but many analyses were qualified as estimates. However, less common problems (such as the retention time of compounds being outside established windows, retention time of $\mathrm{DBC}$ criteria not being met, and no second column confirmation) did result in the rejection of $4.5 \%$ (68 of 1508 ) of the analyses.

The number of analyses that were rejected was $<5 \%$ of the total and was fairly evenly distributed among the various sites sampled. Thus, the effect of these few missing analyses on the ultimate data analysis and risk screening assessment will probably be minimal. A potentially more important problem is the poor recoveries of matrix and surrogate spikes. This resulted in no rejections primarily because of the lack of specific EPA criteria for fish analyses. MSR averages were $45.5 \%, 44.8 \%$, and $70.4 \%$ for the three spiked compounds. Most of the surrogate recoveries were below the minimum acceptable limit of $60 \%$ for water samples. The concentrations of these pesticide and PCB compounds as reported by the OAL probably should be considered to be lower than actual values by about a factor of two. An additional problem with the analysis of some pesticides is the potential for interference from high concentrations of other compounds, resulting in quantitation difficulties. The laboratory analysts recommended that reported concentrations of aldrin, DDE, and DDD be considered suspect because of interference from high concentrations of PCBs and chlordanes.

\subsubsection{PCB Analysis of Fish Tissue}

PCB analyses of fish tissue were also performed by the CPA of the ORNL ACD. An internal procedure was used for sample preparation and analysis.

One hundred and seventy-five samples (162 regular samples and 13 field splits) were analyzed for two PCBs in nine batches. The major QC problems were (1) holding times were exceeded, (2) second column confirmation was not performed, (3) conventional procedures were not followed, and (4) validity of methods used was undocumented. Most of the QC problems resulted in the data being flagged as an estimated value but not rejected outright. Two of these problems (conventional procedures not being followed and validity of methods being undocumented) alone or in combination did result in the rejection of $10.9 \%$ (38 of 350) of the analyses.

The validation process resulted in the rejection of $<5 \%$ of the analyses from the regular samples. The rejected analyses were distributed among several reaches, so adequate data were 
still available for all reaches. Accuracy information from the matrix spike samples and LCSs. suggests that the method provided fairly reliable data that would be sufficient for Phase 1 data analysis and risk screening. Because the PCB accuracy information from this laboratory [the ORNL Chemical and Physical Analysis Group (CPA)] was markedly better than that from OAL, these PCB data were selected over those from OAL for data analysis and risk screening.

\subsection{RADIOLOGICAL ANALYSES}

\subsubsection{Gamma Analysis of Sediment, Water, and Fish Tissue}

Gamma analysis was done by the ESD RAL at ORNL. The method used by the laboratory was nondestructive and did not require any additional sample preparation prior to analysis. Target radionuclides and sample matrixes were ${ }^{137} \mathrm{Cs}$ and ${ }^{60} \mathrm{Co}$ in sediment, fish, and water. The laboratory used two spectrometers to analyze the Clinch River ER Program samples. The ND9900 is a minicomputer-based spectrometer connected to eight solid-state detectors and was used primarily for low-level gamma ray analyses. However, only detectors 1, 2, 3, 6, and 7 were used for the Clinch River ER Program samples. The ND6700 spectrometer consists of three solid-state detectors connected to a microcomputer-based data acquisition and analysis system. This instrument was generally used for the analysis of higher activity samples. Only detectors 1 and 3 were used for the analyses. The data acquisition and analysis components of both instruments were manufactured by Canberra Industries (formerly Nuclear Data). The detectors and associated electronic components were manufactured by several vendors, including Canberra, EG\&G ORTEC, and Princeton Gamma.

The ESD RAL analyzed 1195 regular samples consisting of 948 sediment, 210 fish, and 37 water samples. Of these 1195 samples, 28 were field splits. In addition, 100 laboratory duplicates and 395 LCSs were analyzed. An independent validator reviewed these data for sensitivity, precision, accuracy, representativeness, completeness, and comparability (SPARCC). For the purposes of validation, the samples were grouped into 112 batches based on the instrument and week in which they were analyzed.

It should be noted that nationally recognized guidelines for the validation of radiological data were not established at the time of these analyses. Of the 2323 measurements submitted for validation, only 3 were rejected. Additional information on the validation results is presented below.

This section discusses the quality of the results for the regular (including field splits) samples from the perspective of laboratory SPARCC. Section 2.4 defines and describes these data quality indicators in greater detail. The summary of the validation results is the basis of this discussion.

There are 1195 possible apalyses for each of the two target radionuclides. Of these, the ESD RAL performed $1187{ }^{13} \mathrm{Cs}$ analyses (99.3\% complete) and $1134^{60} \mathrm{Co}$ analyses (94.9\% complete). The two rejected ${ }^{137} \mathrm{Cs}$ and one rejected ${ }^{60} \mathrm{Co}$ results do not significantly lower these completeness estimates. The missing ${ }^{60} \mathrm{Co}$ results were all below the sample detection limit or MDA. These analyses were performed early in the Clinch River ER Program when MDA estimates were not required from the laboratory. 
The validators noted accuracy problems in $22{ }^{60} \mathrm{Co}(1.9 \%)$ and $25^{137} \mathrm{Cs}(2.1 \%)$ analyses. Low recovery in the associated LCSs was the reason for qualifying these results. However, none of the results were rejected for this reason, and the effect on data quality was minimal.

Precision problems were noted in $14^{60} \mathrm{Co}(1.2 \%)$ and $10{ }^{137} \mathrm{Cs}(0.8 \%)$ analyses. These problems were caused by high values of the associated DER. No results were rejected because of precision problems, and the effect on data quality was minimal.

Based on the results of the EPA interlaboratory comparison study, the data generated by the ESD RAL are comparable with those generated by other laboratories. Furthermore the EPA data indicate that the ESD RAL also produced accurate and precise measurements.

The laboratory experienced minor problems related to representativeness. Sixty-seven ${ }^{60} \mathrm{Co}(5.9 \%)$ and fifty-eight ${ }^{137} \mathrm{Cs}(4.2 \%)$ results exceeded holding time requirements. Nine ${ }^{60} \mathrm{Co}(0.8 \%)$ and eight ${ }^{37} \mathrm{Cs}(0.7 \%)$ results were improperly preserved. However, neither of these problems was serious enough to warrant rejection of results.

\subsubsection{Alpha and Beta Analysis of Sediment, Water, and Fish Tissue}

The ORAU Environmental Survey and Site Assessment Program (ESSAP) radiological laboratory conducted the alpha and beta analyses on the Phase 1 samples. Target radionuclides and matrixes included ${ }^{3} \mathrm{H}$ in water; ${ }^{90} \mathrm{Sr}$ in fish and sediment; and ${ }^{241} \mathrm{Am}$, ${ }^{238} \mathrm{Pu},{ }^{239-240} \mathrm{Pu},{ }^{234} \mathrm{U},{ }^{235} \mathrm{U}$, and ${ }^{238} \mathrm{U}$ in sediment. In addition, curium isotopes were estimated from the ${ }^{241} \mathrm{Am}$ spectrum, but these results were not necessarily accurate or precise. Alpha and beta determinations were destructive techniques that required laboratory preparation of the samples prior to spectrometric analysis. The ORAU ESSAP used three instruments in the analysis of the Clinch River ER Program samples. A Tennelec model LB5110 low-background alpha and beta counter was used for the ${ }^{90} \mathrm{Sr}$ determinations. Tritium determinations were made with a Packard model 1900 liquid scintillation spectrometer. A spectrometer containing components from Canberra, Tennelec, and EG\&G ORTEC was used for alpha analyses.

The ORAU ESSAP analyzed 196 sediment, 87 fish, and 32 water samples for a total of 315 regular samples. In addition, 40 laboratory duplicates, 56 blanks, 8 spikes, and 11 LCSs were analyzed. An independent validator reviewed these data for SPARCC. For the purposes of validation, the samples were grouped into eight batches.

It must be noted that national guidelines for the validation of radiological data were not established at the time of these analyses. Of the 981 measurements submitted for validation, 38 were rejected. Additional detail on the validation results is presented below.

This section discusses the quality of the results for the regular (including field splits) samples from the perspective of laboratory SPARCC. Section 2.4 defines and describes these data quality indicators in greater detail. The summary of the validation results is the basis of this discussion.

There are 98 possible analyses for the target alpha radionuclides. Of these, the laboratory performed all of the americium, plutonium, and uranium isotopic analyses. Two rejected $241 \mathrm{Am}$ results (98.0\% complete) and three rejected plutonium and uranium results (97.0\%) lowered the completeness estimates slightly. Analyses for ${ }^{245} \mathrm{Cu},{ }^{246} \mathrm{Cu}$, and ${ }^{248} \mathrm{Cu}$ were 
reported in less than half of the samples. Curium is estimated from the americium spectrum, and the interference because of ${ }^{241} \mathrm{Am}$ was too large to permit accurate measurement of the curium isotopes. Three ${ }^{90} \mathrm{Sr}$ results $(1.5 \%)$ and $16^{3} \mathrm{H}(100 \%)$ results were rejected. The ${ }^{3} \mathrm{H}$ rejections were caused by improper sample preservation prior to laboratory submission.

The validators noted accuracy problems in $24{ }^{90} \mathrm{Sr}$ (13.6\%) analyses. Low recovery in the associated LCSs was the reason for qualifying these results. However, none of the results were rejected for this reason, and the effect on data quality was minimal.

Precision problems were noted in six ${ }^{90} \mathrm{Sr}(3.0 \%)$ analyses. These problems were caused by high values of the associated DERs. No results were rejected because of precision problems, and the effect on data quality was minimal.

The laboratory experienced several problems related to representativeness. Sixteen ${ }^{3} \mathrm{H}$, $142{ }^{90} \mathrm{Sr}$, and numerous alpha results exceeded the holding time requirements. All of the ${ }^{3} \mathrm{H}$ samples were improperly preserved, leading to rejection of all of these data. The violation of holding times for the ${ }^{9} \mathrm{Sr}$ and alpha radionuclides was not severe enough to warrant rejection of these data.

\subsection{PERFORMANCE EVALUATION AND INTERLABORATORY COMPARISON SAMPLE RESULTS}

\subsubsection{ORNL}

ORNL ACD performance evaluation sample results were reviewed for the year 1990, during which Clinch River fish tissue samples were being analyzed. Inorganic analytes in water and soil and organics in water were analyzed. Sample results were scored by the sponsoring organization and determined to be within predetermined acceptable/unacceptable ranges. The results are summarized in Komegay et al. 1991.

\subsubsection{EPA Environmental Monitoring Systems Laboratory, Las Vegas (EMSL-LV)}

The results of quarterly performance evaluation samples for inorganic CLP methods were reviewed. The laboratory performed consistently until the fourth quarter, when a preparation error resulted in a low score, making actual performance difficult to review. Review of the sample reports and laboratory responses for the other quarters showed a positive bias for quantifying zinc in both soil and water. For several out-of-range analytes, reanalysis of the performance evaluation samples often gave results within the EPA ranges, leading ACD to speculate that high results may be because of contamination.

Organic CLP performance evaluation results showed improvement over the year. First and second quarter scores were low because of low recoveries of chlorinated hydrocarbon semivolatiles. Corrective measures were taken to improve recovery, as evidenced by better scores in the third and fourth quarter. These results were for water samples and may not reflect properly on the analysis of fish tissue. 


\subsubsection{PETC Program at ORNL}

PETC samples were analyzed at a monthly frequency for inorganic and organic constituents in water at two concentration levels. Performance was rated as acceptable, marginal, or unacceptable, based on the mean results of all laboratories participating that month. The summary of results for 1990 show few marginal and even fewer unacceptable results.

\subsubsection{EPA Performance Evaluation Discharge Monitoring Report (DMR)-QA Study Number 010-ORNL}

Analysis results for inorganic and other analytes in water were compared to known values. Performance was acceptable overall, with only cadmium exceeding the warning limits.

\subsubsection{Water Supply Performance Evaluation Study}

Four Water Supply Performance Evaluation samples (WP-024, WP-025, WS-025, and WS-026) were analyzed for inorganics and organics in 1990. Trace metal results were generally within acceptance limits, but a few exceeded warning limits. There were no trends nor systematic biases evident for any given trace metal. Organic performance was not as consistent. Several unacceptable results were noted for lower concentrations of insecticide, phthalate, and trihalomethane analytes. Methoxychlor was the only analyte misquantified in both organic samples. Unacceptable results were not consistently greater than or lower than the limits. Therefore, there is no indication of whether the problems might have been contamination or poor recovery.

\subsection{TT Corporation}

The IT Corporation analytical laboratory was subcontracted by the K-25 laboratory to conduct inorganic analyses of sediment samples. During this time IT Corporation was also analyzing samples for the ORNL RI/feasibility study project under the management of Bechtel National, Inc. Bechtel performed on-site inspections of the laboratories and reviewed their participation in performance evaluation programs. Our review of the Bechtel audit reports revealed no findings that caused us to question the integrity of the IT data.

\subsection{EPA EMSL-LV}

IT analyzed EMSL-LV performance evaluation samples in 1990 and had a laboratory average score of $88 \%$. Accuracy of performance evaluation samples was, therefore, determined to be acceptable.

\subsection{K-25 Site}

K-25 analyzed water samples for both inorganics and organics and sediment samples for organics. Sample results were scored by the sponsoring organization and determined to be within predetermined acceptable/unacceptable ranges. The results are summarized in Kornegay et al. 1991. 


\subsubsection{EPA EMSL-LV}

CLP performance evaluation summary results for organics were reviewed. The laboratory response to EPA for the fourth quarter revealed a temperature control problem that resulted in the misquantification of three semivolatile compounds. The laboratory reported values exceeded upper action levels, giving a positive bias to subsequent interpretations. Overall, laboratory performance was good.

CLP performance evaluation summary results for inorganics were available only for the first and second quarter. Performance for these samples was acceptable. The lower score was because of misquantification of cadmium and lead in the soil sample and silver in one of the water samples. No obvious errors were noted in the response. Cadmium and silver both exceeded limits, and slightly elevated blank values were cited.

\subsubsection{PETC Program at K-25}

PETC samples were analyzed at a monthly frequency for inorganic and organic constituents in water at two concentration levels. Level 2 is generally two to five times more concentrated than Level 1. Performance was rated as acceptable, marginal, or unacceptable, based on the mean results of all laboratories participating that month.

The summary of inorganic results for 1990 were reviewed. Several metals had more than one result determined to be marginal or unacceptable. For example, aluminum had 5 of 12 results marginal or unacceptable for Level 1 . The average aluminum recovery was $150 \%$. Similarly, zinc had consistently high recoveries, with an average of $120 \%$ and two unacceptable results. Selenium had three unacceptable values because of either very high $(250 \%)$ or very low $(<50 \%)$ recoveries. Lead and arsenic also had several marginal or unacceptable values.

Organic results were reviewed for the one reported month. One month of data does not allow us to draw conclusions about long-term laboratory performance. However, these general observations were noted for contaminants of interest at the Clinch River: recoveries were good for pesticides, polycyclic aromatics, and contaminants observed in K-25 source monitoring (e.g., chloroform and trichloroethene), and recoveries were low for phthalates and for some substituted phenols (e.g., 4-nitrophenol and pentachlorophenol).

\subsubsection{EPA Performance Evaluation DMR-QA Study Number 010-K-25}

The DMR-QA study results for 1990 were reviewed. Analysis results for inorganic and other analytes in water were compared to known values. Performance was acceptable overall, with arsenic and manganese exceeding the warning limits.

\subsubsection{Water Supply Performance Evaluation Study}

Four Water Supply Performance Evaluation samples (WP-024, WP-025, and WP-026) were analyzed in 1990. Only WP-026 included trace metals and organics. Three trace metal results exceeded acceptance limits. Beryllium and cadmium were positively biased, and mercury was negatively biased. Notes indicate that metal analysis problems were operational and resulted from poor technique. Organic performance was acceptable. 


\section{OVERALL DATA ASSESSMENT}

This chapter provides an overall assessment of the Phase 1 water, sediment, and fish data. This assessment is based on the field and laboratory QC results presented in Chaps. 3 and 4, respectively. Sections 5.1-5.3 provide an assessment of each matrix in terms of the data quality indicators (representativeness, sensitivity, precision, accuracy, completeness, and comparability). This assessment is quantitative when possible and qualitative when necessary. When the impact of an individual quality indicator (e.g., completeness) on the overall objectives of Phase 1 could be adequately expressed as a proportion of the samples affected, letter grades and descriptions were assigned as follows:

A $>90 \%$ acceptable data (very adequate)

B $70-90 \%$ acceptable data (mostly adequate with some deficiencies)

C $<70 \%$ acceptable data (inadequate)

When the assessment of the adequacy of a given data matrix was based on more than one factor (and was therefore subjective to some degree), the letter grade assigned was based on the best judgment of CRRI personnel. An overall grade was also assigned for each of the three matrixes. Section 5.4 includes a list of lessons learned during Phase 1 that were applicable to Phase 2 planning.

\subsection{DATA ASSESSMENT OF WATER RESULTS}

The overall assessment of water data collected during Phase 1 is presented in Table 5.1. The inorganic results were assessed as being $>90 \%$ acceptable overall, with representativeness and comparability graded between $70 \%$ and $90 \%$ acceptable. Pesticide/PCB organic analytes were graded as $70 \%$ to $90 \%$ acceptable, a function of the completeness grade of $<70 \%$ acceptable because of the absence of results from Poplar Creek. Semivolatile organic (SVO) compounds and radionuclides (with the exception of ${ }^{3} \mathrm{H}$ ) were all graded as $>90 \%$ acceptable; ${ }^{3} \mathrm{H}$ data were graded inadequate.

Precision and completeness for field activities are very adequate. However, representativeness and comparability assessed for field activities indicate inorganic crosscontamination from a source other than collection or preparation procedures (Sect. C.1.4). Precision, accuracy, and sensitivity as assessed for laboratory observation were within acceptable ranges for all analyte groups. However, review of inorganic results for blank samples suggests that contamination of certain samples was introduced by the analytical scheme, impacting representativeness and comparability of the results and supporting the conclusions drawn in Sect. 3.1.2. Completeness of analyses for PCBs/pesticides was not acceptable, with no results reported for the Poplar Creek K-25 Site area. During Phase 2 a number of samples are planned to be collected from the Poplar Creek area for PCBs/ pesticides analyses.

\subsubsection{Representativeness}

Measures used to ensure representativeness of the water samples include careful site selection, standard operating procedures, field blanks, field rinsates, trip blanks, analytical method blanks, proper preservation, standard analytical methods, and adherence to holding 
Table 5.1. Overall assessment of water data collected during Phase $1^{\mathrm{a}}$

\begin{tabular}{|c|c|c|c|c|c|c|c|}
\hline & \multicolumn{7}{|c|}{ Parameters $\underline{b}$} \\
\hline & Total & Repr. & Sens. & Prec. & Accu. & Cmpl. & Cmpa. \\
\hline \multicolumn{8}{|c|}{ Inorganics } \\
\hline Antimony & $\mathbf{A}$ & B & A & A & A & A & A \\
\hline Arsenic & $\mathbf{A}$ & B & A & $\mathbf{A}$ & $\mathbf{A}$ & $A$ & $A$ \\
\hline Beryllium & A & B & A & A & A & A & A \\
\hline Cadmium & A & B & A & A & $\mathbf{A}$ & A & $A$ \\
\hline Calcium & A & B & A & A & A & A & A \\
\hline Chromium & $\mathbf{A}$ & B & A & A & A & A & A \\
\hline Copper & A & B & A & A & A & A & A \\
\hline Iron & $\mathbf{A}$ & B & A & $\mathbf{A}$ & $\mathbf{A}$ & A & $A$ \\
\hline Lead & $\mathbf{A}$ & B & $\mathbf{A}$ & $\mathbf{A}$ & A & A & $\mathbf{A}$ \\
\hline Magnesium & $\mathbf{A}$ & B & $\mathbf{A}$ & $\mathbf{A}$ & $\mathbf{A}$ & A & A \\
\hline Nickel & A & B & $\mathbf{A}$ & A & $\mathbf{A}$ & A & A \\
\hline Mercury & A & B & $\mathbf{A}$ & $\mathbf{A}$ & A & A & A \\
\hline Potassium & A & B & $\mathbf{A}$ & $\mathbf{A}$ & $\mathbf{A}$ & A & A \\
\hline Selenium & A & B & A & A & $\mathbf{A}$ & $\mathbf{A}$ & A \\
\hline Silver & A & B & A & $\mathbf{A}$ & A & A & A \\
\hline Sodium & A & B & A & A & A & A & A \\
\hline Thallium & $\mathbf{A}$ & B & $\mathbf{A}$ & $\mathbf{A}$ & $\mathbf{A}$ & $\mathbf{A}$ & A \\
\hline Zinc & $\mathbf{A}$ & B & $\mathbf{A}$ & A & A & A & A \\
\hline
\end{tabular}

\section{Organics-Pesticides/PCBs}

Aldrin

Alpha-BHC

Alpha-chlordane

Aroclor-1016

Aroclor-1221

Aroclor-1232

Arocior-1242

$\begin{array}{lllllll}\mathbf{A} & \mathbf{B} & \mathbf{A} & \mathbf{A} & \mathbf{A} & \mathbf{C} & \mathbf{A}\end{array}$

A B

A

A

A

C

A

A $B$

A

A

A

C

A

A $\mathbf{B}$

A

A

A

C

A

A B

A

A

A

C

A

A B

A

A

A

C

A

A B

A

A

C

A 
Table 5.1 (continued)

\begin{tabular}{lccccccc}
\hline & \multicolumn{7}{c}{ Parameters } \\
\cline { 2 - 7 } & Total & Repr. & Sens. & Prec. & Accu. & Cmpl. & Cmpa. \\
\hline Aroclor-1248 & A & B & A & A & A & C & A \\
Aroclor-1254 & A & B & A & A & A & C & A \\
Aroclor-1260 & A & B & A & A & A & C & A \\
Beta-BHC & A & B & A & A & A & C & A \\
Delta-BHC & A & B & A & A & A & C & A \\
Dieldrin & A & B & A & A & A & C & A \\
Endosulfan I & A & B & A & A & A & C & A \\
Endosulfan II & A & B & A & A & A & C & A \\
Endosulfan sulfate & A & B & A & A & A & C & A \\
Endrin & A & B & A & A & A & C & A \\
Endrin ketone & A & B & A & A & A & C & A \\
Gamma-BHC (Lindane) & A & B & A & A & A & C & A \\
Gamma-chlordane & A & B & A & A & A & C & A \\
Heptachlor & A & B & A & A & A & C & A \\
Heptachlor epoxide & A & B & A & A & A & C & A \\
Toxaphene & A & B & A & A & A & C & A \\
4,4'-DDD & A & B & A & A & A & C & A \\
4,4'-DDE & A & B & A & A & A & C & A \\
4,4'-DDT & A & A & A & A & C & A \\
\hline & & & & & & &
\end{tabular}

\section{Organics-Semivolatiles}

$\begin{array}{llllllll}\text { Acenaphthene } & \text { A } & \text { B } & \text { C } & \text { A } & \text { A } & \text { A } & \text { A } \\ \text { Acenaphthylene } & \text { A } & \text { B } & \text { C } & \text { A } & \text { A } & \text { A } & \text { A } \\ \text { Anthracene } & \text { A } & \text { B } & \text { C } & \text { A } & \text { A } & \text { A } & \text { A } \\ \text { Benzo(a)anthracene } & \text { A } & \text { B } & \text { A } & \text { A } & \text { A } & \text { A } & \text { A } \\ \text { Benzo(a)pyrene } & \text { A } & \text { B } & \text { C } & \text { A } & \text { A } & \text { A } & \text { A } \\ \text { Benzo(b)fluoranthene } & \text { A } & \text { B } & \text { A } & \text { A } & \text { A } & \text { A } & \text { A } \\ \text { Benzo(g,h,i)perylene } & \text { A } & \text { B } & \text { C } & \text { A } & \text { A } & \text { A } & \text { A } \\ \text { Benzo(k)fluoranthene } & \text { A } & \text { B } & \text { A } & \text { A } & \text { A } & \text { A } & \text { A }\end{array}$


Table 5.1 (continued)

\begin{tabular}{|c|c|c|c|c|c|c|c|}
\hline & \multicolumn{7}{|c|}{ Parameters $^{b}$} \\
\hline & Total & Repr. & Sens. & Prec. & Accu. & Cmpl. & Cmpa. \\
\hline Benzoic acid & A & B & $A$ & A & A & A & A \\
\hline Benzyl alcohol & $\mathbf{A}$ & B & A & A & A & A & A \\
\hline Bis(2-chloroethoxy)methane & A & B & A & A & A & A & A \\
\hline Bis(2-chloroethyl)ether & A & B & A & A & $A$ & $A$ & A \\
\hline Bis(2-ethylhexyl)phthalate & A & $\mathrm{B}$ & A & A & A & $A$ & A \\
\hline Chrysene & A & $\mathrm{B}$ & A & $A$ & A & A & A \\
\hline Di-n-butylphthalate & A & B & A & A & A & $A$ & $A$ \\
\hline Di-n-octylphthalate & A & B & $A$ & A & A & $A$ & A \\
\hline Dibenz(a,h)anthracene & A & B & $\mathrm{C}$ & A & A & A & A \\
\hline Dibenzofuran & A & B & A & A & A & A & A \\
\hline Diethylphthalate & A & B & A & $A$ & A & A & $\mathbf{A}$ \\
\hline Dimethylphthalate & A & B & A & A & A & A & A \\
\hline Fluoranthene & A & B & $\mathrm{C}$ & A & A & A & A \\
\hline Fluorene & A & B & $\mathrm{C}$ & A & A & A & A \\
\hline Hexachlorobenzene & A & $\mathrm{B}$ & A & A & A & A & A \\
\hline Hexachlorobutadiene & A & B & $\mathbf{A}$ & A & A & A & A \\
\hline Hexachlorocyclopentadiene & A & B & A & A & A & A & A \\
\hline Hexachloroethane & A & B & A & $A$ & A & A & A \\
\hline Indeno(1,2,3-cd)pyrene & A & B & A & A & A & A & A \\
\hline Isophorone & A & B & A & A & A & A & A \\
\hline Methoxychlor & $\mathbf{A}$ & B & A & A & A & A & A \\
\hline N-nitroso-di-n-propylamine & A & B & $\mathrm{C}$ & A & A & A & $\mathbf{A}$ \\
\hline $\mathrm{N}$-nitrosodiphenylamine & A & B & A & A & A & A & A \\
\hline Naphthalene & A & B & A & A & $\mathbf{A}$ & A & A \\
\hline Nitrobenzene & $\mathbf{A}$ & B & A & A & A & $\mathbf{A}$ & A \\
\hline Pentachlorophenol & A & B & $A$ & A & A & $A$ & A \\
\hline Phenanthrene & $\mathbf{A}$ & $\mathrm{B}$ & C & A & A & A & A \\
\hline Phenol & A & B & A & A & A & A & A \\
\hline Pyrene & $\mathbf{A}$ & B & $\mathrm{C}$ & A & A & A & A \\
\hline 1,2-dichlorobenzene & A & B & A & A & A & A & A \\
\hline
\end{tabular}


Table 5.1 (continued)

\begin{tabular}{|c|c|c|c|c|c|c|c|}
\hline & & & & rameter & & & \\
\hline & Total & Repr. & Sens. & Prec. & Accu. & Cmpl. & Cmpa. \\
\hline 1,2,4-trichlorobenzene & A & B & A & A & A & A & A \\
\hline 1,3-dichlorobenzene & A & B & A & A & $\mathbf{A}$ & A & A \\
\hline 1,4-dichlorobenzene & A & B & A & A & $\mathbf{A}$ & A & A \\
\hline 2-chloronaphthalene & A & B & $\mathbf{A}$ & $\mathbf{A}$ & $\mathbf{A}$ & $\mathbf{A}$ & A \\
\hline 2-chlorophenol & A & B & $\mathbf{A}$ & A & A & A & A \\
\hline 2-methylnaphthalene & A & B & $\mathbf{A}$ & $\mathbf{A}$ & A & A & A \\
\hline 2-methylphenol & A & B & A & A & A & A & A \\
\hline 2-nitroaniline & A & B & $\mathbf{A}$ & A & A & A & A \\
\hline 2-nitrophenol & $\mathbf{A}$ & B & A & A & A & A & A \\
\hline 2,4-dichlorophenol & A & B & A & A & $\mathbf{A}$ & A & A \\
\hline 2,4-dimethylphenol & $\mathbf{A}$ & B & $\mathbf{A}$ & A & $\mathbf{A}$ & A & A \\
\hline 2,4-dinitrophenol & $\mathbf{A}$ & B & $\mathbf{A}$ & $\mathbf{A}$ & $\mathbf{A}$ & $\mathbf{A}$ & A \\
\hline 2,4-dinitrotoluene & A & B & $\mathbf{A}$ & A & A & A & A \\
\hline 2,4,5-trichlorophenol & $\mathbf{A}$ & B & A & $\mathbf{A}$ & A & $\mathbf{A}$ & $\mathbf{A}$ \\
\hline 2,4,6-trichlorophenol & $\mathbf{A}$ & B & $\mathbf{A}$ & A & $\mathbf{A}$ & A & $\mathbf{A}$ \\
\hline 2,6-dinitrotoluene & $\mathbf{A}$ & B & $\mathbf{A}$ & $\mathbf{A}$ & $\mathbf{A}$ & A & $\mathbf{A}$ \\
\hline 3-nitroaniline & $\mathbf{A}$ & B & A & A & A & $\mathbf{A}$ & $\mathbf{A}$ \\
\hline 3,3'-dichlorobenzidine & $\mathbf{A}$ & B & $\mathbf{A}$ & A & $\mathbf{A}$ & $\mathbf{A}$ & A \\
\hline 4-bromophenyl-phenylether & A & B & $\mathbf{A}$ & A & $\mathbf{A}$ & A & $\mathbf{A}$ \\
\hline 4-chloro-3-methylphenol & $\mathbf{A}$ & B & $\mathbf{A}$ & $\mathbf{A}$ & $\mathbf{A}$ & $\mathbf{A}$ & A \\
\hline 4-chloroaniline & $\mathbf{A}$ & B & $\mathbf{A}$ & $\mathbf{A}$ & A & A & A \\
\hline 4-chlorophenyl-phenylether & $\mathbf{A}$ & B & $\mathbf{A}$ & $\mathbf{A}$ & $\mathbf{A}$ & $\mathbf{A}$ & A \\
\hline 4-methylphenol & $\mathbf{A}$ & B & $\mathbf{A}$ & $\mathbf{A}$ & A & $\mathbf{A}$ & $\mathbf{A}$ \\
\hline 4-nitroaniline & $\mathbf{A}$ & B & $\mathbf{A}$ & $\mathbf{A}$ & $\mathbf{A}$ & $\mathbf{A}$ & $\mathbf{A}$ \\
\hline 4-nitrophenol & $\mathbf{A}$ & B & $\mathbf{A}$ & $\mathbf{A}$ & $\mathbf{A}$ & $\mathbf{A}$ & $\mathbf{A}$ \\
\hline 4,6-dinitro-2-methylphenol & A & B & C & $\mathbf{A}$ & $\mathbf{A}$ & $\mathbf{A}$ & A \\
\hline
\end{tabular}


Table 5.1 (continucd)

\begin{tabular}{lccccccc}
\hline \multicolumn{7}{c}{ Parameters $^{b}$} \\
\cline { 2 - 7 } & Total & Repr. & Sens. & Prec. & Accu. & Cmpl. & Cmpa. \\
\hline & Radionuclides & & & & & \\
${ }^{60} \mathrm{Co}$ & A & B & A & A & A & A & A \\
${ }^{137} \mathrm{Cs}$ & A & B & A & A & A & A & A \\
${ }^{3} \mathrm{H}$ & A & B & A & A & A & C & C \\
${ }^{90} \mathrm{Sr}$ & A & B & A & A & A & A & A \\
\hline
\end{tabular}

Grades: A, $>90 \%$ acceptable (very adequate); B, 70 to $90 \%$ acceptable (mostly adequate with some deficiencies); $\mathrm{C},<70 \%$ acceptable (inadequate)

${ }^{b}$ Repr. $=$ representativeness, Sens. $=$ sensibility, Prec. $=$ precision, Accu. $=$ accuracy, Cmpl. $=$ completeness, Cmpa. $=$ comparability . 
times. Tritium results were rejected because of improper preservation. Because of lead contamination in rinse blanks, contamination from sources other than the sample matrix may be responsible for dissolved lead at PCK 9.6 (Reach 13) and total lead at PCK 7.6 (Reach 3). Values for dissolved inorganic contaminants from site CRM 50.5 are considered suspicious because of blank contamination. Analytes detected in both blank and regular samples did not consist of contaminants of concern for Phase 1 of the CRRI (Energy Systems 1990) and, therefore, should not affect risk assessment calculations.

\subsubsection{Sensitivity}

All nondetect results from the CRRI Phase I, which represent DLs for the particular analysis, were compared to the DLs for the analysis methods used. For the purpose of this discussion, use of the term "acceptable performance" indicates the mean analysis DL is equal to or less than the method-prescribed DL. The inorganic and organic analyses generally exhibited acceptable performance.

The DL associated with each measurement is used as the quantitative measure of sensitivity. The CRRI plan (Energy Systems 1990) defined Phase 1 sensitivity requirements as those DLs specified in the requested analytical method. The adequacy of the analytical DLs was assessed by estimating the risk posed to human health based on a nonconservative screening of the nondetected contaminants. This approach identified 13 carcinogens and one noncarcinogen for which lower analytical DLs are needed to provide DLs for these compounds that do not produce screening indexes of $>10^{-4}$ for carcinogens or $>1.0$ for noncarcinogens. All the carcinogens identified are either polycyclic aromatic hydrocarbons or nitrosamines. Table 5.1 does not list two-benzidine and N-nitrosodimethylamine-because they are usually tentatively identified compounds. The noncarcinogen identified was $4,6-$ dinitro-2-methylphenol. The findings for all 13 compounds identified resulted from the fish and water exposure pathways. These 13 compounds should be compared to records of releases from the ORR so that those compounds not released from the ORR can be eliminated from consideration. Appropriate analytical methods may then be sought that can achieve the desired sensitivity.

\subsubsection{Precision}

Precision was evaluated through the use of field and laboratory duplicates. Acceptable RSD results for calcium, magnesium, potassium, and sodium indicate that the sample collection method had acceptable precision. However, precision was unacceptable for dissolved cadmium and lead at CRM 1, bis(2-ethylhexyl)phthalate at TRM 531, dissolved iron and total lead at TRM 547, dissolved lead at CRM 0.5, and dissolved iron and dissolved zinc at CRM 43. Overall, for inorganics, the CLP objectives for analytical precision of less than $20 \%$ RPD on samples with concentrations greater than five times the CRDL have been met. For organics, no water laboratory duplicates were performed.

\subsubsection{Accuracy}

Accuracy was assessed by reviewing the results of LCSs, performance evaluation samples, matrix spikes, and surrogate spikes. Because of a baseline shift causing negative values, iron results for samples $1422 \mathrm{M}, 1432 \mathrm{M}, 1442 \mathrm{M}, 145 \mathrm{M}, 1452 \mathrm{M}, 146 \mathrm{M}$, and $147 \mathrm{M}$ were rejected. The effect of these rejections was that only one result was available for iron for Reach 13. Overall, for inorganics analyzed by AA and ICP, the CLP objectives for bias of $<25 \%$ have 
been met. For organics, five of the six surrogates indicate good accuracy ( $\geq 97 \%$ recovery) for the CLP method. Recoveries for pesticide surrogates and matrix spike compounds, as well as calibrations, indicate that accuracy was acceptable.

\subsubsection{Completeness}

The completeness objective of $95 \%$ was obtained for metals, SVOs, and gammaspectrometric analyses; $50 \%$ of the alpha and beta analyses was rejected because of the tritium preservation problem discussed in Sect. 5.1.1. Results for one third of the samples for $\mathrm{PCB} /$ pesticide analyses were not reported from the analytical laboratory.

\subsubsection{Comparability}

Comparability is ensured by the use of like methods for sampling and analysis. All analytical methods used in the analyses of water samples for inorganic and semivolatile compounds were approved by EPA. However, a modified version of the CLP method for analysis of pesticides and PCBs was used that did not verify results by second column confirmation.

\subsubsection{Risk Assessment}

Results of the screening of the surface water data are inconclusive for human health risk because of the limited number of Phase 1 samples and the uncertainty associated with using the source monitoring data to predict the concentrations of the contaminants in the different reaches. Additionally, since no PCB/pesticide results are reported for the Poplar Creek K-25 site area, risk evaluations for these contaminants could not be completed for Reach 3.

One potential impact to the human health risk assessment due to the unacceptable representativeness of the available water data is an inaccurate approximation of contaminant concentrations that could lead to either overestimated or underestimated risk and hazard estimates. As a result, the level of uncertainty associated with these calculations is increased.

\subsection{DATA ASSESSMENT OF SEDIMENT RESULTS}

The overall data assessment for the sediment results is presented in Tables 5.2 and 5.3. All gamma-emitting radionuclide analyses for both sediment grab and core samples were judged to be very adequate. Organic and inorganic analyses of sediment grabs were judged to be inadequate, and further sampling and analysis is warranted. Inorganic analyses of sediment core samples were judged to be adequate except for arsenic, chromium, copper, lead, nickel, mercury, selenium, and zinc, which were determined to be inadequate because of excessive DLs. Organic data from sediment cores were judged to be adequate for risk screening analysis. However, because of high DLs and the number of rejected samples, additional sampling is warranted. Alpha-emitting radionuclide data were judged to be adequate; the only limitation is that there is no measure of field precision. Only one reference site sample was collected, which prevents statistically valid comparisons to be made with affected sites. This limits the value of the entire sediment data base. 
Table 5.2 Overall assessment of sediment core data collected during Phase 1

\begin{tabular}{|c|c|c|c|c|c|c|c|}
\hline & \multicolumn{7}{|c|}{ Parameters $\mathrm{a}$} \\
\hline & Total & Repr. & Sens. & Prec. & Accu. & Cmpl. & Cmpa. \\
\hline \multicolumn{8}{|c|}{ Inorganics } \\
\hline Antimony & B & $\mathrm{C}$ & $\mathbf{A}$ & B & C & $\mathrm{C}$ & A \\
\hline Arsenic & C & A & $\mathrm{C}$ & B & $\mathrm{B}$ & $\mathbf{A}$ & A \\
\hline Beryllium & A & A & A & B & A & A & A \\
\hline Cadmium & A & A & A & B & B & A & A \\
\hline Chromium & C & A & C & B & B & A & A \\
\hline Copper & C & $\mathbf{A}$ & C & B & B & A & $\mathbf{A}$ \\
\hline Lead & C & $\mathbf{A}$ & $\mathrm{C}$ & B & B & A & A \\
\hline Nickel & C & A & C & B & A & A & A \\
\hline Mercury & $\mathrm{C}$ & A & $\mathrm{C}$ & B & C & C & $\mathbf{A}$ \\
\hline Selenium & B & $\mathrm{C}$ & A & B & B & $\mathbf{A}$ & A \\
\hline Silver & B & $\mathbf{A}$ & A & B & $\mathrm{C}$ & C & A \\
\hline Thallium & B & C & B & B & $\mathbf{A}$ & A & A \\
\hline Zinc & C & $\mathbf{A}$ & $\mathrm{C}$ & B & B & A & A \\
\hline \multicolumn{8}{|c|}{ Organics-Pesticides/PCBs } \\
\hline Aldrin & B & $\mathbf{B}$ & A & B & $\mathbf{A}$ & B & A \\
\hline Alpha-BHC & B & B & A & B & A & B & $\mathbf{A}$ \\
\hline Alpha-chlordane & B & B & A & B & A & B & $\mathbf{A}$ \\
\hline Aroclor-1016 & B & B & $\mathbf{A}$ & B & A & B & A \\
\hline Aroclor-1221 & B & B & $\mathbf{A}$ & B & $\mathbf{A}$ & B & $\mathbf{A}$ \\
\hline Aroclor-1232 & B & B & A & B & A & B & A \\
\hline Aroclor-1242 & B & B & $\mathbf{A}$ & B & A & B & A \\
\hline Aroclor- 1248 & B & B & A & B & A & B & A \\
\hline Aroclor-1254 & $\mathbf{A}$ & $\mathbf{A}$ & $\mathbf{A}$ & B & $\mathbf{A}$ & $\mathbf{A}$ & $\mathbf{A}$ \\
\hline Aroclor -1260 & $\mathbf{A}$ & $\mathbf{A}$ & $\mathbf{A}$ & B & $\mathbf{A}$ & $\mathbf{A}$ & $\mathbf{A}$ \\
\hline Beta-BHC & $\mathbf{B}$ & $\mathbf{B}$ & $\mathbf{A}$ & B & $\mathbf{A}$ & B & $\mathbf{A}$ \\
\hline Delta-BHC & $\mathbf{B}$ & B & $\mathbf{A}$ & B & $\mathbf{A}$ & B & $\mathbf{A}$ \\
\hline Dieldrin & $\mathbf{A}$ & $\mathbf{A}$ & $\mathbf{A}$ & B & $\mathbf{A}$ & $\mathbf{A}$ & $\mathbf{A}$ \\
\hline Endosulfan I & $\mathbf{B}$ & B & $\mathbf{A}$ & $\mathbf{B}$ & $\mathbf{A}$ & B & A \\
\hline Endosulfan II & $\mathbf{A}$ & $\mathbf{A}$ & $\mathbf{A}$ & B & $\mathbf{A}$ & $\mathbf{A}$ & $\mathbf{A}$ \\
\hline Endosulfan sulfate & $\mathbf{A}$ & $\mathbf{A}$ & $\mathbf{A}$ & B & $\mathbf{A}$ & $\mathbf{A}$ & $\mathbf{A}$ \\
\hline Endrin & $\mathbf{A}$ & $\mathbf{A}$ & $\mathbf{A}$ & B & $\mathbf{A}$ & $\mathbf{A}$ & $\mathbf{A}$ \\
\hline Endrin ketone & $\mathbf{A}$ & $\mathbf{A}$ & $\mathbf{A}$ & B & $\mathbf{A}$ & $\mathbf{A}$ & $\mathbf{A}$ \\
\hline Gamma-BHC (Lindane) & B & $\mathbf{B}$ & $\mathbf{A}$ & B & $\mathbf{A}$ & B & A \\
\hline Gamma-chlordane & $\mathbf{B}$ & B & $\mathbf{A}$ & B & $\mathbf{A}$ & B & $\mathbf{A}$ \\
\hline Heptachlor & B & B & $\mathbf{A}$ & B & $\mathbf{A}$ & B & $\mathbf{A}$ \\
\hline Heptachlor epoxide & B & B & $\mathbf{A}$ & B & $\mathbf{A}$ & B & $\mathbf{A}$ \\
\hline Toxaphene & $\mathbf{A}$ & $\mathbf{A}$ & $\mathbf{A}$ & B & $\mathbf{A}$ & A & $\mathbf{A}$ \\
\hline
\end{tabular}


Table 5.2 (Continued)

\begin{tabular}{|c|c|c|c|c|c|c|c|}
\hline & \multicolumn{7}{|c|}{ Parameters $\underline{\mathrm{a}}$} \\
\hline & Total & Repr. & Sens. & Prec. & Accu. & Cmpl. & Cmpa. \\
\hline 4,4'-DDD & A & A & A & $\mathrm{B}$ & $\mathrm{A}$ & $\bar{A}$ & $\bar{A}$ \\
\hline 4,4'-DDE & A & A & A & B & A & A & A \\
\hline 4,4'-DDT & A & A & $\mathbf{A}$ & B & A & A & A \\
\hline \multicolumn{8}{|c|}{ Organics-Semivolatiles } \\
\hline Acenaphthene & A & $\mathbf{A}$ & A & B & A & A & A \\
\hline Acenaphthylene & A & A & $\mathbf{A}$ & B & A & A & A \\
\hline Anthracene & $\mathbf{A}$ & A & $\mathbf{A}$ & B & $\mathbf{A}$ & A & A \\
\hline Benzo(a)anthracene & A & A & A & $\mathrm{B}$ & A & A & A \\
\hline Benzo(a)pyrene & A & A & A & B & A & A & A \\
\hline Benzo(b)fluoranthene & A & A & A & B & $\mathbf{A}$ & A & $\mathbf{A}$ \\
\hline Benzo(g,h,i)pyrylene & A & $\mathbf{A}$ & A & B & A & A & $\dot{A}$ \\
\hline Benzo(k)fluoranthene & A & A & $\mathbf{A}$ & B & A & $\mathbf{A}$ & A \\
\hline Benzoic acid & $\mathbf{A}$ & A & A & B & A & A & $A$ \\
\hline Benzyl alcohol & A & A & A & B & $\mathbf{A}$ & A & A \\
\hline Bis(2-chloroethoxy)methane & $\mathbf{A}$ & A & $\mathbf{A}$ & B & A & $A$ & A \\
\hline Bis(2-chloroethyl)ether & A & $\mathbf{A}$ & $\mathbf{A}$ & B & A & A & A \\
\hline Bis(2-ethylhexyl)phthalate & $\mathbf{A}$ & A & A & B & A & A & $\mathbf{A}$ \\
\hline Chrysene & $\mathbf{A}$ & $\mathbf{A}$ & A & B & A & A & A \\
\hline Di-n-butylphthalate & $\mathbf{A}$ & $\mathbf{A}$ & $\mathbf{A}$ & B & $\mathbf{A}$ & $\mathbf{A}$ & $\mathbf{A}$ \\
\hline Di-n-octyphthalate & $\mathbf{A}$ & A & $\mathbf{A}$ & B & A & A & A \\
\hline Dibenz(a,h)anthracene & $\mathbf{A}$ & $\mathbf{A}$ & $\mathbf{A}$ & B & $\mathbf{A}$ & A & A \\
\hline Dibenzofuran & $\mathbf{A}$ & $\mathbf{A}$ & $\mathbf{A}$ & B & $\mathbf{A}$ & $\mathbf{A}$ & A \\
\hline Diethylphthalate & $\mathbf{A}$ & $\mathbf{A}$ & $\mathbf{A}$ & B & $\mathbf{A}$ & $\mathbf{A}$ & $\mathbf{A}$ \\
\hline Dimethylphthalate & $\mathbf{A}$ & $\mathbf{A}$ & $\mathbf{A}$ & B & $\mathbf{A}$ & $\mathbf{A}$ & A \\
\hline Fluoranthene & A & $\mathbf{A}$ & $\mathbf{A}$ & B & A & $\mathbf{A}$ & $\mathbf{A}$ \\
\hline Fluorene & A & $\mathbf{A}$ & A & B & $\mathbf{A}$ & $\mathbf{A}$ & $\mathbf{A}$ \\
\hline Hexachlorobenzene & $\mathbf{A}$ & $\mathbf{A}$ & $\mathbf{A}$ & B & $\mathbf{A}$ & $\mathbf{A}$ & $\mathbf{A}$ \\
\hline Hexachlorobutadiene & $\mathbf{A}$ & $\mathbf{A}$ & $\mathbf{A}$ & B & $\mathbf{A}$ & $\mathbf{A}$ & $\mathbf{A}$ \\
\hline Hexachlorocyclopenta-diene & $\mathbf{A}$ & $\mathbf{A}$ & A & B & $\mathbf{A}$ & $\mathbf{A}$ & A \\
\hline Hexachloroethane & $\mathbf{A}$ & $\mathbf{A}$ & $\mathbf{A}$ & B & $\mathbf{A}$ & $\mathbf{A}$ & $\mathbf{A}$ \\
\hline Indeno(1,2,3-cd)pyrene & $\mathbf{A}$ & $\mathbf{A}$ & A & B & $\mathbf{A}$ & $\mathbf{A}$ & $\mathbf{A}$ \\
\hline Isophorone & A & $\mathbf{A}$ & $\mathbf{A}$ & B & $\mathbf{A}$ & $\mathbf{A}$ & A \\
\hline Methoxychior & $\mathbf{A}$ & $\mathbf{A}$ & $\mathbf{A}$ & B & A & A & $\mathbf{A}$ \\
\hline N-nitro-di-n-propylamine & $\mathbf{A}$ & $\mathbf{A}$ & $\mathbf{A}$ & B & $\mathbf{A}$ & A & A \\
\hline N-nitrosodiphenylamine & $\mathbf{A}$ & $\mathbf{A}$ & A & B & $\mathbf{A}$ & A & $\mathbf{A}$ \\
\hline Napthalene & $\mathbf{A}$ & $\dot{A}$ & $\mathbf{A}$ & B & A & A & $\mathbf{A}$ \\
\hline Nitrobenzene & $\mathbf{A}$ & $\mathbf{A}$ & $\mathbf{A}$ & B & A & A & A \\
\hline Pentachlorophenol & $\mathbf{A}$ & $\mathbf{A}$ & $\mathbf{A}$ & B & $\mathbf{A}$ & $\mathbf{A}$ & A \\
\hline
\end{tabular}


Table 5.2 (Continued)

\begin{tabular}{|c|c|c|c|c|c|c|c|}
\hline & \multicolumn{7}{|c|}{ Parameters ${ }^{\mathrm{a}}$} \\
\hline & Total & Repr. & Sens. & Prec. & Accu. & Cmpl. & Cmpa. \\
\hline Phenanthrene & A & A & A & B & $\mathbf{A}$ & A & $\mathrm{A}$ \\
\hline Phenol & A & A & A & B & A & A & A \\
\hline Pyrene & A & $\mathbf{A}$ & A & B & $\mathbf{A}$ & A & A \\
\hline 1,2-dichlorobenzene & A & A & A & B & $\mathbf{A}$ & A & A \\
\hline 1,2,4-trichlorobenzed & A & $\mathbf{A}$ & A & B & A & $\mathbf{A}$ & A \\
\hline 1,3-dichlorobenzene & $\mathbf{A}$ & $\mathbf{A}$ & $\mathbf{A}$ & B & A & $\mathbf{A}$ & A \\
\hline 1,4-dichlorobenzene & A & A & $\mathbf{A}$ & B & A & $\mathbf{A}$ & A \\
\hline 2-chloronaphthalene & A & $\mathbf{A}$ & $\mathbf{A}$ & B & $\mathbf{A}$ & A & $\mathbf{A}$ \\
\hline 2-chlorophenol & A & A & $\mathbf{A}$ & B & A & A & A \\
\hline 2-methylnaphthalene & A & A & A & B & A & A & $\mathbf{A}$ \\
\hline 2-methylphenol & A & A & A & B & $\mathbf{A}$ & $\mathbf{A}$ & A \\
\hline 2-nitroanilene & $\mathbf{A}$ & A & A & B & A & A & A \\
\hline 2-nitrophenol & A & A & $\mathbf{A}$ & B & $\mathbf{A}$ & $\mathbf{A}$ & A \\
\hline 2,4-dichlorophenol & $\mathbf{A}$ & $\mathbf{A}$ & $\mathbf{A}$ & B & $\mathbf{A}$ & $\mathbf{A}$ & A \\
\hline 2,4-dimethylphenol & A & $\mathbf{A}$ & $\mathbf{A}$ & B & $\mathbf{A}$ & $\mathbf{A}$ & $\mathbf{A}$ \\
\hline 2,4-dinitrophenol & $\mathbf{A}$ & $\mathbf{A}$ & $\mathbf{A}$ & B & $\mathbf{A}$ & B & A \\
\hline 2,4-dinitrotoluene & $\mathbf{A}$ & $\mathbf{A}$ & $\mathbf{A}$ & B & $\mathbf{A}$ & $\mathbf{A}$ & A \\
\hline 2,4,5-trichlorophenol & $\mathbf{A}$ & A & A & B & $\mathbf{A}$ & A & $\mathbf{A}$ \\
\hline 2,4,6-trichlorophenol & $\mathbf{A}$ & $\mathbf{A}$ & A & B & $\mathbf{A}$ & $\mathbf{A}$ & $\mathbf{A}$ \\
\hline 2,6-dinitrotoluene & $\mathbf{A}$ & $\mathbf{A}$ & $\mathbf{A}$ & B & $\mathbf{A}$ & $\mathbf{A}$ & $\mathbf{A}$ \\
\hline 3-nitroaniline & $\mathbf{A}$ & $\mathbf{A}$ & $\mathbf{A}$ & B & $\mathbf{A}$ & $\mathbf{A}$ & $\mathbf{A}$ \\
\hline 3,3'-dichlororbenzidine & A & A & A & B & $\mathbf{A}$ & A & A \\
\hline 4-bromophenyl-phenylether & $\mathbf{A}$ & $\mathbf{A}$ & $\mathbf{A}$ & B & $\mathbf{A}$ & $\mathbf{A}$ & $\mathbf{A}$ \\
\hline 4-chloro-3-methylphenol & $\mathbf{A}$ & $\mathbf{A}$ & $\mathbf{A}$ & B & $\mathbf{A}$ & $\mathbf{A}$ & A \\
\hline 4-chloroaniline & $\mathbf{A}$ & $\mathbf{A}$ & $\mathbf{A}$ & B & $\mathbf{A}$ & $\mathbf{A}$ & A \\
\hline 4-chlorophenyl-phenylether & $\mathbf{A}$ & $\mathbf{A}$ & $\mathbf{A}$ & $\mathbf{B}$ & $\mathbf{A}$ & $\mathbf{A}$ & A \\
\hline 4-methylphenol & $\mathbf{A}$ & $\mathbf{A}$ & $\mathbf{A}$ & B & A & A & A \\
\hline 4-nitroaniline & $\mathbf{A}$ & $\mathbf{A}$ & $\mathbf{A}$ & B & $\mathbf{A}$ & $\mathbf{A}$ & A \\
\hline 4-nitrophenol & A & $\mathbf{A}$ & A & B & A & $\mathbf{A}$ & $\mathbf{A}$ \\
\hline 4,6-dinitro-2-methylphenol & $\mathbf{A}$ & $\mathbf{A}$ & A & B & $\mathbf{A}$ & A & A \\
\hline \multicolumn{8}{|c|}{$\underline{\text { Radionuclides }}$} \\
\hline${ }^{241}$ Am & $\mathbf{A}$ & $\mathbf{A}$ & $\mathbf{A}$ & B & $\mathbf{A}$ & $\mathbf{A}$ & $\mathbf{A}$ \\
\hline $243,244 \mathrm{Cm}$ & C & C & $\mathrm{C}$ & C & C & $\mathbf{A}$ & $\mathbf{A}$ \\
\hline $245,246 \mathrm{Cm}$ & $\mathbf{C}$ & C & C & C & C & A & A \\
\hline${ }^{248} \mathrm{Cm}$ & $\mathbf{C}$ & C & C & C & C & $\mathbf{A}$ & $\mathbf{A}$ \\
\hline${ }^{60} \mathrm{Co}$ & $\mathbf{A}$ & $\mathbf{A}$ & $\mathbf{A}$ & B & $\mathbf{A}$ & $\mathbf{A}$ & $\mathbf{A}$ \\
\hline${ }^{137} \mathrm{Cs}$ & $\mathbf{A}$ & $\mathbf{A}$ & $\mathbf{A}$ & B & $\mathbf{A}$ & $\mathbf{A}$ & $\mathbf{A}$ \\
\hline${ }^{238} \mathrm{Pu}$ & $\mathbf{A}$ & $\mathbf{A}$ & A & B & $\mathbf{A}$ & $\mathbf{A}$ & $\mathbf{A}$ \\
\hline
\end{tabular}


Table 5.2 (Continued)

\begin{tabular}{|c|c|c|c|c|c|c|c|}
\hline & \multicolumn{7}{|c|}{ Parameters $\underline{\text { a }}$} \\
\hline & Total & Repr. & Sens. & Prec. & Accu. & Cmpl. & Cmpa. \\
\hline $239,240 \mathrm{Pu}$ & $\bar{A}$ & A & A & B & $\bar{A}$ & $\mathrm{~A}$ & $\bar{A}$ \\
\hline${ }^{90} \mathrm{Sr}$ & A & A & A & B & A & A & A \\
\hline${ }^{234} U$ & A & A & A & B & A & A & A \\
\hline${ }^{235_{U}}$ & A & A & A & B & A & A & A \\
\hline${ }^{238} \mathrm{U}$ & A & $\mathbf{A}$ & A & B & A & A & A \\
\hline
\end{tabular}

Table 5.3. Overall assessment of sediment grab data collected during Phase 2

\begin{tabular}{|c|c|c|c|c|c|c|c|}
\hline & \multicolumn{7}{|c|}{ Parameters $\stackrel{\mathrm{a}}{ }$} \\
\hline & Total & Repr. & Sens. & Prec. & Accu. & Cmpl. & Cmpa. \\
\hline${ }^{60} \mathrm{Co}$ & A & A & B & A & A & A & A \\
\hline${ }^{137} \mathrm{Cs}$ & $\mathbf{A}$ & A & A & A & A & A & A \\
\hline
\end{tabular}




\subsubsection{Representativeness}

Sediment samples were intentionally biased toward areas of known or suspected deposition areas. These sites included deep-channel areas of Watts Bar Reservoir and the Clinch River arm of the reservoir and Poplar Creek. Therefore, results from the Phase 1 sediment sampling do not represent the average reservoir conditions but do represent the higher levels found in reservoir sediment. Additionally, near-shore sediment grabs were collected to characterize sediment contamination in the shallow-water, near-shore areas. Although some grabs were taken in deep water, the majority of near-shore samples collected are representative of the near-shore sediment conditions in the reservoir.

Most of the PCB/pesticide data from the sediment core from Norris Reservoir (18000) were rejected. Because there is only one reference site sample, there are no background/ reference concentrations with which to compare. This is a critical failure of the Phase 1 sampling and analysis that must be accounted for during the first part of Phase 2 . The same PCBs/pesticides were rejected from one core from lower Watts Bar Reservoir (30000). However, because data from two other cores in this reach were collected, the overall utility of the data is still adequate. Data for 2,4-dinitrophenol, 2-methylphenol, and benzyl alcohol from CRM 9.5 in Reach 4 were rejected. Because this area is the focus of additional sampling and analysis, the loss of these data is not significant.

Measures used to ensure representativeness include field blanks, field rinsates, trip blanks, analytical method blanks, proper preservation, standard analytical methods, and adherence to holding times. Samples $14420,19090,19120,19150,31070,33030,31110$, $31120,73040,73050,73060$, and 73070 were rejected for a large number of analytes because of exceeded holding times. All of the samples except 14420 were from the homogenized reference cores used to check laboratory analytical consistency over time. Rejection of these samples does not affect the quality of the overall data.

\subsection{Sensitivity}

The inorganic analyses exhibited acceptable performance. The organic analyses mean DLs were greater than the method DLs for the semivolatile compounds by a factor of 4 . The analyses mean DLs were greater than the method DLs for many of the pesticide/PCB compounds by a factor of $\sim 40$. A major contributing factor to the elevated pesticide/PCB DLs was the presence of interference peaks in the chromatograms which required dilution analysis for most of those samples. These interferences may be due to lab contamination and/or matrix effects. One possible corrective measure for the elevated DLs for organic analysis in sediment samples is the use of a modified preparation procedure for these samples to remove the interfering compounds.

\subsubsection{Precision}

Precision was evaluated by laboratory duplicates. No field duplicates were collected, and consequently precision of field methods alone could not be evaluated. However field splits were collected and analyzed, which provides a measure of precision that includes both field and laboratory variability. Results from the field splits for inorganics, organics, and gammaemitting radionuclides were all acceptable except for some pesticides in core 71000. No field splits were collected for alpha-emitting radionuclides; therefore, no evaluation of field precision could be made. Because all the organic contaminants were below the DLs, no evaluation of RPD was performed. Average RPDs for the inorganics and gamma-emitting 
radionuclides were within the $35 \%$ field duplicate criteria, except for selenium. Overall, for inorganics, the CLP objectives for analytical precision have been met, except for aluminum, chromium, copper, magnesium, manganese, and zinc. Overall, for organics, the CLP objectives for analytical precision were met more than $85 \%$ of the time. The average level of precision for the sediment pesticide laboratory duplicates was $15 \%$ despite matrix interference problems. According to the LCS and performance evaluation sample results, at least $95 \%$ of the radiological data were of acceptable precision.

\subsubsection{Accuracy}

To assess accuracy during the CRRI site characterization, LCSs, performance evaluation samples, matrix spikes, and surrogate spikes were evaluated. Overall, for inorganics analyzed by AA and ICP, the CLP objectives for bias of $<25 \%$ have been met for arsenic, lead, thallium, beryllium, cadmium, and nickel. Chromium, copper, zinc, antimony, mercury, selenium, and silver results may be biased because of spike recoveries that did not meet the CLP requirements. For organics, all of the six semivolatile surrogates indicate good accuracy ( $297 \%$ recovery) for the CLP method. The matrix spike compounds averaged $82-95 \%$ recovery. Calibration difficulties affected quantitation of 2,4-dinitrophenol, 4-nitrophenol, benzyl alcohol, 2-methylphenol, 4-ethylphenol, 2,4,6-trichlorophenol, and 2,4,5-trichlorophenol for a few of the samples. Surrogate recoveries for the pesticide analyses indicate possible positive bias because of interferences. According to the LCS and performance evaluation sample results, at least $95 \%$ of the radiological data were of acceptable accuracy.

\section{Completeness}

The completeness objective of $95 \%$ was obtained for core samples analyzed for semivolatile and radiological analyses. Approximately $92 \%$ of the pesticide/PCB samples were completed. Because a large number of these rejected data was from the reference cores that were homogenized and submitted over time, the actual number of rejected samples is higher than expected. Eliminating these samples from the data set would raise the percent completeness for PCB/pesticides above 95\%. Eighty-eight percent of the inorganics were completed. Incompleteness resulted from rejection of antimony, mercury, selenium, and silver results because of inadequate spike recoveries and analysis interferences. Less than five grab samples were analyzed for pesticides/PCBs and semivolatiles, and all were rejected because of exceeded holding times. All of the grab radiological analyses met the completeness objective.

The total number of sediment cores collected equaled the number planned. However, several sites were changed during the implementation of Phase 1 sampling. No sediment cores were collected at Poplar Creek mile 1.4 (PCK 2.2), which is at the K-1007B holding pond outfall, or Poplar Creek at the confluence of East Fork Poplar Creek (PCK 8.9); although an attempt was made, no sediment was present. Additionally, no sediment samples were collected from Fort Loudon Reservoir. Sediment cores and surface grabs were collected in Grassy Creek embayment (CRM 14.5), middle Melton Hill Reservoir in Walker Branch embayment (CRM 33), and upper Melton Hill Reservoir at the Solway Bridge (CRM 44.1).

\subsubsection{Comparability}

Comparability was ensured by the use of like methods for sampling and analysis. All analytical methods used in the analyses of core and grab samples for inorganic and 
semivolatile compounds were approved by EPA. However, a modified version of the CLP method for analysis of pesticides and PCBs was used for the cores, which did not verify results by second column confirmation.

\subsection{Risk Assessment}

The high percentage of rejected samples for mercury, selenium, and silver is largely due to the lack of completeness (inadequate spike recoveries and analysis interferences) associated with these metals. This deficit could impact the useability of the data, especially since the samples were biased (i.e., critical samples). The majority of the sites having a large number of rejected samples indicated that concentrations of the remaining samples were below the DLs, thus the effect on the risk assessment is not of major concern. A far greater deficiency in the sediment sampling, which would significantly impact the risk assessment, is the lack of background/reference core data and the relatively few numbers of deep core samples. It will be necessary in the baseline risk assessment to differentiate between naturally occurring/anthropogenic levels of constituents and site-related contaminants. With no data or relatively little data, this distinction cannot be made, and it will be assumed that all contaminants included in the baseline risk assessment is site related.

\subsection{DATA ASSESSMENT OF FISH TISSUE RESULTS}

To provide an overall qualitative assessment of the fish tissue analytical results, each analyte (or analyte group) was assigned a letter grade of A, B, or C (Table 5.4).

- All inorganic analyses were given a grade of A, except for lead, which was assigned a B.

- The PCB (ORNL CPA) and the radionuclides data were also graded A.

- The pesticides data met validation requirements and were judged adequate for risk assessment (grade B), but some QC results (e.g., MSRs) were less than desirable. Therefore, further sampling and analysis for pesticides should be considered in Phase 2.

- Although 50\% of the SVO data were usable, the overall objective was compromised, so the SVO data were given a grade of $\mathrm{C}$ and considered inadequate.

The field and laboratory QC assessments used to quantify the overall quality of fish data are summarized below. More detailed discussions of the QC assessment are included in Chaps. 3 and 4.

\subsection{Representativeness}

Because fish are mobile organisms and sometimes travel great distances every effort was made to collect samples that were representative of the location being sampled. The ability to detect gradually decreasing concentrations of mercury and ${ }^{137} \mathrm{Cs}$ from the sites nearest the sources of the contaminants [White Oak Creek (WOC) and East Fork Poplar Creek (EFPC)] to those downstream suggests that our samples were indeed representative of the sites that were sampled (Cook et al. 1992). Ensuring representativeness also included maintaining standard sampling and processing techniques and consistent sample preservation. Standardization was maintained throughout Phase 1 except for the processing of largemouth bass tissue. Bass fillets were skinned, which is contrary to the procedures used by TVA, which 
Table 5.4. Data assessment summary for fish tissue analyses for each of the data quality indicators and in total ${ }^{a}$

\begin{tabular}{|c|c|c|c|c|c|c|c|}
\hline & Total & Repr. & Sens. & Prec. & Accu. & Cmpl. & Cmpa. \\
\hline \multicolumn{8}{|c|}{ Inorganics } \\
\hline Antimony & A & $A$ & A & A & A & A & A \\
\hline Arsenic & A & A & A & A & A & A & A \\
\hline Beryllium & A & A & A & $\mathrm{C}$ & A & A & A \\
\hline Cadmium & $\mathbf{A}$ & A & A & A & A & A & A \\
\hline Chromium & A & A & $\mathbf{A}$ & A & A & A & A \\
\hline Copper & A & A & A & B & A & A & A \\
\hline Lead & B & $\mathbf{A}$ & A & A & B & B & A \\
\hline Nickel & A & A & A & A & A & B & A \\
\hline Mercury & A & A & A & A & A & A & A \\
\hline Selenium & A & A & A & A & A & A & A \\
\hline Silver & A & A & A & A & A & A & A \\
\hline Thallium & A & $\mathbf{A}$ & $\mathbf{A}$ & A & A & A & A \\
\hline Zinc & $\mathbf{A}$ & $\mathbf{A}$ & $\mathbf{A}$ & A & A & $\mathbf{A}$ & $\mathbf{A}$ \\
\hline \multicolumn{8}{|c|}{ Organics-Pesticides/PCBs } \\
\hline Aldrin & B & $\mathbf{A}$ & $\mathbf{A}$ & A & $\mathrm{C}$ & A & B \\
\hline Alpha-chlordane & B & $\mathbf{A}$ & $\mathbf{A}$ & B & $\mathrm{C}$ & A & B \\
\hline Alpha-chlordene & B & $\mathbf{A}$ & A & A & $\mathrm{C}$ & A & B \\
\hline Aroclor-1254 (CPA) ${ }^{b}$ & A & B & $\mathbf{A}$ & B & A & $\mathbf{A}$ & A \\
\hline Aroclor-1254 (OAL) ${ }^{b}$ & B & B & $\mathbf{A}$ & B & C & $\mathbf{A}$ & B \\
\hline Aroclor-1260 (CPA) ${ }^{b}$ & $\mathbf{A}$ & B & $\mathbf{A}$ & B & A & A & A \\
\hline Aroclor-1260 (OAL) $)^{b}$ & B & B & $\mathbf{A}$ & $\mathbf{A}$ & C & $\mathbf{A}$ & B \\
\hline Clordene & B & $\mathbf{A}$ & $\mathbf{A}$ & $\mathbf{A}$ & $\mathrm{C}$ & $\mathbf{A}$ & B \\
\hline Gamma-chlordane & B & $\mathbf{A}$ & $\mathbf{A}$ & A & B & $\mathbf{A}$ & B \\
\hline Gamma-chlordene & B & $\mathbf{A}$ & A & A & C & $\mathbf{A}$ & B \\
\hline Tech chlordane & B & $\mathbf{A}$ & $\mathbf{A}$ & A & $\mathrm{C}$ & A & B \\
\hline Oxychlordane & B & $\mathbf{A}$ & $\mathbf{A}$ & B & C & $\mathbf{A}$ & B \\
\hline 4,4'-DDD & B & $\mathbf{A}$ & $\mathbf{A}$ & A & $\mathrm{C}$ & $\mathbf{A}$ & B \\
\hline 4,4'-DDE & B & $\mathbf{A}$ & $\mathbf{A}$ & B & C & $\mathbf{A}$ & B \\
\hline 4,4'-DDT & B & $\mathbf{A}$ & A & $\mathbf{A}$ & C & $\mathbf{A}$ & $\mathbf{B}$ \\
\hline
\end{tabular}


Table 5.4 (Continued)

\begin{tabular}{|c|c|c|c|c|c|c|c|}
\hline & Total & Repr. & Sens. & Prec. & Accu. & Cmpl. & Cmpa. \\
\hline \multicolumn{8}{|c|}{ Organics-Semivolatiles } \\
\hline Acenaphthene & $\mathrm{C}$ & A & A & $\mathrm{C}$ & $\mathrm{C}$ & $\mathrm{C}$ & B \\
\hline Acenaphthylene & $\mathrm{C}$ & $\mathbf{A}$ & $\mathbf{A}$ & $\mathrm{C}$ & $\mathrm{C}$ & $\mathrm{C}$ & B \\
\hline Anthracene & $\mathrm{C}$ & $\mathbf{A}$ & $\mathbf{A}$ & C & $\mathrm{C}$ & $\mathrm{C}$ & B \\
\hline Benzo(a)anthracene & $\mathrm{C}$ & $\mathbf{A}$ & $\mathbf{A}$ & C & $\mathrm{C}$ & $\mathrm{C}$ & B \\
\hline Benzo(a)pyrene & C & $\mathbf{A}$ & $\mathbf{A}$ & $\mathrm{C}$ & $\mathrm{C}$ & $\mathrm{C}$ & B \\
\hline Benzo(b)fluoranthene & C & $\mathbf{A}$ & $\mathbf{A}$ & $\mathrm{C}$ & $\mathrm{C}$ & $\mathrm{C}$ & B \\
\hline Benzo(g,h,i)pyrylene & C & $\mathbf{A}$ & A & C & $\mathrm{C}$ & $\mathrm{C}$ & B \\
\hline Benzo(k)fluoranthene & $\mathrm{C}$ & A & A & $\mathrm{C}$ & $\mathrm{C}$ & $\mathrm{C}$ & B \\
\hline Benzoic acid & C & A & A & C & $\mathrm{C}$ & $\mathrm{C}$ & B \\
\hline Benzyl alcohol & $\mathrm{C}$ & A & $\mathbf{A}$ & $\mathrm{C}$ & $\mathrm{C}$ & $\mathrm{C}$ & B \\
\hline Bis(2-chloroethoxy)methane & $\mathrm{C}$ & $\mathbf{A}$ & A & C & $\mathrm{C}$ & $\mathrm{C}$ & B \\
\hline Bis(2-chloroethyl)ether & $\mathbf{C}$ & $\mathbf{A}$ & A & C & $\mathrm{C}$ & C & B \\
\hline Bis(2-chloroisopropyl)ether & $\mathbf{C}$ & $\mathbf{A}$ & A & C & $\mathrm{C}$ & $\mathrm{C}$ & B \\
\hline Bis(2-ethylhexyl)phthalate & $\mathbf{C}$ & $\mathbf{A}$ & $\mathbf{A}$ & $\mathbf{C}$ & $\mathrm{C}$ & $\mathrm{C}$ & B \\
\hline Butylbenzylphthalate & $\mathbf{C}$ & $\mathbf{A}$ & $\mathbf{A}$ & $\mathrm{C}$ & $\mathrm{C}$ & $\mathrm{C}$ & B \\
\hline Chrysene & $\mathbf{C}$ & $\mathbf{A}$ & A & C & $\mathrm{C}$ & $\mathrm{C}$ & B \\
\hline Di-n-butylphthalate & C & $\mathbf{A}$ & A & $\mathbf{C}$ & C & C & B \\
\hline Di-n-octyphthalate & C & $\mathbf{A}$ & $\mathbf{A}$ & C & C & C & B \\
\hline Dibenz(a,h)anthracene & $\mathbf{C}$ & $\mathbf{A}$ & A & $\mathbf{C}$ & $\mathrm{C}$ & $\mathbf{C}$ & B \\
\hline Dibenzofuran & C & $\mathbf{A}$ & $\mathbf{A}$ & C & C & C & B \\
\hline Diethylphthalate & C & $\mathbf{A}$ & $\mathbf{A}$ & $\mathrm{C}$ & $\mathrm{C}$ & $\mathrm{C}$ & B \\
\hline Dimethylphthalate & C & $\mathbf{A}$ & $\mathbf{A}$ & C & C & C & B \\
\hline Fluoranthene & C & $\mathbf{A}$ & $\mathbf{A}$ & C & $\mathrm{C}$ & C & B \\
\hline Fluorene & $\mathrm{C}$ & $\mathbf{A}$ & $\mathbf{A}$ & C & C & $\mathbf{C}$ & B \\
\hline Hexachlorobenzene & C & $\mathbf{A}$ & $\mathbf{A}$ & C & C & C & B \\
\hline Hexachlorobutadiene & C & $\mathbf{A}$ & $\mathbf{A}$ & $\mathrm{C}$ & C & $\mathrm{C}$ & B \\
\hline Hexachlorocyclopentadiene & C & $\mathbf{A}$ & $\mathbf{A}$ & C & C & C & B \\
\hline Hexachloroethane & C & $\mathbf{A}$ & $\mathbf{A}$ & C & C & C & B \\
\hline Indeno(1,2,3-cd)pyrene & C & $\mathbf{A}$ & $\mathbf{A}$ & $\mathbf{C}$ & C & C & B \\
\hline Isophorone & C & $\mathbf{A}$ & $\mathbf{A}$ & C & C & C & B \\
\hline
\end{tabular}


Table 5.4 (Continued)

\begin{tabular}{|c|c|c|c|c|c|c|c|}
\hline & Total & Repr. & Sens. & Prec. & Accu. & Cmpl. & Cmpa. \\
\hline N-nitro-di-n-propylamine & $\mathrm{C}$ & A & A & $\mathrm{C}$ & $\mathrm{C}$ & $\mathrm{C}$ & B \\
\hline $\mathrm{N}$-nitrosodiphenylamine & $\mathrm{C}$ & $\mathbf{A}$ & A & $\mathrm{C}$ & $\mathrm{C}$ & $\mathrm{C}$ & B \\
\hline Napthalene & $\mathrm{C}$ & $\mathbf{A}$ & A & $\mathrm{C}$ & $\mathrm{C}$ & C & B \\
\hline Nitrobenzene & C & $\mathbf{A}$ & $\mathbf{A}$ & $\mathrm{C}$ & C & $\mathrm{C}$ & B \\
\hline Pentachlorophenol & C & $\mathbf{A}$ & A & $\mathrm{C}$ & $\mathrm{C}$ & $\mathrm{C}$ & B \\
\hline Phenanthrene & C & $\mathbf{A}$ & $\mathbf{A}$ & $\mathrm{C}$ & C & $\mathrm{C}$ & B \\
\hline Phenol & C & $\mathbf{A}$ & A & $\mathrm{C}$ & C & C & B \\
\hline Pyrene & $\mathrm{C}$ & $\mathbf{A}$ & $\mathbf{A}$ & $\mathrm{C}$ & C & C & B \\
\hline 1,2-dichlorobenzene & C & A & A & C & $\mathrm{C}$ & C & B \\
\hline 1,2,4-trichlorobenzed & $\mathrm{C}$ & $\mathbf{A}$ & $\mathbf{A}$ & $\mathrm{C}$ & C & C & B \\
\hline 1,3-dichlorobenzene & $\mathrm{C}$ & $\mathbf{A}$ & $\mathbf{A}$ & C & $\mathrm{C}$ & C & B \\
\hline 1,4-dichlorobenzen & $\mathrm{C}$ & $\mathbf{A}$ & $\mathbf{A}$ & C & C & C & B \\
\hline 2-chloronaphthalene & $\mathrm{C}$ & $\mathbf{A}$ & $\mathbf{A}$ & C & $\mathrm{C}$ & C & B \\
\hline 2-chlorophenol & $\mathrm{C}$ & $\mathbf{A}$ & $\mathbf{A}$ & $\mathrm{C}$ & $\mathrm{C}$ & $\mathrm{C}$ & B \\
\hline 2-methylnaphthalene & $\mathrm{C}$ & $\mathbf{A}$ & $\mathbf{A}$ & C & $\mathrm{C}$ & C & B \\
\hline 2-methylphenol & C & $\mathbf{A}$ & $\mathbf{A}$ & C & C & C & B \\
\hline 2-nitroanilene & C & $\mathbf{A}$ & $\mathbf{A}$ & C & C & C & B \\
\hline 2-nitrophenol & C & $\mathbf{A}$ & $\mathbf{A}$ & C & C & C & B \\
\hline 2,4-dichlorophenol & C & $\mathbf{A}$ & $\mathbf{A}$ & C & C & C & B \\
\hline 2,4-dimethylphenol & C & $\mathbf{A}$ & $\mathbf{A}$ & $\mathrm{C}$ & $\mathrm{C}$ & $\mathbf{C}$ & B \\
\hline 2,4-dinitrophenol & C & $\mathbf{A}$ & $\mathbf{A}$ & $\mathrm{C}$ & C & C & B \\
\hline 2,4-dinitrotoluene & C & $\mathbf{A}$ & $\mathbf{A}$ & C & C & c & B \\
\hline 2,4,5-trichlorophenol & C & $\mathbf{A}$ & $\mathbf{A}$ & C & C & C & B \\
\hline 2,4,6-trichlorophenol & C & $\mathbf{A}$ & $\mathbf{A}$ & C & C & C & B \\
\hline 2,6-dinitrotoluene & C & $\mathbf{A}$ & $\mathbf{A}$ & C & C & C & B \\
\hline 3-nitroaniline & $\mathbf{C}$ & $\mathbf{A}$ & $\mathbf{A}$ & C & C & C & B \\
\hline 3,3'-dichlororbenzidine & C & $\mathbf{A}$ & $\mathbf{A}$ & C & C & C & B \\
\hline 4-bromophenyl-phenylether & $\mathrm{C}$ & $\mathbf{A}$ & $\mathbf{A}$ & $\mathrm{C}$ & $\mathrm{C}$ & $\mathrm{C}$ & B \\
\hline 4-chloro-3-methylphenol & C & $\mathbf{A}$ & $\mathbf{A}$ & C & C & C & B \\
\hline 4-chloroaniline & C & $\mathbf{A}$ & $\mathbf{A}$ & C & C & C & B \\
\hline 4-chlorophenyl-phenylether & C & $\mathbf{A}$ & $\mathbf{A}$ & C & C & C & B \\
\hline
\end{tabular}


Table 5.4 (Continued)

\begin{tabular}{|c|c|c|c|c|c|c|c|}
\hline & Total & Repr. & Sens. & Prec. & Accu. & Cmpl. & Cmpa. \\
\hline 4-methylphenol & $\mathrm{C}$ & A & A & $\mathrm{C}$ & $\mathrm{C}$ & C & B \\
\hline 4-nitróaniline & $\mathrm{C}$ & $\mathbf{A}$ & $\mathbf{A}$ & $\mathrm{C}$ & $\mathrm{C}$ & $\mathrm{C}$ & B \\
\hline 4-nitrophenol & $\mathrm{C}$ & A & A & $\mathrm{C}$ & $\mathrm{C}$ & $\mathrm{C}$ & B \\
\hline 4,6-dinitro-2-methylphenol & $\mathrm{C}$ & A & $\mathbf{A}$ & $\mathrm{C}$ & C & $\mathrm{C}$ & B \\
\hline \multicolumn{8}{|c|}{$\underline{\text { Radionuclides }}$} \\
\hline${ }^{60} \mathrm{Co}$ & $\mathbf{A}$ & $\mathbf{A}$ & $\mathbf{A}$ & A & $\mathbf{A}$ & A & A \\
\hline${ }^{137} \mathrm{Cs}$ & $\mathbf{A}$ & $\mathbf{A}$ & A & A & A & A & A \\
\hline${ }^{90} \mathrm{Sr}$ & B & A & $\mathbf{A}$ & A & B & B & A \\
\hline
\end{tabular}

${ }^{a}$ Repr. $=$ representativeness, Sens. $=$ sensibility, Prec. $=$ precision, Accu. $=$ accuracy, Cmpl. = completeness, Cmpa. = comparability.

$b_{\text {Largemouth bass data were not representative. }}$ 
has a large regional data base on PCBs in fish tissue. Because of this difference in the preparation of fillets, direct comparisons to much of the historical data were not possible. In addition, skinning of fillets during preparation is not representative of the way many consumers prepare this species and could, therefore, result in an underestimate of the PCB concentrations and the ultimate risk to consumers. As a result, the largemouth bass PCB data were not used in data analysis or risk assessment. The lack of largemouth bass PCB data compromise our Phase 1 objectives to a small degree. However, because PCB concentrations in bass are typically lower than those found in catfish, the mean concentrations used for risk assessment, probably result in an overestimation of the risk associated with the consumption of multiple species.

\section{3 .2 Sensitivity}

The inorganic analyses exhibited acceptable performance. The organic analyses exhibited acceptable performance with the exception of all BNA compounds (factor of 2), Aldrin (factor of 4), and 4,4'-DDT, 4,4'-DDD, and 4,4'-DDE (factor of 2.5).

\subsubsection{Precision}

Laboratory precision was evaluated with true laboratory duplicates only for the radionuclides $\left({ }^{137} \mathrm{Cs},{ }^{60} \mathrm{Co}\right.$, and $\left.{ }^{90} \mathrm{Sr}\right)$, and those results indicated an acceptable level of precision for those analytes. Because matrix spike duplicate (MSD) analyses were not performed during the inorganic and organic analyses, a true measure of analytical precision could not be made. However, field split samples provided a measure of precision that included both field and laboratory variability. Although many of the split samples provided no useful information because of the lack of detectable concentrations, those samples with detectable levels indicated that precision estimates were good for four metals (arsenic, mercury, selenium, and zinc), all the pesticides, and Aroclor 1260. Poor results were obtained for beryllium and Aroclor 1254 analyses. Beryllium was rarely detected and even then at relatively low levels, so the lack of better precision for this analyte probably has little effect on the resulting data analyses and risk calculations. Aroclor 1254 is a contaminant of concern, and the lack of more precise analytical techniques is of concern. However, because Aroclor 1254 is often summed with Aroclor 1260 (which has a mean concentration five times greater than Aroclor 1254 over the entire system) (Cook et al. 1992), to provide an estimate of total PCBs, the precision of Aroclor 1254 estimation is not nearly as crucial as that of Aroclor 1260, which is fairly good. The resulting effect of any precision deficiencies on the completion of Phase 1 objectives is minor.

\subsubsection{Accuracy}

Analytical accuracy was evaluated with LCSs, matrix spikes, and surrogate spikes. Because no EPA-established guidelines exist that define acceptable recovery rates for lab control samples, matrix spikes, or surrogate spikes for fish tissue, the data were not rejected based on poor recoveries and the overall assessment of accuracy was therefore a subjective one. The accuracy of inorganic analyses measured with LCSs (mercury) and matrix spikes (ICP metals) was excellent. Mean percent recoveries were within $15 \%$ of full recovery for all metals except for lead, which was still within acceptable limits (mean $=77 \%$ ). Phase 1 objectives were not compromised as a result of the accuracy of inorganic analyses of fish tissue. 
The accuracy of organic analyses was measured with LCSs, matrix spikes, and surrogate recoveries. The results of these analyses suggest that (1) PCB data from the ORNL CPA are reliable, (2) PCB and pesticide data from the ORNL OAL are suspect because of low matrix spike and surrogate spike recoveries and may underestimate actual concentrations by a factor of 2 or more, and (3) SVO data from ORNL OAL are highly suspect because of poor matrix spike and surrogate spike recoveries. Poor PCB data from ORNL OAL do not impact the achievement of Phase 1 objectives because good PCB data were obtained from ORNL CPA. The accuracy of the pesticides data is suspect; any conclusions resulting from its use should be viewed with caution. The suspected quality of the SVO data is also worrisome, but high concentrations of these compounds are not anticipated in fish tissue anyway.

The accuracy of radionuclide analyses was measured with LCSs and chemical spike recoveries. The results of these analyses were generally within control limits, and only a few ${ }^{90} \mathrm{Sr}$ analyses were rejected because of control limits being exceeded. The effect of these few rejections is minimal on the completion of Phase 1 objectives.

\subsubsection{Completeness}

Nearly all planned fish samples were collected, and two additional sites were sampled as well. Laboratory completeness is summarized in Tables 5.5 and 5.6. The Clinch River ER Program completeness objective of $95 \%$ was attained for all analysis types except for the SVOs. Except for the SVOs, 95\% completeness was attained for all individual analytes except beryllium, lead, nickel, and Aroclor 1254, which had completeness percentages of $91 \%, 70 \%$, $88 \%$, and $93 \%$, respectively. Lead and nickel were not detected in any samples, so the rejection of some analyses probably has an insignificant impact on the Phase 1 objectives. Beryllium and Aroclor 1254 were detected in several samples, but so few were rejected (15 and 8 , respectively) that the impact is also considered rather insignificant.

\subsubsection{Comparability}

The ORNL CPA, ORNL OAL, and the ESD Radiological Analysis Laboratory (RAL) participated in interlaboratory comparison programs with external laboratories to evaluate the comparability of $\mathrm{PCB}$, chlordane, and radionuclide analyses, respectively. The results of these comparisons suggest that our PCB and radionuclide data are comparable with that of other laboratories but that chlordane results may underestimate the results obtained by others. In addition, the fish collection, preparation, and analysis are nearly identical to those of the ORNL Biological Monitoring and Abatement Program (BMAP), which allows a direct comparison of results between the two programs. The BMAP program evaluates contamination in the biotic communities of EFPC and WOC, both tributaries of Watts Bar Reservoir. The resulting effect of any comparability deficiencies on the completion of Phase 1 objectives is minor.

\subsubsection{Risk Assessment}

The lack of PCB data for largemouth bass because of inconsistent preparation had little effect on the results of the risk assessment screening exercise performed during Phase 1. Without the bass data, only catish data were used in the assessment. Because PCB concentrations in catfish are typically higher than those in bass, the absence of bass data probably resulted in slightly higher risk values associated with human consumption of fish. However, in keeping with the conservative approach of the risk screening exercise, the use 
Table 5.5. Summary of water, sediment, and fish samples submitted to laboratory and rejected during validation

\begin{tabular}{|c|c|c|c|c|c|c|c|c|c|c|c|c|}
\hline \multirow[b]{2}{*}{ Analyte } & \multicolumn{3}{|c|}{ Water } & \multicolumn{3}{|c|}{ Buried sediment } & \multicolumn{3}{|c|}{ Surface sediment } & \multicolumn{3}{|c|}{ Fish } \\
\hline & Sub. & Rej. & \% Rej. & Sub. & Rej. & $\%$ Rej. & Sub. & Rej. & $\%$ Rej. & Sub. & Rej. & $\%$ Rej. \\
\hline \multicolumn{13}{|c|}{ Inorganics } \\
\hline Antimony & 38 & 0 & 0.0 & 332 & 163 & 49.1 & & & & 169 & 0 & 0.0 \\
\hline Arsenic & 38 & 0 & 0.0 & 332 & 1 & 0.3 & & & & 169 & 0 & 0.0 \\
\hline Beryllium & 36 & 0 & 0.0 & 332 & 0 & 0.0 & & & & 169 & 15 & 8.9 \\
\hline Cadmium & 38 & 0 & 0.0 & 332 & 0 & 0.0 & & & & 169 & 0 & 0.0 \\
\hline Calcium & 36 & 0 & 0.0 & & & & & & & & & \\
\hline Chromium & 36 & 0 & 0.0 & 332 & 0 & 0.0 & & & & 169 & 0 & 0.0 \\
\hline Copper & 36 & 0 & 0.0 & 332 & 0 & 0.0 & & & & 169 & 0 & 0.0 \\
\hline Iron & 36 & 3 & 8.3 & & & & & & & & & \\
\hline Lead & 38 & 0 & 0.0 & 332 & 0 & 0.0 & & & & 169 & 50 & 29.6 \\
\hline Magnesium & 36 & 0 & 0.0 & & & & & & & & & \\
\hline Mercury & 38 & 0 & 0.0 & 332 & 115 & 34.6 & & & & 169 & 0 & 0.0 \\
\hline Nickel & 36 & 0 & 0.0 & 332 & 0 & 0.0 & & & & 169 & 20 & 11.8 \\
\hline Potassium & 36 & 0 & 0.0 & & & & & & & & & \\
\hline Selenium & 38 & 0 & 0.0 & 332 & 59 & 17.8 & & & & 169 & 0 & 0.0 \\
\hline Silver & 38 & 0 & 0.0 & 331 & 157 & 47.4 & & & & 169 & 0 & 0.0 \\
\hline Sodium & 36 & 0 & 0.0 & & & & & & & & & \\
\hline Thallium & 38 & 1 & 2.6 & 330 & 0 & 0.0 & & & & 169 & 9 & 5.3 \\
\hline Zinc & 36 & 0 & 0.0 & 332 & 0 & 0.0 & & & & 168 & 0 & 0.0 \\
\hline
\end{tabular}


Table 5.5 (Continued)

\begin{tabular}{|c|c|c|c|c|c|c|c|c|c|c|c|c|}
\hline \multirow[b]{2}{*}{ Analyte } & \multicolumn{3}{|c|}{ Water } & \multicolumn{3}{|c|}{ Buried sediment } & \multicolumn{3}{|c|}{ Surface sediment } & \multicolumn{3}{|c|}{ Fish } \\
\hline & Sub. & Rej. & $\%$ Rej. & Sub. & Rej. & $\%$ Rej. & Sub. & Rej. & $\%$ Rej. & Sub. & Rej. & \% Rej. \\
\hline \multicolumn{13}{|c|}{ Organics } \\
\hline Acenaphthene & 18 & $\mathbf{0}$ & 0.0 & 279 & 0 & 0.0 & 1 & 1 & 100.0 & 116 & 59 & 50.9 \\
\hline Acenaphthylene & 18 & $\mathbf{0}$ & 0.0 & 279 & $\mathbf{0}$ & 0.0 & 1 & 1 & 100.0 & 116 & 59 & 50.9 \\
\hline Aldrin & 12 & $\mathbf{0}$ & 0.0 & 278 & 37 & 13.3 & 1 & 1 & 100.0 & 116 & 5 & 4.3 \\
\hline Alpha-BHC & 12 & 0 & 0.0 & 278 & 37 & 13.3 & 1 & 1 & 100.0 & & & \\
\hline Alpha-chlordane & 12 & 0 & 0.0 & 278 & 37 & 13.3 & 1 & 1 & 100.0 & 116 & 7 & 6.0 \\
\hline Alpha-chlordene & & & & & & & & & & 116 & 3 & 2.6 \\
\hline Anthracene & 18 & 0 & 0.0 & 279 & 0 & 0.0 & 1 & 1 & 100.0 & 116 & 59 & 50.9 \\
\hline Aroclor-1016 & 12 & 0 & 0.0 & 278 & 37 & 13.3 & 1 & 1 & 100.0 & & & \\
\hline Aroclor-1221 & 12 & 0 & 0.0 & 278 & 37 & 13.3 & 1 & 1 & 100.0 & & & \\
\hline Aroclor-1232 & 12 & 0 & 0.0 & 278 & 37 & 13.3 & 1 & 1 & 100.0 & & & \\
\hline Aroclor -1242 & 12 & 0 & 0.0 & 278 & 37 & 13.3 & 1 & 1 & 100.0 & & & \\
\hline Aroclor-1248 & 12 & 0 & 0.0 & 278 & 37 & 13.3 & 1 & 1 & 100.0 & & & \\
\hline Aroclor-1254 & 12 & 0 & 0.0 & 278 & 3 & 1.1 & 1 & 1 & 100.0 & 119 & 13 & 10.9 \\
\hline Aroclor- 1260 & 12 & 0 & 0.0 & 278 & 5 & 1.8 & 1 & 1 & 100.0 & 119 & 0 & 0.0 \\
\hline Benzo(a)anthracene & 18 & 0 & 0.0 & 278 & 0 & 0.0 & 1 & 1 & 100.0 & 116 & 59 & 50.9 \\
\hline Benzo(a)pyrene & 18 & 0 & 0.0 & 279 & 0 & 0.0 & 1 & 1 & 100.0 & 116 & 60 & 51.7 \\
\hline Benzo(b)fluoranthene & 18 & 0 & 0.0 & 279 & 0 & 0.0 & 1 & 1 & 100.0 & 116 & 60 & 51.7 \\
\hline Benzo(g,h,i)perylene & 18 & 0 & 0.0 & 279 & 0 & 0.0 & 1 & 1 & 100.0 & 116 & 61 & 52.6 \\
\hline
\end{tabular}


Table 5.5 (Continued)

\begin{tabular}{|c|c|c|c|c|c|c|c|c|c|c|c|c|}
\hline \multirow[b]{2}{*}{ Analyte } & \multicolumn{3}{|c|}{ Water } & \multicolumn{3}{|c|}{ Buried sediment } & \multicolumn{3}{|c|}{ Surface sediment } & \multicolumn{3}{|c|}{ Fish } \\
\hline & Sub. & Rej. & $\%$ Rej. & Sub. & Rej. & \% Rej. & Sub. & Rej. & $\%$ Rej. & Sub. & Rej. & $\%$ Rej. \\
\hline Benzo(k)fluoranthene & 18 & $\mathbf{0}$ & 0.0 & 279 & 0 & 0.0 & 1 & 1 & 100.0 & 116 & 60 & 51.7 \\
\hline Benzoic acid & 18 & 0 & 0.0 & 279 & 0 & 0.0 & 1 & 1 & 100.0 & 116 & 66 & 56.9 \\
\hline Benzyl alcohol & 18 & 0 & 0.0 & 279 & 8 & 2.9 & 1 & 1 & 100.0 & 116 & 59 & 50.9 \\
\hline Beta-BHC & 12 & 0 & 0.0 & 278 & 37 & 13.3 & 1 & 1 & 100.0 & & & \\
\hline Bis(2-chloroethoxy)methane & 18 & 0 & 0.0 & 279 & 0 & 0.0 & 1 & 1 & 100.0 & 116 & 59 & 50.9 \\
\hline Bis(2-chloroethyl)ether & 18 & 0 & 0.0 & 279 & 0 & 0.0 & 1 & 1 & 100.0 & 116 & 58 & 50.0 \\
\hline Bis(2-chloroisopropyl)ether & 18 & 0 & 0.0 & 279 & 0 & 0.0 & 1 & 1 & 100.0 & 116 & 59 & 50.9 \\
\hline Bis(2-ethylhexyl)phthalate & 18 & 0 & 0.0 & 279 & 0 & 0.0 & 1 & 1 & 100.0 & 116 & 60 & 51.7 \\
\hline Butylbenzylphthalate & 18 & 0 & 0.0 & 279 & 0 & 0.0 & 1 & 1 & 100.0 & 116 & 59 & 50.9 \\
\hline Chlordene & & & & & & & & & & 116 & 0 & 0.0 \\
\hline Chrysene & 18 & 0 & 0.0 & 279 & 0 & 0.0 & 1 & 1 & 100.0 & 116 & 59 & 50.9 \\
\hline Delta-BHC & 12 & 0 & 0.0 & 278 & 37 & 13.3 & 1 & 1 & 100.0 & & & \\
\hline Di-n-butylphthalate & 18 & 0 & 0.0 & 280 & 1 & 0.4 & 1 & 1 & 100.0 & 116 & 59 & 50.9 \\
\hline Di-n-octylphthal & 18 & 0 & 0.0 & 279 & 0 & 0.0 & 1 & 1 & 100.0 & 116 & 60 & 51.7 \\
\hline Dibenz(a,h)anthracene & 18 & 0 & 0.0 & 279 & 0 & 0.0 & 1 & 1 & 100.0 & 116 & 60 & 51.7 \\
\hline Dibenzofuran & 18 & 0 & 0.0 & 279 & 0 & 0.0 & 1 & 1 & 100.0 & 116 & 59 & 50.9 \\
\hline Dieldrin & 12 & 0 & 0.0 & 278 & 5 & 1.8 & 1 & 1 & 100.0 & & & \\
\hline Diethylphthalate & 18 & 0 & 0.0 & 279 & $\mathbf{0}$ & 0.0 & 1 & 1 & 100.0 & 116 & 59 & 50.9 \\
\hline Dimethylphthalate & 18 & 0 & 0.0 & 279 & 0 & 0.0 & 1 & 1 & 100.0 & 116 & 59 & 50.9 \\
\hline
\end{tabular}


Table 5.5 (Continued)

\begin{tabular}{|c|c|c|c|c|c|c|c|c|c|c|c|c|}
\hline \multirow[b]{2}{*}{ Analyte } & \multicolumn{3}{|c|}{ Water } & \multicolumn{3}{|c|}{ Buried sediment } & \multicolumn{3}{|c|}{ Surface sediment } & \multicolumn{3}{|c|}{ Fish } \\
\hline & Sub. & Rej. & \% Rej. & Sub. & Rej. & \% Rej. & Sub. & Rej. & \% Rej. & Sub. & Rej. & $\%$ Rej. \\
\hline Endosulfan I & 12 & 0 & 0.0 & 278 & 37 & 13.3 & 1 & 1 & 100.0 & & & \\
\hline Endosulfan II & 12 & 0 & 0.0 & 278 & 5 & 1.8 & 1 & 1 & 100.0 & & & \\
\hline Endosulfan sulfate & 12 & $\mathbf{0}$ & 0.0 & 278 & 5 & 1.8 & 1 & 1 & 100.0 & & & \\
\hline Endrin & 12 & $\mathbf{0}$ & 0.0 & 278 & 5 & 1.8 & 1 & 1 & 100.0 & & & \\
\hline Endrin ketone & 12 & $\mathbf{0}$ & 0.0 & 278 & 5 & 1.8 & 1 & 1 & 100.0 & & & \\
\hline Fluoranthene & 18 & $\mathbf{0}$ & 0.0 & 279 & 0 & 0.0 & 1 & 1 & 100.0 & 116 & 58 & 50.0 \\
\hline Fluorene & 18 & $\mathbf{0}$ & 0.0 & 279 & 0 & 0.0 & 1 & 1 & 100.0 & 116 & 59 & 50.9 \\
\hline Gamma-BHC (Lindane) & 12 & $\mathbf{0}$ & 0.0 & 278 & 37 & 13.3 & 1 & 1 & 100.0 & & & \\
\hline Gamma-chlordane & 12 & 0 & 0.0 & 278 & 37 & 13.3 & 1 & 1 & 100.0 & 116 & 6 & 5.2 \\
\hline Gamma-chlordene & & & & & & & & & & 116 & 3 & 2.6 \\
\hline Heptachlor & 12 & $\mathbf{0}$ & 0.0 & 278 & 37 & 13.3 & 1 & 1 & 100.0 & & & \\
\hline Heptachlor epoxide & 12 & $\mathbf{0}$ & 0.0 & 278 & 37 & 13.3 & 1 & 1 & 100.0 & & & \\
\hline Hexachlorobenzene & 18 & 0 & 0.0 & 279 & 0 & 0.0 & 1 & 1 & 100.0 & 116 & 59 & 50.9 \\
\hline Hexachlorobutadiene & 18 & $\mathbf{0}$ & 0.0 & 279 & 0 & 0.0 & 1 & 1 & 100.0 & 116 & 59 & 50.9 \\
\hline Hexachlorocyclopentadiene & 18 & 0 & 0.0 & 279 & 0 & 0.0 & 1 & 1 & 100.0 & 116 & 59 & 50.9 \\
\hline Hexachloroethane & 18 & 0 & 0.0 & 279 & 0 & 0.0 & 1 & 1 & 100.0 & 116 & 59 & 50.9 \\
\hline Indeno(1,2,3-cd) & 18 & $\mathbf{0}$ & 0.0 & 279 & 0 & 0.0 & 1 & 1 & 100.0 & 116 & 60 & 51.7 \\
\hline Isophorone & 18 & 0 & 0.0 & 279 & 0 & 0.0 & 1 & 1 & 100.0 & 116 & 59 & 50.9 \\
\hline Methoxychlor & 12 & 0 & 0.0 & 278 & 5 & 1.8 & 1 & 1 & 100.0 & & & \\
\hline
\end{tabular}


Table 5.5 (Continued)

\begin{tabular}{|c|c|c|c|c|c|c|c|c|c|c|c|c|}
\hline \multirow[b]{2}{*}{ Analyte } & \multicolumn{3}{|c|}{ Water } & \multicolumn{3}{|c|}{ Buried sediment } & \multicolumn{3}{|c|}{ Surface sediment } & \multicolumn{3}{|c|}{ Fish } \\
\hline & Sub. & Rej. & \% Rej. & Sub. & Rej. & \% Rej. & Sub. & Rej. & \% Rej. & Sub. & Rej. & $\%$ Rej. \\
\hline $\mathrm{N}$-nitroso-di-n-propylamine & 18 & 0 & 0.0 & 279 & 0 & 0.0 & 1 & 1 & 100.0 & 116 & 59 & 50.9 \\
\hline $\mathrm{N}$-nitrosodiphenylamine & 18 & 0 & 0.0 & 279 & 0 & 0.0 & 1 & 1 & 100.0 & 116 & 59 & 50.9 \\
\hline Naphthalene & 18 & 0 & 0.0 & 279 & 0 & 0.0 & 1 & 1 & 100.0 & 116 & 58 & 50.0 \\
\hline Nitrobenzene & 18 & 0 & 0.0 & 279 & 0 & 0.0 & 1 & 1 & 100.0 & 116 & 59 & 50.9 \\
\hline Oxychlordane & & & & & & & & & & 116 & 6 & 5.2 \\
\hline Pentachlorophenol & 18 & 1 & 5.6 & 279 & 0 & 0.0 & 1 & 1 & 100.0 & 116 & 40 & 34.5 \\
\hline Phenanthrene & 18 & $\mathbf{0}$ & 0.0 & 279 & 0 & 0.0 & 1 & 1 & 100.0 & 116 & 59 & 50.9 \\
\hline Phenol & 18 & 1 & 5.6 & 279 & 0 & 0.0 & 1 & 1 & 100.0 & 116 & 40 & 34.5 \\
\hline Pyrene & 18 & 0 & 0.0 & 279 & 0 & 0.0 & 1 & 1 & 100.0 & 116 & 59 & 50.9 \\
\hline Toxaphene & 12 & 0 & 0.0 & 278 & 17 & 6.1 & 1 & 1 & 100.0 & & & \\
\hline 1,2-dichlorobenzene & 18 & 0 & 0.0 & 279 & 0 & 0.0 & 1 & 1 & 100.0 & 116 & 59 & 50.9 \\
\hline 1,2,4-trichlorobenzene & 18 & 0 & 0.0 & 279 & 0 & 0.0 & 1 & 1 & 100.0 & 116 & 59 & 50.9 \\
\hline 1,3-dichlorobenzene & 18 & 0 & 0.0 & 279 & 0 & 0.0 & 1 & 1 & 100.0 & 116 & 59 & 50.9 \\
\hline 1,4-dichlorobenzene & 18 & 0 & 0.0 & 279 & 0 & 0.0 & 1 & 1 & 100.0 & 116 & 59 & 50.9 \\
\hline 2-chloronaphthalene & 18 & 0 & 0.0 & 279 & 0 & 0.0 & 1 & 1 & 100.0 & 116 & 59 & 50.9 \\
\hline 2-chlorophenol & 18 & 1 & 5.6 & 279 & 0 & 0.0 & 1 & 1 & 100.0 & 116 & 39 & 33.6 \\
\hline 2-methylnaphthal & 18 & 0 & 0.0 & 279 & 0 & 0.0 & 1 & 1 & 100.0 & 116 & 56 & 48.3 \\
\hline 2-methylphenol & 18 & 1 & 5.6 & 279 & 8 & 2.9 & 1 & 1 & 100.0 & 116 & 40 & 34.5 \\
\hline 2-nitroaniline & 18 & 0 & 0.0 & 279 & 0 & 0.0 & 1 & 1 & 100.0 & 116 & 60 & 51.7 \\
\hline
\end{tabular}


Table 5.5 (Continued)

\begin{tabular}{|c|c|c|c|c|c|c|c|c|c|c|c|c|}
\hline \multirow[b]{2}{*}{ Analyte } & \multicolumn{3}{|c|}{ Water } & \multicolumn{3}{|c|}{ Buried sediment } & \multicolumn{3}{|c|}{ Surface sediment } & \multicolumn{3}{|c|}{ Fish } \\
\hline & Sub. & Rej. & \% Rej. & Sub. & Rej. & \% Rej. & Sub. & Rej. & \% Rej. & Sub. & Rej. & \% Rej. \\
\hline 2-nitrophenol & 18 & 1 & 5.6 & 279 & 0 & 0.0 & 1 & 1 & 100.0 & 116 & 40 & 34.5 \\
\hline 2,4-dichlorophenol & 18 & 1 & 5.6 & 279 & 0 & 0.0 & 1 & 1 & 100.0 & 116 & 39 & 33.6 \\
\hline 2,4-dimethylphenol & 18 & 1 & 5.6 & 279 & 0 & 0.0 & 1 & 1 & 100.0 & 116 & 39 & 33.6 \\
\hline 2,4-dinitrophenol & 18 & 1 & 5.6 & 279 & 23 & 8.2 & 1 & 1 & 100.0 & 116 & 40 & 34.5 \\
\hline 2,4-dinitrotoluene & 18 & 0 & 0.0 & 279 & 0 & 0.0 & 1 & 1 & 100.0 & 116 & 59 & 50.9 \\
\hline 2,4,5-trichlorophenol & 18 & 3 & 16.7 & 279 & $\mathbf{0}$ & 0.0 & 1 & 1 & 100.0 & 116 & 40 & 34.5 \\
\hline 2,4,6-trichlorophenol & 18 & 3 & 16.7 & 279 & $\mathbf{0}$ & 0.0 & 1 & 1 & 100.0 & 116 & 40 & 34.5 \\
\hline 2,6-dinitrotoluene & 18 & 0 & 0.0 & 279 & $\mathbf{0}$ & 0.0 & 1 & 1 & 100.0 & 116 & 59 & 50.9 \\
\hline 3-nitroaniline & 18 & 0 & 0.0 & 279 & $\mathbf{0}$ & 0.0 & 1 & 1 & 100.0 & 116 & 81 & 69.8 \\
\hline 3,3'-dichlorobenzidine & 18 & 0 & 0.0 & 279 & $\mathbf{0}$ & 0.0 & 1 & 1 & 100.0 & 116 & 59 & 50.9 \\
\hline 4-bromophenyl-phenylether & 18 & 0 & 0.0 & 279 & $\mathbf{0}$ & 0.0 & 1 & 1 & 100.0 & 116 & 59 & 50.9 \\
\hline 4-chloro-3-methylphenol & 18 & 1 & 5.6 & 279 & $\mathbf{0}$ & 0.0 & 1 & 1 & 100.0 & 116 & 38 & 32.8 \\
\hline 4-chloroaniline & 18 & 0 & 0.0 & 279 & $\mathbf{0}$ & 0.0 & 1 & 1 & 100.0 & 116 & 65 & 56.0 \\
\hline 4-chlorophenyl-phenylether & 18 & 0 & 0.0 & 279 & 0 & 0.0 & 1 & 1 & 100.0 & 116 & 59 & 50.9 \\
\hline 4-methylphenol & 18 & 1 & 5.6 & 280 & 1 & 0.4 & 1 & 1 & 100.0 & 115 & 38 & 33.0 \\
\hline 4-nitroaniline & 18 & 0 & 0.0 & 279 & 0 & 0.0 & 1 & 1 & 100.0 & 116 & 66 & 56.9 \\
\hline 4-nitrophenol & 18 & 1 & 5.6 & 279 & 13 & 4.7 & 1 & 1 & 100.0 & 116 & 40 & 34.5 \\
\hline 4,4'-DDD & 12 & 0 & 0.0 & 278 & 5 & 1.8 & 1 & 1 & 100.0 & 116 & 2 & 1.7 \\
\hline 4,4'-DDE & 12 & 0 & 0.0 & 278 & 5 & 1.8 & 1 & 1 & 100.0 & 116 & 3 & 2.6 \\
\hline
\end{tabular}


Table 5.5 (Continued)

\begin{tabular}{|c|c|c|c|c|c|c|c|c|c|c|c|c|}
\hline \multirow[b]{2}{*}{ Analyte } & \multicolumn{3}{|c|}{ Water } & \multicolumn{3}{|c|}{ Buried sediment } & \multicolumn{3}{|c|}{ Surface sediment } & \multicolumn{3}{|c|}{ Fish } \\
\hline & Sub. & Rej. & \% Rej. & Sub. & Rej. & $\%$ Rej. & Sub. & Rej. & $\%$ Rej. & Sub. & Rej. & $\%$ Rej. \\
\hline 4,4'-DDT & 12 & 0 & 0.0 & 278 & 5 & 1.8 & 1 & 1 & 100.0 & 116 & 2 & 1.7 \\
\hline 4,6-dinitro-2-methylphenol & 18 & 1 & 5.6 & 279 & 0 & 0.0 & 1 & 1 & 100.0 & 116 & 41 & 35.3 \\
\hline \multicolumn{13}{|c|}{$\underline{\text { Radionuclides }}$} \\
\hline${ }^{241} \mathrm{Am}$ & & & & 94 & 2 & 2.1 & & & & & & \\
\hline $243,244 \mathrm{Cm} 94$ & & & & 94 & 2 & 2.1 & & & & & & \\
\hline $245,246 \mathrm{Cm}$ & & & & 36 & 1 & 2.8 & & & & & & \\
\hline${ }^{248} \mathrm{Cm}$ & & & & 34 & 0 & 0.0 & & & & & & \\
\hline${ }^{60} \mathrm{Co}$ & 33 & 0 & 0.0 & 390 & 0 & 0.0 & 509 & 1 & 0.2 & 211 & 0 & 0.0 \\
\hline${ }^{137} \mathrm{Cs}$ & 33 & 0 & 0.0 & 440 & 0 & 0.0 & 509 & 2 & 0.4 & 214 & 0 & 0.0 \\
\hline${ }^{3} \mathrm{H}$ & 16 & 16 & 100.0 & & & & & & & & & \\
\hline${ }^{238} \mathrm{Pu}$ & & & & 94 & 3 & 3.2 & & & & & & \\
\hline $239,240 \mathrm{Pu}$ & & & & 94 & 3 & 3.2 & & & & & & \\
\hline${ }^{90} \mathrm{Sr}$ & 16 & 0 & 0.0 & 94 & 1 & 1.1 & & & & 87 & 0 & 0.0 \\
\hline${ }^{234} \mathrm{U}$ & & & & 94 & 3 & 3.2 & & & & & & \\
\hline${ }^{235} \mathrm{U}$ & & & & 94 & 3 & 3.2 & & & & & & \\
\hline${ }^{238} \mathrm{U}$ & & & & 94 & 3 & 3.2 & & & & & & \\
\hline
\end{tabular}


Table 5.6 Summary of the number of regular samples (i.e., excludes QC samples) rejected as a result of data validation

\begin{tabular}{|c|c|c|c|c|c|}
\hline Analysis type & Laboratory & $\begin{array}{c}\text { Total } \\
\text { number of } \\
\text { analyses }\end{array}$ & $\begin{array}{l}\text { Number } \\
\text { of } \\
\text { accepted } \\
\text { analyses }\end{array}$ & $\begin{array}{l}\text { Number } \\
\text { of } \\
\text { rejected } \\
\text { analyses }\end{array}$ & $\begin{array}{l}\text { Percent } \\
\text { rejected } \\
\text { of total } \\
\end{array}$ \\
\hline \multicolumn{6}{|c|}{$\underline{\text { Field matrix }- \text { water }}$} \\
\hline Metals & $\mathrm{K}-25$ & 664 & 660 & 4 & 0.6 \\
\hline Pesticide/PCBs & $\mathrm{K}-25$ & 324 & 324 & 0 & 0 \\
\hline Semivolatiles & $\mathrm{K}-25$ & 1,170 & 1,152 & 18 & 1.5 \\
\hline Rads & ORAU & 32 & 16 & 16 & 50.0 \\
\hline Rads & ORNL/ESD & 66 & 66 & 0 & 0 \\
\hline Totals for water analyses & & 2,256 & 2,218 & 38 & 1.7 \\
\hline \multicolumn{6}{|c|}{ Field matrix-core } \\
\hline Metals & $\mathrm{K}-25 / \mathrm{TT}$ & 4,313 & 3,818 & 495 & 11.5 \\
\hline Pesticide/PCBs & $\mathrm{K}-25$ & 7,506 & 6,881 & 625 & 8.3 \\
\hline Semivolatiles & $\mathrm{K}-25$ & 18,136 & 18,082 & 54 & 0.3 \\
\hline Rads & ORAU & 822 & 801 & 21 & 2.6 \\
\hline Rads & ORNL/ESD & 830 & 830 & 0 & 0 \\
\hline Totals for core analyses & & 31,607 & 30,412 & 1,195 & 3.8 \\
\hline \multicolumn{6}{|c|}{ Field matrix - grab } \\
\hline Pesticide/PCBs & $\mathrm{K}-25 / \mathrm{IT}$ & 27 & 0 & 27 & 100 \\
\hline Semivolatiles & $\mathrm{K}-25 / \mathrm{TT}$ & 65 & 0 & 65 & 100 \\
\hline Rads & ORNL/ESD & 1,018 & 1,015 & 3 & 0.3 \\
\hline Totals for grab analyses & & 1,110 & 1,015 & 95 & 8.6 \\
\hline \multicolumn{6}{|c|}{ Field matrix-fish } \\
\hline Metals & ORNL/CPA & 2,027 & 1,933 & 94 & 4.6 \\
\hline Mercury & ORNL/EAL & 169 & 169 & 0 & 0 \\
\hline PCBs & ORNL/CPA & 238 & 230 & 8 & 3.4 \\
\hline Pesticide/PCBs & ORNL/OAL & 1,508 & 1,440 & 68 & 4.5 \\
\hline Semivolatiles & ORNL/OAL & 7,539 & 3,930 & 3,609 & 47.9 \\
\hline Rads & ORAU & 87 & 87 & 0 & 0 \\
\hline Rads & ORNL/ESD & 425 & 425 & 0 & 0 \\
\hline Totals for fish analyses & & 11,993 & 8,214 & 3,779 & 31.5 \\
\hline Totals for all anayses & & 46,966 & 41,859 & 5,107 & 10.9 \\
\hline
\end{tabular}


of only the most contaminated species (catfish in this case) was probably more appropriate in any case.

SVO data analyzed in fish tissue are considered inadequate because of low accuracy and completeness evaluations. Impacts to the human health risk assessment from this inadequacy are possible overestimates or underestimates of the contaminant concentrations in fish tissue, resulting in erroneous cancer risk or hazard index calculations. However, from a human health risk standpoint, the semivolatile concentrations would be greatly reduced by the cooking of the fish before human consumption; therefore, the impact from the rejection of SVO samples on the risk assessment is considered minimal.

It should be noted that all samples for the eleven carcinogenic contaminants identified as requiring lower analytical DLs to ensure adequate protection of human health, were rejected in Reaches 5, 10, and 13. More than 50\% of the samples in Reaches 1 and 4 were also rejected. The samples for the noncarcinogen having elevated DLs were all rejected in Reach 10, and greater than $50 \%$ of the samples were rejected in Reaches 1,5 , and 13 . For those reaches having no useable data, risk estimates obviously cannot be calculated, and for those reaches with a large percentage of rejected samples, the remaining data may not be representative of the site conditions. If data were available for these reaches, lower DLs could possibly be achieved, and thus, reduce the number of nondetected contaminants having risk estimates $>10^{-4}$.

Another limitation of the fish analyses is that no reference data are available from Reach 18 (the Tennessee River). These data are needed to differentiate between anthropogenic levels of contamination and site related contamination.

\subsection{LESSONS LEARNED}

The purpose of this report was not only to evaluate the quality and applicability of the Phase 1 data but also to identify those problems that can be addressed and corrected during future sampling and analysis. These problems are presented by field matrix and by laboratory analysis.

\subsubsection{Water Sampling, Processing, and Preservation}

- Do not acidify tritium water samples.

\subsection{Sediment Sampling, Processing, and Preservation}

- Collect additional samples in reference locations.

- Collect field duplicates, equipment rinse blanks, and trip blanks to provide a better method of evaluating data for representativeness and precision.

- Deliver samples to the laboratory in time to meet holding time restrictions.

- Evaluate QC data immediately upon receipt from laboratory.

- Have data base that links QC data to sample batches. 
5.4.3 Fish Sampling, Processing, and Preservation

- Prepare fish tissue such that it is consistent with EPA guidelines and the methods of other agencies gathering similar information (i.e., do not skin the bass fillets).

- Select additional reference sites.

- Provide a sufficient amount of tissue to the laboratories for matrix spike and MSD analyses.

- Deliver fish samples to the laboratories in time to be extracted within 180 days of collection so that the concern of prolonged pre-extraction holding times is minimized.

- Collect equipment rinse blanks to provide a better method of evaluating data for representativeness and precision.

\subsubsection{Laboratory Analysis}

- Ensure that the quantity of matrix spike is sufficient for the required accuracy and precision analyses.

- Insist that the laboratories perform at least one matrix spike and spike duplicate with every batch of 20 or fewer samples.

- Develop control limits for matrix spike and surrogate spike recovery rates specific to fish tissue analysis.

- Find a better method to analyze several pesticides (aldrin and DDT derivatives) in fish that are affected by high concentrations of PCBs and chlordane in the present method.

- Obtain and validate a modified sample preparation procedure for organics in sediment samples that permits removing matrix-interfering compounds from sample extract without removing the target compounds.

- Require that laboratories provide all data in electronic format.

- Require that laboratories provide all supporting QC data.

- Require that radiological laboratories provide documentation that links each sample with appropriate efficiency and background spectra.

- Require that radiological laboratories provide net activity estimates in addition to minimum detectable activity for all analyses below the sample quantitation limit.

- Require that radiological laboratories perform background determinations on a regular schedule.

- Require that laboratories establish statistical process control procedures to provide a quantitative measure of laboratory performance.

- Require that radiological laboratories ensure that spectrometer sensitivity is set properly to provide reliable estimates of minimum detectable activity.

- Improve DLs for inorganics in sediments. 


\subsubsection{Sample Tracking}

- Improve sample tracking to ensure that all required data are received from the analytical laboratories or, if data are not received, that resampling can be performed. 


\section{REFERENCES}

ASME (American Society of Mechanical Engineers). 1989. Quality Assurance Program Requirements for Nuclear Facilities, ASME NQA-1, New York.

Blaylock, B. G., M. L. Frank, L. A. Hook, F. O. Hoffman, and C. J. Ford. 1993. White Oak Creek Embayment Site Characterization and Contaminant Screening Report, ORNL/ER81, Martin Marietta Energy Systems, Inc., Oak Ridge National Laboratory, Oak Ridge, Tennessee.

Cook, R. B. et al. 1992. Phase I Data Summary Report for the Clinch River Remedial Investigation: Health Risk and Ecological Risk Screening Analysis, ORNL/ER-155, Oak Ridge National Laboratory, Martin Marietta Energy Systems, Inc., Oak Ridge, Tennessee, December.

Energy Systems (Martin Marietta Energy Systems, Inc.). 1990. Clinch River RCRA Facility Investigation Plan, ES/ER-1/D1, Oak Ridge, Tennessee.

EPA (U.S. Environmental Protection Agency), 1979. Radiochemical Analytical Procedures for Analysis of Environmental Samples, EMSL-LV-0539-17, Environmental Monitoring and Support Laboratory, Las Vegas, Nevada.

EPA (U.S. Environmental Protection Agency), 1980a. Interim Guidelines and Specifications for Preparing Quality Assurance Project Plans, QAMS-005/80, EPA-600/4-83-004, Office of Monitoring Systems and Quality Assurance, Washington, D.C., December.

EPA (U.S. Environmental Protection Agency), 1986. Quality Control in Remedial Site Investigation: Hazardous and Industrial Solid Waste Testing, Vol. 5, ASTM Standard Publication 925, New Orleans, Louisiana, May.

EPA (U.S. Environmental Protection Agency), 1987. EPA Contract Laboratory Program Statement of Work for Inorganic Analysis, Multi-Media, Multi-Concentration, July.

EPA (U.S. Environmental Protection Agency), 1988a. EPA Contract Laboratory Program Statement of Work for Inorganic Analysis, Multi-Media, Multi-Concentration, July.

EPA (U.S. Environmental Protection Agency), 1988b. EPA Contract Laboratory Program Statement of Work for Organic Analysis, Multi-Media, Multi-Concentration, February.

EPA (U.S. Environmental Protection Agency), 1988c. Laboratory Data Validation Functional Guidelines for Evaluating Inorganics Analyses.

EPA (U.S. Environmental Protection Agency), 1988d. Laboratory Data Validation Functional Guidelines for Evaluating Organics Analyses.

EPA (U.S. Environmental Protection Agency). 1990. Quality Assurance/Quality Control Guidance for Removal Activities, Sampling QA/QC Plan and Data Validation Procedures. Interim Final. EPA/540/G-90/004. Environmental Protection Agency, Washington, D.C. 
FDA (U.S. Food and Drug Administration). 1990. Pesticide Analytical Manual, Volumes I and II. FDA/OMO-90/15A. U.S. Dept. of Health and Human Serivces, Washington, D.C.

Hoffman, F. O., B. G. Blaylock, M. L. Frank, L. A. Hook, E. L. Etnier, and S. S. Talmage. 1991. Preliminary Screening of Contaminants in the Off-Site Surface Water Environment Downstream of the U.S. Department of Energy Oak Ridge Reservation. ORNL/ER-9. Oak Ridge National Laboratory, Oak Ridge, Tennessee.

Kimbrough, C. W., L. W. Long, and L. W. McMahon. 1990. Environmental Surveillance Procedures Quality Control Program, Martin Marietta Energy System, Inc., Oak Ridge, Tennessee, January.

Kornegay, F. C., D. C. West, R. A. Evans, S. T. Goodpasture, M. F. Tardiff, and A. R. Wilson. 1991. Oak Ridge Reservation Environmental Report for 1990. Volume 2: Data Presentation, ES/ESH-18/V2, Martin Marietta Energy Systems, Inc., Oak Ridge, Tennessee.

Olsen, C. R., I. L. Larsen, P. D. Lowry, C. R. Moriones, C. J. Ford, K. C. Dearstone, R. R. Turner, B. L. Kimmel, and C. C. Brandt. 1992. Transport and Accumulation of Cesium-137 and Mercury in the Clinch River and Watts Bar Reservoir System, ORNL/ER-7, Oak Ridge National Laboratory, Oak Ridge, Tennessee.

SAIC (Science Applications International Corporation), 1991. Laboratory Data Validation Guidelines for Evaluating Radionuclide Analyses, Revision 3, Oak Ridge, Tennessee, November.

Suter, G. W., II. 1991. Screening Level Risk Assessment for Off-Site Ecological Effects in Surface Waters Downstream from the U.S. Department of Energy Oak Ridge Reservation. ORNL/ER-8, Martin Marietta Energy Systems, Inc., Oak Ridge National Laboratory, Oak Ridge, Tennessee.

Taylor, J. K. 1987. Quality Assurance of Chemical Measurements, Lewis Publishers. Chelsea, Michigan. 
Appendix A.

ANALYTICAL DATA EVALUATION 
- 


\section{A ANALYTICAL DATA EVALUATION}

A total of 198 packages containing -1700 inorganic samples, 1500 organic samples, and 2200 radiological samples, were analyzed by various laboratories during Phase 1.

\section{A.1 INORGANIC ANALYSES}

\section{A1.1 Atomic Absorption Water Analyses}

Atomic Absorption (AA) analyses of water samples were conducted at the K-25 Analytical Chemistry Division (ACD) by graphite furnace for antimony, arsenic, cadmium, lead, selenium, silver, and thallium. Mercury was determined by cold vapor AA (CVAA). The USEPA Contract Laboratory Program Statement of Work for Inorganic Analysis, Multimedia, Multi-Concentration (EPA 1987) was used as the analytical protocol. Sixty-eight samples were analyzed in four batches (Tables A.1, A.2).

Holding times. All holding times were within limits.

Calibration. Calibration specifications ensure that the instrument is capable of producing acceptable quantitative data. The calibrations for four of the batches either met all the requirements or deviations did not warrant any action by the validator. The continuing calibration verification for thallium in batch $1462 \mathrm{M}$ was outside the appropriate control limits. However, no action was recommended by the validators because no thallium was reported in the samples (1472M and 1472T).

Blanks. The analysis of blanks provides a means of assessing the existence and magnitude of contamination introduced by way of the analytical scheme. No contamination that required action was reported in batches CRMI-I, 1462M, or 136M. Because the lead levels in the blanks for batches $1462 \mathrm{M}$ and $1422 \mathrm{M}$ were greater than the instrument detection limit (IDL) but less than the action level, the lead results in all samples in each batch were reported as not detected with the detection limit (DL) raised.

Matrix spikes. Spiked sample analysis provides information about the effect of the sample matrix on the digestion and measurement methodology. Spike recovery must be within the limits of 75-125\%. However, spike recovery limits do not apply when sample concentration exceeds the spike concentration by a factor of 4 or more. All criteria were met, except for batch $1422 \mathrm{M}$, where antimony results were flagged J/UJ in all samples. The spike recoveries for antimony were affected by either a problem with the autosampler or with sample deposition during analysis. Table A.3 summarizes the matrix spike recoveries (MSRs). All of the recoveries were within limits, except for antimony and selenium. Seventy-five percent of the spike recoveries for these two elements were within limits.

Duplicates. Results of duplicate analyses serve as an indicator of the precision of the methods and the sample results. A control limit of $20 \%$ is used for the relative percent difference (RPD) when the sample values are greater than five times the contract-required 
detection limit (CRDL). A control limit of plus or minus the CRDL is used for the limit when the sample results are less than five times CRDL. All criteria were met for four of the batches; no actions were warranted for the fifth batch. All of the laboratory duplicates were within the limits (Table A.4).

Laboratory quality control samples. The laboratory control sample (LCS) analysis is designed to serve as a monitor of the efficiency of the digestion procedure. An aqueous LCS must be analyzed on a digestion batch basis. All aqueous LCS results must fall within the control limits of 80-120\% recovery except antimony and silver, which have no control limits. All of the samples met the criteria as shown in Table A.5.

Method of standard additions. All criteria were generally met when required except for batch CRMI-I. Arsenic failed to meet the spike recoveries in all samples, so results were qualified as UJ.

\section{A.1.2 AA Soil/Sediment Analyses}

AA analyses of soil/sediment samples were conducted at International Technology (IT) laboratories by graphite furnace for antimony, arsenic, lead, selenium, silver, and thallium. Mercury was determined by CVAA. The USEPA Contract Laboratory Program Statement of Work for Inorganic Analysis, Multi-media, Multi-Concentration, (EPA 1987) was used as the analytical protocol for most of the samples. Three hundred seventy-two samples were analyzed in 14 batches for the seven metals listed above (Tables A6, A.7).

Holding times. All samples met the holding time requirements, with the following exceptions. The mercury results were qualified with a $J$ for 13 samples. In batch 900531-005, all AA results and all positive mercury results for samples 1410T, 1411T, 260TT, and 2608T were qualified as estimated, and all mercury nondetects were qualified as rejected. All mercury results for samples $7101 \mathrm{~T}$ and $7102 \mathrm{~T}$ were qualified as estimated (J/UJ). In batch 900308-014, two samples, 900308-071 and -072, were flagged J.

Calibration. Calibration specifications ensure that the instrument is capable of producing acceptable quantitative data. The calibrations for the data either met all the requirements or deviations did not warrant any action by the validator, with the following exceptions. In batches 900323-137, 900404-076, and 900412-003, apparently the mercury standard curve was established with only three standards instead of the required four. As a consequence, $-33 \%$ of the mercury data analyzed at IT was estimated. In batch 891212-086, the positive selenium results in 891214-044, $-045,-046$, and -047 were qualified as estimated (J). Antimony results in all samples in batch 900223-007 were qualified as estimated nondetects (UJ), because the calibration curve correlation coefficient was less than 0.995 . The time of sample analysis was not provided for mercury, thallium, and lead, so calibration frequency could not be evaluated.

Blanks. The analysis of blanks provides a means of assessing the existence and magnitude of contamination introduced by way of the analytical scheme. All criteria were met or deviations did not warrant any action by the validator except for batches 900611-035 and 900412-003. In batch 900611-035, a soil preparation blank was not analyzed for lead by the graphite furnace AA method. As a result, lead results in all samples were estimated (J). In batch 900412-003, silver results less that the action level were qualified as undetected (U). For batch 891212-086, the antimony result in sample 891212-040 was qualified U, and the DL 
was raised to the quantitated value. The time of sample analysis was not provided for mercury, thallium, and lead, so frequency of blank analysis could not be evaluated.

Matrix spikes. Spiked sample analysis provides information about the effect of the sample matrix on the digestion and measurement methodology. Spike recovery must be within the limits of 75-125\%. However, spike recovery limits do not apply when sample concentration exceeds the spike concentration by a factor of 4 or more. All MSRs were met with the following exceptions: for batch 910607, antimony results were qualified J/UJ, and selenium results were qualified J/R; for batch 900627-014, some selenium, arsenic, cadmium, and zinc results were qualified J or UJ. In batch $900323-137$, recoveries did not meet criteria for antimony, arsenic, selenium, and silver; results were flagged accordingly. For batch 900404 076, all sample results for selenium (J/UJ), silver (J/R), antimony (J/R), and arsenic (J/UJ) were qualified as noted because recovery limits were exceeded. In batch 900117-002, antimony, silver, and zinc in samples 900117-021 and 900177-029 and mercury and selenium in sample 900117-021 did not meet the required recovery criteria and were flagged accordingly. In batch $900427-161$, arsenic and silver failed the spike recovery criteria. Arsenic also failed criteria in batch 900611-035. In batch 900412-003, all samples results were flagged $\mathrm{J} / \mathrm{UJ}$ for selenium and silver, $\mathrm{J} / \mathrm{R}$ for antimony, and $\mathrm{J} / \mathrm{U}$ for arsenic because of failure to meet recovery criteria. For batch $900531-005$, arsenic results were qualified J/U. In batch $891212-$ 086, the matrix spike analysis for samples 891214-039 failed to meet the required recovery criterion for antimony, arsenic, and selenium. Therefore, antimony and arsenic results in selected samples were qualified as estimated (J/UJ), and selenium results in selected samples were qualified as estimated (J) or unusable (R). Matrix spike analysis did not meet the required recovery for antimony, mercury, and lead in batch 900223-007 and was, thus, qualified as follows: nondetected antimony results were rejected, and all other results were flagged J. Nondetected selenium results in batch $900308-014$ were rejected because of MSRs. Matrix spike did not meet the required recoveries for antimony, lead, and selenium in batch 900612-050 and were qualified J/UJ, J/U, or J/R accordingly. Tables A.8 and A.9 summarize the spike and postdigestion spike recoveries. Approximately $50 \%$ or less of the spike recoveries for antimony, arsenic, selenium, and silver were within the control limits.

Duplicates. Results of duplicates analyses serve as an indicator of the precision of the methods and the sample results. A control limit of 35\% is used for the RPD when the sample values are greater than five times CRDL A control limit of plus or minus CRDL is used for the limit when the sample results are less than five times CRDL No deviations were found for batches $910607,900323-137,900117-002$, and 900223-007. No laboratory duplicate analysis was performed for batches $900627-014,900404-076,900427-161,900611-035$, and 900308-014. No duplicate forms were included in the data package for batches 900412-003 and 900612050. Table A.10 summarizes the duplicate performance. Eighty-three percent or more of the duplicate results were within the limits for the seven AA metals.

Laboratory control samples. All solid LCS results must fall within the control limits established by the supplier [usually Environmental Protection Agency (EPA) or National Institute of Standards and Technology (NIST)]. All criteria were met or warranted no action by the validators for batches 900117-002, 900611-035, 900427-161, 900223-007. In batch 900627-014, the LCS was outside the windows for arsenic, lead, selenium, silver, and thallium, resulting in some results being qualified $J$ or UJ. Control limits were not presented for batches 910607, 900323-137, 900404-076, and 900412-003. All of the LCSs met the 80-120\% recovery requirements at least $90 \%$ of the time (Table A.11). 


\section{A-6}

Method of standard additions. The duplicate injection for sample $900627-030$ in batch 900627-014 did not agree within 20\% for antimony. One lead sample in batch $900412-003$ did not meet the duplicate injection criterion. Because antimony was undetected in the sample, no action was taken by the validator. Results for sample 900412-030 in batch 900412-003 were flagged because method of standard addition (MSA) was required but not done. For batch 900531-005, the positive lead results in sample 900531-005 was qualified J, the nondetected selenium results in all samples except 900531-023 were qualified UJ, and the thallium results in samples 900531-008 and 900531-010 were qualified UJ. In batch 891212-086, nondetected antimony, selenium, and thallium results in selected samples were qualified as estimated (UJ), and positive arsenic and selenium results in selected samples were qualified as estimated (J). MSA was not used to measure selenium in sample 891214-039; therefore, the positive selenium result in that sample was qualified as estimated (J). Criteria were not evaluated for batch $900427-161$ because of the format of the data presented.

\section{A1.3 AA Analysis of Fish Tissue}

AA analysis of fish tissue was conducted by the Environmental Analysis Laboratory (EAL) at the Oak Ridge National Laboratory (ORNL) ACD. Fish tissue was prepared by the ORNL $\mathrm{HNO}_{3} / \mathrm{HClO}_{4}$ method (AC-MM10915) and analyzed by a CVAA method (ACMM1214922) for mercury. The cold vapor method measures mercury using a standard addition technique. An NIST standard was used for the standard addition. One hundred seventy-eight samples (169 regular samples and 9 field splits) were analyzed for mercury in 12 batches (Tables A.12, A.13).

Holding times. The problem here was for pre-extraction holding times (from sample collection to extraction), which exceeded the 7-d criteria for water. No data were rejected because no specific pre-extraction holding time criteria existed for fish tissue and because the 7-d water criteria are not applicable to fish tissue that has been maintained in a frozen state as these samples were. Postextraction holding times were all within the 40-d limit established for mercury in water.

Calibration. Calibration curves were not established for the 12 batches; however, eight of the batches were accompanied by analysis of one or two known EPA standards. EPA standards ICV5 $(490 \mu \mathrm{g} / \mathrm{L})$, WP386 $(500 \mu \mathrm{g} / \mathrm{L})$, and WP287 $(500 \mu \mathrm{g} / \mathrm{L})$ were used with a range of $99.4-103.4 \%$ recovery (\%R). The MSA, not standard curves, was used for quantitation; therefore, no calibration curves were generated.

Blanks. Instrument blank analyses were not required for MSA method. Either one or two preparation blanks accompanied each of 11 batches; one large batch of 71 samples used four. The average preparation blank value found was $0.05 \mu \mathrm{g} / \mathrm{L}$, with a range of 0.04 to $0.07 \mu \mathrm{g} / \mathrm{L}$. All samples were greater than acceptable levels, so no action was needed. The laboratory reported the samples with the blanks subtracted.

Surrogate spikes. No surrogate compounds were spiked into the samples prior to extraction.

Matrix spikes. One sample from 8 of the 12 batches was spiked with mercury, but the amount of the spike was too small compared with the concentration in the tissue to provide useful information. 
Laboratory control samples. Forty-two LCSs were analyzed in the 12 batches, with recovery rates ranging from $85 \%$ to $109 \%$ and an average recovery rate of $98 \%$. All LCSs were within the acceptable range.

Method of standard addition. A one-point standard addition method was used for all analyses according to ORNL ACD method AC-MM1214922. A dilution of NIST 3133 was used for the MSA standard. A known amount of NIST 3133 was added to the CVAA sample to obtain each MSA value.

\section{A.1.4 Inductively Coupled Plasma Water Analyses}

Inductively coupled plasma (ICP) analysis of water samples was conducted by the K-25 ACD for beryllium, calcium, chromium, copper, iron, magnesium, nickel, potassium, sodium, and zinc. The USEPA Contract Laboratory Program Statement of Work for Inorganic Analysis, Multi-media, Multi-Concentration, (EPA 1988a) was used as the analytical protocol. Sixty-four samples were analyzed in four batches for the ten metals listed above (Tables A.14, A.15).

Holding times. All holding times were within limits.

Calibration. Calibration specifications ensure that the instrument is capable of producing acceptable quantitative data. Calibration sequences and frequencies were within requirements.

Blanks. The analysis of blanks provides a means of assessing the existence and magnitude of contamination introduced via the analytical scheme. No contamination that required action was reported in batches $1462 \mathrm{M}$ and $112 \mathrm{M}$. In batch $1422 \mathrm{M}$, higher than acceptable values were determined for calcium, iron, magnesium, sodium, and zinc from levels of contaminants found in either the preparation blank or the continuing calibration blank. Sample results less than the action levels for those analytes were qualified as U. Because of a baseline shift causing negative values for iron greater than twice the IDL in the calibration blanks, the results for iron in all samples for this batch were rejected (samples 1422M, 1432M, 1442M, $145 \mathrm{M}, 1452 \mathrm{M}, 146 \mathrm{M}$, and $147 \mathrm{M}$ ). Four of the samples were rinsate blanks. In batch $136 \mathrm{M}$, beryllium, calcium, iron, magnesium, sodium, and zinc were found at concentrations greater than the IDL; therefore, sample results were reported as nondetected (U-12) with the DL raised.

Matrix spikes. Spiked sample analysis provides information about the effect of the sample matrix on the digestion and measurement methodology. All criteria were met. Table A.3 summarizes the MSRs in water.

Duplicates. Results of duplicates analyses serve as an indicator of the precision of the methods and the sample results. All criteria were met. Table A.4 summarizes the duplicates in water.

Laboratory control samples. The LCS analysis is designed to serve as a monitor of the efficiency of the digestion procedure. An aqueous LCS must be analyzed on a digestion batch basis. All samples met criteria (Table A.5).

Serial dilution. Serial dilution analysis is performed to ascertain whether significant physical or chemical interferences exist because of the sample matrix. All criteria were met. 


\section{A.1.5 ICP Sediment Analyses}

ICP analysis of sediment samples was conducted by IT laboratories for beryllium, calcium, chromium, copper, iron, magnesium, nickel, potassium, sodium, and zinc. The USEPA Contract Laboratory Program Statement of Work for Inorganic Analysis, Multi-media, MultiConcentration, (EPA 1988a) was used as the analytical protocol for most of the samples. Fourteen sample batches containing -372 samples were processed for six metals (Tables A.16, A.17).

Holding times. All requirements for holding times were met with one exception. In batch 900531-005, all ICP results for samples 1410T, 1411T, 2607T, and 2608T were qualified as estimated (J/UJ) because the holding times were exceeded.

Calibration. Calibration specifications ensure that the instrument is capable of producing acceptable quantitative data. The calibration requirements for the data either met all the requirements or deviations did not warrant any action by the validator.

Blanks. The analysis of blanks provides a means of assessing the existence and magnitude of contamination introduced via the analytical scheme. All requirements were met, or deviations did not warrant any action by the validator. Zinc contamination was found in several of the preparation blanks, but sample results exceeded the action level with the following exception. In batch 900531-005, zinc was detected at a concentration greater than the IDL, so the zinc result for sample 900531-023 was qualified as U. In batch 891212-086, copper and zinc were detected; therefore, the copper results in selected samples were qualified as $U$, with the $D L$ raised to the quantitated values.

Interference check samples. The ICP interference check samples (ICS) verified the laboratory's interelement and background correction factors. No deviations were found except for batches $900611-035,900117-002$, and $900223-007$. In these batches, positive results greater than twice the IDL were found. The iron levels in all samples were greater than $50 \%$ of their levels in the check sample solution. As a result, positive zinc results in all samples were estimated because of iron interference. In batch 900223-007, the ICS solution A was not analyzed at the end of the run, which caused several analytes to be flagged as estimated (J).

Matrix spikes. Spiked sample analysis provides information about the effect of the sample matrix on the digestion and measurement methodology. All MSRs were within limits for batches 910607, 900611-035, 900427-161, and 900611-035. For batch 900627-014, some cadmium and zinc results were qualified J or UJ. For batch 900404-076, all sample results for zinc $(\mathrm{J} / \mathrm{UJ})$, chromium $(\mathrm{J} / \mathrm{U})$, and copper $(\mathrm{J} / \mathrm{U})$ were qualified as noted because recovery limits were exceeded. In batch 900117-002, zinc results in samples 900117-021 and 900177-029 did not meet the required recovery criteria and were flagged accordingly. For batch 900412-003, zinc results were flagged J because recovery was out of limits. For batch 900531-005, positive zinc results were qualified J, and copper, chromium, and cadmium results were qualified J/UJ. For batch 891212-086, the matrix spike analyses did not meet the required recovery criteria; therefore, the nondetected silver results in all samples were qualified as unusable (R), and the copper results in selected samples were qualified as estimated (J/UJ). For batch 900223 007, the matrix spike analysis did not meet the required recovery for beryllium, cadmium, chromium, copper, nickel, and zinc and was, therefore, flagged as estimated (J). Matrix spikes did not meet the required recoveries for cadmium and copper in batch 900612-050 and were qualified $\mathrm{J} / \mathrm{UJ}, \mathrm{J} / \mathrm{U}$, or $\mathrm{J} / \mathrm{R}$ accordingly. Tables $A .8$ and A.9 summarize the spike and 
postdigestion spike recoveries. Cadmium, copper, and zinc were the only three metals that did not meet the $75-125 \%$ limits for the spike recoveries at least $80 \%$ of the time. For the postdigestion spike recovery, aluminum and manganese only met the limits $50 \%$ of the time.

Duplicates. Results of duplicates analyses serve as an indicator of the precision of the methods and the sample results. All requirements were met for batches 910607 and 900323 137. No laboratory duplicate analysis was performed for batches $900627-014$, 900404-076, 900427-161, 900611-035, 900223-007, or 900308-014. The laboratory duplicate in batch 900117-002 did not meet the required RPD criteria for zinc, so results were flagged J. Table A.10 summarizes the duplicate performance. Aluminum, chromium, copper, magnesium, manganese, and zinc were within the limits less than $75 \%$ of the time.

Laboratory control samples. The LCS analysis is designed to serve as a monitor of the efficiency of the digestion procedure. A solid LCS must be analyzed at least on a monthly basis. All criteria were met or did not require any action by the validators. LCSs were not evaluated for batches 910607, 900323-137, 900404-076, and 900412-003 because EPA control limits were not provided by the laboratory. Table A.11 summarizes the performance of the LCSs. Criteria were met for all analytes at least $90 \%$ of the time.

ICP serial dilution. Serial dilution analysis is performed to ascertain whether significant physical or chemical interferences exist because of the sample matrix. All requirements were met, except for batches 900323-137, 900404-076, 900611-035, 900427-161, and 891212-086. In batches 900323-137 and 900404-076, the zinc results were qualified $\mathrm{J}$ because of failure to meet criteria. For batch $900611-035$, the percent difference (\%D) for zinc exceeded requirements, so zinc results were flagged J. Serial dilutions were needed for almost all samples for zinc for batch 900427-161, but only two sample reports were provided indicating serial dilution. However, no action was taken by the validator. In batch 891212-086, the ICP serial dilution analysis \%D for zinc in sample 891214-039 exceeded the 15\% difference requirement; therefore, the positive zinc results in samples 891212-104 through -109 and 891214-037 through -052 were qualified as estimated (J).

\section{A.6 ICP and ICP/Mass Spectrometry Analysis of Fish Tissue}

ICP and ICP/mass spectrometry (MS) analysis of fish tissue was conducted by ORNL CPA. For the analysis of metals, ICP/MS was used to measure arsenic, beryllium, and thallium, and ICP/atomic emission spectroscopy (AES) was used to measure antimony, cadmium, chromium, copper, lead, nickel, selenium, silver, and zinc. An internal method was used for sample preparation. A VG Plasma Quad PQ2 was used for the ICP/MS analyses and a JY-48 instrument was used for the ICP/AES analyses. The ICP/MS measurements were made using the standard addition technique. One hundred seventy-seven samples (169 regular samples and 8 field splits) were analyzed for 12 metals in 10 batches (Tables A.18, A.19, A.20).

Holding times. Pre-extraction holding times (sample collection to extraction) exceeded the 7-d criteria for water for some analyses. No data were rejected because no specific preextraction holding time criteria exist for fish tissue and because the 7-d water criteria are not applicable to fish tissue. Postextraction holding times were all within limits.

Calibration. Single-element NIST standards were used to prepare calibration solutions for the ICP/MS; multi-element Spex standards were used for ICP/AES standard solution 
preparation. EPA solution ICAP-19 was used as a calibration verification solution with recoveries in the range of $85-109 \%$. Lead failed calibration recovery criteria in some batches, resulting in the rejection of 52 samples. There was a question as to whether the ICP/AES was calibrated initially with a one-point standard, but the calibration was verified. For this reason, along with other calibration discrepancies, some data were reported as estimated (J or UJ). Some results for nickel, beryllium, and thallium were rejected for failure to meet calibration criteria. The ICP/MS was properly calibrated, and verification samples were analyzed. Calibration \%R ranges for the ICP/AES were from $64 \%$ to $120 \%$ for all parameters and all concentrations. Calibration \%R ranges for the ICP/MS were from $78 \%$ to $124 \%$ except for beryllium, which was near the DL with a $146 \%$ recovery. Fifteen beryllium analyses were rejected because of calibration deficiencies.

Blanks. Preparation blanks were performed with each batch. Results were similar to recovery ranges listed for metals in soils. ICP/MS analyses (As, Be, and $\mathrm{Tl}$ ) showed measurable concentrations in preparation blanks. Preparation blank corrections were performed on reported values. Calibration (instrument) blanks were not performed with the ICP/MS analyses.

Surrogate spikes. No surrogate compounds were spiked into the samples prior to extraction.

Matrix spikes. Ten samples in eight different batches were spiked with known quantities of all 12 metals. Except for three values for lead, all recoveries were between 75 and $125 \%$ (Fig. A.15). Mean recoveries for each metal ranged from $89 \%$ to $107 \%$ except for lead, which had an average recovery of $77 \%$. No samples were qualified or rejected because of matrix spike results.

\section{A.2 ORGANIC ANALYSES}

\section{A.2.1 Semivolatile Water and Sediment Analyses}

Semivolatile analyses of water and sediment samples were conducted at the K-25 ACD by gas chromatography (GC)/MS for the analytes listed in Tables A.21 and A.22. The USEPA Contract Laboratory Program Statement of Work for Organic Analysis, Multi-media, MultiConcentration, (EPA 1988b) was used as the analytical protocol. Sample 35800 was analyzed by IT, but the data were rejected because of exceeded holding times. Three hundred forty-two samples were analyzed for 65 organic compounds in 23 batches (Table A.21).

Holding times. All holding time requirements were met or warranted no action by the validator with the following exceptions. Some samples missed the holding time by $1 \mathrm{~d}$, but the data were used "as is" by the validator. Samples in batch 040590 were extracted 7 days outside the holding time except one. Sample 19120 was extracted 109 days outside the holding time, resulting in all nondetects being rejected. Samples 31070 and 19150 in batch 041990 were extracted 84 days and 122 days outside of the holding time, respectively. Nondetects were qualified as rejected (R) for these samples and detects estimated (J). Samples in batches $041690,041390,032290,070690$ were extracted 3 to 8 days outside the holding time, so the positive results were flagged estimated. Samples in batch 062190 were extracted and analyzed outside the contractually required holding time limit, and all results were qualified as J/UJ. Holding times for extraction exceeded 30 days for batch 061690 , 
resulting in rejected data for $73070,73060,73050,73040,31120$, and 31110. Sample results for 73080 and 73090 in batch 061490 missed the extraction holding time by 37 days and 33030 by 146 days. Sample data for 33030 were rejected; the results for the other two samples were flagged J/UJ. Sample data for 19090 in batch 030690 were rejected because of extraction holding times exceeding limits. Other samples in the batch were flagged J/UJ. All samples in batch 050890 exceeded extraction holding time by 6 days, and sample 33020 exceeded the analysis holding time by 19 days. All sample results for batch 050890 were qualified as estimated (J/UJ).

Calibration. Calibration specifications ensure that the instrument is capable of producing acceptable quantitative data. All calibration requirements were met or warranted no action by the validators with the following exceptions. Some compounds were outside the limits for the percent relative standard deviation (RSD) and \%D and were flagged J/UJ, as appropriate. For several batches, the calibrations for 2,4,6-trichlorophenol and 2,4,5-trichlorophenol were not properly done, so data for these compounds were rejected. In batch 121989, two compounds were outside the limits in the initial calibration verification, and 33 compounds were outside the limits in the five continuing calibration verification analysis runs, but no action was taken because none of the compounds were detected in any of the environmental samples and the percent RSD and \%D values were all less than 50\%. In batches 050890 and 070690, benzyl alcohol and 2-methylphenol were not quantitated, resulting in rejected data for both compounds. In batch $050890,2,4$-dinitrophenol was not detected in the continuing calibration for June 8, 1990. The results for 2,4-dinitrophenol were rejected in all associated samples. Hexachlorocyclopentadiene had a \%D of $52.6 \%$, which required flagging nondetects (UJ) for samples 73110, 86100, 86110, and 87010. Exceeded calibration limits in batch 061490 affected numerous compounds and samples.

Instrument tuning. All tuning criteria were met or warranted no action by the validator.

Blanks. The analysis of blanks provides a means of assessing the existence and magnitude of contamination introduced via the analytical scheme. All blanks met the method requirements or were flagged accordingly. For batch 012490 , bis(2-ethylhexyl)phthalate was found in the blank, but the sample concentrations exceeded the action level. This compound was also found in the method blanks for batch $\mathbf{0 1 2 2 9 0}$. Some results in batches 121989, 122089, and 030690 were qualified at the contract-required DL with a $U$ because of bis(2ethylhexyl)phthalate contamination in the blank. In batches 041990 and 062190 , an unknown compound and diacetone alcohol contamination required that data be flagged accordingly. Phthalate and tentatively identified compound contamination in the blanks for batch 032290 resulted in data flags. Samples in batch 061490 were affected by blank contamination and flagged accordingly. Several tentatively identified compounds were detected in all the blanks for batch 050890 , and data were qualified appropriately.

Surrogate spikes. All surrogate recoveries met the method requirements or were flagged accordingly. Tables A.23 and A.24 summarize the surrogate recoveries for this data set. All samples in batch 012990 had values for terphenyl-d14, which were outside the control limits. Samples in batch 061690 were reanalyzed because of zero surrogate recoveries during the first analysis. No deviations for the samples occurred during reanalysis, but the blank analysis recoveries were still zero.

Matrix spikes and duplicates. All criteria were met or no action was warranted by the validator, with the following exceptions. No matrix spike or matrix spike duplicate (MSD) was 
analyzed for batches $011690,012090,012490,012990,041890,041390,021390$, and 021090 . Table A.25 summarizes the MSRs for this data set. Table A.26 summarizes the matrix spike RPDs. For batch 122089 , several compounds did not meet the criteria, but no action was taken because none of the spike compounds were detected in the environmental samples. However, 4-nitrophenol results were rejected for sample 2221-O. In batch 040590, positive results for 2,4-dinitrotoluene and pentachlorophenol for sample 19120 were qualified as $\mathrm{J}$ because of missed limits. A mix-up in the matrix spike pair for batch 032290 could not be resolved because of inadequate documentation (see NCR-92-CRR-068, no. 5). For batch 030690, the \% $\mathrm{R}$ for 4-nitrophenol was outside limits, but no action was taken because the compound was not present in the samples.

Internal standards. All criteria were met. Sample 1210 had an internal standard area greater than $100 \%$. Area counts for perylene-d12 were outside the acceptable range for samples 2208-0 and 2210-0, but no action was taken because none of the compounds associated with this chromatographic region were detected in the environmental samples. One internal standard area was outside criteria in batch 041690 , resulting in sample results for 57270 being qualified as J/UJ. One internal standard area was outside criteria in batch 050890 for matrix spike sample 69030 , and no action was taken.

\section{A.22 Semivolatile Organic Analysis of Fish Tissue}

Semivolatile analyses of fish tissue were performed by the Organic Analysis Laboratory (OAI) of ORNL ACD. Semivolatiles were analyzed using a modified GC/MS procedure with no acid surrogates. Laboratory quality control (QC) elements included matrix spikes, method blanks, internal standardization, initial calibration, continuing calibration, and GC/MS tuning. One hundred twenty-three samples (116 regular samples and 7 field splits) were analyzed for 65 semivolatile organics in 17 batches (Tables A.27, A.28).

Holding times. The holding times problem was for pre-extraction holding times (from sample collection to extraction), which exceeded the 7-d criteria for water. No data were rejected because (1) no specific pre-extraction holding time criteria exist for fish tissue and (2) the 7-d water criteria are not applicable to fish tissue.

Calibration. Most of the 17 batches had acceptable tuning criteria. One batch (D409) incurred tuning problems; six batches (C503, C522, C524, C405, D403, D507) had one or more samples analyzed outside the 12-h tuning window, causing the positive results to be flagged as estimated. C517 had one daily standard outside the $12-\mathrm{h}$ window. Two initial calibration forms (D410, D417) had dates incorrectly listed; one form (C523) reported a different sample batch number on April 12, 1990; seven batches (C503, C504, C507, C517, C522, C524, C405) had one compound that failed the percent RSD criteria. Various problems were encountered with all batches of continuing calibration data, the majority of which included one or more compounds that failed relative response factor criteria and several compounds that failed $\% \mathrm{D}$ criteria.

Blanks. Most of the 17 batches had no major problems, except for the omission of Form 1F and tentatively identified compound (TIC) raw data from over half of the packages. Three batches (D403, D410, D425) had target compound lists (TCLs) greater than the reportable level; one batch (D403) had 11 TICs incorrectly reported on Form 1F. These problems did not result in any rejected analyses. 
Matrix spikes. One sample in 8 of 17 batches was spiked with known quantities of pyrene and benzo(a)anthracene. Spike recoveries for pyrene ranged from 1.8 to $11.8 \%$, with a mean recovery of $6.0 \%(n=8)$. Spike recoveries for benzo(a)anthracene ranged from $4.6 \%$ to $29.3 \%$, with a mean recovery of $6.0 \%(n=8)$. MSDs were not performed. Because there are no official control limits for MSR in fish tissue, no analyses were qualified.

Surrogate spikes. Surrogate recoveries of nitrobenzene-d5 ranged from $0 \%$ to $32 \%$, with 8 of 139 values within sediment control limits of $23-120 \%$. Surrogate recoveries of 2-fluorophenol ranged from $8 \%$ to $68 \%$, with 58 of 139 values within sediment control limits of 30 to $115 \%$. Surrogate recoveries of terphenyl-d14 ranged from $10 \%$ to $106 \%$, with 131 of 139 values within sediment control limits of $18-137 \%$. Because there are no official control limits for surrogate recovery in fish tissue, no analyses were rejected because of surrogate recoveries being substandard.

\section{A.2.3 Pesticide/Polychlorinated Biphenyl Water and Sediment Analyses}

Pesticide/polychlorinated bipheynl (PCB) analyses of water and sediment samples were conducted at the K-25 ACD by gas chromatography/electron capture detector for the TCL of pesticides/PCBs. The sediment samples were extracted at IT Corporation in Knoxville in accordance with the preparation protocol outlined in the USEPA Contract Laboratory Program Statement of Work for Organic Analysis, Multi-Media, Multi-Concentration, (EPA 1988b). The water samples were extracted by K-25 ACD personnel, using an extraction procedure that differed slightly from that outlined in the EPA Contract Laboratory Program (CLP) statement of work (SOW). Semivolatile and pesticide/ PCB extracts were prepared from separate sample aliquots. A separatory funnel extraction procedure was used. A modified version of the EPA CLP SOW that required analysis on only a single column was used as the analytical protocol. The analyses were performed on two Hewlett Packard Model HP5890 gas chromatographs equipped with electron capture detectors. Twenty-one sample batches were processed containing 364 samples (Tables A.29, A.30).

Holding times. Approximately 300 samples were extracted outside the holding time limit for water samples. All results for these samples, both positive and nondetect, were qualified as estimated for these samples. Several samples were analyzed outside holding time limits. All of these samples were also extracted outside holding time limits. Therefore, no additional data qualification was required.

Calibration. Five sample batches had one or two compounds that failed the initial calibration criterion. One batch could not be evaluated for initial calibration linearity because of the lack of initial calibration standard analysis. Seventeen sample batches had one or more compounds that failed the continuing calibration $\% \mathrm{D}$ criterion at some time in the analytical sequence. The initial calibration linearity criterion affects only single-component analytes (all pesticides except toxaphene). These violations require qualification of positive results for those compounds in affected samples as estimated. Because very few positive results were noted in these samples, there was a minimal impact on data quality.

Blanks. There were no positive results reported for the target compounds. Therefore, there should be no bias contributed to the data because of blank contamination. However, one data package case narrative mentioned there were potential interference peaks on two blank chromatograms. 
Surrogate spikes. The percentage of surrogate recoveries that failed to meet the established recovery criterion was $20 \%$ of sediment samples and $4 \%$ of water samples. The average recovery of surrogate spike was $132 \%$ for sediment samples and $90 \%$ for water samples. Surrogate recovery for water and sediment sample data is presented in Tables A.31 and A.32, respectively.

Matrix spikes and spike duplicates. The percentage of matrix spike/MSD recoveries that failed to meet the established recovery criterion was $35 \%$ for sediment samples (Table A.33) and $0 \%$ for water samples. The percentage of matrix spike/MSD RPDs that failed to meet the established RPD criterion was $9 \%$ for sediment samples (Table A.33) and $0 \%$ for water samples. The average sediment matrix spike/MSD RPD was $15 \%$.

\section{A.24 Pesticide/PCB Analysis of Fish Tissue}

Pesticide/PCB analyses of fish tissue were performed by the OAL of ORNL ACD. Fish tissue was extracted by sonification in methylene chloride with sodium sulfate. Extracts were concentrated and solvent-exchanged with hexane using Kuderna-Danish concentrators and nitrogen blowdown. Pesticide extracts were acid washed using concentrated sulfuric acid. The extracts were analyzed on a DB-5 capillary column and a DB-1701 megabore column using electron capture collection. One hundred twenty-three samples (116 regular samples and 7 field splits) were analyzed for 11 pesticides (aldrin, DDE, DDD, DDT, alpha chlordane, alpha chlordene, gamma chlordane, gamma chlordene, oxychlordane, chlordene, and technical chlordane) and two PCBs (Aroclor 1254 and Aroclor 1260) in 11 batches (Tables A.34, A.35).

Holding times. The holding times problem was primarily for pre-extraction holding times (from sample collection to extraction), which exceeded the 7-d criteria for water. No data were rejected because no specific pre-extraction holding time criteria exist for fish tissue and because the 7-d water criteria are not applicable to fish tissue.

Calibration. A single-point calibration was used for all analyses. The analytical method for water and soil requires a three-point calibration. All positive results were qualified as estimated (J).

Blanks. Contamination was detected in at least one method blank in 7 of 12 sample batches. These method blanks were associated with 71 samples. The major contaminants found were Aroclor 1254 and technical chlordane.

Matrix spikes. One sample in 8 of 11 batches was spiked with $0.5 \mathrm{ppm}$ of alpha chlordane, $0.5 \mathrm{ppm}$ of gamma chlordane, and $10 \mathrm{ppm}$ of Aroclor 1260 . Spike recoveries for alpha chlordane ranged from $14.1 \%$ to $62.8 \%$, with a mean recovery of $44.8 \%$. Spike recoveries for gamma chlordane ranged from $12.5 \%$ to $111.8 \%$, with a mean recovery of 70.4\%. Spike recoveries for Aroclor 1260 ranged from $18.3 \%$ to $64.6 \%$, with a mean recovery of $45.5 \%$. These results are illustrated in Fig. A.16. MSDs were not performed. Because there are no official control limits for MSR in fish tissue, no analyses were qualified.

Surrogate spikes. Surrogate recoveries of decachlorobiphenyl ranged from $13 \%$ to $111 \%$, with 36 of 152 values within sediment control limits of $60-150 \%$. Surrogate recoveries of tetrachloro-m-xylene ranged from $10 \%$ to $111 \%$, with 27 of 152 values within sedimentcontrol limits of $60-150 \%$. Because there are no official control limits for surrogate recovery in fish tissue, no analyses were rejected for surrogate recoveries being substandard. 
Interlaboratory performance evaluation. An additional measure of analytical quality was provided by an interlaboratory split sample study. Four cooperating laboratories (ORNL OAL, Tennessee Valley Authority (TVA), the state of Tennessee Environmental Laboratory, and the EPA Region IV facility) received identically prepared aliquots of the same samples for analysis of total chlordane (sum of all detectable congeners). The OAL values for total chlordane were consistently lower than those of the other laboratories. ORNL values were on average $68 \%$ lower than the mean of the other laboratories for those samples in which chlordane was detected.

\section{A.25 PCB Analysis of Fish Tissue}

PCB analyses of fish tissue were also performed by ORNL CPA. An internal procedure was used for sample preparation and analysis. One hundred and seventy-five samples (162 regular samples and 13 field splits) were analyzed for two PCBs in nine batches (Tables A.36, A.37).

Holding times. The holding times problem was for pre-extraction holding times (from sample collection to extraction) which exceeded the 7-d criteria for water. No data were rejected, because no specific pre-extraction holding time criteria exist for fish tissue and the 7-d water criteria are not applicable to fish tissue. Postextraction holding times were all within limits.

Calibration. A single-point calibration, which is acceptable for PCB analyses, was used. Calibrations for Aroclor 1254 were within control limits and ranged from 85\% to $113 \% \mathrm{R}$.

Blanks. In most batches, both calibration and preparation blanks were used. Calibration blank results were at or below the reporting limit in each batch, and preparation blanks were very low (near the reporting limits in each case where analyzed). No action was required on any blank, and blank corrections were not performed.

Surrogate spikes. No surrogate compounds were spiked into the samples prior to extraction.

Matrix spikes. At least one sample in eight of nine batches was spiked with a known quantity of Aroclor 1254 (5.3 ppm) and Aroclor 1260 (4.7 ppm). In two cases, only one of the Aroclors was spiked. Spike recoveries for Aroclor 1254 ranged from 77.3\& to $125.5 \%$, with a mean recovery of $101.6 \%(n=12)$. Spike recoveries for Aroclor 1260 ranged from $93.6 \%$ to $111.4 \%$, with a mean recovery of $101.8 \%(n=12)$. These results are summarized in Fig. A.17. MSDs were not performed. Because there are no official control limits for MSR in fish tissue, no analyses were qualified.

Laboratory control samples. At least one LCS for both Aroclor 1254 and 1260 was analyzed in every batch. Percent recoveries for Aroclor 1254 ranged from 83.3 to 154.0, with a mean recovery of $112.6(n=21)$. Percent recoveries for Aroclor 1260 ranged from 63.8 to 108.3 , with a mean recovery of $91.1(n=21)$. No analyses were qualified because of laboratory control deficiencies.

Interlaboratory performance evaluation. An additional measure of analytical quality was provided by an interlaboratory split sample study. Four cooperating laboratories (ORNL CPA, TVA, the state of Tennessee Environmental Laboratory, and the EPA Region IV facility) 
received identically prepared aliquots of 18 samples for analysis of total PCBs (Aroclor 1254 plus Aroclor 1260). The results from CPA for total PCBs were not statistically different from those of the other laboratories.

\section{A.3 RADIOLOGICAL ANALYSES}

\section{A3.1 Gamma Analysis of Sediment, Water, and Fish Tissue}

Gamma analysis was done by the Environmental Sciences Division (ESD) Radiological Analysis Laboratory (RAL) at ORNL. The method used by the laboratory was nondestructive and did not require any additional sample preparation prior to analysis. Target radionuclides and sample matrixes were ${ }^{137} \mathrm{Cs}$ and ${ }^{60} \mathrm{Co}$ in sediment, fish, and water. The laboratory used two spectrometers to analyze the Clinch River ER Program samples. The ND9900 is a minicomputer-based spectrometer connected to eight solid-state detectors and was used primarily for low-level gamma ray analyses. However, only detectors 1, 2, 3, 6, and 7 were used for the Clinch River ER Program samples. The ND6700 spectrometer consists of three solid-state detectors connected to a microcomputer-based data acquisition and analysis system. This instrument was generally used for the analysis of higher activity samples. Only detectors 1 and 3 were used for the analyses. The data acquisition and analysis components of both instruments were manufactured by Canberra Industries (formerly Nuclear Data). The detectors and associated electronic components were manufactured by several vendors, including Canberra, EG\&G ORTEC, and Princeton Gamma.

The ESD RAL analyzed 1195 regular samples consisting of 948 sediment, 210 fish, and 37 water samples. Of these 1195 samples, 28 were field splits. In addition, 100 laboratory duplicates and 395 LCSs were analyzed. An independent validator reviewed these data for precision, accuracy, representativeness, completeness, and comparability. For the purposes of validation, the samples were grouped into 112 batches based on the instrument and week in which they were analyzed. Tables A.38 and A.39 list the type and number of samples analyzed by instrument and batch.

Initial calibrations. Initial energy and resolution calibrations were performed when each detector was initially placed into service. Efficiency calibrations for the various sample geometries were done intermittently during the period of the Clinch River ER Program analyses. Aliquots of certified standards traceable to NIST were placed into the sample containers routinely used by the laboratory and counted long enough to minimize the uncertainty resulting from counting errors. Although most calibration data were available, there was insufficient documentation to fully trace the efficiency factors used for analysis to the calibration standard data.

Calibration checks. A calibration check was done daily for each detector by counting a ${ }_{137} \mathrm{Cs}$ standard for $1 \mathrm{~min}$. The date and peak area were recorded in a laboratory notebook, and the peak area was plotted on a control check for each detector. Weekly energy and resolution checks were also performed for each detector by counting a mixed-source New England Nuclear standard. The peak channel and resolution corresponding to low-, medium-, and high-energy lines were checked and recorded in a laboratory notebook. The validators found $11^{137} \mathrm{Cs}$ and $11^{60} \mathrm{Co}$ analyses to have an unacceptable change in calibration checks (Table A.40). However, none of these measurements were rejected. 
Holding times. Fifty-eight ${ }^{137} \mathrm{Cs}$ and $67{ }^{60} \mathrm{Co}$ measurements were flagged during validation as exceeding holding time requirements. In none of these cases were the data rejected.

Backgrounds. Background analyses were performed intermittently for each detector using distilled water as the sample. Typical counting times ranged from 3000 to $6000 \mathrm{~min}$ to remove short-term variations and minimize the propagated error when subtracting a background from a sample result. Table A.41 shows the frequency by instrument and detector of the background determinations during the time period of Clinch River ER Program analyses. None of the background analyses showed evidence of contamination.

Laboratory control samples. Analytical accuracy was assessed by measuring a variety of LCSs containing a known concentration of one or more radionuclides. An EPA-supplied clay sample spiked with ${ }^{137} \mathrm{Cs}$ was analyzed most frequently. In addition, several other control samples were run less frequently. These include NIST sediment samples 4350 (NBS-4350) and 4354 (NBS-4354) and a tuna fish sample from the International Atomic Energy Agency (IAEA-352). The ratio of measured activity to known activity was used as the accuracy measure. Table A.42 presents a summary of the LCS results. Only seven instances of analyses outside of limits were encountered. Twenty-five ${ }^{137} \mathrm{Cs}$ results and twenty-two ${ }^{60} \mathrm{Co}$ results were flagged during validation as having LCS results out of limits (Table A.40). Because none of these results was rejected, the effect on data quality is minimal.

Laboratory duplicates. Laboratory precision was monitored by periodically performing reanalysis of regular samples that had been submitted to the laboratory. The RPD typically used to assess precision can be misleading when applied to radiological results. The RPD does not consider the uncertainty in the measurement because of the statistical fluctuations of the spectrometric counting process. These fluctuations can result in an RPD falling outside of the acceptable limits when, actually, the two measurements are statistically indistinguishable. The duplicate error ratio (DER) is a measure that takes into account the uncertainty associated with radiometric results. A DER $<1$ indicates acceptable precision, and a value $>1$ indicates unacceptable precision. Table A.43 summarizes these results by instrument and matrix. Eight ${ }^{137} \mathrm{Cs}$ and twelve ${ }^{60} \mathrm{Co}$ results were affected by a DER out of limits (Table A.40). Because none of these results were rejected by the validators, the effect on data quality is minimal.

Performance evaluation. The ESD RAL participated in the environmental radioactivity laboratory intercomparison program conducted by EPA. A major objective of this program is to aid laboratories in developing and maintaining both an intralaboratory and interlaboratory QC program. Simulated environmental samples containing known amounts of one or more radionuclides were periodically distributed to the ESD RAL and other participating laboratories. The ESD RAL performed the required analyses in triplicate and submitted the results to EPA. EPA statistically analyzed the data from all participating laboratories and prepared a summary report.

During 1989, 1990, and 1991, 17 EPA performance evaluation samples were analyzed by the ESD RAL. Table A.44 presents the mean and standard deviations of the ESD RAL analyses. These statistics measure the central tendency and dispersion of the analytical results. The normalized range and deviation are also given in Table A44. The normalized range is an indicator of laboratory precision. A value less than 2.0 indicates acceptable precision. If the value is between 2.0 and 3.0, the precision is in the warning zone; if it exceeds 3.0 , it is out of control. All of the normalized ranges shown in Table A.44 are less than 1.0, indicating 
acceptable precision in the results. The normalized deviation is a measure of accuracy. The upper and lower warning levels are +2 and -2 . All of the values presented in Table A.44 fall within this range.

\section{A3.2 Alpha and Beta Analysis of Sediment, Water, and Fish Tissue}

The Oak Ridge Associated Universities (ORAU) Environmental Survey and Site Assessment Program (ESSAP) radiological laboratory conducted the alpha and beta analyses on the Phase 1 samples. Target radionuclides and matrixes included ${ }^{3} \mathrm{H}$ in water; ${ }^{90} \mathrm{Sr}$ in fish and sediment; and ${ }^{241} \mathrm{Am},{ }^{238} \mathrm{Pu},{ }^{239-240} \mathrm{Pu},{ }^{234} \mathrm{U},{ }^{235} \mathrm{U}$, and ${ }^{238} \mathrm{U}$ in sediment. In addition, curium isotopes were estimated from the ${ }^{241}$ Am spectrum, but these results were not necessarily accurate or precise. Alpha and beta determinations were destructive techniques that required laboratory preparation of the samples prior to spectrometric analysis. The ORAU ESSAP used three instruments in the analysis of the Clinch River ER Program samples. A Tennelec model LB-5110 low-background alpha and beta counter was used for the ${ }^{90} \mathrm{Sr}$ determinations. Tritium determinations were made with a Packard model 1900 liquid scintillation spectrometer. A spectrometer containing components from Canberra, Tennelec, and EG\&G ORTEC was used for alpha analyses.

The ORAU ESSAP analyzed 196 sediment, 87 fish, and 32 water samples for a total of 315 regular samples. In addition, 40 laboratory duplicates, 56 blanks, 8 spikes, and 11 LCSs were analyzed. An independent validator reviewed these data for sensitivity, precision, accuracy, representativeness, completeness, and comparability. For the purposes of validation, the samples were grouped into eight batches. Tables A.45 and A.46 list the type and number of samples analyzed in each batch.

Initial calibrations. Initial energy and resolution calibrations were performed when each detector was initially placed into service. Recalibrations were also made when control charts, equipment repair, or moving of equipment invalidate earlier calibration data. Efficiency calibrations for the various sample geometries were done using certified standards traceable to NIST. If NIST standards were unavailable, then other industry-recognized standards such as New Brunswick Laboratory were used.

Calibration checks. Counts of check sources were made prior to each day's use. The results of these analyses were plotted and tracked on control charts. None of the results for the regular samples were flagged because of calibration problems.

Sample preservation. The 16 water samples submitted for ${ }^{3} \mathrm{H}$ analysis (batch 741 ) werre not acidified following collection. Failure to acidify these samples could result in a loss of ${ }^{3} \mathrm{H}$ prior to analysis. Consequently, these results were rejected. In addition, the $16{ }^{90} \mathrm{Sr}$ water samples (batch 740) were flagged as estimated (J) because of improper sample preservation.

Holding times. Holding times were exceeded for 742 analyses. As a result, 726 analyses were flagged as estimated (J). The $16^{3} \mathrm{H}$ analyses that were rejected because of improper sample preservation were also flagged as having exceeded holding times.

Blanks. The number of blanks run with each batch is shown in Table A.47. Evidence of contamination was found in several of the blank analyses. No results were rejected because of this problem, but 144 analyses were flagged as estimated (J). 
Chemical recovery. Chemical recovery for alpha analyses was determined by spiking each sample with a known amount of a radionuclide tracer and analyzing for this tracer in addition to the target radionuclides. Chemical recovery for ${ }^{90} \mathrm{Sr}$ was determined gravimetrically. Table A.48 summarizes the recovery for each alpha batch, and Table A.49 summarizes the ${ }^{90} \mathrm{Sr}$ recoveries. Twenty analyses were rejected because of out-of-limit recoveries, and an additional 113 analyses were flagged as estimated (J).

Laboratory control samples. Analytical accuracy was assessed by measuring a variety of LCSs containing a known concentration of one or more radionuclides. Two EPA-supplied standards were analyzed for ${ }^{90} \mathrm{Sr}$ and ${ }^{3} \mathrm{H}$ (EPA 2454-1 and EPA 2458-1, respectively). A mixed-source standard from NIST (NBS 4353) was used to assess the accuracy of the uranium measurements. This sample was later spiked with known amounts of ${ }^{241} \mathrm{Am}$ and ${ }^{239} \mathrm{Pu}$ (NBS $4353+$ ) and used to assess accuracy for these radionuclides. Table A.50 presents a summary of the LCS results. Only four instances of analyses outside of limits were encountered. Twenty-seven ${ }^{90} \mathrm{Sr}$ results were flagged during validation as having LCS results out of limits (Table A.40). Because none of these results were rejected, the effect on data quality is minimal.

Laboratory duplicates. Laboratory precision was monitored by periodically performing duplicate analyses of regular samples that had been submitted to the laboratory. Precision was measured by the DER for the reasons discussed previously in Sect. 4.5.1. Table A.51 summarizes these results. Six analyses were flagged as estimated (J) because of the DER being out of limits. 
Table A. Atomic absorption analyses of water samples conducted at K-25

\begin{tabular}{lccccc}
\hline & \multicolumn{2}{c}{ Total } & & \multicolumn{2}{c}{ Water } \\
\cline { 2 - 3 } \cline { 5 - 6 } Batch & $\begin{array}{c}\text { Field } \\
\text { samples }\end{array}$ & $\begin{array}{c}\text { Routine } \\
\text { samples }\end{array}$ & & $\begin{array}{c}\text { Field } \\
\text { samples }\end{array}$ & $\begin{array}{c}\text { Routine } \\
\text { samples }\end{array}$ \\
\hline $112 \mathrm{M}$ & 6 & 14 & & 6 & 14 \\
$136 \mathrm{M}$ & 8 & 12 & & 8 & 12 \\
$1422 \mathrm{M}$ & 10 & 10 & & 10 & 10 \\
$1462 \mathrm{M}$ & 2 & & & 2 & \\
CRMI-1 & 2 & 2 & & 2 & 2 \\
Total & 28 & 38 & & 28 & 38 \\
\hline
\end{tabular}

Table A.2 Atomic absorption analyses of water samples conducted at K-25

\begin{tabular}{|c|c|c|c|c|c|c|c|c|}
\hline \multirow[b]{2}{*}{ Analyte } & \multicolumn{3}{|c|}{ Measurements } & \multicolumn{4}{|c|}{ Accept } & \multirow{2}{*}{$\frac{\text { Reject }}{26}$} \\
\hline & Total & Accept & Reject & 0 & 12 & 14 & 26 & \\
\hline Antimony & 66 & 66 & 0 & 34 & & 18 & 14 & \\
\hline Arsenic & 66 & 66 & 0 & 46 & & & 20 & \\
\hline Cadmium & 66 & 66 & 0 & 65 & 1 & & & \\
\hline Lead & 66 & 66 & 0 & 24 & 42 & & 1 & \\
\hline Mercury & 66 & 66 & 0 & 66 & & & & \\
\hline Selenium & 66 & 66 & 0 & 46 & & 20 & 9 & \\
\hline Silver & 66 & 66 & 0 & 49 & & & 17 & \\
\hline Thallium & 66 & 65 & 1 & 64 & & & 1 & 1 \\
\hline Total & 528 & 527 & 1 & 394 & 43 & 38 & 62 & 1 \\
\hline
\end{tabular}


Table A.3. Inorganic accuracy in water samples summary of matrix spike recoveries conducted at the K-25 laboratory

\begin{tabular}{|c|c|c|c|c|}
\hline Metals & $\begin{array}{c}\text { Control } \\
\text { limits } \\
(\%)\end{array}$ & $\begin{array}{l}\text { Number } \\
\text { in }\end{array}$ & $\begin{array}{c}\text { Number } \\
\text { out }\end{array}$ & $\begin{array}{l}\text { Percentage } \\
\text { within } \\
\text { limits }\end{array}$ \\
\hline Aluminum & $75-125$ & 0 & 0 & NS \\
\hline Antimony & $75-125$ & 3 & 1 & 75 \\
\hline Arsenic & $75-125$ & 3 & 0 & 100 \\
\hline Barium & $75-125$ & 0 & 0 & NS \\
\hline Beryllium & $75-125$ & 4 & 0 & 100 \\
\hline Cadmium & $75-125$ & 4 & 0 & 100 \\
\hline Calcium & $75-125$ & 0 & 0 & NS \\
\hline Chromium & $75-125$ & 3 & 0 & 100 \\
\hline Cobalt & $75-125$ & 0 & 0 & NS \\
\hline Copper & $75-125$ & 3 & 0 & 100 \\
\hline Iron & $75-125$ & 3 & 0 & 100 \\
\hline Lead & $75-125$ & 4 & 0 & 100 \\
\hline Magnesium & $75-125$ & 0 & 0 & NS \\
\hline Manganese & $75-125$ & 0 & 0 & NS \\
\hline Mercury & $75-125$ & 5 & 0 & 100 \\
\hline Nickel & $75-125$ & 3 & 0 & 100 \\
\hline Potassium & $75-125$ & 0 & 0 & NS \\
\hline Selenium & $75-125$ & 3 & 1 & 75 \\
\hline Silver & $75-125$ & 4 & 0 & 100 \\
\hline Sodium & $75-125$ & 0 & 0 & NS \\
\hline Thallium & $75-125$ & 4 & 0 & 100 \\
\hline Vanadium & $75-125$ & 0 & 0 & NS \\
\hline Zinc & $75-125$ & 3 & 0 & 100 \\
\hline
\end{tabular}


Table A4. Inorganic precision in water samples summary of laboratory duplicates conducted at the $\mathrm{K}-25$ laboratory

\begin{tabular}{lcccc}
\hline \multicolumn{1}{c}{ Metals } & $\begin{array}{c}\text { RPD } \\
\text { limit }\end{array}$ & $\begin{array}{c}\text { Number } \\
\text { in }\end{array}$ & $\begin{array}{c}\text { Number } \\
\text { out }\end{array}$ & $\begin{array}{c}\text { Percentage } \\
\text { wiithin limits }\end{array}$ \\
\hline Aluminum & 20 & 0 & 0 & \\
Antimony & 20 & 4 & 0 & 100 \\
Arsenic & 20 & 4 & 0 & 100 \\
Barium & 20 & 0 & 0 & \\
Beryllium & 20 & 3 & 0 & 100 \\
Cadmium & 20 & 4 & 0 & 100 \\
Calcium & 20 & 3 & 0 & 100 \\
Chromium & 20 & 3 & 0 & 100 \\
Cobalt & 20 & 0 & 0 & \\
Copper & 20 & 3 & 0 & 100 \\
Iron & 20 & 3 & 0 & 100 \\
Lead & 20 & 4 & 0 & 100 \\
Magnesium & 20 & 3 & 0 & 100 \\
Manganese & 20 & 0 & 0 & 100 \\
Mercury & 20 & 5 & 0 & 100 \\
Nickel & 20 & 3 & 0 & 100 \\
Potassium & 20 & 3 & 0 & 100 \\
Selenium & 20 & 4 & 0 & \\
Silver & 20 & 4 & 0 & 100 \\
Sodium & 20 & 3 & 0 & \\
Thallium & 20 & 4 & 0 & \\
Vanadium & 20 & 0 & 0 & \\
Zinc & 20 & 3 & 0 & \\
\hline & 20 & & \\
\hline
\end{tabular}

'relative percent difference 
Table A5. Inorganic accuracy in water samples summary of laboratory control samples conducted by the K-25 laboratory

\begin{tabular}{|c|c|c|}
\hline Metals & $\begin{array}{c}\text { Total } \\
\text { number }\end{array}$ & $\begin{array}{c}\text { Percentage } \\
\text { within } \\
80-120 \%\end{array}$ \\
\hline Aluminum & 0 & \\
\hline Antimony & 5 & 100 \\
\hline Arsenic & 5 & 100 \\
\hline Barium & 0 & \\
\hline Beryllium & 4 & 100 \\
\hline Cadmium & 5 & 100 \\
\hline Calcium & 4 & 100 \\
\hline Chromium & 4 & 100 \\
\hline \multicolumn{3}{|l|}{ Cobalt0 } \\
\hline Copper & 4 & 100 \\
\hline Iron & 4 & 100 \\
\hline Lead & 5 & 100 \\
\hline Magnesium & 4 & 100 \\
\hline Manganese & 0 & \\
\hline Mercury & 0 & \\
\hline Nickel & 4 & 100 \\
\hline Potassium & 4 & 100 \\
\hline Selenium & 5 & 100 \\
\hline Silver & 5 & 60 \\
\hline Sodium & 4 & 100 \\
\hline Thallium & 5 & 100 \\
\hline Vanadium & 0 & \\
\hline Zinc & 4 & 100 \\
\hline
\end{tabular}


Table A6. Atomic absorption anyalyses conducted at International Technology laboratories

\begin{tabular}{|c|c|c|c|c|c|c|}
\hline \multirow[b]{2}{*}{ Batch } & \multicolumn{2}{|c|}{ Total } & \multicolumn{2}{|c|}{ Core } & \multirow{2}{*}{$\begin{array}{c}\text { Grab } \\
\text { field } \\
\text { samples }\end{array}$} & \multirow{2}{*}{$\begin{array}{c}\text { Water } \\
\text { field } \\
\text { samples }\end{array}$} \\
\hline & $\begin{array}{c}\text { Field } \\
\text { samples }\end{array}$ & $\begin{array}{l}\text { Routine } \\
\text { samples }\end{array}$ & $\begin{array}{c}\text { Field } \\
\text { samples }\end{array}$ & $\begin{array}{l}\text { Routine } \\
\text { samples }\end{array}$ & & \\
\hline $891212-086$ & & 40 & · & 40 & & \\
\hline $900117-002$ & & 25 & & 25 & & \\
\hline $900223-007$ & & 15 & & 15 & & \\
\hline $900308-014$ & & 30 & & 30 & & \\
\hline $900323-137$ & 1 & 21 & 1 & 21 & & \\
\hline $900404-076$ & & 51 & & 51 & & \\
\hline $900412-003$ & & 47 & & 47 & & \\
\hline $900427-161$ & 1 & 39 & 1 & 39 & & \\
\hline $900531-005$ & & 19 & & 19 & & \\
\hline $900611-035$ & 1 & 16 & 1 & 16 & & \\
\hline $900612-050$ & & 9 & & 9 & & \\
\hline $900627-014$ & & 17 & & 17 & & \\
\hline 900629 & & 2 & & 2 & & \\
\hline 910510 & & 1 & & 1 & & \\
\hline 910607 & 1 & 2 & & 2 & 1 & \\
\hline 910614-044 & 6 & 28 & 4 & 28 & & 2 \\
\hline Total & 10 & 362 & 7 & 362 & 1 & 2 \\
\hline
\end{tabular}


Table A7. Atomic absorption anyalyses conducted at International Technology laboratories

\begin{tabular}{|c|c|c|c|c|c|c|c|c|c|c|c|c|c|c|c|c|c|c|c|c|}
\hline \multirow[b]{2}{*}{ Analyte } & \multicolumn{3}{|c|}{ Measurements } & \multicolumn{13}{|c|}{ Accept } & \multicolumn{4}{|c|}{ Reject } \\
\hline & Total & Accept & Reject & $\mathbf{0}$ & 1 & 12 & 14 & 18 & 19 & 22 & 24 & 25 & 26 & 27 & 50 & 54 & $\mathbf{0}$ & 10 & 14 & 54 \\
\hline Antimony & 372 & 201 & 171 & 127 & 6 & 1 & 53 & & & & & & 28 & & & & & & 171 & \\
\hline Arsenic & 372 & 371 & 1 & 119 & 6 & & 248 & & & & 17 & & 27 & 7 & & & & 1 & & \\
\hline Lead & 372 & 372 & o & 155 & 6 & & 125 & & & & 16 & 5 & 17 & 2 & 17 & 37 & & & & \\
\hline Mercury & 370 & 370 & $\mathbf{0}$ & 204 & 17 & & 27 & 122 & & & & & & & & & & & & \\
\hline Selenium & 372 & 306 & 66 & 14 & 6 & & 228 & & 3 & & 17 & 2 & 200 & 11 & & & & & 66 & \\
\hline Sitver & 371 & 204 & 167 & 83 & 6 & 12 & 87 & & & 4 & 17 & & 70 & & & & 2 & & 140 & 25 \\
\hline Thallium & 369 & 369 & 0 & 330 & 6 & & 1 & & & & 17 & & 16 & & & & & & & \\
\hline Total & 2598 & 2193 & 405 & 1032 & 53 & 13 & 769 & 122 & 3 & 4 & 84 & 7 & 358 & 20 & 17 & 37 & 2 & 1 & 377 & 25 \\
\hline
\end{tabular}


Table A8. Inorganic accuracy in soil samples summary of spike recoveries conducted at International Technology laboratories

\begin{tabular}{|c|c|c|c|c|}
\hline Metals & $\begin{array}{l}\text { Control } \\
\text { Limits } \\
(\%)\end{array}$ & $\begin{array}{c}\text { Number } \\
\text { in }\end{array}$ & $\begin{array}{c}\text { Number } \\
\text { out }\end{array}$ & $\begin{array}{c}\text { Percentage } \\
\text { within } \\
\text { limits } \\
\end{array}$ \\
\hline Aluminum & $75-125$ & 4 & 0 & 100 \\
\hline Antimony & $75-125$ & 11 & 28 & 28 \\
\hline Arsenic & $75-125$ & 21 & 18 & 54 \\
\hline Barium & $75-125$ & 4 & 0 & 100 \\
\hline Beryllium & $75-125$ & 31 & 3 & 91 \\
\hline Cadmium & $75-125$ & 28 & 10 & 74 \\
\hline Calcium & $75-125$ & 0 & 0 & NS \\
\hline Chromium & $75-125$ & 31 & 6 & 84 \\
\hline Cobalt & $75-125$ & 4 & 0 & 100 \\
\hline Copper & $75-125$ & 28 & 9 & 76 \\
\hline Iron & $75-125$ & 4 & 0 & 100 \\
\hline Lead & $75-125$ & 35 & 7 & 83 \\
\hline Magnesium & $75-125$ & 0 & 0 & NS \\
\hline Manganese & $75-125$ & 4 & 0 & 100 \\
\hline Mercury & $75-125$ & 32 & 3 & 91 \\
\hline Nickel & $75-125$ & 35 & 0 & 100 \\
\hline Potassium & $75-125$ & 0 & 0 & NS \\
\hline Selenium & $75-125$ & 11 & 28 & 28 \\
\hline Silver & $75-125$ & 15 & 26 & 37 \\
\hline Sodium & $75-125$ & 0 & 0 & NS \\
\hline Thallium & $75-125$ & 37 & 1 & 97 \\
\hline Vanadium & $75-125$ & 4 & 0 & 100 \\
\hline Zinc & $75-125$ & 26 & 11 & 70 \\
\hline
\end{tabular}

NS $=$ not spiked 
Table A.9. Inorganic accuracy in soil samples summary of postdigestion

\begin{tabular}{|c|c|c|c|}
\hline Metals & $\begin{array}{c}\text { Number } \\
\text { in }\end{array}$ & $\begin{array}{c}\text { Number } \\
\text { out }\end{array}$ & $\begin{array}{c}\text { Percentage } \\
\text { within } \\
\text { limits }\end{array}$ \\
\hline Aluminum & 1 & 1 & 50 \\
\hline Antimony & 14 & 0 & 100 \\
\hline Arsenic & 15 & 0 & 100 \\
\hline Barium & 2 & 0 & 100 \\
\hline Beryllium & 4 & 0 & 100 \\
\hline Cadmium & 7 & 1 & 88 \\
\hline Calcium & 0 & 0 & NS \\
\hline Chromium & 6 & 0 & 100 \\
\hline Cobalt & 2 & 0 & 100 \\
\hline Copper & 6 & 0 & 100 \\
\hline Iron & 0 & 2 & 0 \\
\hline Lead & 7 & 2 & 78 \\
\hline Magnesium & 0 & 0 & NS \\
\hline Manganese & 1 & 1 & 50 \\
\hline Mercury & 0 & 0 & NS \\
\hline Nickel & 4 & 0 & 100 \\
\hline Potassium & 0 & 0 & NS \\
\hline Selenium & 16 & 2 & 89 \\
\hline Silver & 8 & 4 & 67 \\
\hline Sodium & 0 & 0 & NS \\
\hline Thallium & 4 & 0 & 100 \\
\hline Vanadium & 2 & 0 & 100 \\
\hline Zinc & 11 & 0 & 100 \\
\hline
\end{tabular}

NS $=$ not spiked 
Table A10. Inorganic precision in soil samples summary of laboratory duplicates conducted at International Technology laboratories

\begin{tabular}{|c|c|c|c|c|}
\hline Metals & $\begin{array}{c}\text { RPD' } \\
\text { limits } \\
(\%)\end{array}$ & $\begin{array}{c}\text { Number } \\
\text { in }\end{array}$ & $\begin{array}{c}\text { Number } \\
\text { out }\end{array}$ & $\begin{array}{c}\text { Percentage } \\
\text { within } \\
\text { limits }\end{array}$ \\
\hline Aluminum & 35 & 0 & 3 & 0 \\
\hline Antimony & 35 & 23 & 0 & 100 \\
\hline Arsenic & 35 & 19 & 4 & 83 \\
\hline Barium & 35 & 3 & 0 & 100 \\
\hline Beryllium & 35 & 18 & 0 & 100 \\
\hline Cadmium & 35 & 20 & 0 & 100 \\
\hline Calcium & 35 & 3 & 1 & 75 \\
\hline Chromium & 35 & 9 & 9 & 50 \\
\hline Cobalt & 35 & 4 & 0 & 100 \\
\hline Copper & 35 & 13 & 5 & 72 \\
\hline Iron & 35 & 2 & 2 & 50 \\
\hline Lead & 35 & 23 & 2 & 92 \\
\hline Magnesium & 35 & 3 & 1 & 75 \\
\hline Manganese & 35 & 1 & 1 & 50 \\
\hline Mercury & 35 & 12 & 2 & 86 \\
\hline Nickel & 35 & 12 & 3 & 80 \\
\hline Potassium & 35 & 5 & 0 & 100 \\
\hline Selenium & 35 & 24 & 0 & 100 \\
\hline Silver & 35 & 21 & 2 & 91 \\
\hline Sodium & 35 & 4 & 0 & 100 \\
\hline Thallium & 35 & 19 & 3 & 86 \\
\hline Vanadium & 35 & 3 & 0 & 100 \\
\hline Zinc & 35 & 11 & 7 & 61 \\
\hline
\end{tabular}

'relative percent difference 
Table A.11. Inorganic accuracy in soil samples summary of laboratory control samples

\begin{tabular}{|c|c|c|}
\hline Metals & $\begin{array}{c}\text { Total } \\
\text { number }\end{array}$ & $\begin{array}{c}\text { Percentage } \\
\text { within } \\
80-120 \%\end{array}$ \\
\hline Aluminum & 17 & 100 \\
\hline Antimony & 50 & 100 \\
\hline Arsenic & 51 & 100 \\
\hline Barium & 17 & 100 \\
\hline Beryllium & 36 & 100 \\
\hline Cadmium & 46 & 98 \\
\hline Calcium & 19 & 95 \\
\hline Chromium & 37 & 95 \\
\hline Cobalt & 18 & 94 \\
\hline Copper & 38 & 95 \\
\hline Iron & 19 & 95 \\
\hline Lead & 50 & 100 \\
\hline Magnesium & 19 & 95 \\
\hline Manganese & 19 & 95 \\
\hline Mercury & 42 & 100 \\
\hline Nickel & 36 & 97 \\
\hline Potassium & 19 & 95 \\
\hline Selenium & 55 & 96 \\
\hline Silver & 33 & 91 \\
\hline Sodium & 19 & 95 \\
\hline Thallium & 52 & 100 \\
\hline Vanadium & 18 & 94 \\
\hline Zinc & 37 & 97 \\
\hline
\end{tabular}


Table A.12 Atomic absorption analyses of fish tissue conducted by Environmental Analysis Laboratory at

Oak Ridge National Laboratory

\begin{tabular}{cccccc}
\hline & \multicolumn{2}{c}{ Total } & & \multicolumn{2}{c}{ Fish } \\
\cline { 2 - 3 } \cline { 5 - 6 } Batch & $\begin{array}{c}\text { Field } \\
\text { samples }\end{array}$ & $\begin{array}{c}\text { Routine } \\
\text { samples }\end{array}$ & & $\begin{array}{c}\text { Field } \\
\text { samples }\end{array}$ & $\begin{array}{c}\text { Routine } \\
\text { samples }\end{array}$ \\
\hline EAL11914 & 1 & 20 & 1 & 20 \\
EAL11953 & & 10 & & 10 \\
EAL11954 & 1 & 7 & & 1 & 7 \\
EAL11955 & 1 & 3 & & 1 & 3 \\
EAL11956 & & 10 & & 10 \\
EAL11957 & & 10 & & 10 \\
EAL12033 & 3 & 58 & & 3 & 58 \\
EAL12098 & & 8 & & 8 \\
EAL12161 & 1 & 13 & & 1 & 13 \\
EAL12162 & 1 & 17 & & 1 & 17 \\
EAL12163 & 1 & 5 & & 1 & 5 \\
EAL12306 & & 8 & & 9 \\
Total & 9 & 169 & 9 & 169 \\
\hline
\end{tabular}

Table A13. Atomic absorption analyses of fish tissue camined for mercury by Environmental Analysis Laboratory at Oak Ridge National Laboratory

\begin{tabular}{ccccccccc}
\hline & \multicolumn{3}{c}{ Measurements } & & \multicolumn{4}{c}{ Accept } \\
\cline { 2 - 5 } \cline { 6 - 8 } Analyte & Total & Accept & Reject & & 0 & 1 & 52 & 60 \\
\hline Mercury & \multirow{2}{*}{178} & \multirow{2}{*}{178} & 0 & & 4 & 174 & 174 & 166 \\
Total & & & & & 4 & 174 & 174 & 166 \\
\hline
\end{tabular}


Table A.14. Inductively coupled plasma analyses of water samples conducted by the K-25 Analytical Chemistry Division

\begin{tabular}{lccccc}
\hline \multirow{2}{*}{ Batch } & \multicolumn{2}{c}{ Total } & & \multicolumn{2}{c}{ Water } \\
\cline { 2 - 3 } \cline { 5 - 6 } & $\begin{array}{c}\text { Field } \\
\text { samples }\end{array}$ & $\begin{array}{c}\text { Routine } \\
\text { samples }\end{array}$ & & $\begin{array}{c}\text { Field } \\
\text { samples }\end{array}$ & $\begin{array}{c}\text { Routine } \\
\text { samples }\end{array}$ \\
\hline $112 \mathrm{M}$ & 6 & 14 & & 6 & 14 \\
$136 \mathrm{M}$ & 8 & 12 & & 8 & 12 \\
$1422 \mathrm{M}$ & 10 & 10 & & 10 & 10 \\
$1462 \mathrm{M}$ & 2 & & & 2 & \\
Total & 26 & 36 & 26 & 36 \\
\hline
\end{tabular}

Table A.15. Inductively coupled plasma analyses of water samples conducted by the K-25 Analytical Chemistry Department for ten metals

\begin{tabular}{|c|c|c|c|c|c|c|c|}
\hline \multirow[b]{2}{*}{ Analyte } & \multicolumn{3}{|c|}{ Measurements } & \multicolumn{3}{|c|}{ Accept } & \multirow{2}{*}{$\frac{\text { Reject }}{61}$} \\
\hline & Total & Accept & Reject & 0 & 12 & 61 & \\
\hline Beryllium & 62 & 62 & 0 & 57 & 5 & & \\
\hline Calcium & 62 & 62 & 0 & 51 & 11 & & \\
\hline Chromium & 62 & 62 & 0 & 62 & & & \\
\hline Copper & 62 & 62 & 0 & 62 & & & \\
\hline Iron & 62 & 55 & 7 & 26 & 22 & 13 & 7 \\
\hline Magnesium & 62 & 62 & 0 & 47 & 15 & & \\
\hline Nickel & 62 & 62 & 0 & 62 & & & \\
\hline Potassium & 61 & 61 & 0 & 61 & & & \\
\hline Sodium & 61 & 61 & 0 & 47 & 14 & & \\
\hline Zinc & 62 & 62 & 0 & 14 & 48 & & \\
\hline Total & 618 & 611 & 7 & 489 & 115 & 13 & 7 \\
\hline
\end{tabular}


Table A16. Inductively coupled plasma anatyses of sediment conducted by International Technology laboratories

\begin{tabular}{|c|c|c|c|c|c|c|}
\hline \multirow[b]{2}{*}{ Batch } & \multicolumn{2}{|c|}{ Total } & \multicolumn{2}{|c|}{ Core } & \multirow{2}{*}{$\begin{array}{c}\text { Grab } \\
\text { field } \\
\text { samples } \\
\end{array}$} & \multirow{2}{*}{$\begin{array}{c}\text { Water } \\
\text { field } \\
\text { samples }\end{array}$} \\
\hline & $\begin{array}{c}\text { Field } \\
\text { samples }\end{array}$ & $\begin{array}{l}\text { Routine } \\
\text { samples }\end{array}$ & $\begin{array}{c}\text { Field } \\
\text { samples }\end{array}$ & $\begin{array}{l}\text { Routine } \\
\text { samples }\end{array}$ & & \\
\hline $891212-086$ & & 40 & & 40 & & \\
\hline $900117-002$ & & 25 & & 25 & & \\
\hline $900223-007$ & & 15 & & 15 & & \\
\hline $900308-014$ & & 30 & & 30 & & \\
\hline $900323-137$ & 1 & 21 & 1 & 21 & & \\
\hline $900404-076$ & & 51 & & 51 & & \\
\hline $900412-003$ & & 47 & & 47 & & \\
\hline $900427-161$ & 1 & 39 & 1 & 39 & & \\
\hline 900531-005 & & 19 & & 19 & & \\
\hline $900611-035$ & 1 & 16 & 1 & 16 & & \\
\hline $900612-050$ & & 9 & & 9 & & \\
\hline $900627-014$ & & 17 & & 17 & & \\
\hline 900629 & & 2 & & 2 & & \\
\hline 910510 & & 1 & & 1 & & \\
\hline 910607 & 1 & 2 & & 2 & 1 & \\
\hline 910614-044 & 6 & 28 & 4 & 28 & & \\
\hline Total & 10 & 362 & 7 & 362 & 1 & 2 \\
\hline
\end{tabular}


Table A.17. Inductively coupled plasma analyses of sediment samples conducted by International Technology laboratories

\begin{tabular}{|c|c|c|c|c|c|c|c|c|c|c|c|c|c|c|}
\hline \multirow{2}{*}{ Analyte } & \multicolumn{3}{|c|}{ Measurements } & \multicolumn{11}{|c|}{ Accept } \\
\hline & Total & Accept & Reject & 0 & 1 & 12 & 14 & 15 & 22 & 23 & 26 & 27 & 28 & 54 \\
\hline Beryllium & 372 & 372 & 0 & 340 & 6 & 11 & 15 & & 14 & & & & & \\
\hline Cadmium & 372 & 372 & $\mathbf{0}$ & 249 & 6 & 1 & 97 & & & 2 & 28 & 5 & & \\
\hline Calcium & 1 & 1 & 0 & 1 & & & & & & & & & & \\
\hline Chromium & 372 & 372 & 0 & 266 & 6 & & 106 & & 14 & 1 & & & & \\
\hline Copper & 372 & 372 & 0 & 221 & 6 & 17 & 144 & & 14 & 2 & & & & \\
\hline Iron & 1 & 1 & 0 & & & & & - & & 1 & & & & \\
\hline Magnesium & 1 & 1 & 0 & 1 & & & & & & & & & & \\
\hline Nickel & 372 & 372 & 0 & 351 & 6 & & 15 & & 14 & & & & & \\
\hline Potassium & 1 & 1 & 0 & 1 & & & & & & & & & & \\
\hline Sodium & 1 & 1 & 0 & & & 1 & & & & & & & & \\
\hline Zinc & 372 & 372 & $\mathbf{0}$ & 108 & 6 & 1 & 201 & 13 & 15 & 2 & & & 112 & 21 \\
\hline Total & 2237 & 2237 & $\mathbf{0}$ & 1538 & 36 & 31 & 578 & 13 & 71 & 8 & 28 & 5 & 112 & 21 \\
\hline
\end{tabular}




\section{A-34}

Table A18. Inductively coupled plasma and inductively coupled plasma and mass spectrometry analyses of fish tissue conducted at Oak Ridge

National Laboratory/Chemical and Physical Analysis Group

\begin{tabular}{cccccc}
\hline \multirow{2}{*}{$\begin{array}{c}\text { Systems } \\
\text { Development } \\
\text { Group }\end{array}$} & $\begin{array}{c}\text { Field } \\
\text { samples }\end{array}$ & $\begin{array}{c}\text { Routine } \\
\text { samples }\end{array}$ & & $\begin{array}{c}\text { Field } \\
\text { samples }\end{array}$ & $\begin{array}{c}\text { Routine } \\
\text { samples }\end{array}$ \\
\hline CPA10495 & 1 & 17 & & 1 & 17 \\
CPA10497 & 1 & 21 & & 1 & 21 \\
CPA10549 & 2 & 20 & & 2 & 20 \\
CPA10550 & & 20 & & 20 \\
CPA10682 & 1 & 20 & & 1 & 20 \\
CPA10772 & & 20 & & 20 \\
CPA10885 & 1 & 12 & & 1 & 12 \\
CPA10886 & & 8 & & 8 \\
CPA10915 & 2 & 23 & & 2 \\
CPA11093 & & 8 & & 23 \\
Total & 8 & 169 & 8 & 169 \\
\hline
\end{tabular}

Table A.19. Inductively coupled plasma and inductively coupled plasma and mass spectrometry analyses of fish tissue esamined for metals at Oak Ridge National Laboratory/ Chemical and Physical Analysis Group

\begin{tabular}{|c|c|c|c|c|c|c|c|c|c|c|}
\hline \multirow{2}{*}{ Analyte } & \multicolumn{3}{|c|}{ Measurements } & \multicolumn{6}{|c|}{ Accept } & \multirow{2}{*}{$\frac{\text { Reject }}{19}$} \\
\hline & Total & Accept & Reject & 12 & 14 & 19 & 23 & 52 & 53 & \\
\hline Antimony & 177 & 177 & 0 & & & & & 177 & 177 & \\
\hline Cadmium & 177 & 177 & 0 & & & & & 177 & 177 & \\
\hline Chromium & 177 & 177 & 0 & & & & & 177 & 177 & \\
\hline Copper & 177 & 177 & 0 & & & 3 & 8 & 177 & 177 & \\
\hline Lead & 177 & 125 & 52 & & 25 & 26 & & 125 & 125 & 52 \\
\hline Nickel & 177 & 157 & 20 & & & 22 & & 157 & 157 & 20 \\
\hline Selenium & 177 & 177 & 0 & 2 & & & & 177 & 177 & \\
\hline Silver & 177 & 177 & 0 & & & & & 177 & 177 & \\
\hline Zinc & 176 & 176 & 0 & & & 22 & & 176 & 176 & \\
\hline Total & 1592 & 1520 & 72 & 2 & 25 & 73 & 8 & 1520 & 1520 & 72 \\
\hline
\end{tabular}




\section{A-35}

Table A.20. Inductively coupled plasma and inductively coupled plasma and mass spectrometry analyses of fish tissue examined for metals at Oak Ridge National Laboratory/

Chemical and Physical Analysis Group

\begin{tabular}{|c|c|c|c|c|c|c|c|c|c|}
\hline \multirow[b]{2}{*}{ Analytes } & \multicolumn{3}{|c|}{ Measurements } & \multicolumn{4}{|c|}{ Accept } & \multicolumn{2}{|c|}{ Reject } \\
\hline & Total & Accept & Reject & 14 & 19 & 52 & 53 & 19 & 20 \\
\hline Arsenic & 177 & 177 & 0 & 1 & 12 & 177 & 177 & & \\
\hline Beryllium & 177 & 162 & 15 & & 44 & 162 & 162 & 7 & 8 \\
\hline Thallium & 177 & 168 & 9 & & 8 & 168 & 168 & 9 & \\
\hline Total & 531 & 502 & 24 & 1 & 64 & 507 & 507 & 16 & 8 \\
\hline
\end{tabular}

Table A.21. Semivolatile analyses of water and sediment samples conducted at K-25

\begin{tabular}{|c|c|c|c|c|c|c|}
\hline \multirow[b]{2}{*}{ Batch } & \multicolumn{2}{|c|}{ Total } & \multicolumn{2}{|c|}{ Core } & \multicolumn{2}{|c|}{ Water } \\
\hline & $\begin{array}{c}\text { Field } \\
\text { samples }\end{array}$ & $\begin{array}{l}\text { Routine } \\
\text { samples }\end{array}$ & $\begin{array}{c}\text { Field } \\
\text { samples }\end{array}$ & $\begin{array}{l}\text { Routine } \\
\text { samples }\end{array}$ & $\begin{array}{c}\text { Field } \\
\text { samples }\end{array}$ & $\begin{array}{l}\text { Routine } \\
\text { samples }\end{array}$ \\
\hline 011690 & & 2 & & & & 2 \\
\hline 012090 & 5 & 7 & & & 5 & 7 \\
\hline 012290 & & 13 & & 13 & & \\
\hline 012490 & & 4 & & 4 & & \\
\hline 012990 & 3 & 4 & & & 3 & 4 \\
\hline 020490 & 3 & 3 & & & 3 & 3 \\
\hline 021090 & 2 & 2 & & & 2 & 2 \\
\hline 021390 & 1 & & & & 1 & \\
\hline 030690 & & 15 & & 15 & & \\
\hline 032290 & & 26 & & 26 & & \\
\hline 040590 & 1 & 22 & 1 & 22 & & \\
\hline 041390 & & 24 & & 24 & & \\
\hline 041690 & & 14 & & 14 & & \\
\hline 041890 & & 19 & & 19 & & \\
\hline 041990 & & 13 & & 13 & & \\
\hline 050890 & 1 & 38 & 1 & 38 & & \\
\hline 053190 & 1 & 25 & 1 & 25 & & \\
\hline 061490 & 1 & 14 & 1 & 14 & & \\
\hline 061690 & & 4 & & 4 & & . \\
\hline 062190 & & 13 & & 13 & & \\
\hline 070690 & & 9 & & 9 & & \\
\hline 121989 & & 30 & & 30 & & \\
\hline 122089 & & 19 & & 19 & & \\
\hline Total & 18 & 320 & 4 & 302 & 14 & 18 \\
\hline
\end{tabular}


Table A.22 Semivolatile analyses of water and sediment samples conducted at K-25

\begin{tabular}{|c|c|c|c|c|c|c|c|c|c|c|c|c|c|c|c|c|c|c|c|}
\hline \multirow[b]{2}{*}{ Analyte } & \multicolumn{3}{|c|}{ Measurements } & \multicolumn{8}{|c|}{ Accept } & \multicolumn{8}{|c|}{ Reject } \\
\hline & Total & Accept & Reject & 0 & 1 & $\overline{4}$ & $\overline{6}$ & 12 & 13 & 16 & 57 & 1 & 3 & 5 & 6 & 13 & 14 & 18 & 60 \\
\hline 1,2,4-Trichlorobenzene & 338 & 331 & 7 & 90 & 240 & & 7 & 1 & & & & 6 & & & & 4 & & & \\
\hline 1,2-Dichlorobenzene & 338 & 331 & 7 & 90 & 240 & & 7 & 1 & & & & 6 & & & & 4 & & & \\
\hline 1,3-Dichlorobenzene & 338 & 331 & 7 & 90 & 240 & & 7 & 1 & & & & 6 & & & & 4 & & & \\
\hline 1,4-Dichlorobenzene & 338 & 331 & 7 & 90 & 240 & & 7 & 1 & & & & 6 & & & & 4 & . & & \\
\hline 2,4,5-Trichlorophenol & 338 & 327 & 11 & 88 & 238 & & 7 & 1 & & & & 6 & & & & 3 & & 2 & \\
\hline 2,4,6-Trichlorophenol & 338 & 327 & 11 & 88 & 238 & & 7 & 1 & & & & 6 & & & & 3 & & 2 & \\
\hline 2,4-Dichlorophenol & 338 & 329 & 9 & 88 & 240 & & 7 & 1 & & & & 6 & & & & 3 & & & \\
\hline 2,4-Dimethylphenol & 338 & 329 & 9 & 88 & 240 & & 7 & 1 & & & & 6 & & & & 3 & & & \\
\hline 2,4-Dinitrophenol & 338 & 305 & 33 & 88 & 217 & & 8 & & & & & 6 & & 25 & 12 & 3 & & & \\
\hline 2,4-Dinitrotoluene & 338 & 331 & 7 & 90 & 241 & & 8 & & & & & 6 & & & & 5 & & & \\
\hline 2,6-Dinitrotoluene & 338 & 331 & 7 & 90 & 240 & & 7 & 1 & & & & 6 & & & & 4 & & & \\
\hline 2-Chloronaphthalene & 338 & 331 & 7 & 90 & 240 & & 7 & 1 & & & & 6 & & & & 4 & & & \\
\hline 2-Chlorophenol & 338 & 329 & 9 & 88 & 240 & & 7 & 1 & & & & 6 & & & & 3 & & & \\
\hline 2-Methylnaphthalene & 338 & 331 & 7 & 90 & 240 & & 7 & 1 & & & & 6 & & & & 4 & & & \\
\hline 2-Methylphenol & 338 & 320 & 18 & 88 & 231 & & 7 & 1 & & & & 6 & & & & 3 & & & 9 \\
\hline 2-Nitroaniline & 338 & 331 & 7 & 90 & 240 & & 7 & 1 & & & & 6 & & & & 4 & & & \\
\hline 2-Nitrophenol & 338 & 329 & 9 & 88 & 240 & & 7 & 1 & & & & 6 & & & & 3 & & & \\
\hline 3,3'-Dichlorobenzidine & 338 & 331 & 7 & 90 & 241 & & 47 & & & 1 & & 6 & & & & 5 & & & \\
\hline 3-Nitroaniline & 338 & 328 & 10 & 82 & 241 & 40 & 48 & & & & & 6 & 3 & & & 5 & & & \\
\hline 4,6-Dinitro-2-methylphenol & 338 & 329 & 9 & 88 & 241 & & 18 & & & & & 6 & & & & 3 & & & \\
\hline 4-Bromophenyl-phenylether & 338 & 331 & 7 & 90 & 241 & & 8 & & & & & 6 & & & & 5 & & & \\
\hline 4-Chloro-3-methylphenol & 338 & 329 & 9 & 88 & 240 & & 7 & 1 & & & & 6 & & & & 3 & & & \\
\hline 4-Chloroaniline & 338 & 331 & 7 & 68 & 240 & 27 & 29 & 1 & & & & 6 & & & & 4 & & & \\
\hline 4-Chlorophenyl-phenylether & 338 & 331 & 7 & 90 & 241 & & 8 & & & & & 6 & & & & 5 & & & \\
\hline 4-Methylphenol & 338 & 330 & 8 & 88 & 241 & & 7 & 1 & & & & 5 & & & & 3 & & & \\
\hline 4-Nitroaniline & 338 & 331 & 7 & 90 & 241 & 5 & 39 & & & & & 6 & & & & 5 & & & \\
\hline 4-Nitrophenol & 338 & 315 & 23 & 87 & 228 & 1 & 9 & & & & & 6 & & 14 & 1 & 3 & 2 & & \\
\hline Acenaphthene & 338 & 331 & 7 & 90 & 241 & & 8 & & & & & 6 & & & & 5 & & & \\
\hline
\end{tabular}


Table A.22 (continued)

\begin{tabular}{|c|c|c|c|c|c|c|c|c|c|c|c|c|c|c|c|c|c|c|}
\hline \multirow[b]{2}{*}{ Analyte } & \multicolumn{3}{|c|}{ Measurements } & \multicolumn{7}{|c|}{ Accept } & \multicolumn{8}{|c|}{ Reject } \\
\hline & Total & Accept & Reject & $\mathbf{0}$ & 1 & 6 & 12 & 13 & 16 & 57 & 1 & 3 & 5 & 6 & 13 & 14 & 18 & 60 \\
\hline Acenaphthylene & 338 & 331 & 7 & 90 & 240 & 7 & 1 & & & & 6 & & & & 4 & & & \\
\hline Anthracene & 338 & 331 & 7 & 90 & 241 & 8 & & & & & 6 & & & & 5 & & & \\
\hline Benzo(a)anthracene & 338 & 331 & 7 & 90 & 241 & 7 & & & 1 & & 6 & & & & 5 & & & \\
\hline Benzo(a)pyrene & 338 & 331 & 7 & 90 & 241 & 8 & & & 1 & & 6 & & & & 5 & & & \\
\hline Benzo(b)fluoranthene & 338 & 331 & 7 & 90 & 241 & 7 & & & 1 & 1 & 6 & & & & 5 & & & \\
\hline Ben^ $X(g, h, i)$ perylene & 338 & 331 & 7 & 90 & 241 & 8 & & & 1 & & 6 & & & & 5 & & & \\
\hline Benzo(k)fluoranthene & 338 & 331 & 7 & 90 & 241 & 9 & & & 1 & 1 & 6 & & & & 5 & & & \\
\hline Benzoic acid & 338 & 331 & 7 & 83 & 240 & 15 & 1 & & & & 6 & & & & 1 & & & \\
\hline Benzyl alcohol & 338 & 322 & 16 & 90 & 231 & 7 & 1 & & & & 6 & & & & 4 & & & 9 \\
\hline Bis(2-chloroethoxy)methane & 338 & 331 & 7 & 90 & 240 & 7 & 1 & & & & 6 & & & & 4 & & & \\
\hline Bis(2-chloroethyl)ether & 338 & 331 & 7 & 90 & 240 & 7 & 1 & & & & 6 & & & & 4 & & & \\
\hline Bis(2-chloroisopropyl)ether & 338 & 331 & 7 & 90 & 240 & 16 & 1 & & & & 6 & & & & 4 & & & \\
\hline Bis(2-ethylhexyl)phthalate & 338 & 332 & 6 & 53 & 242 & 16 & 98 & & 1 & & 4 & & & & 5 & & & \\
\hline Butylbenzylphthalate & 338 & 331 & 7 & 90 & 241 & 8 & & & 1 & & 6 & & & & 5 & & & \\
\hline Chrysene & 338 & 331 & 7 & 90 & 241 & 7 & & & 1 & & 6 & & & & 5 & & & \\
\hline Di-n-butylphthalate & 338 & 333 & 5 & 90 & 243 & 7 & . & 2 & & & 3 & & & & 3 & & & \\
\hline Di-n-octylphthalate & 338 & 331 & 7 & 90 & 241 & 9 & & & 1 & & 6 & & & & 5 & & & \\
\hline Dibenz $(\mathrm{a}, \mathrm{h})$ anthracene & 338 & 331 & 7 & 90 & 241 & 8 & & & 1 & & 6 & & & & 5 & & & \\
\hline Dibenzofuran & 338 & 331 & 7 & 90 & 241 & 8 & & & & & 6 & & & & 5 & & & \\
\hline Diethylphthalate & 338 & 331 & 7 & 90 & 241 & 19 & 1 & & & & 6 & & & & 5 & & & \\
\hline Dimethylphthalate & 338 & 331 & 7 & 90 & 240 & 7 & 1 & & & & 6 & & & & 4 & & & \\
\hline Fluoranthene & 338 & 331 & 7 & 90 & 241 & 6 & & & & & 6 & & & & 5 & & & \\
\hline Fluorene & 338 & 331 & 7 & 90 & 241 & 8 & & & & & 6 & & & & 5 & & & \\
\hline Hexachlorobenzene & 338 & 331 & 7 & 90 & 241 & 8 & & & & & 6 & & & & 5 & & & \\
\hline Hexachlorobutadiene & 338 & 331 & 7 & 90 & 240 & 7 & 1 & & & & 6 & & & & 4 & & & \\
\hline Hexachlorocyclopentadiene & 338 & 331 & 7 & 90 & 240 & 9 & 1 & & & & 6 & & & & 4 & & & \\
\hline Hexachloroethane & 338 & 331 & 7 & 90 & 240 & 7 & 1 & & & & 6 & & & & 4 & & & \\
\hline Indeno(1,2,3-cd)pyrene & 338 & 331 & 7 & 90 & 241 & 8 & & & 1 & & 6 & & & & 5 & & & \\
\hline
\end{tabular}


Table A.22. (continued)

\begin{tabular}{|c|c|c|c|c|c|c|c|c|c|c|c|c|c|c|c|c|c|c|c|}
\hline \multirow[b]{2}{*}{ Analyte } & \multicolumn{3}{|c|}{ Measurements } & \multicolumn{8}{|c|}{ Accept } & \multicolumn{8}{|c|}{ Reject } \\
\hline & Total & Accept & Reject & 0 & 1 & & 6 & 12 & 13 & 16 & 57 & 1 & 3 & 5 & 6 & 13 & 14 & 18 & 60 \\
\hline Isophorone & 338 & 331 & 7 & 90 & 240 & & 16 & 1 & & & & 6 & & & & 4 & & & \\
\hline N-Nitroso-di-n-propylamine & 338 & 331 & 7 & 90 & 240 & & 16 & 1 & & & & 6 & & & & 4 & & & \\
\hline N-Nitrosodiphenylamine & 338 & 331 & 7 & 90 & 241 & & 8 & & & & & 6 & & & & 5 & & & \\
\hline Naphthalene & 338 & 331 & 7 & 90 & 240 & & 7 & 1 & & & & 6 & & & & 4 & & & \\
\hline Nitrobenzene & 338 & 331 & 7 & 90 & 240 & & 42 & 1 & & & & 6 & & & & 4 & & & \\
\hline Pentachlorophenol & 338 & 329 & 9 & 88 & 241 & & 8 & & & & & 6 & & & & 3 & & & \\
\hline Phenanthrene & 338 & 331 & 7 & 90 & 241 & & 8 & & & & & 6 & & & & 5 & & & \\
\hline Phenol & 338 & 329 & 9 & 88 & 240 & & 8 & 1 & & & & 6 & & & & 3 & & & \\
\hline Pyrene & 338 & 332 & 6 & 90 & 242 & & 19 & & & 1 & & 5 & & & & 5 & & & \\
\hline Total & 18590 & & & 5747 & 15578 & 73 & 729 & 132 & 2 & 13 & 2 & 383 & 3 & 39 & 132 & & 2 & 4 & 18 \\
\hline
\end{tabular}


Table A.23. Organic accuracy in water summary of surrogate recoveries conducted at the K-25 laboratory

\begin{tabular}{lcccc}
\hline \multicolumn{1}{c}{ Analytes } & $\begin{array}{c}\text { Control } \\
\text { Semimits } \\
(\%)\end{array}$ & $\begin{array}{c}\text { Number } \\
\text { in }\end{array}$ & $\begin{array}{c}\text { Number } \\
\text { out }\end{array}$ & $\begin{array}{c}\text { Percentage } \\
\text { within } \\
\text { limits }\end{array}$ \\
\hline S1 $=$ Nitrobenzene-d5 & $35-114$ & 31 & 1 & 97 \\
S2 $=$ 2-Fluorobiphenyl & $43-116$ & 32 & 0 & 100 \\
S3 $=$ Terphenyl-d14 & $33-141$ & 20 & 12 & 62 \\
S4 $=$ Phenol-d6 & $10-94$ & 32 & 0 & 100 \\
S5 $=$ 2-Fluorophenol & $21-100$ & 31 & 1 & 97 \\
S6 $=$ 2,4,6-Tribromophenol & $10-123$ & 32 & 0 & 100 \\
\hline
\end{tabular}

Table A24. Organic accuracy in soil summary of surrogate recoveries conducted at the $\mathrm{K}-25$ laboratory

\begin{tabular}{lccccc}
\hline \multicolumn{1}{c}{ Analytes } & $\begin{array}{c}\text { Control } \\
\text { Limits } \\
\text { Semivolatile }\end{array}$ & $\begin{array}{c}\text { Number } \\
\text { in }\end{array}$ & $\begin{array}{c}\text { Number } \\
\text { out }\end{array}$ & $\begin{array}{c}\text { Percentage } \\
\text { within } \\
\text { limits }\end{array}$ \\
\hline S1 $=$ Nitrobenzene-d5 & $23-120$ & 382 & 14 & 96 \\
S2 $=$ 2-Fluorobiphenyl & $30-115$ & 383 & 13 & 97 \\
S3 $=$ Terphenyl-d14 & $18-137$ & 393 & 3 & 99 \\
S4 $=$ Phenol-d6 & $24-113$ & 379 & 17 & 96 \\
S5 $=$ 2-Fluorophenol & $25-121$ & 384 & 12 & 97 \\
S6 $=$ 2,4,6-Tribromophenol & $19-122$ & 385 & 11 & 97 \\
\hline
\end{tabular}


Table A.25. Organic accuracy in soil summary of matrix spike/matrix spike duplicate conducted at the K-25 laboratory

\begin{tabular}{lcccc}
\hline \multicolumn{1}{c}{ Analytes } & $\begin{array}{c}\text { Control } \\
\text { limits } \\
(\%)\end{array}$ & $\begin{array}{c}\text { Number } \\
\text { in }\end{array}$ & $\begin{array}{c}\text { Number } \\
\text { out }\end{array}$ & $\begin{array}{c}\text { Percentage } \\
\text { within } \\
\text { limits }\end{array}$ \\
\hline Phenol & $26-90$ & 42 & 2 & 95 \\
2-Chlorophenol & $25-102$ & 42 & 2 & 95 \\
1,4-Dichlorobenzene & $28-104$ & 40 & 4 & 91 \\
N-Nitroso-di-n-propylamine & $41-126$ & 39 & 5 & 89 \\
1,2,4-Trichlorobenzene & $38-107$ & 41 & 3 & 93 \\
4-Chloro-3-methyiphenol & $26-103$ & 40 & 4 & 91 \\
Acenapthene & $31-137$ & 42 & 2 & 95 \\
4-Nitrophenol & $11-114$ & 36 & 8 & 82 \\
2,4-Dinitrotoluene & $28-89$ & 37 & 7 & 84 \\
Pentachlorophenol & $17-109$ & 41 & 3 & 93 \\
Pyrene & $35-142$ & 42 & 2 & 95 \\
\hline
\end{tabular}

Table A.26. Organic precision in soil summary of matrix spike/relative percent differences conducted at the K-25 laboratory

\begin{tabular}{lcccc}
\hline \multicolumn{1}{c}{ Analytes } & $\begin{array}{c}\text { Relative } \\
\text { percent } \\
\text { difference } \\
(\%)\end{array}$ & $\begin{array}{c}\text { Number } \\
\text { in }\end{array}$ & $\begin{array}{c}\text { Number } \\
\text { out }\end{array}$ & $\begin{array}{c}\text { Percentage } \\
\text { within } \\
\text { limits }\end{array}$ \\
\hline Phenol & 35 & 22 & 0 & 100 \\
2-Chlorophenol & 50 & 22 & 0 & 100 \\
1,4-Dichlorobenzene & 27 & 19 & 3 & 86 \\
N-Nitroso-di-n-propylamine & 38 & 20 & 2 & 91 \\
1,2,4-Trichlorobenzene & 23 & 19 & 3 & 86 \\
4-Chloro-3-methylphenol & 33 & 21 & 1 & 95 \\
Acenapthene & 19 & 20 & 2 & 91 \\
4-Nitrophenol & 50 & 20 & 2 & 91 \\
2,4-Dinitrotoluene & 47 & 22 & 0 & 100 \\
Pentachlorophenol & 47 & 21 & 1 & 95 \\
Pyrene & 36 & 22 & 0 & 100 \\
\hline
\end{tabular}


Table A.27. Semivolatile analyses of fish tissue (by SDG) conducted by the Organic Analysis Laboratory at Oak Ridge National Laboratory

\begin{tabular}{|c|c|c|c|c|}
\hline \multirow[b]{2}{*}{ Batch } & \multicolumn{2}{|c|}{ Total } & \multicolumn{2}{|c|}{ Fish } \\
\hline & $\begin{array}{c}\text { Field } \\
\text { samples }\end{array}$ & $\begin{array}{l}\text { Routine } \\
\text { samples }\end{array}$ & $\begin{array}{c}\text { Field } \\
\text { samples }\end{array}$ & $\begin{array}{l}\text { Routine } \\
\text { samples }\end{array}$ \\
\hline $\mathrm{C} 405$ & 1 & 2 & 1 & 2 \\
\hline $\mathrm{C} 406$ & & 6 & & 6 \\
\hline C503 & & 8 & & 8 \\
\hline C504 & & 10 & & 10 \\
\hline C507 & 1 & 6 & 1 & 6 \\
\hline C508 & & 2 & & 2 \\
\hline C516 & & 6 & & 6 \\
\hline C517 & 1 & 8 & 1 & 8 \\
\hline C521 & & 9 & & 9 \\
\hline C522 & 1 & 9 & 1 & 9 \\
\hline C523 & & 8 & & 8 \\
\hline C524 & 1 & 10 & 1 & 10 \\
\hline D403 & & 7 & & 7 \\
\hline D409 & & 3 & & 3 \\
\hline D410 & & 10 & & 10 \\
\hline D411 & & 6 & & 6 \\
\hline D417 & 1 & & 1 & \\
\hline D425 & 1 & 6 & 1 & 6 \\
\hline Total & 7 & 116 & 7 & 1 \\
\hline
\end{tabular}


Table A.28. Semivolatile analyses of fish tissue conducted by the Organic Analysis Laboratory at

Oak Ridge National Laboratory

\begin{tabular}{|c|c|c|c|c|c|c|c|c|c|c|c|c|c|c|c|c|c|c|c|c|}
\hline \multirow{2}{*}{ Analyte } & \multicolumn{3}{|c|}{ Measurements } & \multicolumn{10}{|c|}{ Accept } & \multicolumn{7}{|c|}{ Reject } \\
\hline & Total & Accept & Reject & 0 & 1 & 4 & 5 & 6 & 13 & 16 & 52 & 58 & 63 & 5 & 13 & 52 & 53 & 58 & 59 & 63 \\
\hline 1,2,4-Trichlorobenzene & 123 & 61 & 62 & 16 & 45 & & & & & & & & 7 & & 62 & 62 & & 62 & & \\
\hline 1,2-Dichlorobenzene & 123 & 61 & 62 & 16 & 45 & & & & & & & & 7 & & 62 & 62 & & 62 & & \\
\hline 1,3-Dichlorobenzene & 123 & 61 & 62 & 16 & 45 & & & & & & & & 7 & & 62 & 61 & 1 & 62 & & \\
\hline 1,4-Dichlorobenzene & 123 & 61 & 62 & 16 & 45 & & & & & & & & 7 & & 62 & 62 & & 62 & & \\
\hline 2,4,5-Trichlorophenol & 123 & 82 & 41 & 8 & 59 & & & & 25 & & 65 & 14 & 7 & & 27 & 41 & & 41 & & \\
\hline 2,4,6-Trichlorophenol & 123 & 82 & 41 & 8 & 59 & & & & 25 & & 65 & 14 & 7 & & 27 & 41 & & 41 & & \\
\hline 2,4-Dichlorophenol & 123 & 83 & 40 & 8 & 60 & & & & 26 & & 66 & 15 & 7 & & 27 & 40 & & 40 & & \\
\hline 2,4-Dimethylphenol & 123 & 83 & 40 & 8 & 60 & & & & 26 & & 66 & 15 & 7 & & 27 & 40 & & 40 & & \\
\hline 2,4-Dinitrophenol & 123 & 82 & 41 & 8 & 59 & & & 9 & 25 & & 65 & 14 & 7 & 1 & 27 & 41 & & 41 & & \\
\hline 2,4-Dinitrotoluene & 123 & 61 & 62 & 16 & 45 & & & & & & & & 7 & & 62 & 62 & & 62 & & \\
\hline 2,6-Dinitrotoluene & 123 & 61 & 62 & 16 & 45 & & & & & & & & 7 & & 62 & 62 & & 62 & & \\
\hline 2-Chloronaphthalene & 123 & 60 & 63 & 16 & 44 & & & & & & & & 7 & 1 & 62 & 62 & & 62 & & \\
\hline 2-Chlorophenol & 123 & 83 & 40 & 8 & 60 & & & & 26 & & 66 & 15 & 7 & & 27 & 40 & & 40 & & \\
\hline 2-Methylnaphthalene & 123 & 64 & 59 & 16 & 48 & & & & 3 & & 3 & 3 & 7 & & 59 & 59 & & 59 & & \\
\hline 2-Methylphenol & 123 & 82 & 41 & 8 . & 59 & & & 2 & 25 & & 65 & 14 & 7 & & 27 & 41 & & 41 & & \\
\hline 2-Nitroaniline & 123 & 59 & 64 & 14 & 45 & & & 3 & & & & & 7 & 11 & 62 & 62 & & 62 & & \\
\hline 2-Nitrophenol & 123 & 82 & 41 & 8 & 59 & & & & 25 & & 65 & 14 & 7 & & 27 & 41 & & 41 & & \\
\hline 3,3'-Dichlorobenzidine & 123 & 61 & 62 & 10 & 45 & & 10 & 41 & & 1 & & & 7 & & 61 & 62 & & 62 & & \\
\hline 3-Nitroaniline & 123 & 37 & 86 & & 29 & 8 & 25 & 26 & & & & & & 39 & 62 & 62 & & 62 & & \\
\hline 4,6-Dinitro-2-methylphenol & 123 & 81 & 42 & 6 & 58 & & & 22 & 25 & 9 & 64 & 14 & 7 & 1 & 28 & 42 & & 41 & & \\
\hline 4-Bromophenyl-phenylether & 123 & 61 & 62 & 14 & 45 & & & 12 & & & & & 7 & & 62 & 62 & & 62 & & \\
\hline 4-Chloro-3-methylphenol & 123 & 84 & 39 & 8 & 61 & & & & 27 & & 67 & 16 & 7 & & 27 & 39 & & 39 & & \\
\hline 4-Chloroaniline & 123 & 55 & 68 & 2 & 45 & & & 28 & & & & & 7 & 6 & 62 & 62 & & 62 & & \\
\hline 4-Chlorophenyl-phenylether & 123 & 61 & 62 & 16 & 45 & & & & & & & & 7 & & 62 & 62 & & 62 & & \\
\hline 4-Methylphenol & 123 & 83 & 40 & 8 & 60 & & & & 26 & & 66 & 15 & 7 & & 27 & 40 & & 40 & & \\
\hline 4-Nitroaniline & 123 & 54 & 69 & 16 & 38 & & & 19 & & & & & 6 & 8 & 62 & 62 & & 62 & & \\
\hline 4-Nitrophenol & 123 & 82 & 41 & 8 & 59 & & & 2 & 25 & & 65 & 14 & 7 & & 28 & 41 & & 41 & & \\
\hline
\end{tabular}


Table A.28. (continued)

\begin{tabular}{|c|c|c|c|c|c|c|c|c|c|c|c|c|c|c|c|c|c|c|c|c|}
\hline \multirow{2}{*}{ Analyte } & \multicolumn{3}{|c|}{ Measurements } & \multicolumn{10}{|c|}{ Accept } & \multicolumn{7}{|c|}{ Reject } \\
\hline & Total & Accept & Reject & $\mathbf{0}$ & 1 & 4 & 5 & 6 & 13 & 16 & 52 & 58 & 63 & 5 & 13 & 52 & 53 & 58 & 59 & 63 \\
\hline Acenaphthene & 123 & 61 & 62 & 16 & 45 & & & & & & & & 7 & & 62 & 62 & & 62 & & \\
\hline Acenaphthylene & 123 & 61 & 62 & 16 & 45 & & & & & & & & 7 & & 62 & 62 & & 62 & & \\
\hline Anthracene & 123 & 61 & 62 & 14 & 45 & & & 12 & & & & & 7 & & 62 & 62 & & 62 & & \\
\hline Benzo(a)anthracene & 123 & 61 & 62 & 16 & 45 & & & & & 1 & & & 7 & & 62 & 62 & & 62 & & \\
\hline Benzo(a)pyrene & 123 & 60 & 63 & 14 & 44 & & & & & 3 & & & 7 & & 62 & 62 & & 62 & 1 & \\
\hline Benzo(b)fluoranthene & 123 & 60 & 63 & 14 & 44 & & & & & 3 & & & 7 & & 62 & 62 & & 62 & 1 & \\
\hline Benzo(g,h,i)perylene & 123 & 59 & 64 & 14 & 43 & & & & & 3 & & & 6 & & 62 & 62 & & 62 & 1 & 1 \\
\hline Benzo(k)fluoranthene & 123 & 60 & 63 & 14 & 44 & & & & & 3 & & & 7 & & 62 & 62 & & 62 & 1 & \\
\hline Benzoic acid & 123 & 54 & 69 & 16 & 38 & & & & & & & & 6 & 8 & 62 & 62 & & 62 & & \\
\hline Benzyl alcohol & 123 & 61 & 62 & 16 & 45 & & & & & & & & 7 & & 61 & 62 & & 62 & & \\
\hline Bis(2-chloroethoxy)methane & 123 & 61 & 62 & 16 & 45 & & & & & & & & 7 & & 62 & 62 & & 62 & & \\
\hline Bis(2-chloroethyl)ether & 123 & 62 & 61 & 16 & 46 & & & 3 & 1 & & 1 & 1 & 7 & & 61 & 61 & & 61 & & \\
\hline Bis(2-chloroisopropyl)ether & 123 & 61 & 62 & 16 & 45 & & & & & & & & 7 & & 62 & 62 & & 61 & 1 & \\
\hline Bis(2-ethylhexyl)phthalate & 123 & 60 & 63 & 16 & 44 & & & 7 & & 1 & & & 7 & & 62 & 62 & & 62 & 1 & \\
\hline Butylbenzylphthalate & 123 & 61 & 62 & 16 & 45 & & & 1 & & 1 & & & 7 & & 62 & 62 & & 62 & & \\
\hline Chrysene & 123 & 61 & 62 & 16 & 45 & & & & & 1 & & & 7 & & 62 & 62 & & 62 & & \\
\hline Di-n-butylphthalate & 123 & 61 & 62 & 14 & 45 & & & 12 & & & & & 7 & & 62 & 62 & & 62 & & \\
\hline Di-n-octylphthalate & 123 & 60 & 63 & 14 & 44 & & & 16 & & 3 & & & 8 & & 62 & 62 & & 62 & 1 & \\
\hline Dibenz $(a, h)$ anthracene & 123 & 60 & 63 & 14 & 44 & & & & & 3 & & & 7 & & 62 & 62 & & 62 & 1 & \\
\hline Dibenzofuran & 123 & 61 & 62 & 16 & 45 & & & & & & & & 7 & & 62 & 62 & & 62 & & \\
\hline Diethylphthalate & 123 & 61 & 62 & 16 & 45 & & & & & & & & 7 & & 61 & 61 & & 61 & & \\
\hline Dimethylphthalate & 123 & 61 & 62 & 16 & 45 & & & & & & & & 7 & & 62 & 62 & & 62 & & \\
\hline Fluoranthene & 123 & 62 & 61 & 14 & 46 & & & 13 & 1 & & 1 & 1 & 7 & & 61 & 61 & & 61 & & \\
\hline Fluorene & 123 & 61 & 62 & 16 & 45 & & & & & & & & 7 & & 62 & 62 & & 62 & & \\
\hline Hexachlorobenzene & 123 & 61 & 62 & 14 & 45 & & & 12 & & & & & 7 & & 62 & 62 & & 62 & & \\
\hline Hexachlorobutadiene & 123 & 61 & 62 & 16 & 45 & & & & & & & & 7 & & 62 & 62 & & 62 & & \\
\hline Hexachlorocyclopentadiene & 123 & 61 & 62 & 16 & 45 & & & 25 & & & & & 7 & & 62 & 62 & & 62 & & \\
\hline
\end{tabular}


Table A.28. (continued)

\begin{tabular}{|c|c|c|c|c|c|c|c|c|c|c|c|c|c|c|c|c|c|c|c|c|}
\hline \multirow{2}{*}{ Analyte } & \multicolumn{3}{|c|}{ Measurements } & \multicolumn{10}{|c|}{ Accept } & \multicolumn{7}{|c|}{ Reject } \\
\hline & Total & Accept & Reject & $\mathbf{0}$ & 1 & 4 & 5 & 6 & 13 & 16 & 52 & 58 & 63 & 5 & 13 & 52 & 53 & 58 & 59 & 63 \\
\hline Hexachloroethane & 123 & 61 & 62 & 16 & 45 & & & & & & & & 7 & & 62 & 62 & & 62 & & \\
\hline Indeno(1,2,3-cd)pyrene & 123 & 60 & 63 & 13 & 44 & & & 2 & & 3 & & & 7 & & 62 & 62 & & 62 & 1 & \\
\hline Isophorone & 123 & 61 & 62 & 16 & 45 & & & & & & & & 7 & & 61 & 62 & & 62 & & \\
\hline N-Nitroso-di-n-propylamine & 123 & 61 & 62 & 16 & 45 & & & & & & & & 7 & & 62 & 62 & & 62 & & \\
\hline N-Nitrosodiphenylamine & 123 & 61 & 62 & 14 & 45 & & & 11 & & & & & 7 & & 62 & 62 & & 62 & & \\
\hline Naphthalene & 123 & 62 & 61 & 16 & 46 & & & & 1 & & 1 & 1 & 7 & & 61 & 61 & & 61 & & \\
\hline Nitrobenzene & 123 & 61 & 62 & 16 & 45 & & & & & & & & 7 & & 62 & 62 & & 62 & & \\
\hline Pentachlorophenol & 123 & 82 & 41 & 6 & 59 & & & 21 & 25 & 10 & 65 & 14 & 7 & & 27 & 41 & & 41 & & \\
\hline Phenanthrene & 123 & 61 & 62 & 14 & 45 & & & 12 & & & & & 7 & & 62 & 62 & & 62 & & \\
\hline Phenol & 123 & 82 & 41 & 8 & 59 & & & 2 & 25 & & 65 & 14 & 7 & & 28 & 41 & & 41 & & \\
\hline Pyrene & 123 & 61 & 62 & 16 & 45 & & & & & 1 & & & 7 & & 62 & 62 & & 62 & & \\
\hline Total & 7995 & 4214 & 3781 & 857 & 3092 & 8 & 35 & 313 & 362 & 46 & 921 & 208 & 446 & 75 & 3534 & 3723 & 1 & 3722 & 9 & 1 \\
\hline
\end{tabular}


Table A.29. Pesticide/PCB analyses of water and sediment samples conducted at the $\mathrm{K}-25$ laboratory

\begin{tabular}{|c|c|c|c|c|c|c|}
\hline \multirow[b]{2}{*}{ Batch } & \multicolumn{2}{|c|}{ Total } & \multicolumn{2}{|c|}{ Core } & \multicolumn{2}{|c|}{ Water } \\
\hline & $\begin{array}{c}\text { Field } \\
\text { samples }\end{array}$ & $\begin{array}{l}\text { Routine } \\
\text { samples }\end{array}$ & $\begin{array}{c}\text { Field } \\
\text { samples }\end{array}$ & $\begin{array}{l}\text { Routine } \\
\text { samples }\end{array}$ & $\begin{array}{c}\text { Field } \\
\text { samples }\end{array}$ & $\begin{array}{l}\text { Routine } \\
\text { samples }\end{array}$ \\
\hline 3 & 6 & 24 & & 13 & 6 & 11 \\
\hline 4 & 1 & 15 & 1 & 15 & & \\
\hline 5 & 1 & 19 & 1 & 19 & & \\
\hline 6 & & 15 & & 15 & & \\
\hline 7 & & 22 & & 22 & & \\
\hline 9 & 1 & 15 & & 14 & 1 & 1 \\
\hline 10 & & 11 & & 11 & & \\
\hline 11 & & 14 & & 14 & & \\
\hline 12 & & 21 & & 21 & & \\
\hline 13 & & 15 & & 15 & & \\
\hline 14 & 1 & 17 & & 17 & 1 & \\
\hline 15 & & 9 & & 9 & & \\
\hline 17 & & 14 & & 14 & & \\
\hline 18 & 1 & 9 & 1 & 9 & & \\
\hline 19 & . & 20 & & 20 & & \\
\hline 20 & & 22 & & 22 & & \\
\hline 21 & & 1 & & 1 & & \\
\hline 22 & & 15 & & 15 & & \\
\hline 23 & 1 & 28 & 1 & 28 & & \\
\hline 25 & & 8 & & 8 & & \\
\hline Total & 12 & 314 & 4 & 302 & 8 & 12 \\
\hline
\end{tabular}


Table A.30. Pesticide/PCB analyses of water and sediment samples conducted at K-25

\begin{tabular}{|c|c|c|c|c|c|c|c|c|c|c|c|c|}
\hline \multirow[b]{2}{*}{ Analyte } & \multicolumn{3}{|c|}{ Measurements } & \multicolumn{5}{|c|}{ Accept } & \multicolumn{4}{|c|}{ Reject } \\
\hline & Total & Accept & Reject & 0 & 1 & 8 & 13 & $\overline{51}$ & 1 & 11 & 13 & 14 \\
\hline 4,4'-DDD & 326 & 316 & 10 & 58 & 258 & & 35 & 3 & 5 & 3 & 2 & \\
\hline 4,4'-DDE & 326 & 316 & 10 & 58 & 258 & & 35 & & 5 & 3 & 2 & \\
\hline 4,4'-DDT & 326 & 316 & 10 & 58 & 258 & 1 & 35 & 1 & 5 & 3 & 2 & \\
\hline Aldrin & 326 & 276 & 50 & 40 & 236 & & 35 & & 5 & 3 & 2 & 40 \\
\hline Alpha-BHC & 326 & 276 & 50 & 40 & 236 & & 35 & & 5 & 3 & 2 & 40 \\
\hline Alpha-chlordane & 326 & 276 & 50 & 40 & 236 & & 35 & & 5 & 3 & 2 & 40 \\
\hline Aroclor-1016 & 326 & 276 & 50 & 40 & 236 & & 35 & & 5 & 3 & 2 & 40 \\
\hline Aroclor-1221 & 326 & 276 & 50 & 40 & 236 & & 35 & & 5 & 3 & 2 & 40 \\
\hline Aroclor-1232 & 326 & 276 & 50 & 40 & 236 & & 35 & & 5 & 3 & 2 & 40 \\
\hline Aroclor-1242 & 326 & 276 & 50 & 40 & 236 & & 35 & & 5 & 3 & 2 & 40 \\
\hline Aroclor -1248 & 326 & 276 & 50 & 40 & 236 & & 35 & & 5 & 3 & 2 & 40 \\
\hline Aroclor-1254 & 326 & 318 & 8 & 40 & 256 & 2 & 37 & 54 & 5 & 3 & & \\
\hline Aroclor-1260 & 326 & 316 & 10 & 58 & 258 & & 35 & 1 & 5 & 3 & 2 & \\
\hline Beta-BHC & 326 & 276 & 50 & 40 & 236 & & 35 & & 5 & 3 & 2 & 40 \\
\hline Delta-BHC & 326 & 276 & 50 & 40 & 236 & & 35 & & 5 & 3 & 2 & 40 \\
\hline Dieldrin & 326 & 316 & 10 & 58 & 258 & & 35 & & 5 & 3 & 2 & \\
\hline Endosulfan I & 326 & 276 & 50 & 40 & 236 & & 35 & & 5 & 3 & 2 & 40 \\
\hline Endosulfan II & 326 & 316 & 10 & 58 & 258 & & 35 & & 5 & 3 & 2 & \\
\hline Endosulfan sulfate & 326 & 316 & 10 & 58 & 258 & & 35 & & 5 & 3 & 2 & \\
\hline Endrin & 326 & 316 & 10 & 58 & 258 & & 35 & & 5 & 3 & 2 & \\
\hline Endrin ketone & 326 & 316 & 10 & 58 & 258 & & 35 & & 5 & 3 & 2 & \\
\hline $\begin{array}{l}\text { Gamma-BHC } \\
\text { (Lindane) }\end{array}$ & 326 & 276 & 50 & 40 & 236 & & 35 & & 5 & 3 & 2 & 40 \\
\hline Gamma-chlordane & 326 & 276 & 50 & 40 & 236 & & 35 & & 5 & 3 & 2 & 40 \\
\hline Heptachlor & 326 & 276 & 50 & 40 & 236 & & 35 & & 5 & 3 & 2 & 40 \\
\hline Heptachlor epoxide & 326 & 276 & 50 & 40 & 236 & & 35 & & 5 & 3 & 2 & 40 \\
\hline Methoxychlor & 326 & 316 & 10 & 58 & 258 & & 35 & & 5 & 3 & 2 & \\
\hline Toxaphene & 326 & 303 & 23 & 57 & 246 & & 35 & 1 & 5 & 3 & 2 & 13 \\
\hline Total & & & & 1277 & 6622 & 3 & 947 & 60 & 135 & 81 & 52 & 613 \\
\hline
\end{tabular}


Table A.31. Organic accuracy in water samples summary of surrogate recoveries conducted at $\mathrm{K}-25$

\begin{tabular}{ccccc}
\hline & $\begin{array}{c}\text { Recovery } \\
\text { limits } \\
(\%)\end{array}$ & In & Out & $\begin{array}{c}\text { Percentage } \\
\text { within } \\
\text { limits }\end{array}$ \\
\hline Pesticide/PCB & $24-154$ & 27 & 1 & 96 \\
\hline
\end{tabular}

Table A.32 K-25 laboratory organic accuracy and precision in sediment samples of surrogate and matrix spike recoveries

\begin{tabular}{lccccccccc}
\hline \multicolumn{1}{c}{} & $\begin{array}{c}\text { Recovery } \\
\text { Pesticide/ }\end{array}$ & $\begin{array}{c}\text { RPD } \\
\text { limits } \\
(\%)\end{array}$ & $\begin{array}{c}\text { limits } \\
(\%)\end{array}$ & $\begin{array}{c}\text { Rec } \\
\text { in }\end{array}$ & $\begin{array}{c}\text { Rec } \\
\text { out }\end{array}$ & $\begin{array}{c}\text { Percentage } \\
\text { within } \\
\text { recovery } \\
\text { limitis }\end{array}$ & $\begin{array}{c}\text { RPD } \\
\text { in }\end{array}$ & $\begin{array}{c}\text { RPD } \\
\text { out }\end{array}$ & $\begin{array}{c}\text { RPD } \\
\text { limits }\end{array}$ \\
\hline DBC & $20-150$ & & 347 & 89 & 80 & & & \\
Gamma-BHC & $46-127$ & 50 & 15 & 29 & 34 & 15 & 1 & 94 \\
Heptachlor & $35-130$ & 31 & 21 & 23 & 48 & 12 & 4 & 75 \\
Aldrin & $34-132$ & 43 & 20 & 24 & 45 & 11 & 3 & 79 \\
Dieldrin & $31-134$ & 38 & 40 & 4 & 91 & 20 & 1 & 95 \\
Endrin & $42-139$ & 45 & 38 & 6 & 86 & 21 & 0 & 100 \\
4,4'-DDT & $23-134$ & 50 & 37 & 7 & 84 & 20 & 1 & 95 \\
\hline
\end{tabular}

Table A.33. K-25 laboratory pesticide/PCB QC results summary

\begin{tabular}{|c|c|c|c|c|c|}
\hline QC parameter ${ }^{a}$ & $\begin{array}{c}\text { Number } \\
\text { total }\end{array}$ & Low & High & $\begin{array}{l}\text { Percentage } \\
\text { within } \\
\text { limits }\end{array}$ & $\begin{array}{c}\text { Average } \\
\text { REC } \\
\text { or RPD }\end{array}$ \\
\hline Surr rec: water & 28 & 10 & 135 & $96 \%$ & $90 \%$ \\
\hline Surr rec: soil & 436 & 37 & 824 & $80 \%$ & $132 \%$ \\
\hline MS/MSD rec: soil & & 0 & 528 & $65 \%$ & \\
\hline MS/MSD RPD: soil & & 0 & 66 & $91 \%$ & $15 \%$ \\
\hline
\end{tabular}

$a_{M S / M S D}=$ matrix spike/matrix spike duplicate, $R P D=$ relative percent difference.

*One water MS/MSD, recovery range 70-98\%, RPD range 0-14. 


\section{A-48}

Table A.34. Pesticide/PCB analyses of fish tissue conductcd by the Organic Analysis Laboratory at Oak Ridge National Laboratory

\begin{tabular}{lccccc}
\hline & \multicolumn{2}{c}{ Total } & & \multicolumn{2}{c}{ Fish } \\
\cline { 2 - 3 } \cline { 5 - 6 } Batch & $\begin{array}{c}\text { Field } \\
\text { samples }\end{array}$ & $\begin{array}{c}\text { Routine } \\
\text { samples }\end{array}$ & $\begin{array}{c}\text { Field } \\
\text { samples }\end{array}$ & $\begin{array}{c}\text { Routine } \\
\text { samples }\end{array}$ \\
\hline $93212 \mathrm{~A}$ & 1 & 9 & 1 & 9 \\
$93212 \mathrm{~B}$ & & 9 & & 9 \\
$93212 \mathrm{C}$ & 1 & 16 & & 1 & 16 \\
93271 & 1 & 6 & & 1 & 6 \\
93272 & & 8 & & 8 \\
93273 & & 10 & & 10 \\
93274 & 1 & 6 & & 1 & 6 \\
$93332 \mathrm{~A}$ & & 6 & & 6 \\
$93332 \mathrm{~B}$ & 1 & 19 & & 1 & 19 \\
$93383 \mathrm{~A}$ & 1 & 17 & & 1 & 17 \\
$93383 \mathrm{~B}$ & 1 & 10 & & 1 & 10 \\
Total & 7 & 116 & 7 & 116 \\
\hline
\end{tabular}

Table A.35. Samples analyzed for 11 pesticides and 2 PCBs by the Organic Analysis Laboratory at Oak Ridge National Laboratory

\begin{tabular}{|c|c|c|c|c|c|c|c|c|c|c|c|c|c|}
\hline \multirow[b]{2}{*}{ Analyte } & \multicolumn{3}{|c|}{ Measurements } & \multicolumn{7}{|c|}{ Accept } & \multicolumn{3}{|c|}{ Reject } \\
\hline & Total & Accept & Reject & 0 & 1 & 9 & 12 & 18 & 51 & 60 & $\overline{9}$ & 11 & 51 \\
\hline $4,4^{\prime}-\mathrm{DDD}$ & 123 & 121 & 2 & 9 & 95 & & 1 & 47 & 16 & 3 & & & 2 \\
\hline 4,4'-DDE & 123 & 120 & 3 & 17 & 94 & & & 66 & 1 & 18 & & 3 & 1 \\
\hline 4,4'-DDT & 123 & 121 & 2 & 26 & 95 & & & 17 & & 9 & & 2 & \\
\hline Aldrin & 123 & 118 & 5 & 26 & 92 & & & 17 & & 9 & 4 & 1 & 1 \\
\hline Alpha-chlordane & 123 & 116 & 7 & & 90 & & 6 & 93 & 4 & 22 & & 6 & 1 \\
\hline Alpha-chlordene & 123 & 120 & 3 & 9 & 94 & & & 47 & 15 & 3 & & 1 & 2 \\
\hline Aroclor-1254 & 1 & 1 & $\mathbf{0}$ & & 1 & & & & & & & & \\
\hline Aroclor- 1260 & 1 & 1 & 0 & & 1 & & & & & & & & \\
\hline Chlordene & 123 & 123 & 0 & 20 & 97 & & & 21 & 8 & & & & \\
\hline Gamma-chlordane & 123 & 117 & 6 & & 91 & & 14 & 93 & 4 & 22 & 1 & 5 & 1 \\
\hline Gamma-chlordene & 123 & 120 & 3 & 8 & 94 & & & 65 & 16 & 4 & 1 & 1 & 1 \\
\hline Oxychlordane & 123 & 117 & 6 & 10 & 91 & 1 & 3 & 59 & 11 & 13 & 1 & 4 & 3 \\
\hline Technical chlordane & 123 & 116 & 7 & & 90 & & 32 & 38 & 1 & 2 & & 6 & 1 \\
\hline Total & 1355 & 1311 & 44 & 125 & 1025 & 1 & 56 & 563 & 76 & 105 & 7 & 29 & 13 \\
\hline
\end{tabular}


Table A.36. Pesticide/PCB analyses of fish tissue conducted by the Chemical and Physical Analysis Group at Oak Ridge National Laboratory

\begin{tabular}{cccccc}
\hline & \multicolumn{2}{c}{ Total } & & \multicolumn{2}{c}{ Fish } \\
\cline { 2 - 3 } \cline { 5 - 6 } Batch & $\begin{array}{c}\text { Field } \\
\text { samples }\end{array}$ & $\begin{array}{c}\text { Routine } \\
\text { samples }\end{array}$ & $\begin{array}{c}\text { Field } \\
\text { samples }\end{array}$ & $\begin{array}{c}\text { Routine } \\
\text { samples }\end{array}$ \\
\hline CPA10195 & 2 & 8 & 2 & 8 \\
CPA10258 & 2 & 16 & & 2 & 16 \\
CPA10460 & 2 & 36 & & 2 & 36 \\
CPA10548 & 2 & 22 & & 22 \\
CPA10681 & 1 & 17 & 1 & 17 \\
CPA10767 & 1 & 20 & & 20 \\
CPA10884 & 1 & 12 & & 1 \\
CPA10914 & 2 & 23 & 2 & 23 \\
CPA11094 & & 8 & & 8 \\
Total & 13 & 162 & 13 & 162 \\
\hline
\end{tabular}

Table A37. Pesticide/PCB analyses of fish tissue conducted by the Chemical and Physical Analysis Group at Oak Ridge National Laboratory

\begin{tabular}{|c|c|c|c|c|c|c|c|c|c|c|c|c|}
\hline \multirow{2}{*}{ Analyte } & \multicolumn{3}{|c|}{ Measurements } & \multicolumn{6}{|c|}{ Accept } & \multicolumn{3}{|c|}{ Reject } \\
\hline & Total & Accept & Reject & 0 & 1 & 12 & 51 & 52 & 53 & 1 & 52 & 53 \\
\hline Aroclor-1254 & 175 & 146 & 29 & 6 & 120 & 11 & 95 & 130 & 36 & 20 & 24 & 24 \\
\hline Aroclor-1260 & 175 & 166 & 9 & 4 & 140 & & 110 & 158 & 51 & 9 & 9 & 9 \\
\hline Total & 350 & 312 & 38 & 10 & 260 & 11 & 205 & 288 & 87 & 29 & 33 & 33 \\
\hline
\end{tabular}


Table A.38. Gamma analysis of sediment, water, and fish tissue conducted by Environmental Sciences Division at Oak Ridge National Laboratory

\begin{tabular}{|c|c|c|c|c|c|c|c|c|c|}
\hline \multirow[b]{2}{*}{ Batch } & \multicolumn{2}{|c|}{ Total } & \multicolumn{2}{|c|}{ Core } & \multicolumn{2}{|c|}{ Fish } & \multicolumn{2}{|c|}{ Grab } & \multirow{2}{*}{$\begin{array}{l}\text { Water } \\
\text { Routine } \\
\text { samples }\end{array}$} \\
\hline & $\begin{array}{c}\text { Field } \\
\text { samples }\end{array}$ & $\begin{array}{l}\text { Routine } \\
\text { samples }\end{array}$ & $\begin{array}{c}\text { Field } \\
\text { samples }\end{array}$ & $\begin{array}{l}\text { Routine } \\
\text { samples }\end{array}$ & $\begin{array}{c}\text { Field } \\
\text { samples }\end{array}$ & $\begin{array}{l}\text { Routine } \\
\text { samples }\end{array}$ & $\begin{array}{c}\text { Field } \\
\text { samples }\end{array}$ & $\begin{array}{l}\text { Routine } \\
\text { samples }\end{array}$ & \\
\hline 03DEC89 & & 1 & & & & & & 1 & \\
\hline 10DEC89 & & 7 & & 7 & & & & & \\
\hline $17 \mathrm{DEC} 89$ & & 14 & & 14 & & & & & \\
\hline 31DEC89 & & 5 & & 1 & & 3 & & 1 & \\
\hline 07JAN90 & & 18 & & 12 & & 6 & & & \\
\hline 14JAN90 & & 9 & & 4 & & 4 & & 1 & \\
\hline 21JAN90 & & 14 & & 4 & & 10 & & & \\
\hline 28JAN90 & 1 & 13 & & 10 & 1 & 3 & & & \\
\hline 04FEB90 & 1 & 14 & & 6 & 1 & 6 & & & 2 \\
\hline 11 FEB90 & 1 & 13 & & 2 & 1 & 11 & & & \\
\hline 18FEB90 & & 1 & & & & & & 1 & \\
\hline $25 \mathrm{FEB} 90$ & & 18 & & 14 & & & & & 4 \\
\hline 04MAR90 & & 15 & & 5 & & & & 2 & 8 \\
\hline 11MAR90 & & 30 & & 14 & & 12 & & & 4 \\
\hline 18MAR90 & 2 & 27 & & 16 & 2 & 7 & & 1 & 3 \\
\hline 25MAR90 & & 10 & & 3 & & 4 & & 3 & \\
\hline 01APR90 & & 13 & & 11 & & 1 & & 1 & \\
\hline 08APR90 & & 2 & & 1 & & 1 & & & \\
\hline 15APR90 & & 23 & & 12 & & 8 & & 2 & 1 \\
\hline 22APR90 & 3 & 24 & 1 & 11 & 2 & 10 & & & 3 \\
\hline 29APR90 & 1 & 12 & 1 & 6 & & 4 & & & 2 \\
\hline 06MAY90 & & 22 & & 13 & & 8 & & 1 & \\
\hline 13MAY90 & 1 & 15 & 1 & 15 & & & & & \\
\hline 20MAY90 & & 5 & & 1 & & 3 & & 1 & \\
\hline 27MAY90 & & 7 & & 6 & & 1 & & & \\
\hline 03ЛUN90 & & 1 & & 1 & & & & & \\
\hline 10JUN90 & & 4 & & 3 & & & & 1 & \\
\hline 17JUN90 & & 4 & & 4 & & & & & \\
\hline 24JUN90 & 1 & 27 & & 13 & 1 & 14 & & & \\
\hline 01JUL90 & & 6 & & 2 & & 2 & & & 2 \\
\hline 08JUL90 & & 4 & & 3 & & & & & 1 \\
\hline 15JUL90 & & 2 & & & & 2 & & & \\
\hline 22JUL90 & & 9 & & 2 & & 2 & & 5 & \\
\hline 29JUL90 & & 13 & & 3 & & 1 & & 9 & \\
\hline 05AUG90 & & 14 & & 4 & & & & 10 & \\
\hline 12AUG90 & & 15 & & 2 & & & & 13 & \\
\hline 19AUG90 & & 17 & & 2 & & & & 15 & \\
\hline
\end{tabular}


A-51

Table A38. (continued)

\begin{tabular}{|c|c|c|c|c|c|c|c|c|c|}
\hline \multirow[b]{2}{*}{ Batch } & \multicolumn{2}{|c|}{ Total } & \multicolumn{2}{|c|}{ Core } & \multicolumn{2}{|c|}{ Fish } & \multicolumn{2}{|c|}{ Grab } & \multirow{2}{*}{$\begin{array}{c}\text { Water } \\
\text { Routine } \\
\text { samples }\end{array}$} \\
\hline & $\begin{array}{c}\text { Field } \\
\text { samples }\end{array}$ & $\begin{array}{l}\text { Routine } \\
\text { samples }\end{array}$ & $\begin{array}{l}\text { Field } \\
\text { samples }\end{array}$ & $\begin{array}{l}\text { Routine } \\
\text { samples }\end{array}$ & $\begin{array}{c}\text { Field } \\
\text { samples }\end{array}$ & $\begin{array}{l}\text { Routine } \\
\text { samples }\end{array}$ & $\begin{array}{c}\text { Field } \\
\text { samples }\end{array}$ & $\begin{array}{l}\text { Routine } \\
\text { samples }\end{array}$ & \\
\hline 26AUG90 & & 23 & & 1 & & & & 22 & \\
\hline 02SEP90 & & 22 & & 5 & & & & 17 & \\
\hline 09SEP90 & & 34 & & 6 & & 3 & & 25 & \\
\hline 16SEP90 & 1 & 19 & & 3 & 1 & 1 & & 15 & \\
\hline 23SEP90 & & 32 & & 11 & & 1 & & 20 & \\
\hline 30SEP90 & & 36 & & 12 & & 3 & & 21 & \\
\hline 07ОСТ90 & 3 & 60 & 1 & 37 & 2 & 7 & & 16 & \\
\hline $140 C T 90$ & & 57 & & 30 & & 10 & & 16 & 1 \\
\hline $210 \mathrm{CT} 90$ & & 48 & & 25 & & 6 & & 17 & \\
\hline 280 CT90 & & 27 & & 18 & & & & 7 & 2 \\
\hline 04NOV90 & & 38 & & 24 & & & & 14 & \\
\hline 11NOV90 & & 24 & & 19 & & & & 5 & \\
\hline 18NOV90 & & 8 & & 7 & & & & 1 & \\
\hline 25NOV90 & & 2 & & 2 & & & & & \\
\hline 02DEC90 & & 8 & & & & & & 8 & \\
\hline 09DEC90 & & 7 & & & & & & 7 & \\
\hline 16DEC90 & & 10 & & & & & & 10 & \\
\hline 30DEC90 & & 7 & & & & 2 & & 5 & \\
\hline 06JAN91 & & 18 & & & & 4 & & 14 & \\
\hline 13JAN91 & & 19 & & & & 4 & & 15 & \\
\hline 20JAN91 & & 12 & & & & 1 & & 11 & \\
\hline 27JAN91 & & 5 & & & & 3 & & 2 & \\
\hline 03FEB91 & & 3 & & & & 3 & & & \\
\hline 10FEB91 & 1 & 15 & & & & 1 & 1 & 14 & \\
\hline 17FEB91 & & 1 & & & & & & 1 & \\
\hline 24FEB91 & & 22 & & & & & & 22 & \\
\hline 03MAR91 & & 11 & & & & & & 11 & \\
\hline 10MAR91 & & 3 & & & & 1 & & 2 & \\
\hline 17MAR91 & & 2 & & 1 & & 1 & & & \\
\hline 24MAR91 & & 8 & & 6 & & 2 & & & \\
\hline 31MAR91 & & 10 & & 2 & & 4 & & 4 & \\
\hline 07APR91 & & 7 & & & & 4 & & 3 & \\
\hline 14APR91 & & 1 & & & & 1 & & & \\
\hline 21APR91 & & 5 & & & & & & 5 & \\
\hline 28APR91 & 1 & 11 & & & & & 1 & 11 & \\
\hline 05MAY91 & 1 & 12 & & & & & 1 & 12 & \\
\hline 19MAY91 & & 1 & & 1 & & & & & \\
\hline
\end{tabular}


A-52

Table A.38. (continued)

\begin{tabular}{|c|c|c|c|c|c|c|c|c|c|}
\hline \multirow[b]{2}{*}{ Batch } & \multicolumn{2}{|c|}{ Total } & \multicolumn{2}{|c|}{ Core } & \multicolumn{2}{|c|}{ Fish } & \multicolumn{2}{|c|}{ Grab } & \multirow{2}{*}{$\begin{array}{l}\text { Water } \\
\text { Routine } \\
\text { samples }\end{array}$} \\
\hline & $\begin{array}{c}\text { Field } \\
\text { samples }\end{array}$ & $\begin{array}{l}\text { Routine } \\
\text { samples }\end{array}$ & $\begin{array}{c}\text { Field } \\
\text { samples }\end{array}$ & $\begin{array}{l}\text { Routine } \\
\text { samples }\end{array}$ & $\begin{array}{c}\text { Field } \\
\text { samples }\end{array}$ & $\begin{array}{l}\text { Routine } \\
\text { samples }\end{array}$ & $\begin{array}{c}\text { Field } \\
\text { samples }\end{array}$ & $\begin{array}{l}\text { Routine } \\
\text { samples }\end{array}$ & \\
\hline 26MAY91 & & 3 & & & & & & 3 & \\
\hline 02JUN91 & 2 & 14 & & & & & 2 & 14 & \\
\hline 09JUN91 & 3 & 19 & & & & & 3 & 19 & \\
\hline 16JUN91 & 3 & 11 & 1 & & & & 2 & 11 & \\
\hline 23JUN91 & 2 & 24 & & 3 & & 12 & 2 & 9 & \\
\hline 30JUN91 & & 13 & & & & 3 & & 10 & \\
\hline Total & 28 & 1160 & 5 & 440 & 11 & 200 & 12 & 487 & 33 \\
\hline
\end{tabular}


Table A.39. Gamma analysis of sediment, water, and fish tissue conducted by Environmental Sciences Division at Oak Ridge National Laboratory

\begin{tabular}{|c|c|c|c|c|c|c|c|c|c|c|c|c|c|c|c|}
\hline \multirow[b]{2}{*}{ Analyte } & \multicolumn{3}{|c|}{ Measurements } & \multicolumn{10}{|c|}{ Accept } & \multicolumn{2}{|c|}{ Reject } \\
\hline & $\overline{\text { Total }}$ & Accept & Reject & 0 & 1 & 23 & 24 & 29 & 32 & 38 & 39 & 42 & $\overline{47}$ & $\overline{35}$ & 38 \\
\hline $\mathrm{Co}-60$ & 1175 & 1174 & 1 & 272 & 67 & 2 & 22 & 9 & 11 & 2 & 225 & 670 & 12 & 1 & \\
\hline Cs-137 & 1228 & 1226 & 2 & 1013 & 58 & 2 & 25 & 8 & 11 & & & 150 & 8 & & 2 \\
\hline Total & 2403 & 2400 & 3 & 1285 & 125 & 4 & 47 & 17 & 22 & 2 & 225 & 820 & 20 & 1 & 2 \\
\hline
\end{tabular}

Table A40. Number of accepted and rejected analyses and associated explanation codes for Environmental Sciences Division/Radiological Analysis Laboratory

\begin{tabular}{|c|c|c|c|c|c|c|c|c|c|c|c|c|c|c|}
\hline \multirow[b]{2}{*}{ Radionuclide } & \multicolumn{3}{|c|}{ Number of analyses } & \multicolumn{9}{|c|}{ Accept } & \multicolumn{2}{|c|}{ Reject } \\
\hline & Submit & Accept & Reject & 0 & 1 & 24 & 29 & 32 & 38 & 39 & 42 & 47 & $\overline{35}$ & 38 \\
\hline $\mathrm{Co}-60$ & 1134 & 1133 & 1 & 232 & 67 & 22 & 9 & 11 & 2 & 225 & 669 & 14 & 1 & \\
\hline Cs-137 & 1187 & 1185 & 2 & 972 & 58 & 25 & 8 & 11 & & & 150 & 10 & & 2 \\
\hline Total & 2321 & 2318 & 3 & 1204 & 125 & 47 & 17 & 22 & 2 & 225 & 819 & 24 & 1 & 2 \\
\hline
\end{tabular}

Explanation codes

$1=$ holding time exceeded

24 = laboratory control sample recovery outside bimits

29 = sample not properly preserved

32 = calibration verification indicates unacceptable change in system background

$35=$ calibration verification indicates alpha/beta cross-talk factors

38 = activity calculated incorrectly

$39=$ uncertainty overestimated due to incorrect error propagation

42 = minimum detectable activity does not reflect instrument sensitivity

$47=$ duplicate error ratio outside limits 
Table A.41. Frequency by instrument and detector of background analyses conducted by Environmental Sciences Division/Radiological Analysis Laboratory

\begin{tabular}{|c|c|c|c|c|c|c|c|}
\hline \multirow[b]{2}{*}{ Date } & \multirow{2}{*}{$\frac{\begin{array}{c}\text { ND6700 } \\
\text { detector }\end{array}}{1}$} & \multicolumn{6}{|c|}{$\begin{array}{l}\text { ND9900 } \\
\text { detector }\end{array}$} \\
\hline & & 3 & 1 & 2 & 3 & 6 & 7 \\
\hline \multicolumn{8}{|c|}{$\underline{1989}$} \\
\hline November & 1 & 1 & & & & & \\
\hline December & & & & 1 & 1 & 1 & 1 \\
\hline \multicolumn{8}{|c|}{1990} \\
\hline \multicolumn{8}{|l|}{ January } \\
\hline February & & & & 1 & 1 & 1 & 1 \\
\hline March & & & 1 & & & & \\
\hline April & 1 & 1 & 1 & 1 & 1 & 1 & 1 \\
\hline \multicolumn{8}{|l|}{ May } \\
\hline \multicolumn{8}{|l|}{ June } \\
\hline \multicolumn{8}{|l|}{ July } \\
\hline \multicolumn{8}{|l|}{ August } \\
\hline September & & 1 & 1 & & 1 & 1 & \\
\hline October & 3 & 2 & 2 & 2 & 2 & 2 & \\
\hline November & 1 & 1 & 2 & 1 & 2 & 1 & \\
\hline December & 3 & 3 & 1 & 1 & 1 & 1 & 1 \\
\hline \multicolumn{8}{|c|}{$\underline{1991}$} \\
\hline January & 1 & 1 & 1 & 1 & 1 & 1 & 1 \\
\hline February & & & 1 & 1 & 1 & 1 & 1 \\
\hline March & & 2 & 1 & 1 & 1 & 1 & 1 \\
\hline April & & & 2 & 1 & 2 & 1 & 1 \\
\hline May & 2 & 1 & 2 & 2 & 2 & 2 & 2 \\
\hline June & & 1 & 1 & 1 & 1 & 2 & 1 \\
\hline
\end{tabular}


Table A.42 Environmental Sciences Division/Radiological Analysis Laboratory control sample results

\begin{tabular}{lrrrrr}
\hline Description & Radionuclide & $\begin{array}{c}\text { Limits } \\
(\%)\end{array}$ & In & Out & $\begin{array}{c}\text { Percentage } \\
\text { in }\end{array}$ \\
\hline \multirow{2}{*}{ EPA Clay } & Cs-137 & $\begin{array}{c}\text { ND6700 } \\
\text { No-130 }\end{array}$ & 74 & 0 & 100 \\
NBS 4350 & K-40 & $70-130$ & 4 & 0 & 100 \\
& Co-60 & $70-130$ & 4 & 0 & 100 \\
& Cs-13 & $70-130$ & 4 & 0 & 100 \\
& Eu-152 & $70-130$ & 4 & 0 & 100 \\
NBS 4354 & Co-60 & $70-130$ & 9 & 0 & 100 \\
& Cs-137 & $70-130$ & 11 & 1 & 92 \\
EPA Clay & & ND9900 & & & \\
IAEA 352 & Cs-137 & $70-130$ & 184 & 0 & 100 \\
& K-40 & $70-130$ & 24 & 0 & 100 \\
NBS 4350 & Cs-137 & $70-130$ & 20 & 4 & 83 \\
& K-40 & $70-130$ & 3 & 0 & 100 \\
& Co-60 & $70-130$ & 3 & 0 & 100 \\
& Cs-137 & $70-130$ & 3 & 0 & 100 \\
& Eu-152 & $70-130$ & 2 & 1 & 33 \\
NBS 4354 & Co-60 & $70-130$ & 116 & 0 & 100 \\
& Cs-137 & $70-130$ & 116 & 1 & 99 \\
\hline
\end{tabular}

Table A.43. Environmental Sciences Division/Radiological Analysis Laboratory duplicate analysis results by instrument and matrix

\begin{tabular}{lcccc}
\hline Analyte & $\begin{array}{l}\text { DER } \\
\text { limit }\end{array}$ & In & Out & $\begin{array}{c}\text { Percentage } \\
\text { in }\end{array}$ \\
C0-60 & $<1$ & 11 & 1 & 92 \\
Cs-137 & $<1$ & 11 & 1 & 92 \\
\multicolumn{5}{c}{ ND6700-Sediment } \\
C0-60 & \multicolumn{2}{c}{ ND9900-Sediment } \\
Cs-137 & $<1$ & 66 & 0 & 100 \\
& & 69 & 0 & 100 \\
Co-60 & $<1$ & \multicolumn{2}{c}{ ND9900_Fish } & \\
Cs-137 & $<1$ & 21 & 0 & 100 \\
\hline
\end{tabular}


Table A.44. Results of Environmental Protection Agency interlaboratory comparison samples analyzed by Environmental Sciences Division/Radiological Analysis Laboratory

\begin{tabular}{|c|c|c|c|c|c|c|}
\hline Date & Matrix & Analyte & Average & $\begin{array}{c}\text { Standard } \\
\text { development }\end{array}$ & $\begin{array}{l}\text { Normalized } \\
\text { range }\end{array}$ & $\begin{array}{c}\text { Normalized } \\
\text { deviation }\end{array}$ \\
\hline \multirow[t]{6}{*}{ 10FEB89 } & Water & $\mathrm{Cr}-51$ & 223.67 & 3.51 & 0.17 & -0.82 \\
\hline & & $\mathrm{Co}-60$ & 10.00 & 0.00 & 0.00 & 0.00 \\
\hline & & $\mathrm{Zn}-65$ & 169.00 & 3.00 & 0.22 & 1.08 \\
\hline & & $R u-106$ & 169.33 & 2.08 & 0.13 & -0.83 \\
\hline & & Cs-134 & & & & \\
\hline & & Cs-137 & 10.33 & 0.58 & 0.12 & 0.12 \\
\hline \multirow[t]{2}{*}{ 18APR89 } & Water & Cs-134 & 18.67 & 0.58 & 0.12 & -0.46 \\
\hline & & Cs-137 & 20.00 & 0.00 & 0.00 & 0.00 \\
\hline \multirow[t]{6}{*}{ 09JUN89 } & Water & $\mathrm{Ba}-133$ & 48.33 & 0.58 & 0.12 & -0.23 \\
\hline & & $\mathrm{Co}-60$ & 30.00 & 1.00 & 0.24 & -0.35 \\
\hline & & $\mathrm{Zn}-65$ & 170.33 & 6.35 & 0.38 & 0.54 \\
\hline & & Ru-106 & 129.00 & 14.18 & 1.44 & 0.13 \\
\hline & & Cs-134 & 37.67 & 2.08 & 0.47 & -0.46 \\
\hline & & Cs-137 & 20.67 & 1.15 & 0.24 & 0.23 \\
\hline \multirow[t]{6}{*}{ 06OCT89 } & Water & $\mathrm{Ba}-133$ & 56.33 & 2.89 & 0.49 & -0.77 \\
\hline & & $\mathrm{Co}-60$ & 30.33 & 1.53 & 0.36 & 0.12 \\
\hline & & $\mathrm{Zn}-65$ & 129.33 & 2.08 & 0.18 & 0.04 \\
\hline & & Ru-106 & 143.33 & 1.15 & 0.07 & -1.91 \\
\hline & & Cs-134 & 27.00 & 1.73 & 0.36 & -0.69 \\
\hline & & Cs-137 & 61.00 & 4.36 & 0.95 & 0.69 \\
\hline \multirow[t]{2}{*}{$310 C T 89$} & Water & Cs-134 & 5.00 & 0.00 & 0.00 & 0.00 \\
\hline & & Cs-137 & 5.33 & 1.15 & 0.24 & 0.12 \\
\hline \multirow[t]{6}{*}{ 09FEB90 } & Water & $\mathrm{Co}-60$ & 15.67 & 0.58 & 0.12 & 0.23 \\
\hline & & $\mathrm{Zn}-65$ & 146.00 & 4.58 & 0.38 & 0.87 \\
\hline & & $\mathrm{Ru}-106$ & 134.67 & 10.79 & 0.84 & -0.54 \\
\hline & & Cs-134 & 17.33 & 0.58 & 0.12 & -0.23 \\
\hline & & Cs-137 & 18.67 & 0.58 & 0.12 & 0.23 \\
\hline & & $\mathrm{Ba}-133$ & 76.33 & 4.16 & 0.68 & 0.58 \\
\hline \multirow[t]{2}{*}{ 17APR90 } & Water & Cs-134 & 14.33 & 0.58 & 0.12 & -0.23 \\
\hline & & Cs-137 & 15.67 & 1.15 & 0.24 & 0.23 \\
\hline \multirow[t]{6}{*}{ 08UUN90 } & Water & $\mathrm{CO}-60$ & 24.67 & 1.15 & 0.24 & 0.23 \\
\hline & & $\mathrm{Zn}-65$ & 154.33 & 5.86 & 0.43 & 0.73 \\
\hline & & Ru-106 & 209.67 & 6.03 & 0.34 & -0.03 \\
\hline & & Cs-134 & 23.00 & 1.00 & 0.24 & -0.35 \\
\hline & & Cs-137 & 28.00 & 1.00 & 0.24 & 1.04 \\
\hline & & $\mathrm{Ba}-133$ & 102.00 & 4.36 & 0.47 & 0.52 \\
\hline
\end{tabular}


A-57

Table A.44. (continued)

\begin{tabular}{|c|c|c|c|c|c|c|}
\hline Date & Matrix & Analyte & Average & $\begin{array}{c}\text { Standard } \\
\text { development }\end{array}$ & $\begin{array}{l}\text { Normalized } \\
\text { range }\end{array}$ & $\begin{array}{c}\text { Normalized } \\
\text { deviation }\end{array}$ \\
\hline 10AUG90 & Water & I-131 & 38.00 & 0.00 & 0.00 & -0.29 \\
\hline \multirow[t]{6}{*}{ 050СТ90 } & Water & $\mathrm{Co}-60$ & 20.67 & 1.53 & 0.35 & 0.23 \\
\hline & & $\mathrm{Zn}-65$ & 120.33 & 9.29 & 0.89 & 0.77 \\
\hline & & Ru-106 & 145.00 & 8.72 & 0.63 & -0.69 \\
\hline & & Cs-134 & 10.67 & 0.58 & 0.12 & -0.46 \\
\hline & & Cs-137 & 12.67 & 1.15 & 0.24 & 0.23 \\
\hline & & $\mathrm{Ba}-133$ & 110.67 & 7.51 & 0.80 & 0.10 \\
\hline \multirow[t]{2}{*}{$300 С Т 90$} & Water & Cs-134 & 7.00 & 0.00 & 0.00 & 0.00 \\
\hline & & Cs-137 & 5.00 & 0.00 & 0.00 & 0.00 \\
\hline \multirow[t]{6}{*}{ 08FEB91 } & Water & Co-60 & 40.33 & 0.58 & 0.12 & 0.12 \\
\hline & & $\mathrm{Zn}-65$ & 155.00 . & 5.20 & 0.35 & 0.69 \\
\hline & & Ru-106 & 196.00 & 5.29 & 0.31 & 0.91 \\
\hline & & Cs-134 & 7.33 & 0.58 & 0.12 & -0.23 \\
\hline & & Cs-137 & 8.67 & 0.58 & 0.12 & 0.23 \\
\hline & & $\mathrm{Ba}-133$ & 75.00 & 1.00 & 0.15 & 0.00 \\
\hline 15FEB91 & Water & I-131 & 77.33 & 5.51 & 0.74 & 0.51 \\
\hline \multirow[t]{2}{*}{ 16APR91 } & Water & Cs-134 & 22.67 & 0.58 & 0.12 & -0.46 \\
\hline & & Cs-137 & 25.67 & 0.58 & 0.12 & 0.23 \\
\hline \multirow[t]{6}{*}{ 07JUN91 } & Water & $\mathrm{Co}-60$ & 9.67 & 0.58 & 0.12 & -0.12 \\
\hline & & $\mathrm{Zn}-65$ & 113.67 & 4.04 & 0.43 & 0.89 \\
\hline & & $R u-106$ & 145.33 & 4.73 & 0.35 & -0.42 \\
\hline & & Cs-134 & 14.33 & 0.58 & 0.12 & -0.23 \\
\hline & & Cs-137 & 15.67 & 0.58 & 0.12 & 0.58 \\
\hline & & $\mathrm{Ba}-133$ & 61.00 & 1.00 & 0.20 & -0.29 \\
\hline \multirow[t]{6}{*}{$040 C T 91$} & Water & Co-60 & 28.00 & 0.00 & 0.00 & -0.35 \\
\hline & & $\mathrm{Zn}-65$ & 73.00 & 3.61 & 0.59 & 0.00 \\
\hline & & Ru-106 & 194.00 & 13.45 & 0.77 & -0.43 \\
\hline & & Cs-134 & 9.33 & 0.58 & 0.12 & -0.23 \\
\hline & & Cs-137 & 10.33 & 0.58 & 0.12 & 0.12 \\
\hline & & $\mathrm{Ba}-133$ & 93.00 & 1.00 & 0.12 & -0.87 \\
\hline \multirow[t]{3}{*}{$220 C T 91$} & Water & Co- 60 & 18.33 & 0.58 & 0.12 & -0.58 \\
\hline & & Cs-134 & 8.33 & 0.58 & 0.12 & -0.58 \\
\hline & & Cs-137 & 10.33 & 0.58 & 0.12 & -0.23 \\
\hline
\end{tabular}


Table A.45. Alpha and beta analysis of sediment, water, and fish tissue conducted at Oak Ridge Associated Universities

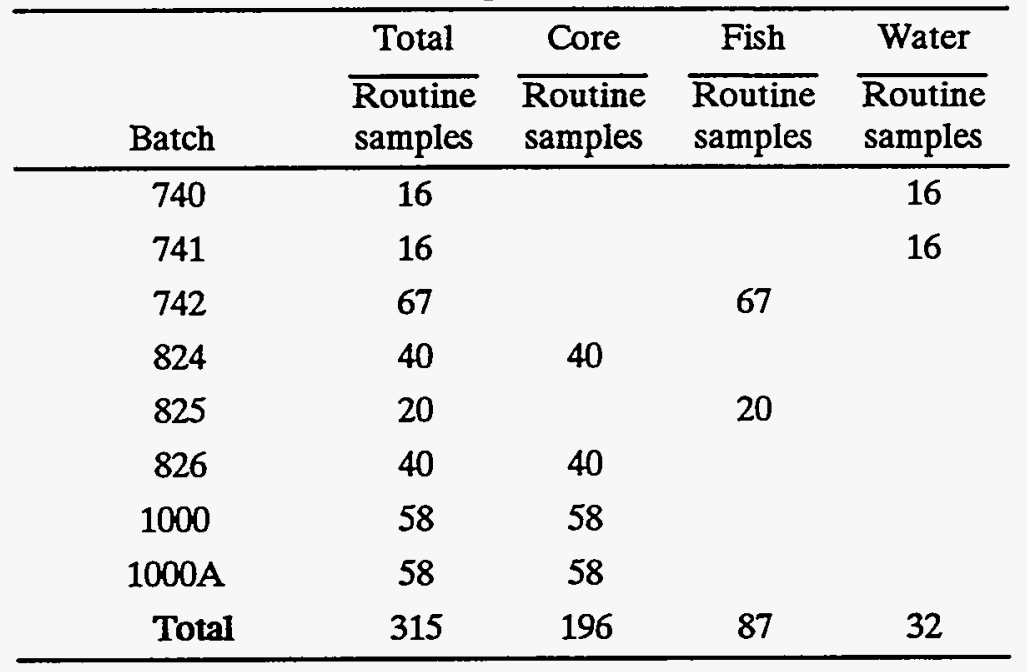

Table A46. Alpha and beta analysis of sediment, water, and fish tissue conducted at Oak Ridge Associated Universities

\begin{tabular}{lcccccccccccccc}
\hline & \multicolumn{1}{c}{ Measurements } & \multicolumn{1}{c}{ Accept } & \multicolumn{8}{c}{ Reject } \\
\multicolumn{1}{c}{ Analyte } & Total & Accept & Reject & 0 & 1 & 12 & 24 & 29 & 37 & 47 & 1 & 29 & 37 & 41 \\
\hline Am-241 & 98 & 96 & 2 & 16 & 78 & 47 & & 8 & & & 2 & \\
Cm-243,244 & 98 & 96 & 2 & 17 & 78 & 47 & & 7 & & & 2 & \\
Cm-245,246 & 40 & 39 & 1 & 17 & 21 & & & & 2 & & & 1 & \\
Cm-248 & 38 & 38 & 0 & 16 & 21 & & & 2 & & & & \\
H-3 & 16 & 0 & 16 & & & & & & & & 16 & 16 & & \\
Pu-238 & 98 & 95 & 3 & 15 & 76 & 8 & & & 9 & & & & 3 & \\
Pu-239,240 & 98 & 95 & 3 & 14 & 76 & 12 & & & 8 & & & & 3 & \\
Sr-90 & 201 & 199 & 2 & 32 & 142 & 5 & 27 & 16 & 8 & 6 & & & & 2 \\
U-234 & 98 & 95 & 3 & 7 & 78 & 19 & & 23 & & & 3 & \\
U-235 & 98 & 95 & 3 & 7 & 78 & 1 & & 23 & & & 3 & \\
U-238 & 98 & 95 & 3 & 7 & 78 & 5 & & 23 & & & 3 & \\
$\quad$ Total & & & & 148 & 726 & 144 & 27 & 16 & 113 & 6 & 16 & 16 & 20 & 2 \\
\hline
\end{tabular}


Table A47. List of samples analyzed by Oak Ridge Associated Universities/Environmental Survey Site Assessment Program

\begin{tabular}{|c|c|c|c|c|c|c|c|}
\hline \multirow[t]{2}{*}{ Batch } & \multicolumn{3}{|c|}{ Regular } & \multicolumn{4}{|c|}{ Quality control } \\
\hline & Sediment & Fish & Water & Duplicates & Blanks & Spikes & Controls \\
\hline \multicolumn{8}{|c|}{ Beta } \\
\hline 740 & 0 & 0 & 16 & 3 & 4 & 0 & 0 \\
\hline 741 & 0 & 0 & 16 & 1 & 2 & 0 & 0 \\
\hline 742 & 0 & 67 & 0 & 6 & 12 & 0 & 5 \\
\hline 825 & 0 & 20 & 0 & 2 & 0 & 0 & 0 \\
\hline 826 & 40 & 0 & 0 & 8 & 10 & 0 & 2 \\
\hline $1000 \mathrm{~A}$ & 58 & 0 & 0 & 3 & 6 & 1 & 2 \\
\hline \multicolumn{8}{|c|}{ Alpha } \\
\hline 824 & 40 & 0 & 0 & 9 & 9 & 0 & 2 \\
\hline 1000 & 58 & 0 & 0 & 8 & 13 & 7 & 0 \\
\hline Total & 196 & 87 & 32 & 40 & 56 & 8 & 11 \\
\hline
\end{tabular}

Table A.48. Chemical recovery results for alpha analyses conducted by Oak Ridge Associated Universities/Environmental Survey Site Assessment Program

\begin{tabular}{|c|c|c|c|c|c|c|}
\hline Batch & $\begin{array}{c}\text { Sample } \\
\text { type }\end{array}$ & Tracer & $\begin{array}{c}\text { Limits } \\
(\%)\end{array}$ & In & $\overline{\text { Out }}$ & $\begin{array}{l}\text { Percentage } \\
\text { in }\end{array}$ \\
\hline \multirow[t]{12}{*}{824} & Regular & Am-243 & $50-100$ & 34 & 6 & 85 \\
\hline & & $\mathrm{Pu}-236$ & $50-100$ & 37 & 3 & 92 \\
\hline & & U-232 & $50-100$ & 33 & 7 & 82 \\
\hline & Blank & Am-243 & $50-100$ & 6 & 2 & 75 \\
\hline & & Pu-236 & $50-100$ & 7 & 2 & 75 \\
\hline & & U-232 & $50-100$ & 5 & 3 & 62 \\
\hline & $\operatorname{LCS}^{\mathrm{a}}$ & Am-243 & $50-100$ & 1 & 0 & 100 \\
\hline & & $\mathrm{Pu}-236$ & $50-100$ & 1 & 0 & 100 \\
\hline & & U-232 & $50-100$ & 2 & 0 & 100 \\
\hline & Duplicate & Am-243 & $50-100$ & 5 & 2 & 71 \\
\hline & & $\mathrm{Pu}-236$ & $50-100$ & 7 & 1 & 88 \\
\hline & & U-232 & $50-100$ & 7 & 0 & 100 \\
\hline \multirow[t]{6}{*}{1000} & Regular & Am-243 & $50-100$ & 51 & 7 & 88 \\
\hline & & $\mathrm{Pu}-236$ & $50-100$ & 51 & 7 & 88 \\
\hline & & U-232 & $50-100$ & 34 & 24 & 59 \\
\hline & Blank & Am-243 & $50-100$ & 9 & 4 & 69 \\
\hline & & $\mathrm{Pu}-236$ & $50-100$ & 10 & 3 & 77 \\
\hline & & U-232 & $50-100$ & 5 & 8 & 38 \\
\hline
\end{tabular}


A- 60

Table A.48. (continued)

\begin{tabular}{ccccccc}
\hline Batch & $\begin{array}{c}\text { Sample } \\
\text { type }\end{array}$ & Tracer & $\begin{array}{c}\text { Limits } \\
(\%)\end{array}$ & In & Out & $\begin{array}{c}\text { Percentage } \\
\text { in }\end{array}$ \\
\hline & Spike & Am-243 & $50-100$ & 6 & 1 & 86 \\
& Pu-236 & $50-100$ & 5 & 2 & 71 \\
& U-232 & $50-100$ & 3 & 2 & 60 \\
& Duplicate & Am-243 & $50-100$ & 7 & 1 & 88 \\
& Pu-236 & $50-100$ & 7 & 1 & 88 \\
& $\mathrm{U}-232$ & $50-100$ & 6 & 2 & 75 \\
\hline
\end{tabular}

alaboratory control sample

Table A.49. Chemical recovery results for strontium-90 analyses conducted by Oak Ridge Associated Universities/Environmental Survey Site Assessment Program

\begin{tabular}{llcccc}
\hline \multirow{2}{*}{ Batch } & $\begin{array}{c}\text { Sample } \\
\text { type }\end{array}$ & $\begin{array}{c}\text { Limits } \\
(\%)\end{array}$ & In & Out & $\begin{array}{c}\text { Percentage } \\
\text { in }\end{array}$ \\
\hline 742 & Regular & $50-100$ & 64 & 3 & 96 \\
& Blank & $50-100$ & 12 & 0 & 100 \\
& LCS & $50-100$ & 5 & 0 & 100 \\
825 & Duplicate & $50-100$ & 6 & 0 & 100 \\
& Regular & $50-100$ & 20 & 0 & 100 \\
& Blank & $50-100$ & 5 & 0 & 100 \\
& LCS & $50-100$ & 2 & 0 & 100 \\
& Duplicate & $50-100$ & 2 & 0 & 100 \\
& Regular & $50-100$ & 40 & 0 & 100 \\
& Blank & $50-100$ & 10 & 0 & 100 \\
& LCS & $50-100$ & 2 & 0 & 100 \\
& Duplicate & $50-100$ & 8 & 0 & 100 \\
& Regular & $50-100$ & 55 & 3 & 95 \\
& Blank & $50-100$ & 4 & 2 & 67 \\
& LCS & $50-100$ & 2 & 0 & 100 \\
& Spike & $50-100$ & 1 & 0 & 100 \\
& Duplicate & $50-100$ & 2 & 1 & 67 \\
\hline \multirow{5}{*}{ (100 } & & & &
\end{tabular}

\footnotetext{
alaboratory control sample
} 
Table A.50. Laboratory control sample results conducted by Oak Ridge Associated Universities/Environmental Survey Site

Assessment Program

\begin{tabular}{lccccc}
\hline Description & Radionuclide & $\begin{array}{c}\text { Limits } \\
(\%)\end{array}$ & In & Out & $\begin{array}{c}\text { Percentage } \\
\text { in }\end{array}$ \\
\hline EPA 2454-1 & Sr-90 & $70-130$ & 17 & 2 & 89 \\
EPA2458-1 & H-3 & $70-130$ & 1 & 0 & 100 \\
NBS 4353 & U-234 & $70-130$ & 3 & 1 & 75 \\
& U-238 & $70-130$ & 4 & 0 & 100 \\
NBS4353+ & Am-241 & $70-130$ & 7 & 0 & 100 \\
& Pu-239 & $70-130$ & 7 & 0 & 100 \\
& U-234 & $70-130$ & 4 & 1 & 80 \\
& U-238 & $70-130$ & 4 & 1 & 80 \\
\hline
\end{tabular}

Table A.51. Duplicate analysis results conducted by Oak Ridge Associated Universities/Environmental Survey Site

Assessment Program

\begin{tabular}{llcccc}
\hline Batch & Radionuclide & $\begin{array}{c}\text { DER } \\
\text { limit }\end{array}$ & In & Out & $\begin{array}{c}\text { Percentage } \\
\text { in }\end{array}$ \\
\hline 741 & Sr-90 & $<1$ & 3 & 1 & 75 \\
742 & Sr-90 & $<1$ & 6 & 0 & 100 \\
824 & Am-241 & $<1$ & 7 & 0 & 100 \\
& Cm-243,244 & $<1$ & 6 & 0 & 100 \\
& Cm-245,246 & $<1$ & 6 & 0 & 100 \\
& Cm-248 & $<1$ & 6 & 0 & 100 \\
& Pu-238 & $<1$ & 8 & 0 & 100 \\
& Pu-239,240 & $<1$ & 8 & 0 & 100 \\
& U-234 & $<1$ & 7 & 0 & 100 \\
& U-235 & $<1$ & 7 & 0 & 100 \\
& U-238 & $<1$ & 7 & 0 & 100 \\
825 & Sr-90 & $<1$ & 2 & 0 & 100 \\
1000 & Sr-90 & $<1$ & 7 & 1 & 88 \\
& Am-241 & $<1$ & 8 & 0 & 100 \\
& Cm-243,244 & $<1$ & 8 & 0 & 100 \\
& Pu-238 & $<1$ & 8 & 0 & 100 \\
& Pu-239,240 & $<1$ & 8 & 0 & 100 \\
& U-234 & $<1$ & 7 & 1 & 88 \\
& U-235 & $<1$ & 8 & 0 & 100 \\
& U-238 & $<1$ & 8 & 0 & 100 \\
& Sr-90 & $<1$ & 3 & 0 & 100 \\
\hline
\end{tabular}

aduplicate error ratios 
Appendix B.

ADDITIONAL FIGURES 


\section{.}

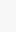


KEYWORD

METHOD USE PROBLEMS

LOGBOOKS/WORKSHEETS PROBLEMS

MISSING INFORMATION

TRANSCRIPTION ERROR

MISSING OC INFORMATION

SPIKE PROBLEMS

CALIBRATION PROBLEMS

(ORGANICINORGANIC)

UNITS INCORRECT OR MISSING

INSTRUMENT DETECTION LIMIT MISSING

DUPLICATE PROBLEMS

COC MISSING

BATCH PROBLEMS

LAB CONTROL SAMPLES MISSING

ILLEGIBLE INFORMATION

SAMPLE ID INCORRECT

REQUEST FOR ANALYSIS

INCONSISTENCIES

CALCULATIONAL PROBLEMS

(ORGANICINORGANIC)

NO BLANKS, CONTAMINATION PRESENT

DUPLICATES

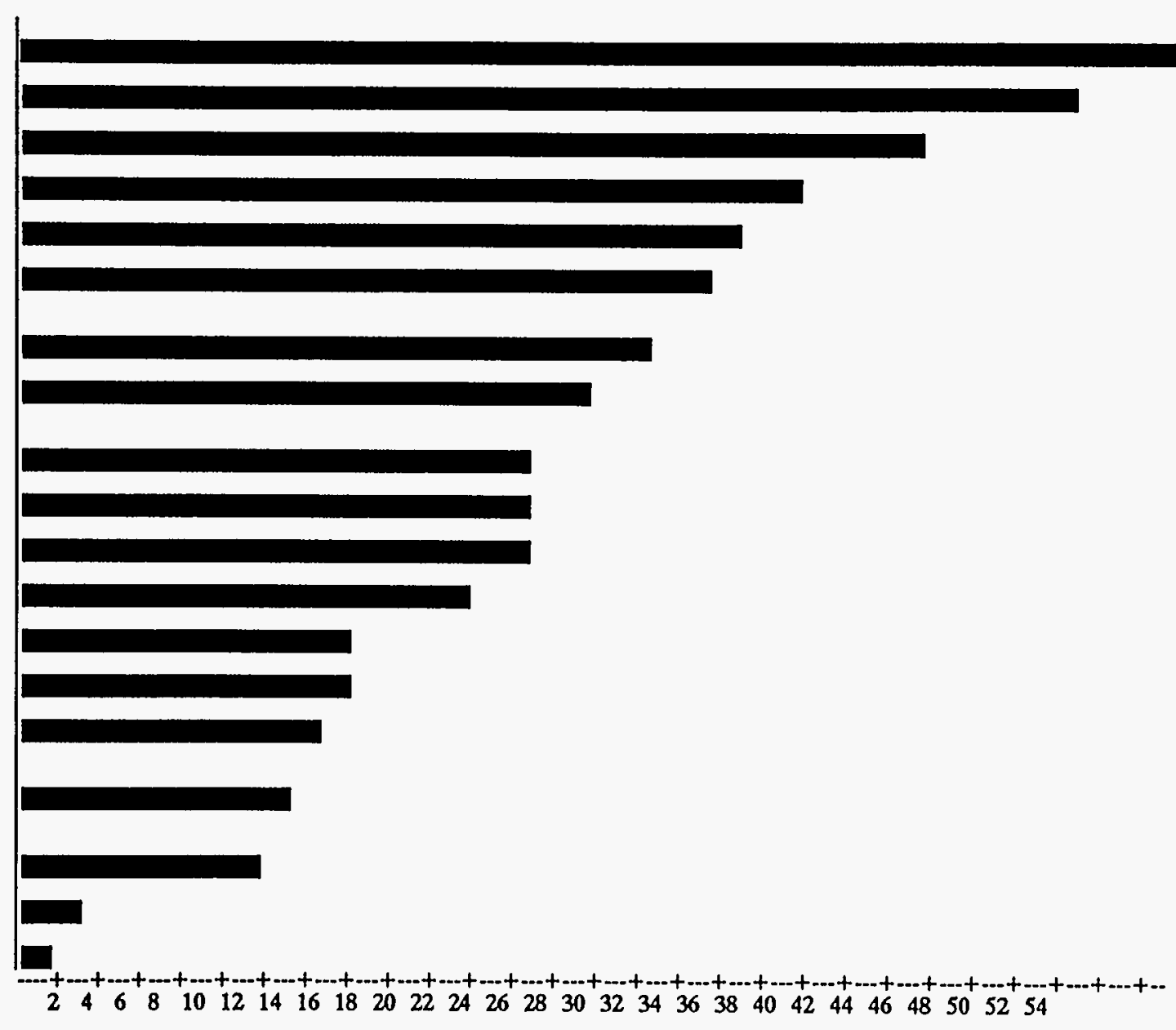

FREQUENCY

Fig. B.1. Nonconformances from analytical validation by the IT laboratory using AA/CP methods. 
FREQUENCY OF KEYWORD

\section{KEYWORD}

LOGBOOKS/WORKSHBETS PROBLEMS

MISSING INFORMATION

CALIBRATION PROBLEMS (ORGANICINORGANIC)

SPIKR PROBLEMS

METHOD USE PROBLEMS

INSTRUMENT DETECTION LIMIT MISSINO

MISSINO QC INFORMATION

COC MISSING

TRANSCRIPTION ERROR

ILLEGIBLE INFORMATION

CALCULATIONAL PROBLEMS (ORGANICINORGANIC)

UNITS INCORRECT OR MISSING

MS/MSD PROBLEMS

BATCH PROBLEMS

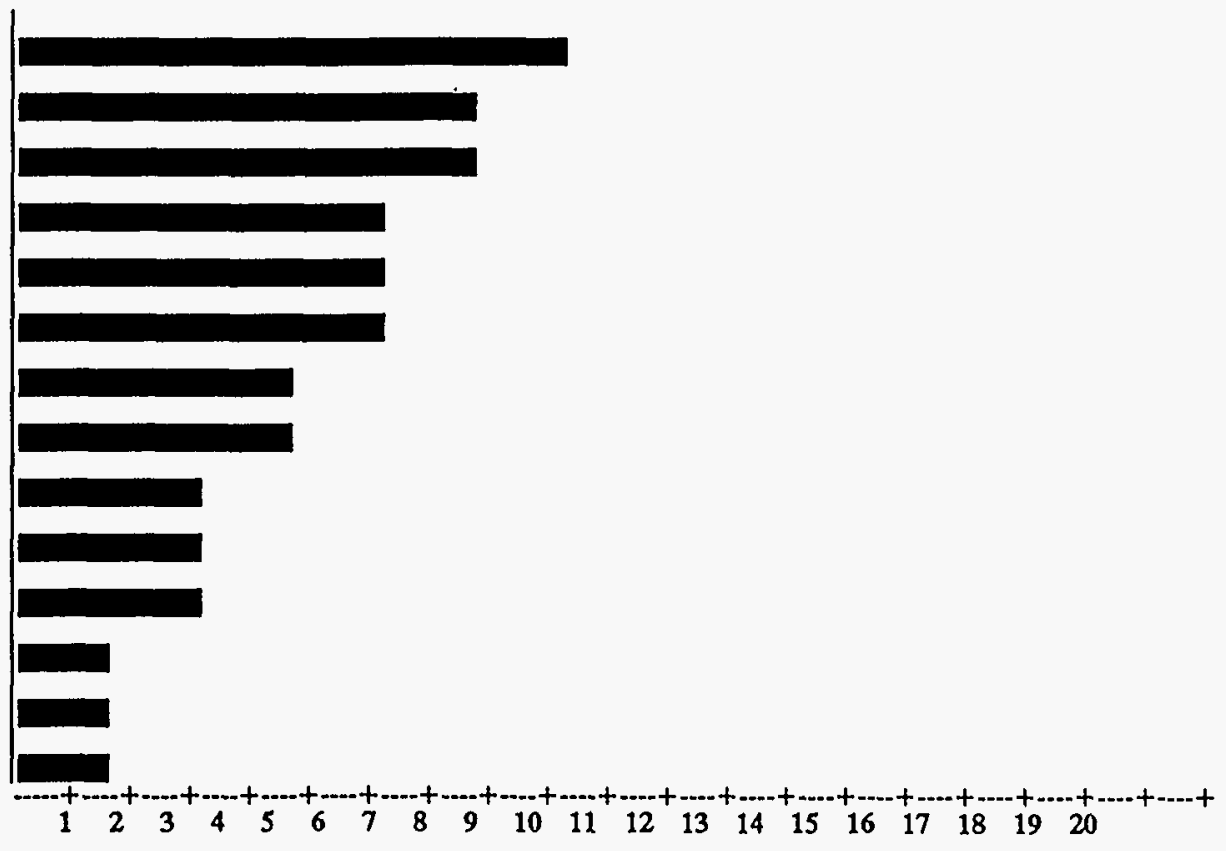

FREQUENCY

Fig. B.2 Nonconformances from analytical validation by the K-25 laboratory using AA/ICP methods. 


\section{FREQUENCY OF KEYWORD}

KEYWORD

METHOD USE PROBLEMS

LOGBOOKS/WORKSHEBTS PROBLEMS

NO BLANKS, CONTAMINATION PRESENT

CALIBRATION PROBLEMS (ORGANICINORGANIC)

UNITS INCORRECT OR MISSINO

MISSING INFORMATION

BATCH PROBLEMS

TRANSCRIPTION ERROR

SPIKB PROBLEMS

MISSING QC INFORMATION

MS/MSD PROBLEMS

SAMPLE ID INCORRECT

LAB CONTROL SAMPLES MISSING

ILLEGIBLE INFORMATION

INSTRUMENT DETECTION LIMIT MISSING

HOLDING TIMES

CALCULATIONAL PROBLEMS (ORGANICINORGANIC)

DUPLICATE PROBLEMS

COC MISSING

REQUEST FOR ANALYSIS INCONSISTENCIES

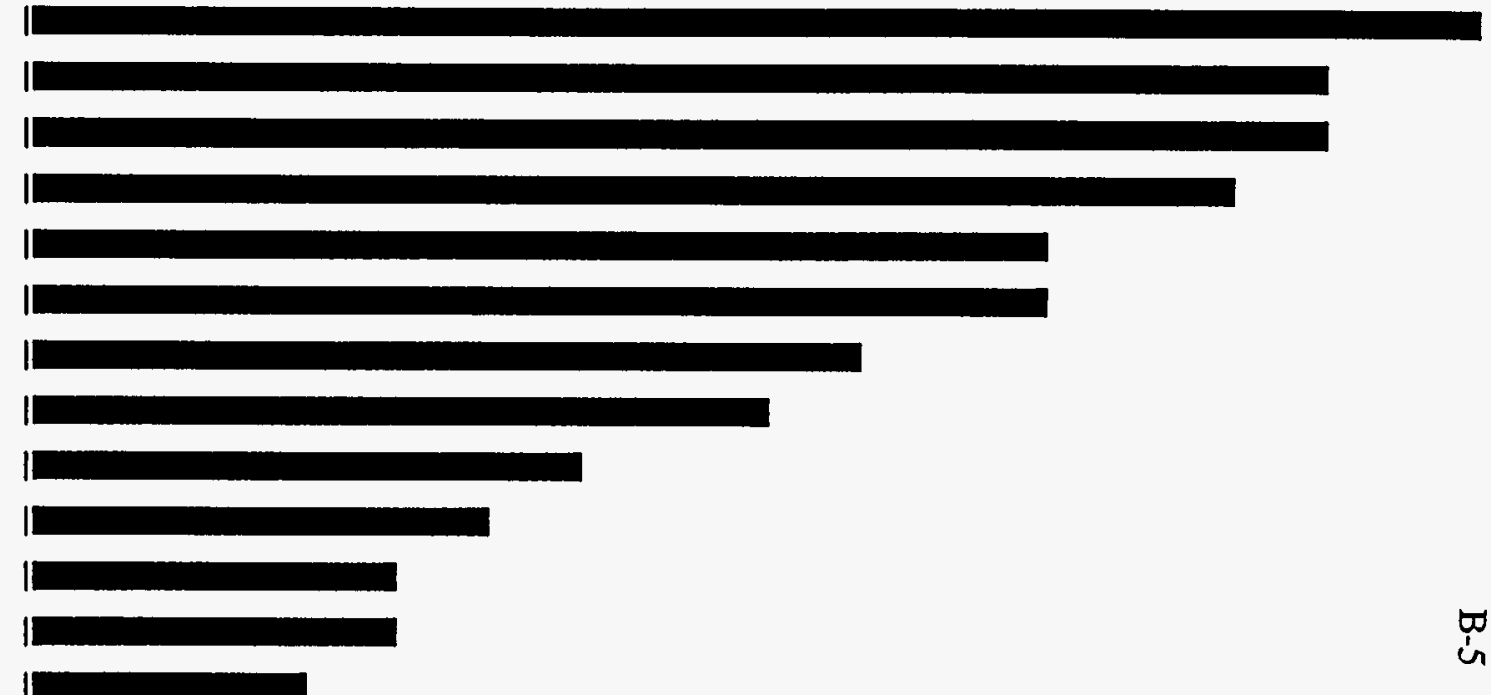


KEYWORD

NO BLANKS, CONTAMINATION PRESENT

METHOD USE PROBLEMS

CALIBRATION PROBLEMS (ORGANICINORGANIC)

BATCH PROBLEMS

LOGBOOKS/WORKSHEETS PROBLEMS

UNITS INCORRECT OR MISSING

\section{TRANSCRIPTION ERROR}

MSMSD PROBLEMS

LAB CONTROL SAMPLES MISSING

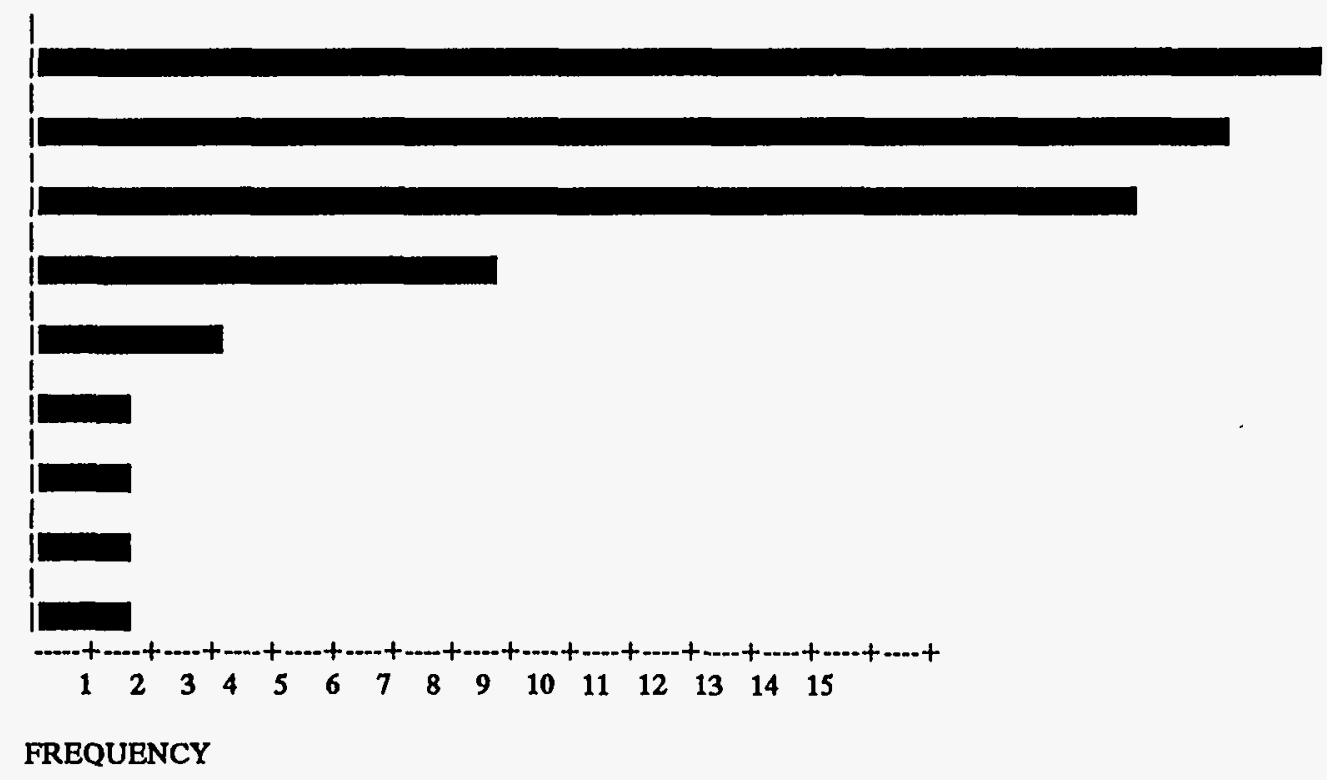

Fig. B.4. Nonconformances from analytical validation by the ORNL/EAL laboratory using the AA method. 

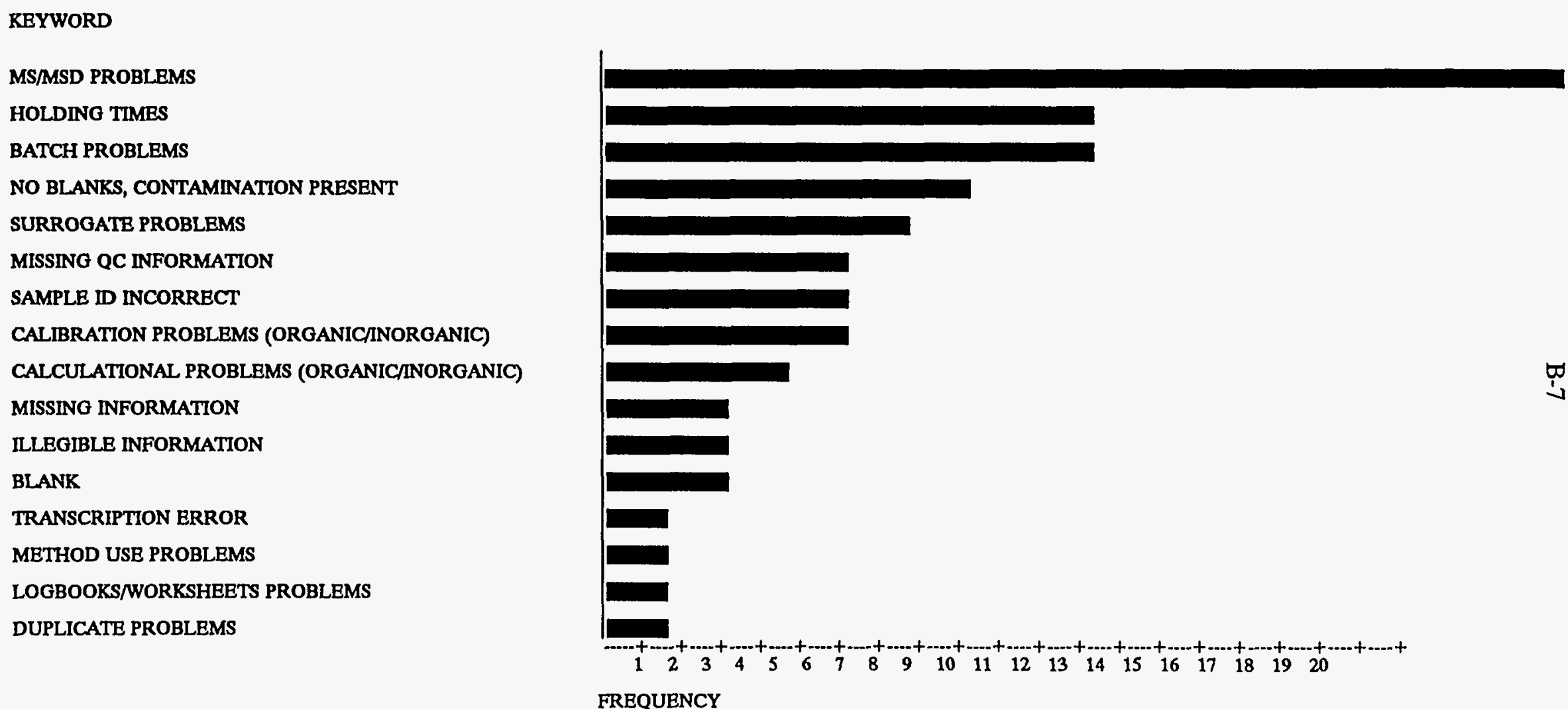

Fig. B.5. Nonconformances from analytical validation by the K-25 laboratory using the semivolatiles method. 
KEYWORD

TRANSCRIPTION ERROR

MS/MSD PROBLEMS

TENTATIVELY IDENTIFIED COMPOUNDS

SURROGATE PROBLEMS

COC MISSINO

SAMPLE ID INCORRECT

CALIBRATION PROBLEMS (ORGANICINORGANIC)

ILLEGIBLE INFORMATION

MISSING INFORMATION

MISSING QC INFORMATION

NO BLANKS, CONTAMINATION PRESENT

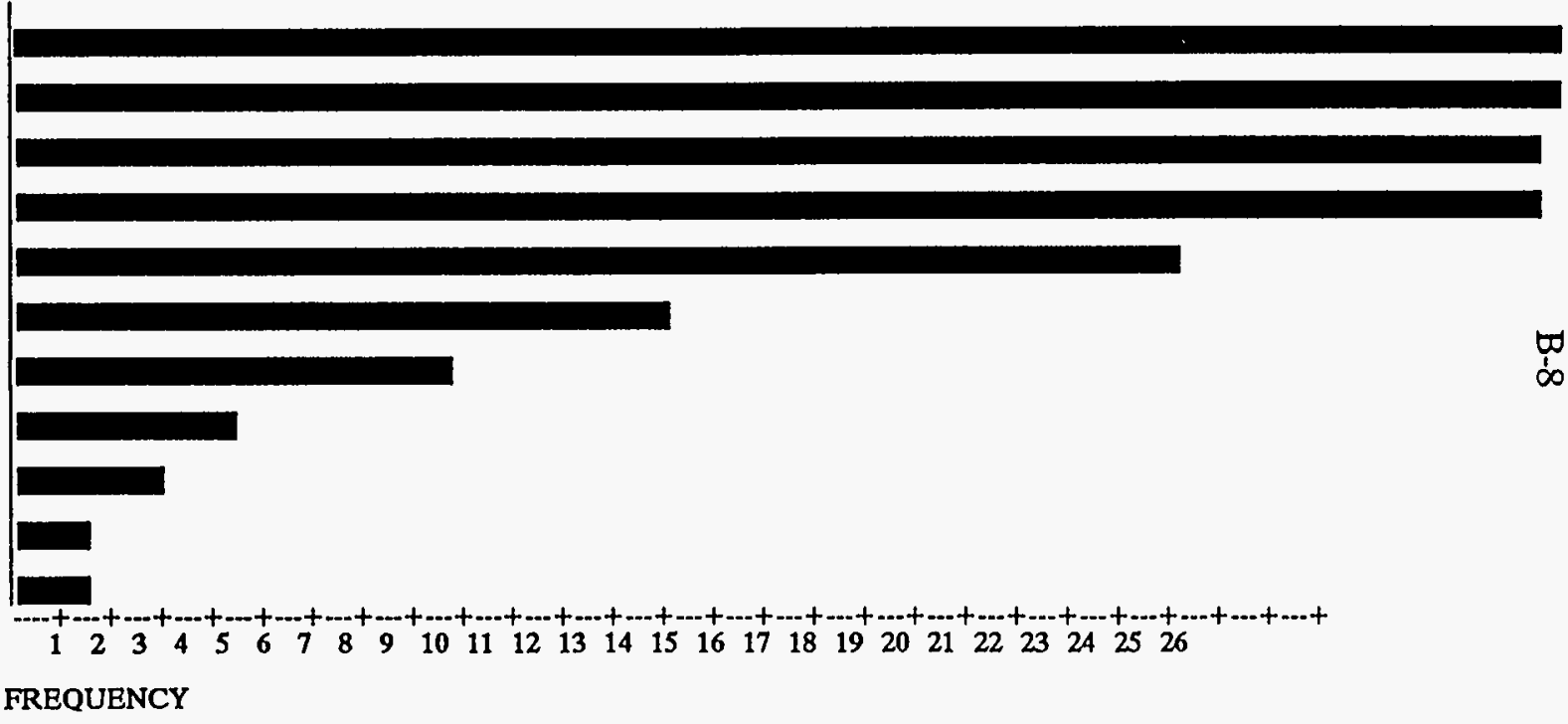

Fig. B.6. Nonconformances from analytical validation by the ORNL/OAL laboratory using the semivolatiles method. 
KEYWORD

TRANSCRIPTION ERROR

METHOD USE PROBLEMS

MISSING QC INFORMATION

HOLDING TIMES

BATCH PROBLEMS

MISSING INFORMATION

SAMPLE ID INCORRECT

MS/MSD PROBLEMS

COC MISSINO

CALIBRATION PROBLEMS (ORGANICINORGANIC)

SURROGATE PROBLEMS

LOGBOOKS/WORKSHEETS PROBLEMS

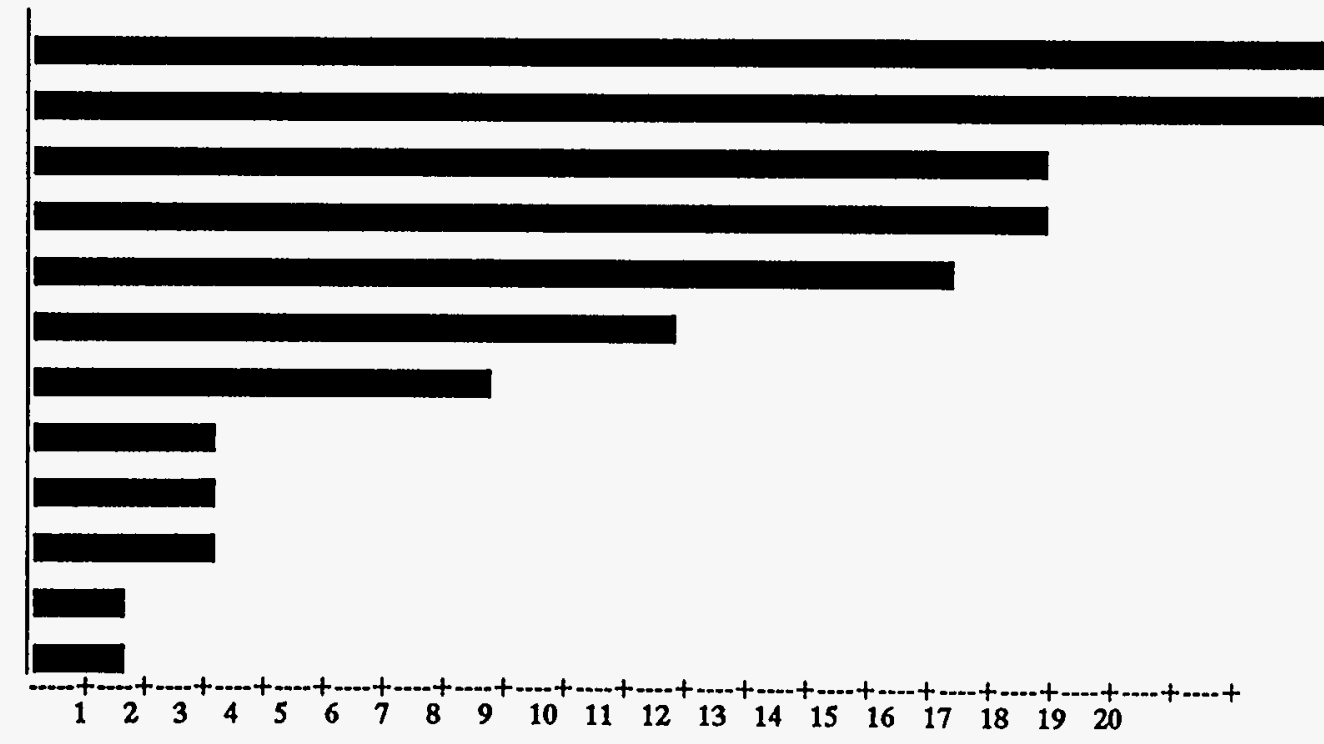

FREQUENCY

Fig. B.7. Nonconformances from analytical validation by the K-25 laboratory using the pesticide/PCB method. 


\section{KEYWORD}

CALIBRATION PROBLEMS (ORGANIC/INORGANIC) SURROGATE PROBLEMS

MS/MSD PROBLEMS

METHOD USE PROBLEMS

COC MISSING

TRANSCRIPTION ERROR

MISSING QC INFORMATION

NO BLANKS, CONTAMINATION PRESENT

BATCH PROBLEMS

SAMPLE ID INCORRECT

HOLDING TIMES

MISSING INFORMATION

LOGBOOKS/WORKSHEETS PROBLEMS

CALCULATIONAL PROBLEMS (ORGANICINORGANIC)

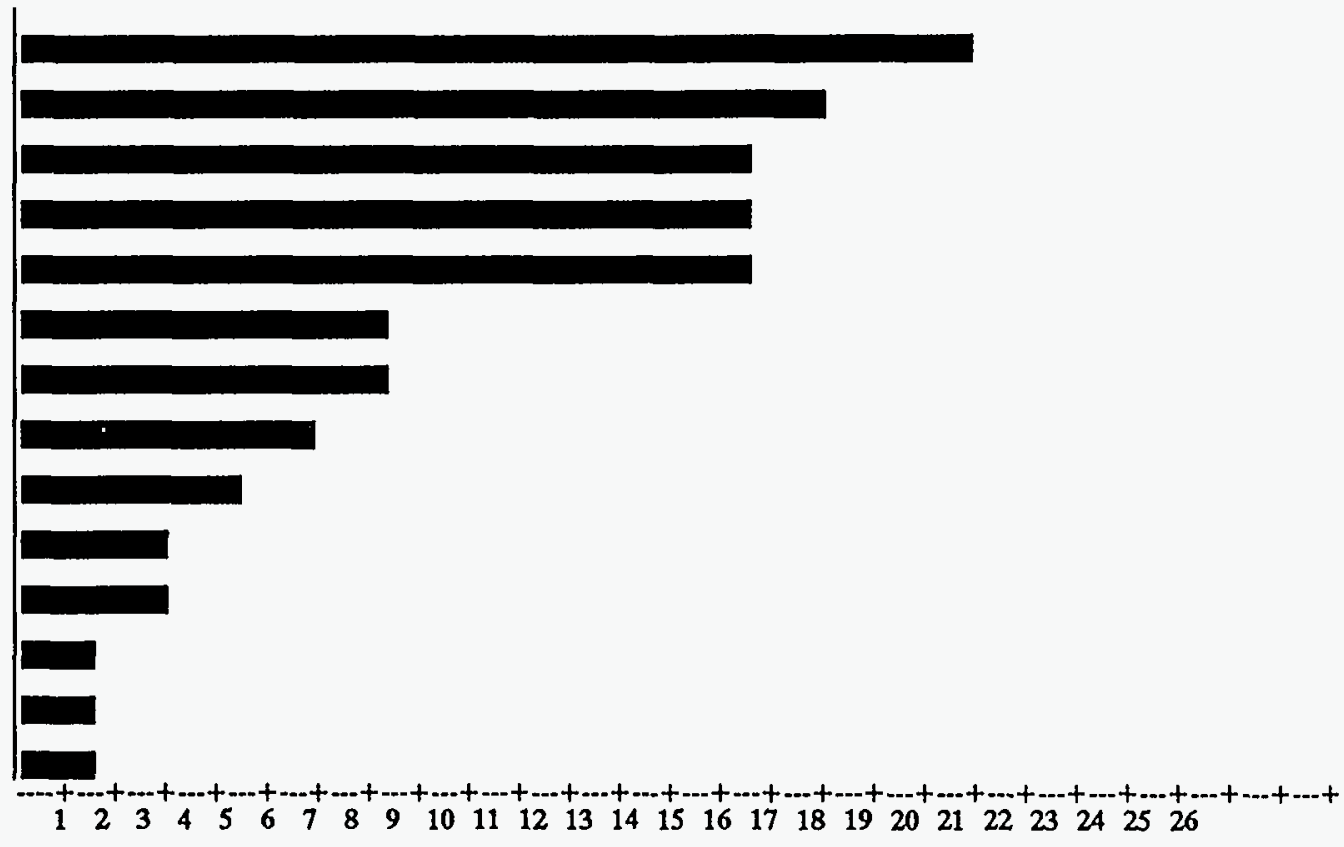

FREQUENCY

Fig. B.8. Nonconformances from analytical validation by the ORNLNOAL laboratory using pesticide/PCB methods. 
FREQUENCY OF KEYWORD

KEYWORD

SURROGATE PROBLEMS

MS/MSD PROBLEMS

NO BLANKS, CONTAMINATION PRESENT

MISSING QC INFORMATION

METHOD USE PROBLEMS

BATCH PROBLEMS

SUROGATE

MISSING INFORMATION

COC MISSING

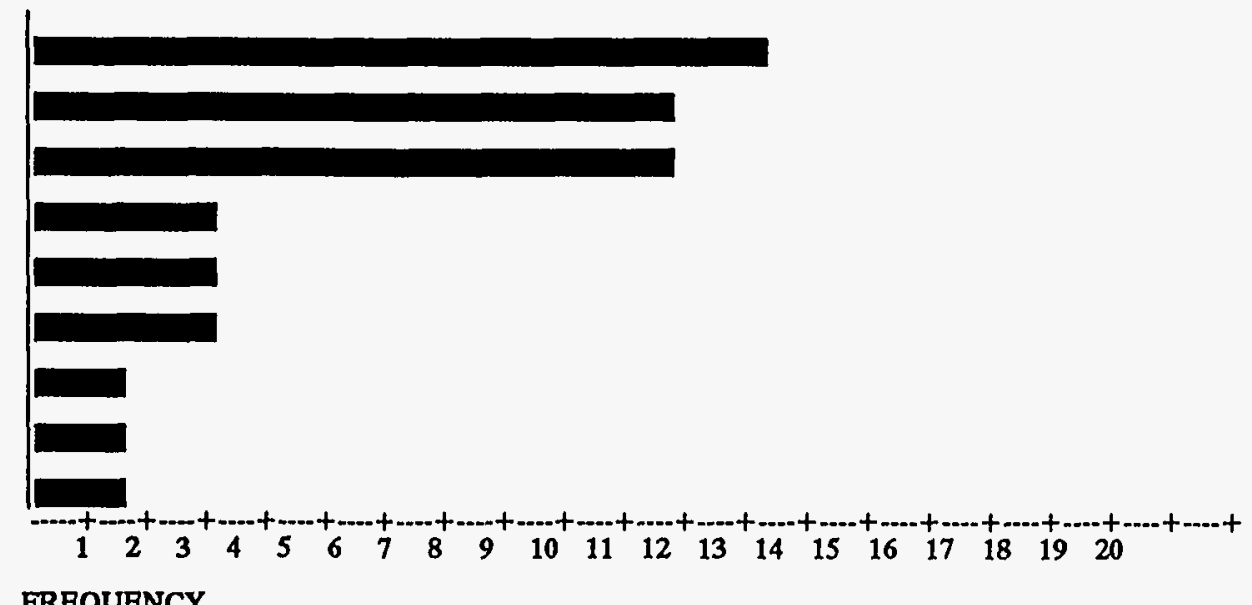

FREQUENCY

Fig. B.9. Nonconformances from anatytical validation by the ORNL/CPA laboratory using pesticide/PCB methods. 
KEYWORD

MISSING INFORMATION

ILLEGIBLE INFORMATION

MINIMUM DETECTION LIMIT MISSING

RCALIBRATION PROBLEMS (ORGANICINORGANIC)

RAD ADJUSTMENT FACTORS

UNITS INCORRECT OR MISSING

SAMPLE ID INCORRECT

CALCULATIONAL PROBLEMS (OROANICINORGANIC)

TRANSCRIPTION ERROR

LAB CONTROL SAMPLES MISSING

MISSING QC INFORMATION

RCALCULATIONAL PROBLEMS (ORGANICINORGANIC)

DUPLICATE PROBLEMS

COC MISSING

BATCH PROBLEMS

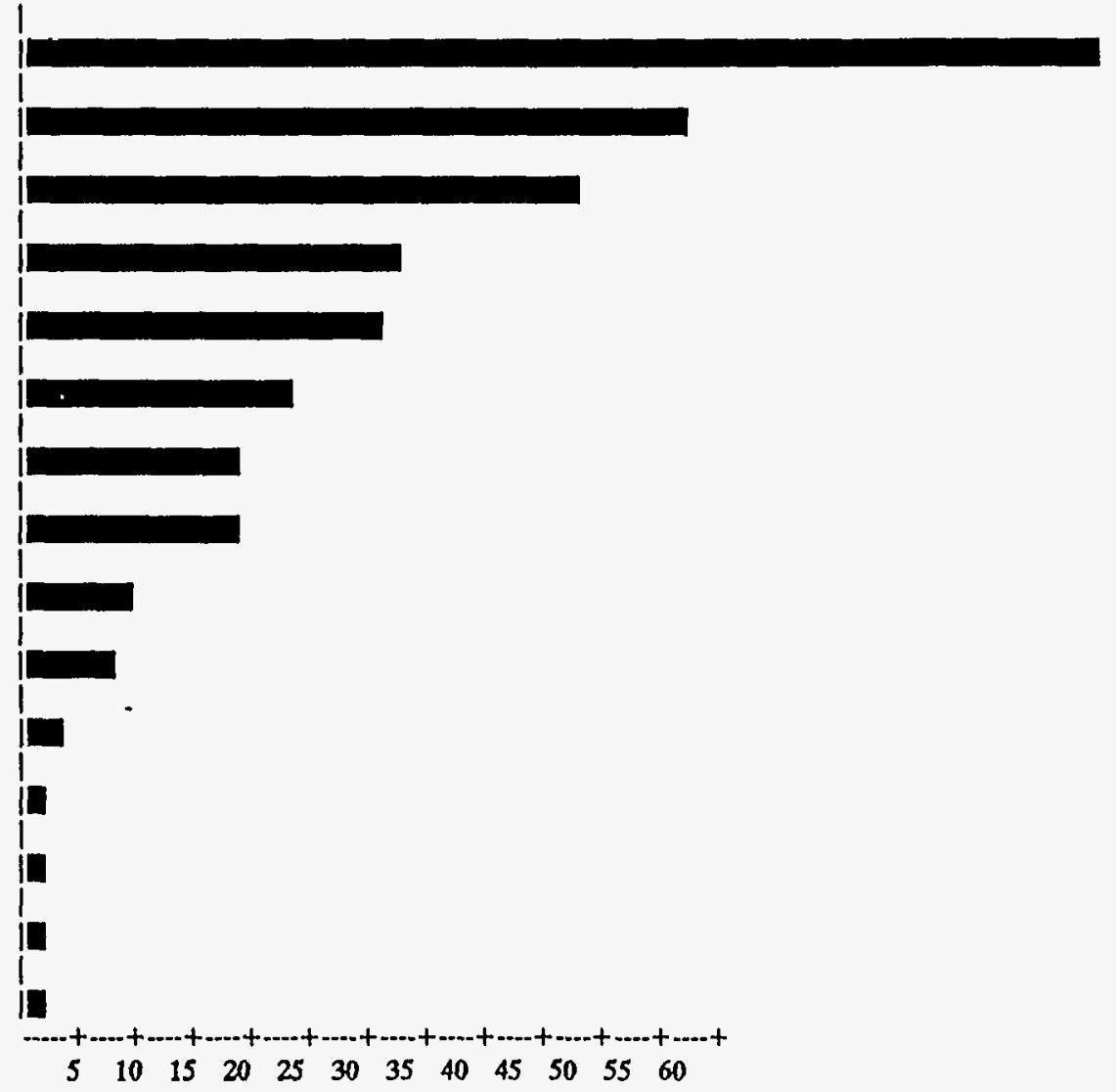

Fig. B.10. Nonconformances from analytical validation by the ORNL/ESD RAL using the gamma spectroscopy method. 
KEYWORD

MISSING INFORMATION

TRANSCRIPTION ERROR

CALIBRATION PROBLEMS (ORGANICINORGANIC)

CALCULATIONAL PROBLEMS (ORGANICINORGANIC)

MISSING QC INFORMATION

UNITS INCORRECT OR MISSING

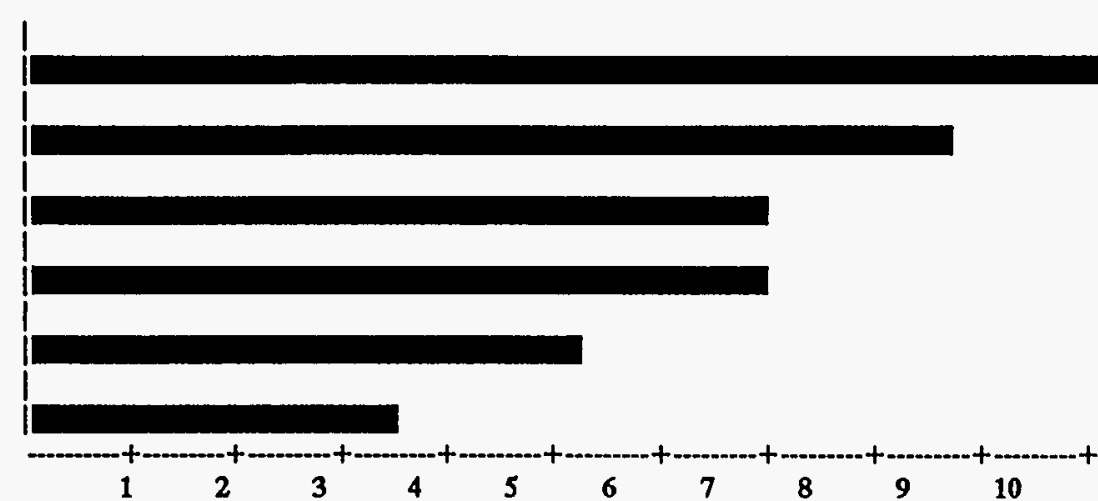

FREQUENCY

Fig. B.11. Nonconformances from analytical validation by the ORAU laboratory using the alpha spectroscopy method.

FREQUENCY OF KEYWORD

KEYWORD

MISSING INFORMATION

CALCULATIONAL PROBLEMS (ORGANICINORGANIC)

TRANSCRIPTION ERROR

REQUEST FOR ANALYSIS INCONSISTENCIES

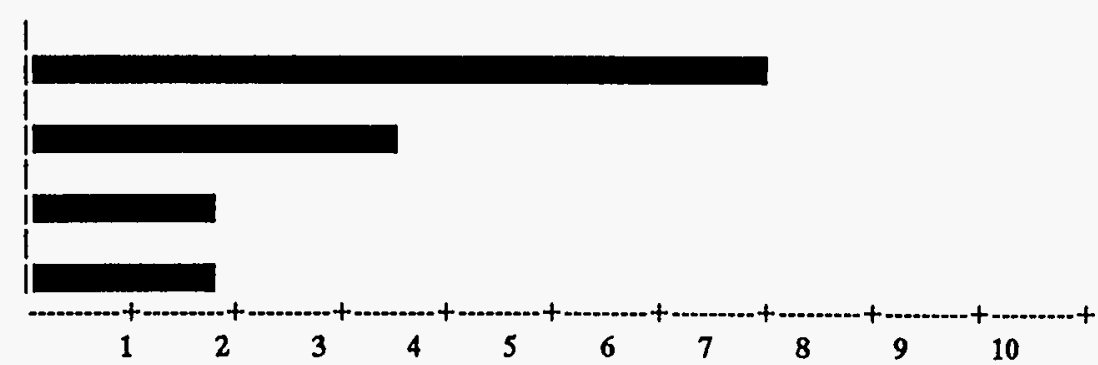

FREQUENCY

Fig. B.12. Nonconformances from analytical validation by the ORAU laboratory using the Sr-90 method. 
FREQUENCY OF KEYWORD

KEYWORD

TRANSCRIPTION ERROR

\section{SPIKE PROBLEMS}

LAB CONTROL SAMPLES MISSING

SAMPLE ID INCORRECT

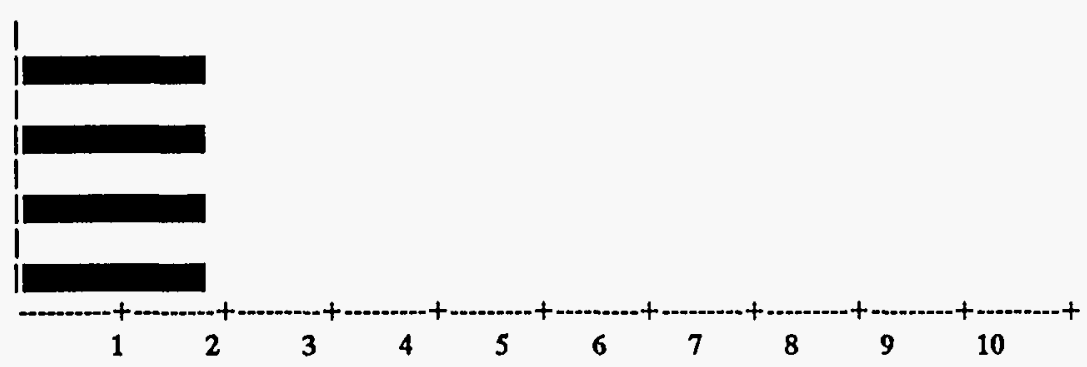

FREQUENCY

Fig B.13. Nonconformances from analytical validation by the ORAU laboratory using the tritium method. 
Appendix C.

FIELD QUALITY CONTROL 



\section{FIELD QUALITY CONTROL}

\section{C.1. WATER SAMPLING}

Water quality control samples were collected to bracket field total organic, total inorganic, and dissolved inorganic samples (Table 3.1). Fifty-four field samples were collected for analytes from 18 sites on nine sample collection dates. For these field samples, 42 QC samples were collected on eight dates from 15 sites. Fifteen duplicate samples were collected for all analytes from five sites on three dates. Six trip blanks were collected for all analytes from five sites on two dates. Eighteen rinse blanks were collected for all analytes from six sites on three dates. Three field blanks were collected from one site on one date for all analytes.

\section{C.1.1 Ficld Sampling Completeness}

The completeness of sample collection for field QC, a comparison of the sites included for sampling in the Clinch River Remedial Investigation (CRRI) Phase 1 plan (Energy Systems 1990) with those actually sampled was $100 \%$; no samples were rejected because of collection errors. Completeness in terms of the processing and submittal of samples compares the samples submitted for a particular analysis with those rejected because of errors in processing, preservation, or other related activities is assessed in Sect. 3.1.

\section{C.1.2 Representativeness}

Results from all rinse water samples from field and laboratory equipment cleaning operations are presented in Table C.1. Sample identification numbers and analytes that were not detected are not presented. Rinse sample contamination was detected for calcium (eight samples), iron, magnesium, sodium, and zinc (four samples each), cadmium and lead (three samples each), nickel and beryllium (one sample each). For organic analytes, bis(2ethylhexyl)phthalate was detected in one sample.

The values from equipment rinsate samples, with the exception of lead noted below, do not reflect measurable increases in these analytes for the field samples with which they were paired (Table 3.1). Calcium and magnesium rinse sample values were $<1 \%$ of the field sample values, sodium was less than $5 \%$, and iron was less than $10 \%$ of the field sample values. Beryllium, cadmium, nickel, and zinc were not observed in the field samples with which they were associated. The values for dissolved lead at Poplar Creek kilometer (PCK) 9.6 and total lead at PCK 7.6 were greater than the associated field sample values (Table C.1); contamination from sources other than the field sampling activity may be responsible. Lead values in associated field samples for these sites were less than the average DL (Cook et al. 1992).

Blank samples were collected to assess the possibility of contamination from sample containers, collection procedures, or other nonmatrix sources (Table C.2). Contamination was detected in two inorganic samples. Cadmium, calcium, chromium, copper, iron, magnesium, nickel, sodium, and zinc were detected in one sample [Clinch River mile (CRM) 50.5]; 
selenium was observed in the other, representing CRM 9.6, CRM 14.5 and CRM 19.6 (Table C.2). Bis(2-ethylhexyl)phthalate was observed in one organic blank sample.

Though selenium was present in a trip blank, it was not detected in any field samples associated with that blank (CRM 9.6, CRM 14.5, or CRM 19.7 [Cook et al. 1992]). It may be concluded that the impact of selenium in this trip blank on completion of Phase 1 objectives is minimal, however the presence of detectable levels of contaminants in blank samples is an unacceptable result.

Analytes detected in the CRM 50.5 field blank sample, which were detected in the associated field sample include dissolved calcium at $10 \%$ of the field sample, dissolved iron at three times the field value, dissolved magnesium at $<5 \%$ of the field sample value, potassium at $38 \%$ of the field sample value, and sodium at $50 \%$ of the field sample value. None of the other analytes observed in the field blank for this site were found in the field sample. Blank results indicate that the field blank for CRM 50.5 was contaminated; thus, any values for dissolved inorganic contaminants from this site should be considered suspicious. Analytes detected in both blank and field samples did not consist of contaminants of concern for Phase 1 of the CRRI (Energy Systems 1990) and, therefore, should not affect risk assessment calculations. However, as stated above, the presence of detectable levels of contaminants at any percentage of field sample values represents an unacceptable result for the representativeness of the samples.

With these exceptions, the comparability and representativeness of Phase 1 results were acceptable. Blanks will be further evaluated for Phase 2 of the CRRI.

\section{C.1.3 Field Duplicates}

Water sample duplicates were collected to assess the precision of the sample collection process. The precision of field duplicate sample collection was assessed by (1) Calculating the analyte-specific RPD for paired duplicate samples with mean values greater than five times the average DL (Table C.3) and (2) Calculating the absolute value of the difference between pairs for comparison with the average DL, for paired duplicate samples with analytespecific mean values less than five times the average DL (Table C.4). Precision is considered acceptable either for RPD values less than $20 \%$ in the first case or absolute values of paired differences less than the average DL in the second case. For values within $5 \%$ of these acceptance levels, environmental variability may influence the perceived precision.

Duplicate pairs for total and dissolved calcium, magnesium, mercury, potassium, and sodium, as well as for organics di-n-octylphthalate and diethylphthalate, had acceptable levels of precision. for all field duplicate pairs in which the analytes were detected (see Tables C.3 and C.4). Precision was unacceptable for bis(2-ethylhexyl)phthalate and dissolved iron at Tennessee River mile (TRM) 531, dissolved iron and total lead at TRM 547, dissolved lead at CRM 0.5, dissolved cadmium and lead at CRM 1, and dissolved iron and dissolved zinc at CRM 43.

The acceptable precision results for all samples analyzed for calcium, magnesium, potassium, and sodium suggest that the sample collection method is acceptable. The low RPD values for these analytes also suggests that, for the sample pairs collected, that environmental variability between duplicate samples is small. Sample pairs with unacceptable levels of precision for particular analytes may reflect specific contaminants originating from 
a source other than the field sampling activity. In general, these results indicate that sampling precision was acceptable for Phase 1 data. Field duplicates will be collected for Phase 2 of the CRRI.

\section{C.1.4 Sample Processing and Preservation}

Quality control of sample processing was assessed through a comparison of dissolved-tototal inorganic analyte pairs. Values for dissolved (filtered through 0.45 - $\mu \mathrm{m}$-pore-sized acidwashed filters) and total concentrations for particular sample pairs were compared. This comparison must consider the differences in solubility between specific analytes. For inorganic elements that are insoluble at the $\mathrm{pH}$, oxidation-reduction and hardness values normally observed for surface waters throughout the Clinch River/Watts Bar Reservoir (CR/WBR) system, both values for which a specific dissolved analyte is equal to or greater than the total are considered unacceptable. For this discussion, the list of insoluble analytes includes beryllium, cadmium, chromium, copper, iron, lead, mercury, nickel, selenium, silver, and zinc. Analytes considered soluble under conditions observed in the CR/WBR should be equally proportioned in total and dissolved samples. Calcium, magnesium, potassium, and sodium should have similar dissolved and total values. QC issues for this comparison include (1) the adequacy of filtration equipment cleaning, (2) inconsistencies in analytical handling, and (3) purity of the preservative.

The field and duplicate dissolved-total sample pair comparisons are presented in Table C.5. Comparison of dissolved with total inorganic results for field and duplicate pairs was acceptable for all detected results for calcium, copper, iron, magnesium, potassium, and sodium. Dissolved-to-total cadmium and zinc values were unacceptable for CRM 1 . Unacceptable dissolved-to-total comparisons were made for both mercury and silver at PCK 7.4. The cadmium dissolved-to-total comparison for CRM 43 was unacceptable. Cadmium and zinc dissolved-to-total values were unacceptable for CRM 103. Lead results for several sites, including CRM 0.5, CRM 1, PCK 9.6, and CRM 50.5, had unacceptable dissolved-to-total comparisons.

The impact of these unacceptable dissolved-to-total comparisons is limited for most sites because acceptable analytical comparisons were observed for similar sites within the same reach. However, unacceptable dissolved-to-total comparisons for lead at PCK 9.6 and cadmium and zinc in Norris Reservoir (CRM 103) are exceptions; contamination from other sources must be accounted for before Phase 1 sampling results from these sites can be used for their intended reference purposes. Additional sample collection will be performed at these and other reference sites in order to better characterize these sites for comparison with field sites during Phase 2 of the CRRI.

Rinse and field QC dissolved-to-total sample comparisons were unacceptable for beryllium and lead in the rinse blank for PCK 9.6; cadmium, calcium, chromium, copper, iron, magnesium, nickel, potassium, sodium, and zinc in the field blank for CRM 50.5; zinc in the rinse check for CRM 50.5; and lead in the rinse blank for TRM 557 (Table C.6). Iron values in the field sample are questionable because the QC blank values are four times greater than that observed in the field sample (Cook et al. 1992). These unacceptable comparisons do not impact the interpretation of Phase 1 results from these sites because the contamination either did not consist of contaminants of concern for Phase 1 (Energy Systems 1990), or do not coincide with measurable levels in field or duplicate samples. However, as noted in 
Sect. C.1.2 above, the presence of detectable quantities of contaminants in blank samples is an unacceptable result.

All tritium results were rejected during validation and verification due to improper preservation. The validation failure of all ${ }^{3} \mathrm{H}$ values was unacceptable for processing completeness, negatively affecting completion of Phase 1 objectives. The improper preservation of ${ }^{3} \mathrm{H}$ represents the importance of defining the parameters for both analytical and verification/validation purposes prior to initiation of sample collection. Tritium will be analyzed for during Phase 2 of the CRRI.

The lack of consistent contamination in either the blanks or the dissolved-to-total pairs for a series of samples collected and processed at the same time indicates that equipment cleaning procedures and preservative purity were adequate to prevent cross contamination. The more random cross contamination observed suggests that inconsistencies in analytical processing may be the source for the observed blank and dissolved sample contamination. Analytical services will be controlled by preparation and negotiation of statements of work with analytical laboratories prior to the beginning of sample collection for Phase 2 of the CRRI.

\section{C.2 SEDIMENT SAMPLING}

\section{C21 Field Sampling Completeness}

Sediment cores and surface grabs were collected at 14 sites throughout the study area. However, substitutions for several sampling locations identified in the plan were made during Phase 1. No sediment cores were collected at Poplar Creek mile 1.4 (PCK 2.2), which is at the K-1007B holding pond outfall, or Poplar Creek at the confluence of East Fork Poplar Creek (EFPC) (PCK 8.9); although an attempt was made, no sediment was present. Additionally, no sediment samples were collected from Fort Loudoun Reservoir. Sediment cores and surface grabs were collected in Grassy Creek embayment (CRM 14.5), middle Melton Hill Reservoir in Walker Branch embayment (CRM 33), and upper Melton Hill Reservoir at the Solway Bridge (CRM 44.1). These sites were not described in the work plan but were identified as possible contaminated areas during Phase 1 . Overall the sampling is $100 \%$ complete.

\section{C22 Representativeness}

One of the goals of Phase 1 sampling for sediment was to quantify the upper range of contaminant concentrations to provide a conservative estimate of the risks associated with exposure. Sediment core sampling sites were intentionally selected to be in areas suspected or known to have the highest concentrations of contaminants; therefore, results should be biased high and do not represent the average concentrations in the system. However, these data do represent the areas they are intended to represent.

During the course of Phase 1, a near-shore sediment characterization task was initiated. Because sediment grabs were collected near the shore in the exact areas where sedimentdisturbing activities were proposed, the grabs are representative of those areas. An additional 400 to 500 sediment surface grabs were collected in near-shore areas throughout WBR, and results are representative of contaminant levels in these areas. 


\section{C.2.3 Field Duplicates}

No field duplicates were collected. However, field splits were collected for both sediment cores and sediment surface grabs. Table C.7 presents the sediment cores, sample identification numbers, depth increments, and study reaches for which field splits were collected. Cores from Poplar Creek (Reach 3) and Norris Reservoir (Reach 10) do not have field splits. No conclusion regarding the precision of the alpha-emitting radionuclides can be made because no field splits were analyzed for these contaminants. The criteria for acceptability of field splits of sediment is for the RPD to be $35 \%$ or less when concentrations are greater than five times the average DL. For sample concentrations less than five times the average DL, the difference between the routine sample and the split sample concentrations must be less than twice the average DL to be acceptable.

All organic contaminants in the field split samples were below DLs; therefore, evaluation of RPDs was not performed. An evaluation of the difference between samples and splits was performed (Table C.8). However, using the DL as a concentration estimate and evaluating the differences between split concentrations (Table C.8) show that DLs for nearly all field splits for organic samples are within acceptable limits. The only splits that were out of control were from core 71000 and are only for some of the pesticides and PCBs (Table C.8).

Table C.9 presents the results for inorganic contaminants evaluations. The first part of Table C.9 presents the acceptability criteria $(\mathrm{DL} \times 2)$ and includes selenium only because this is the only inorganic contaminant that was out of control for any split. The second part of Table C.9 consists of chromium only because this is the only contaminant that was out of control based on the RPDs being less than $35 \%$. Two selenium splits and a single chromium split were the only samples that were out of control. The rest of the inorganic contaminant splits were acceptable.

All four splits for alpha-emitting radionuclides were within acceptable criteria for both ${ }^{60} \mathrm{Co}$ and ${ }^{137} \mathrm{Cs}$.

Table C.10 presents the DERs for ${ }^{60} \mathrm{Co}$ and ${ }^{137} \mathrm{Cs}$ for sediment grab samples. Fourteen field splits were collected. Seven of these had ${ }^{60} \mathrm{Co}$ concentrations below detectable limits for the routine and/or the duplicate sample, and a single ${ }^{137} \mathrm{Cs}$ sample was below the DL. No RPD was calculated for these. All DER values for surface grab split samples were within acceptable criteria except for samples 56000B and 746000B which had values above 1 .

\section{C.2.4 Chain of Custody}

Chain of custody was maintained for all samples from the time of collection to delivery to the analytical laboratories.

\section{C.2.5 Sample Preparation and Preservation}

All sediment core and grab samples were collected, prepared, and stored according to methods appropriate for the analysis for which each sample was submitted. 


\section{C.2. Laboratory Control Sediment Cores}

Four cores were collected and completely homogenized by placing the entire core in a glass mixing bowl and stirring with a Teflon spoon. Appropriately sized aliquots were placed in glass jars, frozen, and submitted for analysis at different times along with routine samples to evaluate consistency over time within each laboratory. These cores were collected and analyzed for inorganic contaminants, one each from Norris Reservoir (1400T), Melton Hill Reservoir (7100T), and the Clinch River arm of Watts Bar Reservoir (2600T). A sample from each of these cores was submitted for analysis on ten different occasions. Four cores were collected for reference analysis of organics, one from Norris Reservoir (19000), two from Melton Hill Reservoir (87000 and 73000), and one from the Clinch River arm of Watts Bar Reservoir (31000). Samples from the organic reference cores were submitted between three and seven times (depending on the core) during Phase 1. A single reference core from Norris Reservoir (1400G) was collected for alpha-emitting radionuclides. A sample from this core was analyzed on four separate occasions.

A mean concentration was calculated for each contaminant within a homogenized core. RPDs were calculated by comparing each aliquot concentration to the mean concentration. An RPD of $35 \%$ or less was defined as acceptable for sediment samples.

RPDs for inorganic contaminants are reported in Table C.11, and RPDs for radionuclides are reported in Table C.12. RPDs for organic contaminants were not calculated, because nearly every sample was below DLs.

Most inorganic contaminants were within acceptable limits throughout Phase 1 analysis. Inorganic contaminants that consistently exceeded control limits include cadmium, copper, chromium, and silver.

Radionuclide contaminants that consistently exceeded control limits include ${ }^{245} \mathrm{Cm}$, ${ }^{246} \mathrm{Cm},{ }^{248} \mathrm{Cm},{ }^{239} \mathrm{Pu}$, and ${ }^{240} \mathrm{Pu}$. These contaminants were designated low priority during the screening risk assessment.

Much of the data from these cores were rejected because holding times were exceeded. This is discussed in more detail in Sect. 4. In fact, most of the rejected sediment data are from these cores.

\section{C3. FISH SAMPLING}

\section{C.3.1 Field Sampling Completeness}

The minimum number of samples required to meet the objectives of Phase 1 was eight bluegill and eight catfish at each of 13 sites (White Oak Creek Embayment excluded). This goal was achieved at all sites except Poplar Creek/K1007 (only two bluegill) and Poplar Creek/Hartland Bridge (only four catfish, Table C.13). Because only two bluegill were collected at Poplar Creek/K1007, these data were combined with those from a nearby site (Poplar Creek embayment) for data analysis. As expected, the availability of largemouth bass was limited throughout the system, and eight samples were collected only at upper Chickamauga Reservoir. The number of bass collected at the other sites ranged from 0 to 5 . 


\section{C.3.2 Representativeness}

To characterize the entire CR/WBR system, sample sites were selected throughout the system ranging from those areas that are immediately impacted by surface water runoff from Oak Ridge Reservation (ORR) to those that are not affected by surface water releases from the ORR. Results will not be presented on a system wide basis but rather by reach or by site. Phase 1 sampling locations throughout the CR/WBR system were selected to generally characterize the extent of the contamination in those reaches of most concern (Reaches 1 , 2, 3, 4, and 5, Table 3.2). More sites were sampled in those areas such as Poplar Creek (sites 8-11, Reach 3) and the Clinch River arm of Watts Bar Reservoir (sites 5, 6, 12, and 13, Reaches 2 and 4) that are nearest the ORR to better define the likely maximum concentrations of contaminants. Fewer sites were sampled in areas further downstream of the ORR (sites 14, 15, and 16, Reaches 5 and 15). Samples were also collected from Reach 1 (Melton Hill Reservoir, sites 2 and 3), which receives a limited amount of surface water input from the ORR. Two reference sites (Norris Reservoir and Poplar Creek at Hartland Bridge) were also sampled to provide background levels of contamination.

Because fish are mobile organisms, they are not necessarily representative of the contamination at the site from which they are collected. However, they are representative of the fish populations at that site. Because some species have larger home ranges and a greater tendency to roam than others, the representativeness of a single fish is highly dependent on the species. For example, bluegill typically have smaller home ranges than either bass or catfish and would be expected to be more representative of the location of their collection than either of those two species. By collecting several fish at each site, we are hopeful that the mean concentration is representative of the site. In addition, every effort was made to collect fish as near to the same size as possible to minimize differences among fish of the same species within a site.

After reviewing the data, the usefulness of the Hartland Bridge site as a reference is questionable. Although the site is upstream of the K-25 facility and of the confluence of EFPC (which is the source of contamination, primarily mercury, from the Y-12 Plant), the data suggest that the Hartland Bridge site is not far enough from the contaminated areas to prevent fish immigration from these areas. Mercury concentrations in most of the fish sampled from the Hartland Bridge site were very low, but a few had levels that were similar to those fish collected from the mouth of EFPC, which is only $1 \mathrm{~km}$ away.

\section{C.3.3 Field Duplicates}

The idea of a field duplicate of a fish sample is somewhat different than that of a water or sediment sample. However, the intent of duplicate samples regardless of the matrix is the same: to provide a measure of the variability from sampling error and/or within site spatial variation in contamination. The reality of collecting a duplicate fish is really not possible because differences in size, diet, and other factors can result in marked differences in contaminant body burdens. Variability because of sampling error is not a concern in this case, but by collecting several fish of the same species and similar size we were able to get an estimate of the among-fish (within-site) variability in contaminant concentrations. Table C.14 presents the RSDs for selected analytes for each site sampled. There are no requirements that these RSDs be within particular control limits. However, this information will be useful for placing other sources of variation in perspective and for determining the number of samples required in future sampling. 


\section{C.3.4 Field Splits}

Selected samples were split into two equal aliquots each and analyzed separately to evaluate sample homogenization and the precision of the analytical methods. Eight bluegill and six bass samples were submitted to the CPA of the ACD of ORNL for split-mercury analysis. All 14 split-sample results were judged to be of acceptable precision (Table C.15). Six bluegill and six bass samples were also submitted to the CPA for split sample analysis of 12 ICP metals. For all the ICP metals combined, 79\% (26 of 33) of those split samples that could be evaluated were within acceptable limits (Table C.15). Only beryllium had more than one unacceptable comparison (three of three were unacceptable). No measure of precision could be made for antimony, chromium, lead, silver, and thallium because there were no detectable results in the split samples.

Eight catfish samples were submitted to the OAL of ACD at ORNL in replicate for split samples of semivolatile organics, pesticides, and PCBs. Of the 520 semivolatile analyses performed, only two measurable results were reported. This is insufficient to make any evaluation of precision based on split sample results. Because $99.9 \%$ of the semivolatile analyses resulted in undetectable concentrations, the lack of a measure of precision is not a problem, assuming the accuracy is correct. Accuracy of these analyses will be discussed in Chap. 4.

Split samples analyzed for 11 pesticides resulted in 54 (of 88 total) split pairs with adequate data to measure precision acceptability (Table C.16). None of the split samples had a detectable value for chlordene, so no evaluation of this analyte could be made. As with semivolatiles, the lack of a precision measure for chlordene analysis is not a serious problem because of the high degree of nondetects (93\%). Of the 54 estimates of precision, 50 (93\%) met acceptable criteria.

Split samples analyzed by the OAL for Aroclor 1254 were within acceptable limits $50 \%$ of the time (four of eight pairs), and Aroclor 1260 split samples were within acceptable limits $100 \%$ of the time (eight of eight pairs, Table C.17). Six bass and 19 catfish samples were also submitted to the CPA for split sample analysis of PCBs. Split samples analyzed for Aroclor 1254 were within acceptable limits $45 \%$ of the time (10 of 22 pairs), and Aroclor 1260 split samples were within acceptable limits $79 \%$ of the time (19 of 24 pairs, Table C.17).

\section{C.3.5 Chain of Custody}

Chain of custody was maintained for all samples from the time of collection to delivery to the analytical laboratories.

\section{C3.6 Sample Preparation and Preservation}

With one notable exception, fish samples were prepared in a proper and acceptable manner, handled and packaged such that any external contamination was prevented, and stored in a constantly frozen state. The exception was in the way that largemouth bass samples were prepared. As per the procedures described in the Phase 1 Plan (Energy Systems 1990), largemouth bass fillets were skinned during processing. This is acceptable for catfish but not for bass or bluegill (the bluegill samples were not skinned), according to Food and Drug Administration (FDA) guidelines for fish tissue preparation (FDA 1990). This is particularly relevant in PCB analysis because of the fine layer of fat tissue (i.e., lipids) located 


\section{C-11}

immediately adjacent to the skin. PCBs are hydrophobic and, thus, accumulate in areas of high lipid concentration. Removal of the skin could result in lower PCB concentrations than what would be found if the fish had not been skinned. The use of skinned bass fillets is also contrary to the methods of Tennessee Valley Authority (TVA), which has collected a large amount of information on contaminants in fish for the CR/WBR system and other east Tennessee reservoirs. The data from skinned bass samples are not directly comparable with the TVA data. For these reasons, largemouth bass PCB data were excluded from the Phase 1 data summary and risk screening.

Rinse blanks of fish processing implements (i.e., fillet knives) were not collected, though it is practically impossible for cross-contamination to occur given the multitude of precautionary actions that are part of standard processing procedures. 
Table C.1. Quality control sample results for equipment rinse blank samples submitted for dissolved and total inorganic analyses (detected analytes only)

\begin{tabular}{|c|c|c|c|c|c|c|c|}
\hline \multirow{2}{*}{$\frac{\text { Analyte (average } \mathrm{DL}^{\mathrm{a}} \text { ) }}{\text { Inorganic }}$} & \multirow{2}{*}{$\begin{array}{c}\text { Poplar Creek } \\
\text { kilometer } \\
9.6 \\
\text { Dissolved }\end{array}$} & \multicolumn{2}{|c|}{$\begin{array}{l}\text { Poplar Creek } \\
\text { kilometer } \\
7.6\end{array}$} & \multicolumn{2}{|c|}{$\begin{array}{c}\text { Tennessee River } \\
\text { mile } \\
557\end{array}$} & \multicolumn{2}{|c|}{$\begin{array}{l}\text { Clinch River } \\
\text { mile } \\
50.5\end{array}$} \\
\hline & & Dissolved & Total & $\overline{\text { Dissolved }}$ & Total & $\overline{\text { Dissolved }}$ & Total \\
\hline \multicolumn{8}{|c|}{ Site affected by these samples/Rinse blank sample identification numbers } \\
\hline Beryllium (3.9 ug/L) & 3.9 & & & & & & \\
\hline Cadmium $(0.2 \mathrm{ug} / \mathrm{L})$ & & & & & & & 0.32 \\
\hline Calcium $(74.4 \mathrm{ug} / \mathrm{L})$ & & 282 & 372 & 107 & 195 & 75 & 67 \\
\hline Iron $(120 \mathrm{ug} / \mathrm{L})$ & & & & & 85 & & 49 \\
\hline Lead $(1.6 \mathrm{ug} / \mathrm{L})$ & 25 & & 1.8 & 1.1 & & & \\
\hline Magnesium (24.2 ug/L) & & & & & & 16 & 22 \\
\hline Nickel $(19 \mathrm{ug} / \mathrm{L})$ & & & & & 19 & & \\
\hline Sodium (186.4 ug/L) & & & & & & 211 & 151 \\
\hline Zinc $(9.6 \mathrm{ug} / \mathrm{L})$ & & & & & & 14 & 13 \\
\hline
\end{tabular}

Table C2. Trip and field blank water samples submitted for dissolved and total inorganic analyses

\begin{tabular}{|c|c|c|}
\hline \multirow{2}{*}{$\begin{array}{c}\text { Inorganic anatyte } \\
\text { (average } \mathrm{DL}^{\mathrm{a}} \text { ) } \\
(\mathrm{ug} / \mathrm{L})\end{array}$} & $\begin{array}{l}\text { CRM }^{\mathrm{b}} 9.6 \\
\text { CRM } 14.5 \\
\text { CRM } 19.6\end{array}$ & CRM 50.5 \\
\hline & $140 \mathrm{~T}$ & $1470 \mathrm{M}$ \\
\hline \multicolumn{3}{|c|}{ Sites affected by these samples/Trip or field blank } \\
\hline Cadmium (0.2) & & 0.21 \\
\hline Calcium (74.4) & & 2350 \\
\hline Chromium (9.8) & & 34 \\
\hline Copper (4.4) & & 28 \\
\hline Iron (12.0) & & 449 \\
\hline Magnesium (24.2) & & 293 \\
\hline Nickel (19) & & 46 \\
\hline Potassium (234) & ' & 641 \\
\hline Selenium $(0.9)$ & 0.97 & \\
\hline Sodium (186.4) & & 2480 \\
\hline Zinc (9.6) & & 229 \\
\hline
\end{tabular}


Table C3. Precision assessment for field duplicate water samples. Relative percent difference values greater than $20 \%$ reflect unacceptable levels of precision

\begin{tabular}{|c|c|c|c|c|c|c|c|c|c|c|c|}
\hline \multirow{2}{*}{$\begin{array}{c}\text { Inorganic analyte } \\
\text { (average } D^{a} \text { ) } \\
(\mathrm{ug} / \mathrm{L})\end{array}$} & \multicolumn{2}{|c|}{$\mathrm{CRM}^{\mathrm{b}} 1.0$} & \multicolumn{2}{|c|}{$\mathrm{TRM}^{\mathrm{C}} 531$} & \multicolumn{2}{|c|}{ TRM 547} & \multicolumn{2}{|c|}{ CRM 0.5} & \multicolumn{2}{|c|}{ CRM 43} & \multirow[b]{2}{*}{$\begin{array}{l}\text { Average } \\
\text { RPD }^{d}\end{array}$} \\
\hline & $\begin{array}{c}102 \mathrm{M} / \\
108 \mathrm{M}\end{array}$ & $\begin{array}{c}102 \mathrm{~T} / \\
108 \mathrm{~T}\end{array}$ & $\begin{array}{l}131 \mathrm{M} / \\
1311 \mathrm{M}\end{array}$ & $\begin{array}{l}131 \mathrm{~T} / \\
1311 \mathrm{~T}\end{array}$ & $\begin{array}{l}132 \mathrm{M} / \\
1321 \mathrm{M}\end{array}$ & $\begin{array}{l}132 \mathrm{~T} / \\
1321 \mathrm{~T}\end{array}$ & $\begin{array}{l}137 \mathrm{M} / \\
1371 \mathrm{M}\end{array}$ & $\begin{array}{l}137 \mathrm{~T} / \\
1371 \mathrm{~T}\end{array}$ & $\begin{array}{l}139 \mathrm{M} / \\
1391 \mathrm{M}\end{array}$ & $\begin{array}{l}139 \mathrm{~T} / \\
1391 \mathrm{~T}\end{array}$ & \\
\hline \multicolumn{12}{|c|}{ Sites affected by these samples/Sample identification numbers (routine/duplicate) } \\
\hline Cadmium (0.2) & $<\mathbf{e}$ & $\mathbf{u}^{\mathbf{f}}$ & $\mathbf{U}$ & $\mathbf{U}$ & $\mathbf{U}$ & $\mathrm{U}$ & $\mathbf{U}$ & $\mathbf{U}$ & $<$ & $\mathbf{U}$ & $\mathrm{N} / \mathrm{A}^{\mathrm{g}}$ \\
\hline Calcium (74.4) & $\mathrm{NA}^{\mathrm{h}}$ & NA & 3.7 & 2.1 & 4.0 & 1.1 & 0.4 & 10.1 & 3.2 & 0.3 & 2.5 \\
\hline Iron (12.0) & NA & NA & $<$ & 3.8 & $<$ & 1.4 & $<$ & 14.3 & 173.8 & 0.3 & N/A \\
\hline Lead (1.6) & $<$ & $<$ & $<$ & $<$ & $<$ & $<$ & 147.8 & $<$ & $<$ & $<$ & N/A \\
\hline Magnesium (24.2) & NA & NA & 2.2 & 1.6 & 3.6 & 1.1 & 1.0 & 8.9 & 3.5 & 1.0 & 2.3 \\
\hline Mercury (0.2) & $\mathrm{U}$ & $\mathrm{U}$ & $\mathbf{U}$ & $\mathbf{U}$ & $\mathrm{U}$ & $\mathrm{U}$ & $\mathrm{U}$ & $<$ & $\mathrm{U}$ & $\mathrm{U}$ & N/A \\
\hline Potassium (234) & NA & NA & 6.9 & 7.2 & 9.0 & 5.1 & 0.0 & 9.0 & 5.2 & 0.0 & 4.2 \\
\hline Sodium (186.4) & NA & NA & 2.9 & 2.3 & 3.0 & 1.5 & 0.8 & 10.5 & 2.6 & 1.1 & 2.5 \\
\hline Zinc (9.6) & $<$ & $<$ & $<$ & $<$ & $\mathbf{U}$ & $\mathrm{U}$ & $<$ & $<$ & $<$ & $<$ & N/A \\
\hline Organic & $\begin{array}{c}1010 / \\
1070\end{array}$ & & $\begin{array}{l}1310 / \\
13110\end{array}$ & & $\begin{array}{l}1320 / \\
13210\end{array}$ & & $\begin{array}{l}1370 / \\
13710\end{array}$ & & $\begin{array}{l}1390 / \\
13910\end{array}$ & & \\
\hline $\begin{array}{l}\text { Bis(2-ethylhexyl)phthalate } \\
(9.4)\end{array}$ & $\mathbf{U}$ & & 195.6 & & $<$ & & $\mathrm{U}$ & & $<$ & & \\
\hline Di-n-octylphthalate (10) & $\mathbf{U}$ & & $\mathbf{U}$ & & $<$ & & $\mathrm{U}$ & & $\mathrm{U}$ & & \\
\hline Diethylphthalate (10) & $\mathbf{U}$ & & $\mathrm{U}$ & & $<$ & & $\mathrm{U}$ & & $\mathrm{U}$ & & \\
\hline $\begin{array}{l}\text { adetection limit, } \\
b_{\text {Clinch River Mile, }} \\
c_{\text {Tennessee River Mile, }} \\
d_{\text {relative percent difference, }} \\
\text { e }_{\text {average duplicate concentration }} \\
f_{\text {not detected, }} \\
\boldsymbol{g}_{\text {not applicable, }} . \\
\text { not analyzed. }^{\text {not }}\end{array}$ & 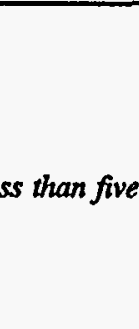 & . & age $D L$ & & & & & & & & \\
\hline
\end{tabular}


Table C4. Test for precision of duplicate pairs with average values $<5$ times the mean detection limit for particular water analytes

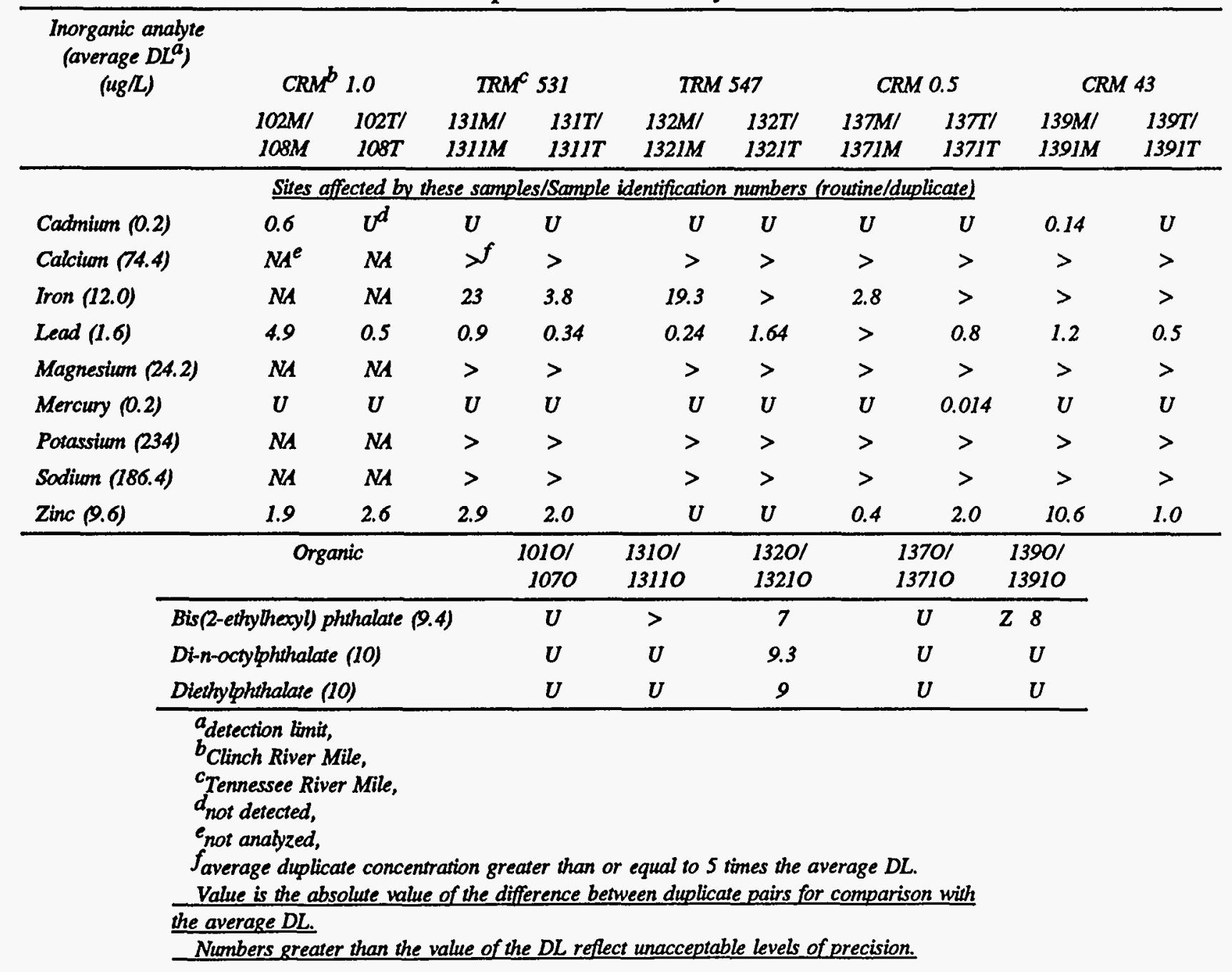




\section{C-15}

C.5. Test comparing dissolved and total inorganic results for regular and field duplicate samples

\begin{tabular}{|c|c|c|c|c|c|c|c|c|}
\hline Analyte & & & & & & & & \\
\hline Sites & number & Cadmium & Copper & Iron & Lead & Mercury & Silver & Zinc \\
\hline \multicolumn{9}{|c|}{ Insoluble inorganic analytes only } \\
\hline \multirow{2}{*}{$\begin{array}{c}\text { TRM } \\
531\end{array}$} & 131 & $\mathrm{U}$ & $\mathrm{U}$ & A & $\mathrm{U}$ & $\mathrm{U}$ & $U$ & $U$ \\
\hline & 1311 & $U$ & $\mathrm{U}$ & A & $\mathrm{U}$ & $U$ & $U$ & $\mathrm{U}$ \\
\hline \multirow{2}{*}{$\begin{array}{c}\text { TRM } \\
547\end{array}$} & 132 & $\mathrm{U}$ & $\mathrm{U}$ & A & $\mathrm{U}$ & $\mathrm{U}$ & $\mathrm{U}$ & $\mathrm{U}$ \\
\hline & 1321 & $U$ & $\mathrm{U}$ & A & $\mathrm{U}$ & $U$ & $U$ & $\mathrm{U}$ \\
\hline $\begin{array}{c}\text { TRM } \\
557\end{array}$ & 146 & $\mathrm{U}$ & $\mathrm{U}$ & A & $\mathrm{U}$ & $\mathrm{U}$ & $\mathrm{U}$ & $\mathrm{U}$ \\
\hline $\begin{array}{c}\text { TRM } \\
567\end{array}$ & 136 & $\mathrm{U}$ & $\mathrm{U}$ & A & $\mathrm{U}$ & $\mathrm{U}$ & $\mathrm{U}$ & $\mathrm{U}$ \\
\hline \multirow[t]{2}{*}{ CRM 0.5} & 137 & $\mathrm{U}$ & $\mathrm{U}$ & A & $U$ & $\mathrm{U}$ & $\mathrm{U}$ & $U$ \\
\hline & 1371 & $\mathrm{U}$ & $\mathrm{U}$ & A & 0 & A & $\mathrm{U}$ & $\mathrm{U}$ \\
\hline \multirow[t]{2}{*}{ CRM 1.0} & 102 & 0 & $\mathrm{U}$ & -- & A & $\mathrm{U}$ & $\mathrm{U}$ & 0 \\
\hline & 108 & 0 & $U$ & - & 0 & $\mathbf{U}$ & $\mathrm{U}$ & A \\
\hline CRM 9.6 & 133 & $\mathbf{U}$ & U & A & $\mathrm{U}$ & $\mathrm{U}$ & $\mathrm{U}$ & $\mathrm{U}$ \\
\hline PCK 9.6 & 145 & $\mathrm{U}$ & $U$ & A & 0 & $U$ & $\mathrm{U}$ & $\mathrm{U}$ \\
\hline PCK 8.8 & 144 & $\mathrm{U}$ & $\mathrm{U}$ & A & A & $U$ & A & $\mathrm{U}$ \\
\hline PCK 7.4 & 143 & $\mathrm{U}$ & $\mathrm{U}$ & $\mathbf{A}$ & A & 0 & 0 & $\mathrm{U}$ \\
\hline PCK 2.2 & 142 & $\mathbf{U}$ & $\mathrm{U}$ & $\mathbf{A}$ & $\mathrm{U}$ & $\mathrm{U}$ & $\mathrm{U}$ & $\mathrm{U}$ \\
\hline PCK 0.25 & 141 & $\mathrm{U}$ & $\mathrm{U}$ & A & $\mathrm{U}$ & $\mathrm{U}$ & $\mathrm{U}$ & $U$ \\
\hline $\begin{array}{c}\text { CRM } \\
14.5\end{array}$ & 134 & $U$ & A & A & $\mathbf{U}$ & $\mathrm{U}$ & $\mathbf{U}$ & A \\
\hline $\begin{array}{c}\text { CRM } \\
19.7\end{array}$ & 135 & $\mathrm{U}$ & $\mathbf{U}$ & $\mathbf{A}$ & $\mathrm{U}$ & U & $\mathbf{U}$ & $\mathrm{U}$ \\
\hline CRM 24 & 138 & $\mathrm{U}$ & $U$ & A & U & $\mathbf{U}$ & $\mathbf{U}$ & $\mathbf{U}$ \\
\hline \multirow[t]{2}{*}{ CRM 43} & 139 & 0 & $\mathbf{U}$ & A & $\mathrm{U}$ & U & $\mathrm{U}$ & $U$ \\
\hline & 1391 & 0 & $\mathrm{U}$ & A & $\mathbf{U}$ & $\mathrm{U}$ & $\mathrm{U}$ & $\mathrm{U}$ \\
\hline $\begin{array}{c}\text { CRM } \\
50.5\end{array}$ & 147 & $\mathbf{U}$ & $\mathrm{U}$ & $\mathbf{A}$ & 0 & $\mathrm{U}$ & $\mathrm{U}$ & $\mathrm{U}$ \\
\hline $\begin{array}{l}\text { CRM } \\
103.0\end{array}$ & 112 & $\mathbf{U}$ & $\mathrm{U}$ & $\mathrm{U}$ & $\mathrm{U}$ & $\mathrm{U}$ & $\mathbf{U}$ & 0 \\
\hline
\end{tabular}

$\mathrm{A}=$ site-analyte combinations with acceptable comparisons, $\mathrm{O}=$ unacceptable comparisions, "-" $=$ nonrequested analytes, and $U=$ nondetected values.

Results for soluble analytes, including calcium, magnesium, potassium and sodium, as well as antimony, arsenic, beryllium, chromium nickel, selenium and thallium, which were not detected in any samples, are not presented. 
Table C.6. Test comparing dissolved and total inorganic results for quality control blank and equipment rinse samples (insoluable, inorganic analytes only)

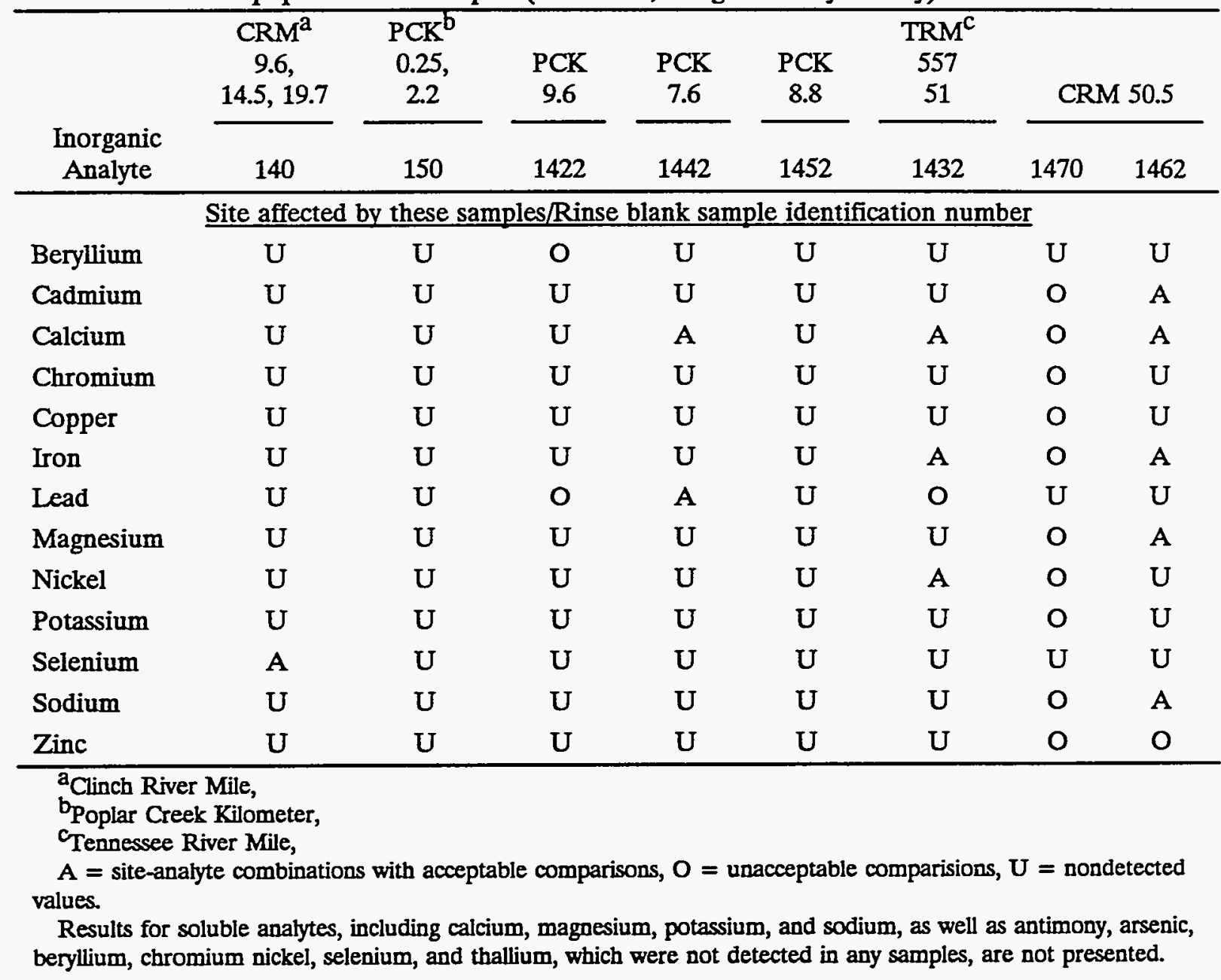

Table C.7. Number of sediment cores and field splits collected during Phase 1

\begin{tabular}{lcc}
\hline & $\begin{array}{c}\text { Total } \\
\text { number } \\
\text { of cores }\end{array}$ & $\begin{array}{c}\text { Number } \\
\text { of field } \\
\text { splits }\end{array}$ \\
\hline Organics & 14 & 4 \\
Inorganics & 14 & 7 \\
Radionuclides & 14 & 4 \\
\hline
\end{tabular}


Table C.8. Evaluation of organic analysis of field splits from sediment cores ${ }^{a}$

\begin{tabular}{lccccc}
\hline & $\begin{array}{c}\mathrm{DL} \times 2^{\mathrm{b}} \\
(\mathrm{mg} / \mathrm{kg})\end{array}$ & 48000 & 69000 & 71000 & 81000 \\
\hline Aldrin & $(0.48)$ & $\mathrm{A}$ & $\mathrm{A}$ & $\mathrm{O}$ & $\mathrm{A}$ \\
Alpha-BHC & $(0.48)$ & $\mathrm{A}$ & $\mathrm{A}$ & $\mathrm{O}$ & $\mathrm{A}$ \\
Alpha-Chlordane & $(4.76)$ & $\mathrm{A}$ & $\mathrm{O}$ & $\mathrm{A}$ & $\mathrm{A}$ \\
Aroclor-1016 & $(4.76)$ & $\mathrm{A}$ & $\mathrm{A}$ & $\mathrm{O}$ & $\mathrm{A}$ \\
Aroclor-1221 & $(4.76)$ & $\mathrm{A}$ & $\mathrm{A}$ & $\mathrm{O}$ & $\mathrm{A}$ \\
Aroclor-1232 & $(4.76)$ & $\mathrm{A}$ & $\mathrm{A}$ & $\mathrm{O}$ & $\mathrm{A}$ \\
Aroclor-1242 & $(4.76)$ & $\mathrm{A}$ & $\mathrm{A}$ & $\mathrm{O}$ & $\mathrm{A}$ \\
Aroclor-1248 & $(4.76)$ & $\mathrm{A}$ & $\mathrm{A}$ & $\mathrm{O}$ & $\mathrm{A}$ \\
Beta-BHC & $(0.48)$ & $\mathrm{A}$ & $\mathrm{A}$ & $\mathrm{O}$ & $\mathrm{A}$ \\
Delta-BHC & $(0.48)$ & $\mathrm{A}$ & $\mathrm{A}$ & $\mathrm{O}$ & $\mathrm{A}$ \\
Endosulfan I & $(0.48)$ & $\mathrm{A}$ & $\mathrm{A}$ & $\mathrm{O}$ & $\mathrm{A}$ \\
Gamma-BHC (Lindane) & $(0.48)$ & $\mathrm{A}$ & $\mathrm{O}$ & $\mathrm{O}$ & $\mathrm{A}$ \\
Gamma-chlordane & $(4.76)$ & $\mathrm{A}$ & $\mathrm{A}$ & $\mathrm{A}$ & $\mathrm{A}$ \\
Heptachlor & $(0.48)$ & $\mathrm{A}$ & $\mathrm{A}$ & $\mathrm{A}$ & $\mathrm{A}$ \\
Heptachlor epoxide & $(0.48)$ & $\mathrm{A}$ & $\mathrm{A}$ & $\mathrm{A}$ & $\mathrm{A}$ \\
\hline
\end{tabular}

a If reported concentrations were less than 5 times the average DL the difference between the routine and duplicate concentrations must be within 2-times the DL to be acceptable. If the reported concentrations was greater than 5 times the average DL or there were no nondetects reported, the relative percent difference (RPD) must be less than 36\%. "A" indicates difference or RPD is within acceptable limits;

betection limit. 


\section{C-18}

Table C9. Evaluation of inorganic analysis of field splits from sediment cores ${ }^{\mathrm{a}}$

DL $\times 2$

$\begin{array}{llllllll}(\mathrm{mg} / \mathrm{kg}) & 4700 \mathrm{t} & 6700 \mathrm{t} & 71000 \mathrm{t} & 71100 \mathrm{t} & 71600 \mathrm{t} & 71700 \mathrm{t} & 7900 \mathrm{t}\end{array}$

Inorganic contaminants with concentrations less than five times DL

Selenium

A A

A

A

O

O

A

Inorganic contaminants with no reported DL

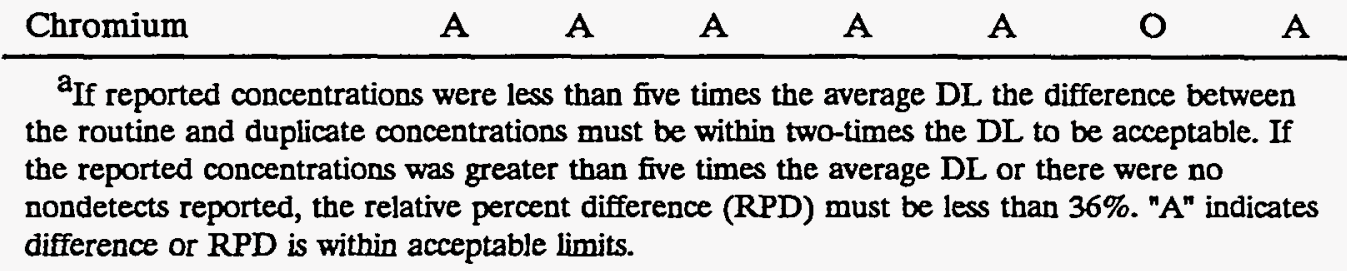

Table C.10. Relative percent differences of radionuclide concentrations for field splits of sediment grabs

\begin{tabular}{cccc}
\hline $\begin{array}{c}\text { Sample } \\
\text { identification }\end{array}$ & $\begin{array}{c}\text { Duplicate } \\
\text { sample } \\
\text { identification }\end{array}$ & $\begin{array}{c}60 \mathrm{Co} \\
\mathrm{DER}^{\mathrm{a}}\end{array}$ & $\begin{array}{c}137 \mathrm{Cs} \\
\mathrm{DER}\end{array}$ \\
\hline $56000 \mathrm{~B}$ & $56100 \mathrm{~B}$ & 0.09 & 2.24 \\
$60500 \mathrm{~B}$ & $60600 \mathrm{~B}$ & & 0.31 \\
$63100 \mathrm{~B}$ & $63200 \mathrm{~B}$ & 0.01 & 1.89 \\
$64300 \mathrm{~B}$ & $64700 \mathrm{~B}$ & 0.11 & 0.72 \\
$65800 \mathrm{~B}$ & $65900 \mathrm{~B}$ & & 0.70 \\
$67000 \mathrm{~B}$ & $67100 \mathrm{~B}$ & 0.41 & 0.47 \\
$68500 \mathrm{~B}$ & $68600 \mathrm{~B}$ & 0.59 & 0.25 \\
$68900 \mathrm{~B}$ & $69000 \mathrm{~B}$ & 0.75 & 0.46 \\
$69100 \mathrm{~B}$ & $69200 \mathrm{~B}$ & & 0.78 \\
$69800 \mathrm{~B}$ & $69900 \mathrm{~B}$ & & 0.03 \\
$70500 \mathrm{~B}$ & $70600 \mathrm{~B}$ & 0.27 & 0.46 \\
$72400 \mathrm{~B}$ & $72500 \mathrm{~B}$ & 0.35 & 0.70 \\
$73300 \mathrm{~B}$ & $73400 \mathrm{~B}$ & & 0.27 \\
$74600 \mathrm{~B}$ & $74700 \mathrm{~B}$ & & 8.18 \\
\hline
\end{tabular}

aduplicate error ratios 
Table C.11. Relative percent differences for laboratory test samples submitted for inorganic analysis

\begin{tabular}{|c|c|c|c|c|c|c|c|c|c|c|c|}
\hline & 1402 & 1403 & 1404 & 1405 & 1406 & 1407 & 1408 & 1409 & 1410 & 1411 & Mean RPD \\
\hline Arsenic & 8.72 & 2.88 & 39.66 & 55.10 & 43.49 & 5.95 & 19.52 & 37.02 & 53.69 & 7.60 & 27.36 \\
\hline Berylliun & 13.21 & 4.52 & 17.74 & 200.00 & 32.99 & 10.88 & 4.52 & 17.74 & 13.21 & 10.88 & 32.57 \\
\hline Chromilan & 7.05 & 6.92 & 15.76 & 200.00 & 65.15 & 2.04 & 34.03 & 5.74 & 22.99 & 26.57 & 38.63 \\
\hline Copper & 14.60 & 23.61 & 29.89 & 200.00 & 68.08 & 19.01 & 27.43 & 3.61 & 6.28 & 1.41 & 39.39 \\
\hline Lead & 17.63 & 24.96 & 17.63 & 36.90 & 26.63 & 28.21 & 62.07 & 1.88 & 51.25 & 11.93 & 27.91 \\
\hline Mercury & 1.24 & 11.76 & 11.76 & 1.24 & 23.78 & 11.76 & 1.24 & 200.00 & 23.78 & 1.24 & 28.78 \\
\hline Nickel & 14.39 & 10.15 & 1.06 & 200.00 & 55.90 & 14.39 & 14.88 & 2.95 & 14.33 & 22.33 & 35.04 \\
\hline \multirow[t]{2}{*}{ Zine } & 15.60 & 34.47 & 19.35 & 175.91 & 52.07 & 0.39 & 5.37 & 13.67 & 14.64 & 25.55 & 35.70 \\
\hline & 2601 & 2602 & 2603 & 2604 & 2605 & 2606 & 2607 & 2608 & 2609 & 2610 & Mean RPD \\
\hline Arsenic & 5.40 & 55.02 & 27.42 & 11.96 & 46.89 & 17.93 & 10.53 & 43.16 & 23.16 & 31.19 & 27.27 \\
\hline Beryllium & 19.78 & 11.50 & 11.50 & 6.72 & 1.98 & 1.98 & 21.96 & 22.05 & 22.05 & 6.72 & 12.62 \\
\hline Cadmium & 18.50 & 12.45 & .51 .05 & 12.45 & 32.25 & 102.79 & 43.60 & 36.38 & 75.97 & 55.37 & 44.08 \\
\hline Chromilon & 12.59 & 8.34 & 26.43 & 5.26 & 8.34 & 12.59 & 8.34 & 37.17 & 12.61 & 6.35 & 13.80 \\
\hline Copper & 10.01 & 1.80 & 1.80 & 20.17 & 5.80 & 7.20 & 7.20 & 41.58 & 1.05 & 15.27 & 11.19 \\
\hline Lead & 17.06 & 4.18 & 18.44 & 2.08 & 4.79 & 16.50 & 5.89 & 33.99 & 13.36 & 9.47 & 12.58 \\
\hline Mercury & 10.92 & 16.82 & 3.61 & 200.00 & 200.00 & 200.00 & 1.82 & 38.65 & 10.36 & 69.52 & 75.17 \\
\hline Nickel & 8.10 & 0.96 & 11.87 & 5.19 & 2.43 & 4.47 & 28.39 & 35.69 & 13.15 & 5.91 & 11.62 \\
\hline Selenium & 40.66 & 77.51 & 35.69 & 35.69 & 200.00 & 200.00 & 0.69 & 42.82 & 67.28 & 0.69 & 70.10 \\
\hline \multirow[t]{2}{*}{ Zinc } & 24.24 & 5.59 & 30.99 & 2.78 & 4.94 & 1.30 & 21.85 & 29.85 & 11.30 & 9.64 & 14.25 \\
\hline & 7101 & 7102 & 7103 & 7104 & 7105 & 7106 & 7107 & 7108 & 7109 & 7110 & Mean RPD \\
\hline Arsenic & 2.12 & 21.71 & 11.46 & 45.61 & 26.09 & 48.16 & 62.39 & 63.97 & 9.52 & 2.12 & 29.31 \\
\hline Beryllium & 7.85 & 47.47 & 25.94 & 47.47 & 1.68 & 1.40 & 1.68 & 27.97 & 32.41 & 29.10 & 22.30 \\
\hline Cadmilun & 125.23 & 200.00 & 125.23 & 106.16 & 117.33 & 200.00 & 78.75 & 72.84 & 26.29 & 20.31 & 107.21 \\
\hline Chromium & 0.68 & 50.79 & 24.67 & 43.79 & 35.26 & 55.18 & 11.88 & 60.72 & 16.58 & 23.61 & 32.32 \\
\hline Copper & 15.44 & 2.76 & 2.76 & 37.96 & 8.57 & 20.13 & 4.78 & 11.09 & 13.77 & 26.35 & 14.36 \\
\hline Lead & 11.06 & 39.20 & 41.79 & 11.42 & 34.88 & 16.92 & 56.43 & 3.71 & 4.70 & 11.42 & 23.16 \\
\hline Mercury & 9.97 & 4.57 & 4.57 & 28.03 & 18.73 & 4.57 & 15.66 & 15.66 & 43.67 & 200.00 & 34.54 \\
\hline Nickel & 44.89 & 103.79 & 5.12 & 57.36 & 3.46 & 53.49 & 3.46 & 5.17 & 40.78 & 84.74 & 40.23 \\
\hline Silver & 126.01 & 126.01 & 111.60 & 126.01 & 66.03 & 57.93 & 48.79 & 45.48 & 200.00 & 200.00 & 110.79 \\
\hline Zinc & 16.82 & 200.00 & 27.90 & 28.88 & 16.42 & 42.19 & 9.88 & 9.03 & 34.22 & 0.78 & 38.61 \\
\hline
\end{tabular}

${ }^{a}$ relative percent difference 
C-20

Table C.12 Relative percent differences for laboratory test samples submitted for alpha-emitting radionuclide analysis

\begin{tabular}{lrrrrr}
\hline & 1413 & 1414 & 1415 & 1416 & Mean RPD \\
\hline Am-241 & 62.86 & 19.61 & 19.61 & 4.26 & 26.58 \\
Cm-243,244 & 9.71 & 47.21 & 72.05 & 0.43 & 32.35 \\
Cm-245,246 & 48.27 & 31.64 & 44.87 & 67.92 & 48.17 \\
Cm-248 & 32.63 & 63.24 & 56.47 & 22.70 & 43.76 \\
Pu-238 & 22.22 & 46.15 & 22.22 & 22.22 & 28.21 \\
Pu-239,240 & 66.67 & 66.67 & 0.00 & 66.67 & 50.00 \\
SI-90 & -1000.00 & & & -90.91 & -545.45 \\
U-234 & 7.71 & 4.54 & 12.28 & 29.54 & 13.52 \\
U-235 & 23.26 & 17.14 & 17.14 & 5.13 & 15.67 \\
U-238 & 2.37 & 8.33 & 13.43 & 9.21 & 8.34 \\
\hline
\end{tabular}

a relative percent difference 
C-21

Table C.13. Number of regular samples submitted for each analytical group by location

\begin{tabular}{|c|c|c|c|c|c|c|c|c|c|c|c|}
\hline \multirow[b]{2}{*}{ Site } & \multicolumn{2}{|c|}{ Mercury } & \multicolumn{2}{|c|}{ Metals } & \multicolumn{2}{|c|}{ PCBs } & \multirow{2}{*}{$\begin{array}{l}\text { SVOs and } \\
\text { pesticides }\end{array}$} & \multicolumn{3}{|c|}{ Gamma rads } & \multirow{2}{*}{$\frac{{ }^{90} \mathrm{Sr}}{\mathrm{CHC}}$} \\
\hline & BG & LMB & BG & LMB & $\mathrm{CHC}$ & $\mathrm{CHC}$ & & $\mathrm{CHC}$ & $\mathrm{BG}$ & LMB & \\
\hline 1 & 10 & 5 & 10 & 5 & 5 & 8 & 8 & 8 & 5 & 4 & 8 \\
\hline 2 & 10 & 5 & 10 & 5 & 5 & 8 & 8 & 8 & 2 & 5 & 8 \\
\hline 3 & 10 & 3 & 10 & 3 & 3 & 8 & 8 & 8 & 2 & 3 & 0 \\
\hline 5 & 11 & 2 & 11 & 2 & 2 & 8 & 8 & 8 & 10 & 2 & 0 \\
\hline 6 & $\mathbf{0}$ & 0 & 0 & 0 & 0 & 6 & 6 & 6 & 0 & 0 & 6 \\
\hline 7 & 10 & 0 & 10 & 0 & 0 & 4 & 4 & 4 & 2 & 0 & 4 \\
\hline 8 & 9 & 0 & 9 & 0 & 0 & 8 & 8 & 8 & 4 & 0 & 8 \\
\hline 9 & 9 & 4 & 9 & 4 & 4 & 8 & 8 & 8 & 2 & 4 & 0 \\
\hline 10 & 2 & 1 & 2 & 1 & 1 & 10 & 10 & 9 & 5 & 1 & 10 \\
\hline 11 & 8 & 2 & 8 & 2 & 2 & 10 & 10 & 7 & 0 & 2 & 10 \\
\hline 12 & 9 & 3 & 9 & 3 & 3 & 8 & 8 & 8 & 9 & 3 & 0 \\
\hline 13 & 10 & 5 & 10 & 5 & 5 & 10 & 10 & 10 & 5 & 5 & 10 \\
\hline 14 & 10 & 2 & 10 & 2 & 2 & 9 & 9 & 8 & 2 & 2 & 9 \\
\hline 15 & 10 & 3 & 30 & 3 & 3 & 10 & 10 & 10 & 2 & 2 & 10 \\
\hline \multirow[t]{2}{*}{16} & 8 & 8 & 8 & 8 & 8 & 4 & 4 & 3 & 2 & 8 & 4 \\
\hline & 126 & 43 & 126 & 43 & 43 & 119 & 119 & 113 & 52 & 41 & 87 \\
\hline
\end{tabular}

PCB = polychlorinated biphenyls, SVOs = semivolatile organics, BG = blue gill, $\mathrm{LMB}=$ largemouth bass, $\mathrm{CHC}=$ channel fish 


\section{C-22}

Table C.14. Summary of relative standard deviations of concentrations of mercury, zinc, ${ }^{137} \mathrm{Cs}$, Aroclor 1254, and Aroclor 1260 in fish tissue for Phase 1 sampling locations

\begin{tabular}{|c|c|c|c|c|c|}
\hline Analyte & Site & Mean & $\begin{array}{l}\text { Standard } \\
\text { deviation }\end{array}$ & $\begin{array}{c}\text { Relative } \\
\text { standard } \\
\text { deviation }\end{array}$ & $\begin{array}{c}\text { Mean relative } \\
\text { standard } \\
\text { deviation }\end{array}$ \\
\hline \multirow[t]{13}{*}{ Mercury } & 1 & 0.21 & 0.10 & 47.6 & \\
\hline & 2 & 0.08 & 0.05 & 62.5 & \\
\hline & 3 & 0.04 & 0.02 & 50.0 & \\
\hline & 5 & 0.09 & 0.10 & 111.1 & \\
\hline & 7 & 0.17 & 0.22 & 129.4 & \\
\hline & 8 & 0.57 & 0.22 & 38.6 & \\
\hline & 9 & 0.55 & 0.19 & 34.5 & \\
\hline & 10 & 0.34 & 0.12 & 35.3 & \\
\hline & 12 & 0.43 & 0.18 & 41.9 & \\
\hline & 13 & 0.11 & 0.06 & 54.5 & \\
\hline & 14 & 0.06 & 0.04 & 66.7 & \\
\hline & 15 & 0.10 & 0.08 & 80.0 & \\
\hline & 16 & 0.15 & 0.09 & 60.0 & 62.5 \\
\hline \multirow[t]{15}{*}{ Cs-137 } & 1 & 0.07 & 0.06 & 85.7 & \\
\hline & 2 & 0.06 & 0.04 & 66.7 & \\
\hline & 3 & 0.06 & 0.04 & 66.7 & \\
\hline & 5 & 0.49 & 0.52 & 106.1 & \\
\hline & 6 & 0.19 & 0.10 & 52.6 & \\
\hline & 7 & 0.08 & 0.04 & 50.0 & \\
\hline & 8 & 0.10 & 0.07 & 70.0 & \\
\hline & 9 & 0.09 & 0.03 & 33.3 & \\
\hline & 10 & 0.08 & 0.04 & 50.0 & \\
\hline & 11 & 0.17 & 0.09 & 52.9 & \\
\hline & 12 & 0.20 & 0.25 & 125.0 & \\
\hline & 13 & 0.13 & 0.06 & 46.2 & \\
\hline & 14 & 0.09 & 0.05 & 55.6 & \\
\hline & 15 & 0.07 & 0.05 & 71.4 & \\
\hline & 16 & 0.08 & 0.05 & 62.5 & 66.3 \\
\hline Aroclor 1260 & 1 & 0.03 & 0.03 & 100.0 & \\
\hline
\end{tabular}


C-23

Table C.14. (continued)

\begin{tabular}{cccccc}
\hline Analyte & Site & Mean & $\begin{array}{c}\text { Standard } \\
\text { deviation }\end{array}$ & $\begin{array}{c}\text { Relative } \\
\text { standard } \\
\text { deviation }\end{array}$ & $\begin{array}{c}\text { Mean relative } \\
\text { standard } \\
\text { deviation }\end{array}$ \\
\hline 2 & 0.74 & 0.95 & 128.4 & \\
3 & 0.21 & 0.10 & 47.6 & 70.7 \\
5 & 0.99 & 0.70 & 75.0 \\
6 & 0.68 & 0.51 & 26.7 \\
7 & 0.30 & 0.08 & 84.8 \\
8 & 0.33 & 0.28 & 92.6 \\
9 & 0.94 & 0.87 & 75.0 & \\
10 & 0.56 & 0.42 & 33.3 \\
11 & 0.36 & 0.12 & 101.4 \\
12 & 0.70 & 0.71 & 117.0 & \\
13 & 0.88 & 1.03 & 57.7 \\
14 & 0.26 & 0.15 & 50.7 \\
15 & 0.67 & 0.34 & 64.1 & \\
16 & 0.39 & 0.25 & & 75.0 \\
\hline & & &
\end{tabular}


Table C.15. Summary of duplicate analyses performed on inorganic analyses of fish samples

\begin{tabular}{lccccccc}
\hline Fish number & As & Be & Cu & Hg & Ni & Se & Zn \\
\hline 1000 & & & Bluegill & & & & \\
1012 & A & - & - & A & - & A & A \\
1087 & & & & A & & & \\
8402 & & & & A & & & \\
8405 & - & - & - & A & - & A & A \\
8430 & - & - & - & A & - & - & A \\
8450 & A & O & - & A & - & - & A \\
8461 & - & - & - & A & - & O & A \\
& & & Bass & & & & \\
1024 & A & - & - & A & - & A & A \\
1050 & A & O & - & A & - & - & A \\
1067 & O & - & - & A & - & A & A \\
1068 & A & - & - & A & - & A & A \\
1456 & A & - & O & A & A & A & A \\
8452 & A & O & - & A & - & - & O \\
\hline
\end{tabular}

$A=$ the duplicate measure was within the aceeptance criteria, $\mathrm{O}=$ the measure was out of control limits, and " $-"$ = no measure was calculated because the concentration of each sample of the replicate pair was undetectable.

Table C.16. Summary of duplicate analyses performed on pesticide analyses of fish samples

\begin{tabular}{|c|c|c|c|c|c|c|c|c|c|c|}
\hline $\begin{array}{l}\text { Fish } \\
\text { number }\end{array}$ & aldrin & $\begin{array}{l}\text { tech } \\
\text { chl }\end{array}$ & DDD & DDE & $\mathrm{DDT}$ & $\begin{array}{l}\text { A-ch } \\
\text { dane }\end{array}$ & $\begin{array}{l}\text { A-ch } \\
\text { dene }\end{array}$ & $\begin{array}{l}\text { G-ch } \\
\text { dane }\end{array}$ & $\begin{array}{l}\text { G-ch } \\
\text { dene }\end{array}$ & $\begin{array}{l}\text { oxy } \\
\text { chl }\end{array}$ \\
\hline \multicolumn{11}{|c|}{ Catfish } \\
\hline 1121 & A & A & - & A & $\mathbf{A}$ & $\mathbf{A}$ & - & A & - & - \\
\hline 5014 & A & A & - & A & A & 0 & $\mathbf{A}$ & A & A & 0 \\
\hline 6559 & - & A & - & - & - & 0 & - & A & $\mathbf{A}$ & A \\
\hline 7796 & - & A & - & - & - & A & - & $\mathbf{A}$ & A & A \\
\hline 9726 & - & A & A & A & - & $\mathbf{A}$ & - & A & A & $A$ \\
\hline 9751 & - & A & $\mathbf{A}$ & 0 & - & A & A & A & A & - \\
\hline 9763 & A & A & A & $\mathbf{A}$ & - & A & A & $\mathbf{A}$ & A & - \\
\hline 9780 & - & A & A & $\mathbf{A}$ & - & $\mathbf{A}$ & A & $\mathbf{A}$ & $\mathbf{A}$ & A \\
\hline
\end{tabular}

$A=$ the duplicate measure was within the acceptance criteria, $O=$ the meausure was out of control limits, and ${ }^{-}{ }^{\prime}$ = no measure was calculated because the concentration of each sample of the replicate pair was undetectable. Analytes inciude aldrin, technical chlordane, DDD, DDE, DDT, alpha chlordane, alpha chlordene, gamma chlordane, gamma chlordene, axychlordane. 


\section{C-25}

Table C.17. Summary of duplicate analyses performed on polychlorinatd biphenyis (PCB) analyses of fish samples

\begin{tabular}{|c|c|c|c|c|}
\hline \multirow{2}{*}{$\begin{array}{c}\text { Fish } \\
\text { number }\end{array}$} & \multicolumn{2}{|c|}{$\mathrm{CPA}^{\mathrm{a}} / \mathrm{ORNL}^{\mathrm{b}}$} & \multicolumn{2}{|c|}{$\mathrm{OAL}^{\mathrm{C}} / \mathrm{ORNL}$} \\
\hline & PCB 1254 & PCB 1260 & PCB 1254 & PCB 1260 \\
\hline & & Bass & & \\
\hline 1024 & A & A & & \\
\hline 1050 & A & - & & \\
\hline 1067 & - & A & & \\
\hline 1068 & - & A & & \\
\hline 1456 & A & A & & \\
\hline \multirow[t]{2}{*}{8452} & 0 & 0 & & \\
\hline & & Catfish & ' & \\
\hline 1121 & - & 0 & A & $\mathbf{A}$ \\
\hline 5007 & 0 & O & & \\
\hline 5013 & $\mathbf{A}$ & A & & \\
\hline 5014 & & & $\mathrm{E}$ & $\mathbf{A}$ \\
\hline 5024 & A & A & & \\
\hline 6559 & O & O & A & A \\
\hline 7499 & 0 & $\mathbf{A}$ & & \\
\hline 7767 & 0 & $\mathbf{A}$ & & \\
\hline 7770 & 0 & A & & \\
\hline 7772 & $\mathbf{O}$ & 0 & & \\
\hline 7775 & 0 & $\mathbf{A}$ & & \\
\hline 7776 & 0 & $\mathbf{A}$ & & \\
\hline 7777 & O & $\mathbf{A}$ & & \\
\hline 7779 & $\mathbf{A}$ & $\mathbf{A}$ & & \\
\hline 7796 & & & $\mathrm{E}$ & A \\
\hline 9726 & $\mathbf{A}$ & A & A & A \\
\hline 9731 & $\mathbf{A}$ & A & & \\
\hline 9732 & 0 & $\mathbf{A}$ & & \\
\hline 9751 & $\mathbf{O}$ & $\mathbf{A}$ & $\mathbf{A}$ & A \\
\hline 9763 & $\mathbf{A}$ & $\mathbf{A}$ & $\mathrm{E}$ & A \\
\hline 9780 & A & A & $E$ & $\mathbf{A}$ \\
\hline $\begin{array}{l}{ }^{\mathrm{a}} \text { Chemical a } \\
\mathrm{b}^{\mathrm{O}} \text { Oak Ridge } \\
\mathrm{c}_{\text {Organic An }} \\
\mathrm{A}=\text { the dup } \\
\text { control limits, } \\
\text { eplicate pair }\end{array}$ & $\begin{array}{l}\text { Analysis G } \\
\text { aboratory, } \\
\text { Jratory, } \\
\text { sure was wi } \\
\text { easure was } \\
\text { table. }\end{array}$ & $\begin{array}{l}\text { acceptan } \\
\text { ed becau }\end{array}$ & $\begin{array}{l}=\text { the me } \\
\text { rration of }\end{array}$ & $\begin{array}{l}\text { as out of } \\
\text { mple of the }\end{array}$ \\
\hline
\end{tabular}




\section{DISTRIBUTION}

1. S. M. Adams

2. J. J. Beauchamp

3. B. A. Berven

4. M. S. Bevelhimer

5. B. G. Blaylock

6. H. L. Boston

7. C. C. Brandt

8. A. L. Brenkert

9. R. B. Cook

10. W. D. Crumby

11. V. H. Dale

12. C. J. Ford

13. M. L. Frank

14. R. S. Halbrook

15. R. A. Harris

16. S. G. Hildebrand

17. S. K. Holladay

18. L. A. Hook

19. J. L. Keith

20. B. L. Kimmel

21. L. A. Kszos

22. I. L. Larsen

23. D. A. Levine
24. J. M. Loar

25. S. E. Madix

26-28. D. M. Matteo

29. C. W. McGinn

30. R. L. Moody

31. S. L. Niemela

32-33. P. T. Owen

34. C. D. Rash

35. K. A. Rose

36. G. W. Suter

37. D. R. Watkins

38. D. C. Wood

39. P. S. Wood

40-44. CR-ERP Doc. Management

Center-RC

45. ORNL ER Doc. Management Center

46. Central ER Doc. Management Center

47-48. ESD Library

49. Laboratory Records Department

50. ORNL Patent Section

51. D. M. Carden, DOE Oak Ridge Operations Office, P.O. Box 2001, Oak Ridge, TN 37831-8541

52. M. Ferre, DOE Oak Ridge Operations Office, P.O. Box 2001, Oak Ridge, TN 37831-8541

53. C. S. Gist, DOE Oak Ridge Operations Office, P.O. Box 2001, Oak Ridge, TN 37831-8541

54. F. O. Hoffman, SENES Oak Ridge, Inc., 677 Emory Valley Road, Suite C, Oak Ridge, TN 37830

55. T. Mattis, Jacobs ER Team, 125 Broadway Avenue, Oak Ridge, TN 37830

56. G. S. Sayler, Professor, 10515 Research Drive, Suite 100, The University of Tennessee, Knoxville, TN 37932-2567

57. R. C. Sleeman, DOE Oak Ridge Operations Office, P.O. Box 2001, Oak Ridge, TN 37831-8541

58. Office of Assistant Manager for Energy Research and Development, DOE Oak Ridge Operations Office, P.O. Box 2001, Oak Ridge, TN 37831-8600

59. Office of Scientific and Technical Information, P.O. Box 62, Oak Ridge, TN 37831 